\title{
Anne Soini
}

\section{Always on the Move?}

\section{Measured Physical Activity of 3-Year-Old Preschool Children}

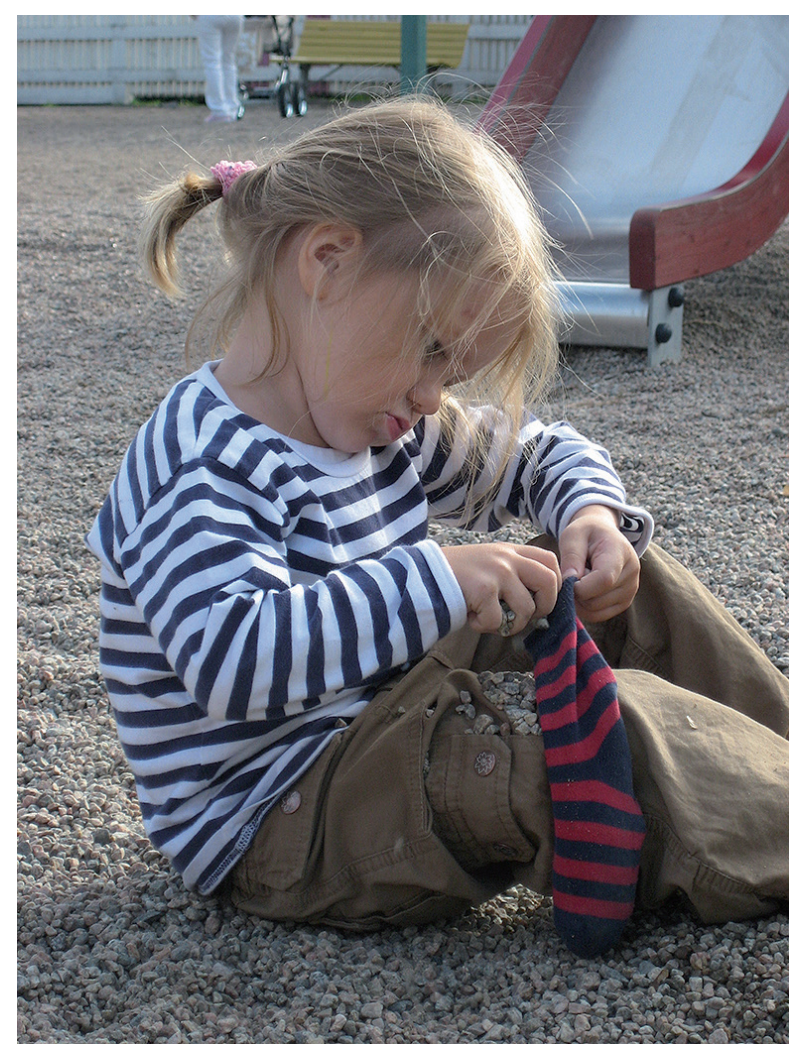




\title{
Anne Soini
}

\section{Always on the Move?}

\author{
Measured Physical Activity of \\ 3-Year-Old Preschool Children
}

Esitetään Jyväskylän yliopiston liikuntatieteellisen tiedekunnan suostumuksella julkisesti tarkastettavaksi yliopiston vanhassa juhlasalissa S212 tammikuun 15. päivänä 2015 kello 12.

Academic dissertation to be publicly discussed, by permission of the Faculty of Sport and Health Sciences of the University of Jyväskylä, in building Seminarium, auditorium S212, on January 15, 2015 at 12 o'clock noon.

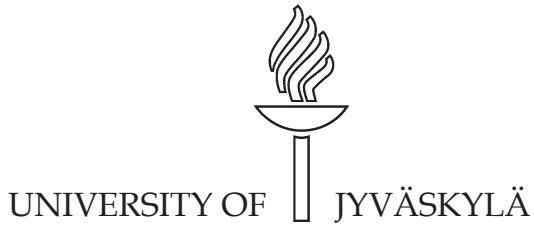

JYVÄSKYLÄ 2015 
Always on the Move?

Measured Physical Activity of 3-Year-Old Preschool Children 


\section{Anne Soini}

\section{Always on the Move?}

Measured Physical Activity of 3-Year-Old Preschool Children

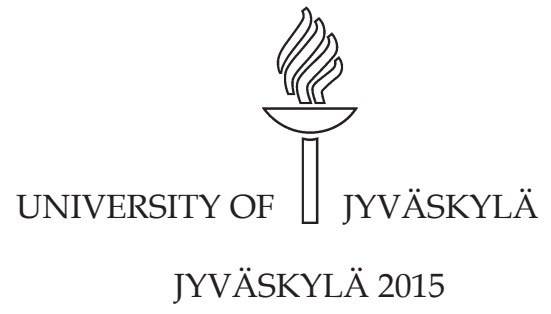


Editors

Ina Tarkka

Department of Health Sciences, University of Jyväskylä

Pekka Olsbo, Ville Korkiakangas

Publishing Unit, University Library of Jyväskylä

Cover picture: Alisa Soini, 3-year-old. Photo by Anne Soini.

URN:ISBN:978-951-39-6029-2

ISBN 978-951-39-6029-2 (PDF)

ISBN 978-951-39-6028-5 (nid.)

ISSN 0356-1070

Copyright (C 2015, by University of Jyväskylä

Jyväskylä University Printing House, Jyväskylä 2015 


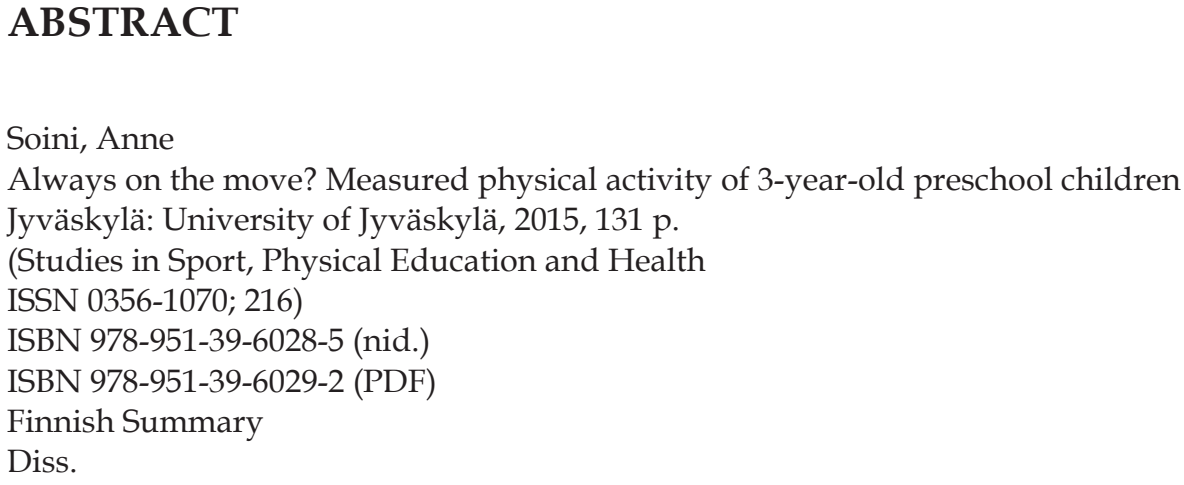

This study addressed the following research questions: 1) What physical activity (PA) intensity levels and patterns exist among Finnish 3-year-old preschool children (studies I, II)? 2) Are there variations between Finland and the Netherlands in 3-year-old children's observed PA levels and contexts in childcare (study III)? 3) Are there variations between Finland and Australia in 3-year-old children's PA intensity levels measured with accelerometers (study IV)? In Finland, 14 childcare centres in the city of Jyväskylä participated in the study. Data were gathered on 96 three-year-old preschool children ( 48 boys and 48 girls) in autumn 2010, and on 94 children (50 boys and 44 girls) in winter 2011. Data were also gathered on 97 (46 boys and 51 girls) 3-year-olds from nine childcare centres in Maastricht, the Netherlands, and on 64 (33 boys and 31 girls) 3-year-olds from 13 childcare centres in Melbourne, Australia. Children's PA intensity levels and sedentary time on five consecutive days, including childcare and homecare days was assessed with ActiGraph GT3X accelerometers. The structured Observational System for Recording Physical Activity in Children-Preschool Version (OSRAC-P) of Brown et al. (2006) was used to obtain descriptive information on the context of PA behaviours in childcare settings. Appropriate statistical analyses were performed. The 3-year-old children spent the major part of their time engaged in sedentary-level activities. During childcare attendance, only $2 \%$ of all observations were recorded as moderate to vigorous PA (MVPA). The children were observed, for the most part, in non-solitary play; however, during solitary play they showed higher levels of PA intensity. In autumn, the children were more physically active in the mornings than afternoons. No major differences were observed in PA levels between days or seasons, although levels of outdoor PA were higher in autumn than winter. The Finnish children spent significantly more time in sedentary-level activities and less time in MVPA than the Dutch children, whereas, during childcare days the Finnish children spent more time in light PA than the Australian children. The childcare setting itself plays an important part in promoting more intensive PA behaviour during early childhood. Throughout the year, children should be encouraged to spend a greater amount of their time playing outdoors, engaged in MVPA-level activities, and to minimize the time spent sitting or engaged in sedentary-level activities. Finnish childcare policy makers should take note of these findings as well as of existing international practices and guidelines that have been demonstrated to be beneficial for children's PA behaviour and thus also health.

Keywords: physical activity, sedentary time, accelerometer, direct observation, childcare centre 


\begin{tabular}{|c|c|}
\hline Author's address & $\begin{array}{l}\text { Anne Soini, MSc } \\
\text { Early Childhood Education } \\
\text { Department of Education } \\
\text { University of Jyväskylä } \\
\text { P.O. Box } 35 \text { (Viv) } \\
\text { FI-40014 University of Jyväskylä } \\
\text { Jyväskylä, Finland } \\
\text { anne.j.soini@jyu.fi }\end{array}$ \\
\hline Supervisors & $\begin{array}{l}\text { Professor Marita Poskiparta } \\
\text { Department of Health Sciences } \\
\text { Research Center for Health Promotion } \\
\text { University of Jyväskylä, Finland } \\
\text { Docent Arja Sääkslahti, PhD } \\
\text { Department of Sport Sciences } \\
\text { University of Jyväskylä, Finland } \\
\text { Professor Tarja Kettunen } \\
\text { Department of Health Sciences } \\
\text { Research Center for Health Promotion } \\
\text { University of Jyväskylä } \\
\text { Unit of Primary Health Care, Central Finland Health Care } \\
\text { District, Jyväskylä, Finland }\end{array}$ \\
\hline Reviewers & $\begin{array}{l}\text { Professor Dianne S. Ward } \\
\text { Department of Nutrition } \\
\text { Gillings School of Global Public Health and School of } \\
\text { Medicine, University of North Carolina at Chapel Hill } \\
\text { Chapel Hill, North Carolina, United States } \\
\\
\text { Professor Anthony D. Okely } \\
\text { Early Start Research Institute } \\
\text { University of Wollongong } \\
\text { Wollongong, New South Wales, Australia }\end{array}$ \\
\hline Opponent & $\begin{array}{l}\text { Professor Greet Cardon } \\
\text { Department of Movement and Sport Sciences } \\
\text { Ghent University } \\
\text { Ghent, Belgium }\end{array}$ \\
\hline
\end{tabular}




\section{ACKNOWLEDGEMENTS}

Physical activity has been a major part of my whole life, becoming a way of life. Besides enjoying being physically active myself, I have had a mission to encourage inactive people to work towards adopting a more physically active lifestyle. I believe that as a part of broadening my own lifelong learning, starting this doctoral study was a natural extension to my professional knowledge.

This journey would not have been accomplished without the tremendous support of many people. I would like to thank everyone who assisted me in the completion of my thesis or otherwise participated in this study. My warm thanks go to the children, parents and early educators in the childcare centres, who gave their time to this study. Without you this thesis would not have been possible to execute.

My greatest depth of gratitude goes to my supervisors: Professor Marita Poskiparta, Docent Arja Sääkslahti, and Professor Tarja Kettunen. Marita, you believed in me as a researcher, and offered a context for doing research, which was a totally new world for me. You gave me responsibility, and academic freedom to carry out my studies in my own way. Arja, your enthusiasm towards physical activity and motor development of young children has continuously been an inspiration for me. You are a very positive and supportive mentor, and I have always been confident that I could count on you. Tarja, I would like to express my gratitude for your kindness, warm guidance and help whenever I needed it. I am appreciative of the many opportunities you all provided so I could grow academically and personally.

I sincerely thank Professor Dianne S. Ward from the University of North Carolina at Chapel Hill, US, and Professor Anthony D. Okely from University of Wollongong, Australia, for serving as the official reviewers of this thesis. You gave me valuable comments and suggestions of how to develop this thesis further. I was honoured to have you to read my work.

I have had the privilege for working with, and learning from, Jessica Gubbels, $\mathrm{PhD}$, from Maastricht University, The Netherlands, and Anthony Watt, PhD, from Victoria University, Australia. Jessica, I admire your knowledge and commitment for the field of research. I was always able to ask you for help and clarifications, whenever I felt a need for it. Tony, "heaps" of thanks for your encouraging words, thoughtful criticism, constructive feedback, and attention to detail which all greatly contributed to my studies. I know, that my journey wouldn't have been the same without your mentoring.

I am also thankful for the continuing support of LIKES - Research Center for Sport and Health Sciences. Tuija Tammelin, PhD, I admire your deep knowledge related to the field of physical activity. I learned a lot about doing research and writing academic papers from you. Warm thanks for your valuable guidance throughout my studies. In addition, I really appreciate the skills and expertise with the accelerometer software and statistics, which Janne Kulmala, MSc, and Harto Hakonen, MSc, have demonstrated, for the benefit of my study.

I also wish to thank Jari Villberg, who very patiently helped in the field of statistics and data analyses. I am grateful for Mr. Michael Freeman for proofreading 
two of my studies and the summarizing report. Additionally, I want to thank Esa Nykänen, MSc, for his technical support, and Ina Tarkka, PhD, for her editing.

Additional thanks go to my colleagues, "the A-team" members: Arja, Anette, Arto, and Susanna, in the University of Jyväskylä. I have been lucky to share your friendship and encouragement. It has been very important for me to share some favourable, as well as the unrewarding moments within the study with you. I am also grateful for Anni and Karin who piloted the OSRAC-P method, and the students, Anne-Maria, Anna and Katri, who helped with the observations in data collection of study.

Many thanks go to my current colleagues and group of TAISTO in Early Childhood Education. Without your support I would not have been able to complete my study while working. Working with students and children in early childhood, and the possibility to apply research into practice, has been a positive educational experience and valuable professional opportunity.

I am grateful for the resources and the financial support from the Urheiluopistosäätiö, Emil Aaltonen Foundation, LIKES, and the University of Jyväskylä.

My sincere thoughts go to all my friends. With you I have been able to share my joys and worries, and most importantly, I have had a possibility to think something else than research. In particular long talks, skype calls, walks, and lunches with my dearest friends have been a saving lifeline throughout the journey.

I also want to sincerely thank my dear parents Marja-Leena and Lauri, and my brother Arto, for teaching me the value of hard work, believing in me, and always supporting my endeavours. Dear Pirjo and Juha, I wish you to know that you are very important to me, and have contributed greatly to my thesis.

Finally, my deepest gratitude and thoughts go to my dear husband Markus, and our daughters Aino and Alisa. Markus, you encouraged me to the road of research, even though you knew the challenges ahead of me. Your love and support have encouraged me on every step of the way. You have always believed in me, even when I had second thoughts. Our lovely daughters, Aino and Alisa, I would like to thank you for the tremendous and unconditional love and joy you have brought into our life. You remind me what is most important in life. I love you all deeply. Your continuous support made my PhD process possible. I dedicate this thesis to you.

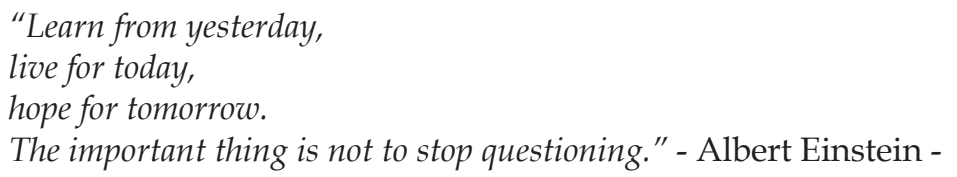

Jyväskylä, December 8, 2014

Anne Soini 


\section{LIST OF ORIGINAL PUBLICATIONS}

This thesis is based on the following original publications, which will be referred to in the text by their Roman numerals (I-IV).

I Soini, A., Tammelin, T., Sääkslahti, A., Watt, A., Villberg, J., Kettunen, T., Mehtälä, A., \& Poskiparta, M. 2014. Seasonal and daily variation in physical activity among three-year-old Finnish preschool children. Early Child Development and Care, 184(4), 586-601.

doi: 10.1080/03004430.2013.804070

II Soini, A., Villberg, J., Sääkslahti, A., Gubbels, J., Mehtälä, A., Kettunen, T., \& Poskiparta, M. 2014. Directly observed physical activity among 3-yearolds in Finnish childcare. International Journal of Early Childhood, 46(2), 253-269. doi: 10.1007/s13158-014-0111-z

III Soini, A., Gubbels, J., Sääkslahti, A., Villberg, J., Kremers, S., Van Kann, D., Mehtälä, A., De Vries, N., \& Poskiparta, M. 2017. A comparison of physical activity levels in childcare context among Finnish and Dutch 3-year-olds.

European Early Childhood Education Research, 25(3). in press

IV Soini, A., Watt, A., Tammelin, T., Soini, M., Sääkslahti, A., \& Poskiparta, M. 2014. Comparing the physical activity patterns of 3-year-old Finnish and Australian children during childcare and homecare days. Baltic Journal of Health and Physical Activity, 6(3), 171-182. doi: 10.2478/bjha-2014-0015 


\section{FIGURES AND TABLES}

\section{FIGURES}

FIGURE 1 The socio-ecological model (adapted from Bronfenbrenner, 1979)

FIGURE 2 Data collection timetable and study procedures............................... 56

FIGURE 3 Conclusions on 3-year-old preschool children's PA behaviour...... 91

\section{TABLES}

TABLE 1 Overview of the physical activity and sedentary behaviour recommendations in preschool children.............................................. 32

TABLE 2 Description of the most common sets of ActiGraph accelerometer cut points used in the preschool-aged population

TABLE 3 Typical daily programmes of childcare centres involved in the

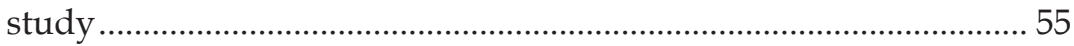

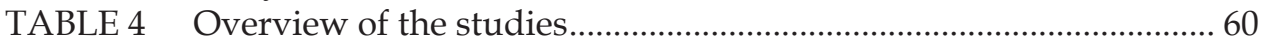

TABLE 5 Differences in predicted physical activity of Finnish children $(n=79)$ according to ActiGraph cut points for preschool children

TABLE 6 Cohen's kappa means for inter-rater reliability (IRR) of two observers for the OSRAC-P categories 


\title{
CONTENTS
}

\author{
ABSTRACT \\ ACKNOWLEDGEMENTS \\ LIST OF ORIGINAL PUBLICATIONS \\ FIGURES AND TABLES \\ CONTENTS \\ ABBREVIATIONS
}

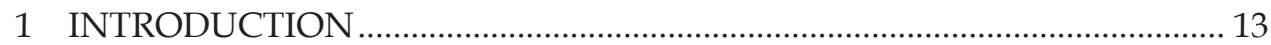

1.1 Definitions of physical activity in early childhood ............................ 13

1.2 Justification of the study ............................................................... 15

2 CHILDREN'S PHYSICAL ACTIVITY IN LIGHT OF SOCIO-ECOLOGICAL

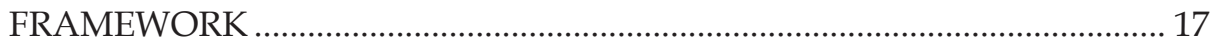

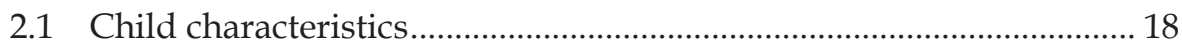

2.1.1 Child development and growth............................................ 18

2.1.2 Biological and psychological factors .................................... 20

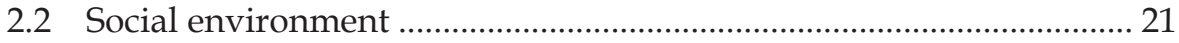

2.2.1 Familial interaction ................................................................. 21

2.2.2 Early educational interaction ............................................. 22

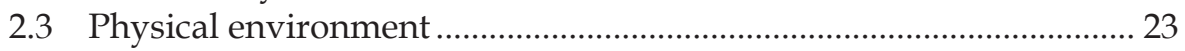

2.3.1 Home settings ............................................................................. 24

2.3.2 Childcare centre settings ........................................................ 26

2.3.3 Time and seasonal variations .................................................. 27

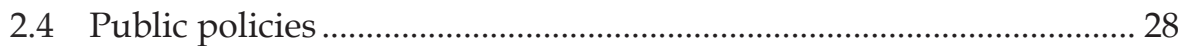

2.4.1 National curriculum guidelines ............................................ 29

2.4.2 Physical activity recommendations...................................... 30

2.4.3 Parental leaves, childcare services, fees, and participation rates ................................................................ 34

2.4.4 Quality of childcare services................................................. 37

2.4.5 The changing socio-economic trends ................................... 39

3 METHODS OF ASSESSING PHYSICAL ACTIVITY IN CHILDREN ........... 41

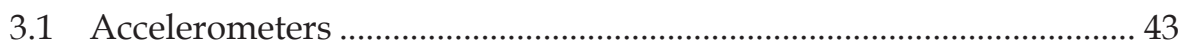

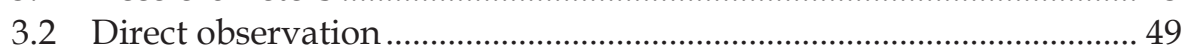

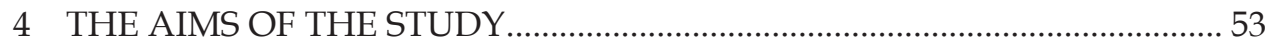

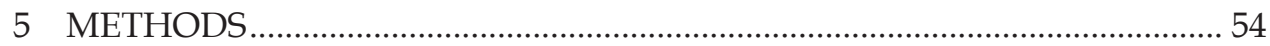

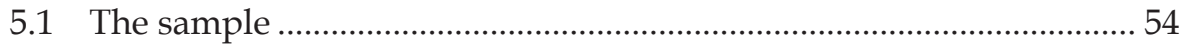

5.1.1 Childcare centre recruitment ............................................. 54

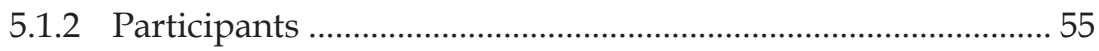

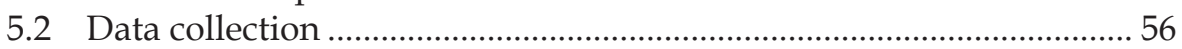

5.2.1 Accelerometer measurements (studies I, IV) ......................... 57 
5.2.2 OSRAC-P observation procedures (studies II, III) ……............ 58

5.3 Data reduction and statistical analyses .................................................... 61

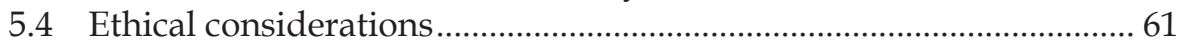

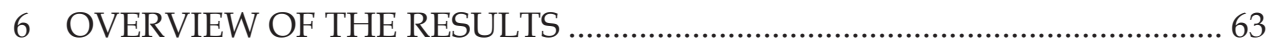

6.1 What physical activity intensity levels and patterns exist among Finnish 3-year-old preschool children? (Studies I, II) ........................... 63

6.2 Are there variations between Finland and the Netherlands in 3-year-old children's observed physical activity levels and contexts in childcare? (Study III)

6.3 Are there variations between Finland and Australia in 3-year-old children's physical activity intensity levels measured with accelerometers? (Study IV)

6.4 Background information and conditions in the studied countries.... 67

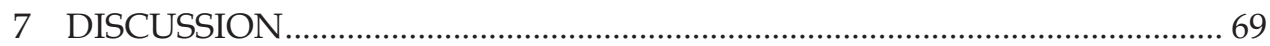

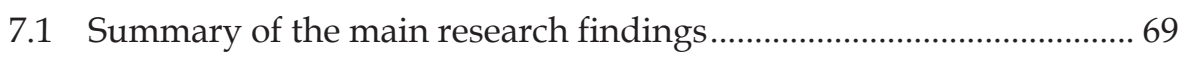

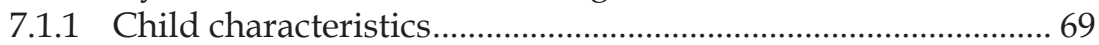

7.1.2 Early educational interaction .................................................... 70

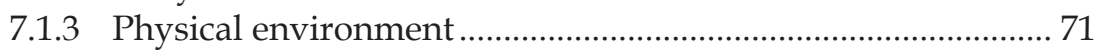

7.1.3.1 Childcare centre environments ........................................ 71

7.1.3.2 Outdoor playtime ……………………………...................... 72

7.1.3.3 Time and seasonal effects ................................................... 73

7.1.4 Childcare policies and practices................................................... 76

7.1.4.1 Physical activity recommendations..................................... 77

7.1.4.2 Cultural variations in practices............................................ 78

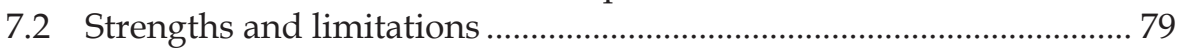

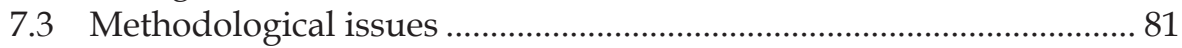

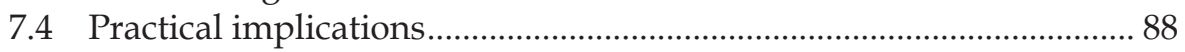

7.5 Conclusions and directions for future research.................................... 91

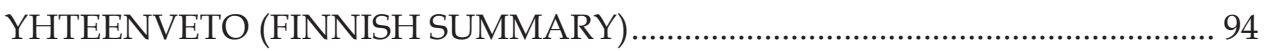

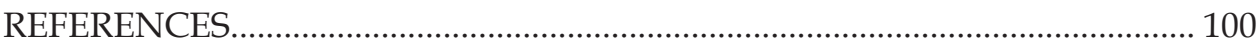

\section{APPENDICES}

ORIGINAL PUBLICATIONS 


\section{ABBREVIATIONS}

\begin{tabular}{|c|c|}
\hline 3DPAR & Three-Day Physical Activity Recall \\
\hline ABS & Australian Bureau of Statistics \\
\hline ANOVA & analysis of variance \\
\hline AUS & Australia \\
\hline BEACHES & $\begin{array}{l}\text { the Behaviors of Eating and Activity for Child Health Evalua- } \\
\text { tion System }\end{array}$ \\
\hline BMI & body mass index, $\mathrm{kg} / \mathrm{m}^{2}$ \\
\hline CARS & the Children's Activity Rating Scale \\
\hline CASPER II & the Code for Active Student Engagement Revised \\
\hline CCB & Child Care Benefit \\
\hline CCR & Child Care Rebate \\
\hline $\mathrm{CHD}$ & coronary heart disease \\
\hline CPAF & the Children's Physical Activity Form \\
\hline CPM & counts per minute \\
\hline DLW & doubly labelled water \\
\hline DOI & digital object identifier \\
\hline ECEC & Early Childhood Education and Care \\
\hline $\begin{array}{l}\text { ECERS-R } \\
\text { EE }\end{array}$ & $\begin{array}{l}\text { The Early Childhood Environment Rating Scale - Revised } \\
\text { energy expenditure }\end{array}$ \\
\hline EGGE & $\begin{array}{l}\text { European Commission's Expert Group on Gender and Em- } \\
\text { ployment Issues }\end{array}$ \\
\hline EMG & electromyography \\
\hline EPAO & the Environment and Policy Assessment and observation \\
\hline FIN & Finland \\
\hline FMS & fundamental motor skills \\
\hline GLM & General Linear Model \\
\hline GDP & gross domestic product \\
\hline GPS & a mobile global positioning system \\
\hline HIPPA & $\begin{array}{l}\text { Home- and childcare-based Intervention to Promote Physical } \\
\text { Activity }\end{array}$ \\
\hline $\mathrm{IOM}$ & Institute of Medicine \\
\hline IRR & the inter-rater reliability \\
\hline LIKES & Research Center for Sport and Health Sciences \\
\hline LMVPA & light to vigorous intensity physical activity \\
\hline M & mean \\
\hline MAD & mean amplitude deviation \\
\hline METs & metabolic equivalents \\
\hline MLR & Multi Linear Regression \\
\hline MVPA & moderate to vigorous intensity physical activity \\
\hline NAP SACC & the Nutrition and PA Self-Assessment for Child Care \\
\hline NASPE & National Association for Sport and Physical Education \\
\hline NED & the Netherlands \\
\hline OECD & Organisation for Economic Co-operation and Development \\
\hline
\end{tabular}


OSRAC-P Observation System for Recording Physical Activity in Children - Preschool version

$p, p$-value significance probability

PA physical activity

PDPAR previous day physical activity recall

PE

SB

SD

SES

SOFIT

SOPLAY

SPSS

TV

physical education

sedentary behaviour

standard deviation

socioeconomic status

the System for Observing Fitness Instruction Time

the System for Observing Play and Leisure Activity in Youth

statistical package for the social sciences

television

UK United Kingdom

US United States

WHO World Health Organization 


\section{INTRODUCTION}

Behavioural habits, such as physical activity (PA) and sedentary behaviour (SB), are formed in early childhood (Janz, Burns, \& Levy, 2005; Timmons, Naylor, \& Pfeiffer, 2007; Ward, Vaughn, McWilliams, \& Hales, 2010). PA has been shown to have many benefits for children's healthy growth, and physical, social and psychological development (Timmons et al., 2012). Recent evidence further suggests that PA is positively, and SB inversely, associated with psychosocial well-being (Hinkley et al., 2014). Preschool children are widely believed to be continuously active; nevertheless, previous studies in early childhood have drawn attention to the fact that levels of PA are typically low and SB high, and currently many children do not achieve the levels of daily PA proposed in global guidelines (e.g., Bornstein, Beets, Byun, \& McIver, 2011; Hinkley, Salmon, Okely, Crawford, \& Hesketh, 2012; Reilly, 2010; Tucker, 2008).

\subsection{Definitions of physical activity in early childhood}

A young child's expanding sense of personal initiative is often observed in their curiosity, willingness to explore and very active behaviour (Gallahue \& Ozmun, 2006, p. 176). Children's play that typically incorporates vigorous physical components and can be termed physically active play (Pellegrini \& Smith, 1998). Such vigorous movements and play activities, as demonstrated by the child's urge to run, climb, and jump, not only enhance muscle growth, but also support the growth of the child's normal physical development (Clements, 2004). Play is a natural component of a child's everyday life and assists the child to make sense of his or her world (Pramling Samuelsson \& Asplund Carlsson, 2008), and learn about their bodies and movement capabilities (Gallahue \& Ozmun, 2006, p. 174). In this study, children's behaviour, which generally occurs as physically active play, will be referred to as PA.

PA is often defined as any bodily movement produced by skeletal muscles that raise energy expenditure above resting values (Caspersen, Powell, \& Chris- 
tenson, 1985). Malina, Bouchard, and Bar-Or (2004, p. 458) emphasize that PA has mechanical, physiological, and behavioural components. PA in preschool children occurs at various levels of intensity and it is rarely performed over a continuous period of time (Timmons et al., 2007). Moreover, young children's PA behaviour should be considered in terms of energy expenditure (EE), oxygen uptake, metabolic energy, and power, type of activity, quality of movements, amount and intensity of activity (i.e., sedentary, light, moderate, vigorous or moderate to vigorous intensity PA [MVPA]), its context, such as the play environment, toys and equipment, and interactions with others (Malina et al., 2004, p. 458; Trost, 2007). In addition, the importance of the relationship between gross motor skills and PA, including both the metabolic and neuromuscular systems, has been emphasised (Laukkanen, Pesola, Havu, Sääkslahti, \& Finni, 2013).

According to Clements (2004), outdoor play is a natural and crucial part of a child's healthy development, and increases children liking for PA. Through freely chosen outdoor play activities, children grow emotionally and academically by developing an appreciation for the environment, participating in imaginative play and learning safety skills (Clements, 2004). Child's activity behaviour also includes other forms of PA, such as structured planned play (e.g., organised and adult-led play and sport), active transport (e.g., commuting between home and childcare), and every day physical tasks (e.g., homework) (Department of Health and Ageing, 2010; Department of Health, Physical Activity, Health Improvement and Protection, 2011; Dwyer, Baur, \& Hardy, 2009).

PA is a complex behaviour, and it should not be confused with exercise (planned, structured, and repetitive bodily movement done to improve or maintain one or more components of physical fitness) or physical fitness (a set of attributes that people have or achieve that relates to the ability to perform PA) (Caspersen et al., 1985). SB is any waking behaviour characterized by EE $(\leq 1.5$ metabolic equivalents [METs]), while in a sitting or reclining posture (e.g., television [TV] viewing and during motorized transportation). Physical inactivity in turn describes those who are performing insufficient amounts of MVPA (i.e., not meeting specified PA guidelines) (Sedentary Behaviour Research Network, 2012; Tremblay et al., 2012).

Accumulating evidence suggests that, PA has many health benefits (Haskell, Blair, \& Hill, 2009), such as favourable changes in biomarkers for cardiovascular disease (Timmons et al., 2012) and metabolic syndrome, increased bone and muscle strength (Strong et al., 2005), and less adiposity (Moore et al., 2003). Further, Kantomaa, Tammelin, Demakakos, Ebeling, and Taanila (2010) concluded that higher levels of PA in adolescents were associated with high self-perceived overall academic performance and plans for higher education. Independent of PA levels, SB has various negative effects on health e.g., high exposure (for more than two hours) of daily SB has been associated with lowered scores for self-esteem and pro-social behaviour, and decreased academic achievement (Tremblay et al., 2011). Taken together, too much sitting and lack of MVPA have shown to represent separate and distinct risk factors for chronic, 
non-communicable diseases (e.g., cardiovascular disease, type 2 diabetes, cancer) (Owen, Healy, Matthews, \& Dunstan, 2010; Sedentary Behaviour Research Network, 2012). Finally, it should be stated that the balance between energy intake and EE is determined not only by the interaction between PA and SB, but also dietary intake; however, discussion of dietary behaviours are beyond the scope of this study.

In recent years, studies have summarized the evidence on tracking, defined as a tendency of individuals to maintain their rank or position in a group over time (Malina, 2001), of PA (Telama, 2009; Telama et al., 2014; Yang, 1997), SB (Biddle, Pearson, Ross, \& Braithwaite, 2010), and overweight (Singh, Mulder, Twisk, van Mechelen, \& Chin A Paw, 2008) from childhood to adolescence and adulthood (Janz et al., 2005; Janz, Dawson, \& Mahoney, 2000; Jones, Hinkley, Okely, \& Salmon, 2013; Kelly et al., 2007). The variations in PA tracking correlations observed between countries may indicate cross-cultural differences (Telama et al., 2014). For instance, it seems that in the Nordic countries PA shows higher stability than in many other countries. Further, the 27-yr followup study by Telama et al. (2014) indicated that the habitual pattern of PA starts to develop very early during preschool age, and that mothers are also aware of their children's PA and are able to evaluate it. Taken together, an active lifestyle in childhood serves as the foundation for an active lifestyle later in life (Janz et al., 2005; Telama et al., 2014; Yang, 1997).

Due to cultural differences and varying practices in this research field, the mixture of definitions adopted in these diverse settings and situational contexts are described in some detail to identify commonality in the use of terms and perspectives. Here, early childhood refers to children aged 0-6 years, and preschool children refer to children as aged 3-to 6-years. Childcare centres include all out-of-home care implemented in formal centre-based arrangements (e.g., early education and preschool) and settings, which provide full-time care for children under school age. As the qualifications and titles of childcare staff members differ greatly from country to country, childcare workers in this research are commonly designated as childcare staff, teacher or early educator, irrespective of their educational background.

\subsection{Justification of the study}

To date, in Finland, a small number of doctoral dissertations have been published on children's PA in early childhood. Two of these studies have investigated parents' and early educators' influence on preschool-aged children's behaviour (Pönkkö, 1999; Siren-Tiusanen, 1996). Of the published intervention studies, Numminen (1991) determined the effects of two different methods on image formation among 3-to 7-year-old children, and Sääkslahti (2005) evaluated the effects of a PA family-based intervention on PA and fundamental motor skills (FMS) and the relationships between PA and coronary heart disease (CHD) risk factors. In one-year follow-ups, Iivonen (2008) 
investigated associations between the Early Steps physical education (PE) curriculum and FMS development of 4-to 5-year-old children, and Halme (2008) described physical fitness, its change and determinants in 3-to 8-year-old children. The most recent study in the field examined 3-to 4-year-old children's socio-emotional skills during PE lessons in childcare (Takala, 2015). Finally, a quality study by Javanainen-Levonen (2009), based on the experiences and views of public health nurses (in child health clinics) explored PA promotion as part of primary health care in early childhood.

Owing to the short intense bursts of PA with frequent rest periods of longer duration that are typical for preschool-aged children, measurement of children's PA behaviour is challenging (e.g., Cliff, Reilly, \& Okely, 2009; Oliver, Schofield, \& Kolt, 2007; Pate, O’Neill, \& Mitchell, 2010; Trost, 2007). Over the past two decades, methods such as accelerometers have become an increasingly popular method for measuring free-living PA in children (Bornstein et al., 2011; Kim, Beets, \& Welk, 2012; Troiano, McClain, Brychta, \& Chen, 2014; Welk, McClain, \& Ainsworth, 2012). However, in Finland the use of these devices has been uncommon in early childhood studies (Aittasalo, Tammelin, \& Fogelholm, 2010; Husu, Paronen, Suni, \& Vasankari, 2011).

In this study, ActiGraph GT3X accelerometers were selected to assess the PA intensity levels and sedentary time of 3-year-old children. The structured Observational System for Recording Physical Activity in Children-Preschool Version (OSRAC-P), developed by Brown and colleagues (2006), was used to provide valuable information on the context of PA behaviours in childcare settings that cannot be derived from using accelerometers. There has been a need for enlarged understanding of how children's PA varies across the day, week and year. To address this concern, daily variations were examined between weekdays and weekend days, and further, between and within childcare and homecare days. An additional aim was to expand knowledge on children's PA patterns across two different seasons, autumn and winter, as Finland is characterised by four different seasons. Although Finnish 3-year-old boys and girls (studies I, II), are the main focus of this research, Finnish observational data were compared to matched Dutch data (study III), and the Finnish accelerometer-based data contrasted with corresponding Australian data (study IV). The purpose was to address the lack of research with similar designs and methodologies and so evaluate parallel PA behaviours in childcare and home settings between same-aged children in different countries. Overall, recent international accelerometer-based and observational studies in the early childhood domain have been used as secondary sources in the present research.

This study is part of larger research and reports the cross-sectional baseline results of the "Physical activity levels in Finnish and Dutch 2-to 6-yearold children, both at home and at the day care centre"- project (https://www.jyu.fi/sport/laitokset/tutkimusyksikot/tetk/vahvuus/terveyso hjaus_arviointi/lapset). It presents new descriptive knowledge and internationally comparable evidence on children's PA behaviour using accelerometers and direct observation methods. 


\section{CHILDREN'S PHYSICAL ACTIVITY IN LIGHT OF A SOCIO-ECOLOGICAL FRAMEWORK}

To understand child's development and health behaviour, one must consider the entire ecological system in which a child's growth occurs (Bronfenbrenner, 1974, 1979, 1994). Urie Bronfenbrenner's ecology of human development (1979) (known also as ecological systems theory), looks at a child's development in the context of the system of relationships that form his or her environment. This system is composed of five socially organized subsystems: the microsystem, mesosystem, exosystem, macrosystem, and chronosystem (Bronfenbrenner, 1979, pp. $7-8,1994)$. The ecological environment is conceived as a set of nested structures, each inside the next (Bronfenbrenner, 1974, 1979, p. 3).

Malina et al. (2004, p. 471) emphasized the numerous biological (e.g., gender, age, body mass index [BMI; $\left.\mathrm{kg} / \mathrm{m}^{2}\right]$ ), psychological (e.g., self-efficacy, selfconcept of activity), and social (e.g., parental and peer attitudes and behaviours, TV viewing) factors that are associated with activity behaviour in children. Further, levels of PA also depend on variation in the physical environment, such as area of residence, day of the week, outdoor play, and season of the year (Malina et al., 2004, p. 471). In addition, many other factors can exert an influence on the level of PA of children, such as indicators of growth and maturity, which were notably lacking in the reviewed studies. In their reviews of PA correlates among preschool children, Sallis, Prochaska, and Taylor (2000) and Hinkley, Crawford, Salmon, Okely, and Hesketh (2008) used a socio-ecological framework across five domains: 1) demographic and biological; 2) psychological, cognitive, and emotional; 3) behavioural; 4) social and cultural; and 5) physical environmental. More recently, also in light of a socio-ecological framework, the review by Hodges, Smith, Tidwell, and Berry (2013) studied contexts such as a) child characteristics, b) interpersonal dynamics between pre-schoolers and their families, childcare providers and health providers, d) childcare setting, and d) neighbourhood environments associated with PA levels in preschool children.

Using a socio-ecological framework, the following discussion briefly considers commonly studied factors that may affect levels of PA during early 
childhood (see Figure 1). Moving from the innermost level to the outside, these structures are described below.

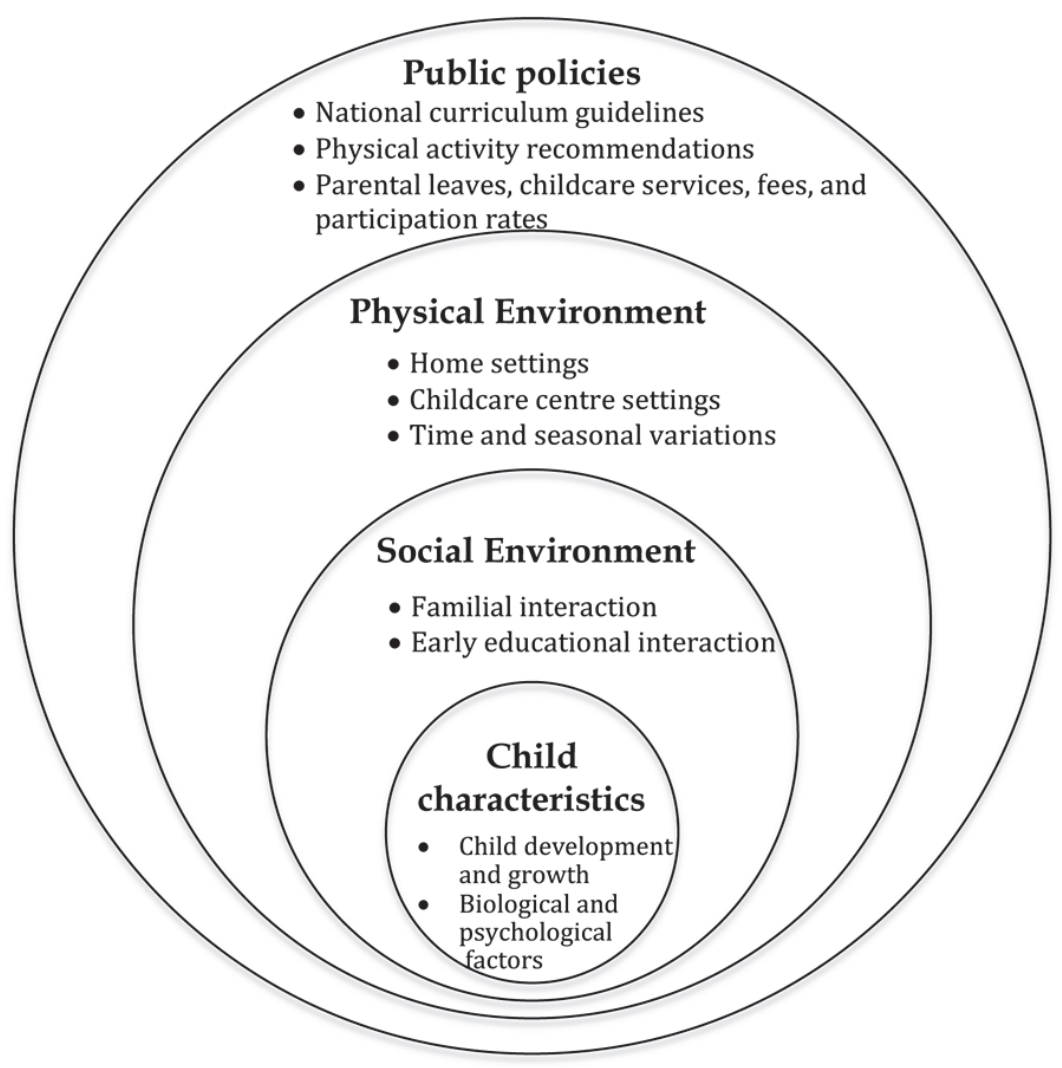

FIGURE 1 The socio-ecological model (adapted from Bronfenbrenner, 1979).

\subsection{Child characteristics}

At the innermost level is the immediate setting containing the developing person (Bronfenbrenner, 1979, p. 3; microsystem).

\subsubsection{Child development and growth}

Development is the process through which a child acquires movement patterns and skills (Malina et al., 2004, p. 196). Early childhood encompasses three developmental periods (infant, toddler and preschool), each of which is characterised by quite different PA patterns (Cliff et al., 2009). First, during the infant period (first 12 months), children begin the process of learning how to interact with the environment (Gallahue \& Ozmun, 2006, p. 155), through reflexes and the learning of rudimentary skills, such as, rolling, crawling, 
standing and finally walking (Cliff et al., 2009). Second, in the toddler period (ages 1 to 3), children start to develop proficiency in locomotor (e.g., running, jumping, hopping, galloping and skipping), manipulative (e.g., kicking, catching and throwing) and stability skills (e.g., static and dynamic balancing and climbing) (Cliff et al., 2009). So far, a comprehensive understanding of PA and SB during the infant and toddler years is lacking (Cardon, Van Cauwenberghe, \& De Bourdeaudhuij, 2011).

During the preschool period, gender differences are minimal; for instance, the body build of both boys and girls is markedly similar (Gabbard, 2004, pp. 85-92; Gallahue \& Ozmun 2006, p. 177). Although children often are egocentric and reluctant to share and get along with others, and fearful of new situations, they have a strong imagination, and a constantly increasing ability to express thoughts and ideas verbally (Gallahue \& Ozmun 2006, p. 177). At the age of three, children progress from parallel play (playing side by side but not interacting) to associative play (Dwyer et al., 2009). Early childhood represents an ideal time for the child to develop and refine a wide variety of fundamental movements (Gabbard, 2004, p. 285; Gallahue \& Ozmun, 2006, p. 171). During this phase, children's gross motor control is developing rapidly; however, their fine motor control is not yet fully established (Gallahue \& Ozmun, 2006, p. 177). At the age of three, a child can stand on one foot, walk on 10-cm-wide beam for a short distance, run fluently (shift from flat-footed running to running heeltoe), jump off the floor with both feet (more upward than forward motion), hop up to 3 times on the preferred foot, throw a ball with forearm extension, basketcatch a ball using the body, and kick at a ball (stationary behind the ball) (Gabbard, 2004, pp. 289-320; Gallahue \& Ozmun, 2006, pp. 189-191). Activity behaviour in 3-year-old children is characterised by frequent stumbling (Dwyer et al., 2009). The movement patterns for most FMS ordinarily develop by 6 or 7 years of age (Gabbard, 2004, p. 330; Malina et al., 2004, p. 205).

A review by Iivonen and Sääkslahti (2014) concluded that age, gender, PA, and preschool-based programmes were positive determinants of FMS in preschool-aged children. In line with this, previous studies have shown that higher PA is related to the development of better motor skills (Stodden et al., 2008; Sääkslahti, 2005, Timmons et al., 2012): even at light intensity, PA seems to have beneficial effects on the development of FMS (Laukkanen et al., 2013). Moreover, the better a child's motor skills, the more possibilities she or he has to be physically active, and vice versa, the better a child's motor skills, the more physically active she or he is (Stodden et al., 2008). For instance, locomotor skills, measured by the sliding and galloping tests were positively associated with children's MVPA, and manipulative skills measured by throwing and catching combination test, were positively associated with both total PA and light to vigorous intensity PA (LMVPA) (Iivonen et al., 2013). It is noteworthy that PA patterns are only guidelines and that considerable variation in stage of development exists across children of the same age (Gallahue \& Ozmun, 2006, p. 193). Improvements in FMS occur as part of normal growth and development, including through specific opportunities to practice activities and receive feed- 
back and encouragement from parents and others (Cliff et al., 2009). During these years when children's self-concept is rapidly developing, wise guidance, success oriented experiences, and positive reinforcement are especially important (Gallahue \& Ozmun, 2006, p. 177).

The effects of regular PA on the maturity indicators used in growth studies are difficult to quantify (Malina et al., 2004, p. 489). The developing organism clearly adapts to the stresses imposed by PA, for instance, PA functions to enhance skeletal mineral content, and PA can be an important factor in the regulation of body weight, and specifically fatness (Malina et al., 2004, p. 490). PA is presumably important in normal growth and maturation, but how much activity is necessary is not known (Malina et al., 2004, p. 490).

\subsubsection{Biological and psychological factors}

Although heredity sets limits to growth (i.e., height and weight), environmental factors such as nutrition, exercise and PA, are major considerations affecting growth (Gallahue \& Ozmun, 2006, p. 181). In addition, cultural and genetic factors seem to transmit across generations, and may predispose an individual to be more or less active (Malina et al., 2004, p. 472). The most frequently studied variable, gender, has showed in several in early childhood studies that boys are significantly more active than girls (Baranowski, Thompson, DuRant, Baranowski, \& Puhl, 1993; Finn, Johannsen, \& Specker, 2002; Hinkley et al., 2008; Nicaise, Kahan, \& Sallis, 2011; Oliver et al., 2007; Pate, McIver, Dowda, Brown, \& Addy, 2008; Pate, Pfeiffer, Trost, Ziegler, \& Dowda, 2004; Reunamo et al., 2014; Sallis et al., 2000). Although several studies have found no association between age and PA among preschool children (De Craemer et al., 2012; Hinkley et al., 2008; Sallis et al., 2000), Pfeiffer, Dowda, McIver, and Pate (2009) reported a positive association between higher amounts of MVPA and age, and Jackson et al. (2003) found a positive association between children's total activity and age. In contrast, Yamamoto, Becker, Fischer, \& De Bock (2011) found a negative association between MVPA and age among girls, suggesting that younger preschool children are more likely to engage in PA.

España-Romero, Mitchell, Dowda, O’Neill, and Pate (2013) concluded that the associations between PA and body composition (e.g., BMI) are complex in young children. Although both obesity and under-nutrition have been associated with reduced levels of PA in children (Malina et al., 2004, p. 472), BMI has consistently showed no association with preschool children's PA (Hinkley et al., 2008; Sallis et al., 2000). However, a recent Dutch study concluded that light PA was associated with a decrease in BMI in heavier boys but not girls, and in normal weight children MVPA was associated with a decrease in BMI in boys but not girls (Remmers et al., 2014). BMI is the only growth-related variable that has been included in several studies, and it is generally used as a proxy for fatness (Malina et al., 2004, p. 471).

Other biological factors, such as health status, sexual maturity and physical fitness, that can also influence patterns and levels of PA in children, need, however, more detailed study, especially in the context of the multiple de- 
mands on children as they grow, mature, and develop (Malina et al., 2004, pp. $471,474)$. Several psychological factors have been associated with level of PA. For instance, in accordance with the model by Stodden et al. (2008), self-efficacy and self-concept have shown a positive correlation, whereas perceptions of barriers to activity, such as limited access to facilities, have correlated negatively with levels of PA (Malina et al., 2004, p. 472). Quite recently, Yamamoto et al. (2011) found that the desire to be active was significantly associated with MVPA, but only in boys. However, no links between PA and personality characteristics, self-confidence, or social adequacy have been demonstrated (Malina et al., 2004, p. 472). The most recent review by Hinkley et al. (2014) suggested that it may be premature to promote PA and SB behaviours in public health programs targeting the early childhood population for their beneficial influence on psychological well-being alone. In summary, the fact that biological, psychological, cognitive, and emotional variables have been studied infrequently in both large-scale surveys and more detailed observational studies of activity habits among preschool children, means that strong conclusions on the effects of PA in young children cannot be drawn (Hinkley et al., 2008; Hinkley et al., 2014; Malina et al., 2004, p. 471), additionally, were not in special consideration in this study.

\subsection{Social environment}

The interpersonal (microsystem) layer is one closest to the child and contains the structures with which child has direct contact. At this level, the child's development is determined by the child's activity roles and involvement with e.g., parents, siblings, peers and early educators, relationships which are characterised by bi-directional influences, both away from the child and toward the child (Bronfenbrenner, 1974, 1979, p. 22, 1994).

\subsubsection{Familial interaction}

The most important setting for a young child is his/her family. Studies have indicated that parenting styles and practices are associated with children's PA, for instance, a permissive parenting style has been associated with the most minutes of child PA and uninvolved parenting style the least, whereas an authoritative parenting style was not associated with child PA (Hennessy, Hughes, Goldberg, Hyatt, \& Economos, 2010). Parental role modelling and beliefs can create opportunities for children to be more physically active. Indeed, parents believe that they can support a healthy lifestyle through positive role modelling, by making time for personal PA a priority, and by participating in active play with their children (Dwyer, Higgs, Hardy, \& Baur, 2008). For young children, it is important that their parents take part in sport, as this inspires them to exercise both together and on their own (Pönkkö, 1999; Sääkslahti, 2005). It seems that children with active parents tend to be more active than children with inac- 
tive parents (Hinkley et al., 2008; Hodges et al., 2013; Sallis et al., 2000). Another study indicated that parents of children who enjoyed PA felt that it was easy to facilitate regular PA (Irwin, He, Bouck, \& Tucker, 2005). Jago, Fox, Page, Brockman, and Thompson (2010), however, highlighted that girls with parents who spend a lot of time sedentary are more likely to be sedentary. Moreover, higher levels of parental reinforcement or monitoring have been associated with higher levels of child PA (Hennessy et al., 2010); in particular the involvement of fathers appear to promote higher levels of MVPA in young children (Cantell, Crawford, \& Dewey, 2012). Similarly, Cools, De Martelaer, Samaey, and Anries (2011) found that father's PA level was positively associated with FMS in preschool boys. Furthermore, it seems that boys are regularly encouraged to engage in more physically active play and games than girls (Pellegrini \& Smith, 1998; Pönkkö, 1999).

Family socioeconomic status (SES) is an important factor that can potentially influence children's PA (Malina et al., 2004, p. 473). However, SES has consistently shown no association with children's PA behaviour (De Craemer et al. 2012; Hinkley et al., 2008). Cools et al. (2011) found that SES may reflect easier access to organized sports and equipment. In addition, lower SES home environments seem to provide more opportunities for SB and fewer for PA (Tandon et al., 2012). For example, low SES home environments have more electronic devices in bedrooms and fewer pieces of play equipment than high SES homes (Cools et al., 2011). SES is variably defined within and among different cultures, which renders generalizations difficult (Malina et al., 2004, p. 473).

Irwin et al. (2005) reported that parents with more than one child felt that their children have more opportunities to be active because they had siblings with whom they could play. Reviews of PA research have also indicated that peers and friends can play an important role in children's PA levels (Fitzgerald, Fitzgerald, \& Aherne, 2012; Salvy, de la Haye, Bowker, \& Hermans, 2012). Barkley et al. (2014) concluded that the presence of a friend contributes to increased PA behaviour in 3-to 6-year-old children. This is supported by Reunamo et al. (2014), who showed that peers played a significant role in enhancing PA among Finnish 1-to 7-year-old children. However, peers and friends need to be involved in children's PA in a variety of ways (e.g., peer support, presence of peers, peer acceptance) if children are to be encouraged to lead a physically lifestyle (Fitzgerald et al., 2012). Nevertheless, more understanding on how, why, and in which contexts peers influence children's PA is needed (Salvy et al., 2012). In summary, nine barriers to and facilitators of adequate PA have been proposed: age, weather, childcare, siblings, finances, time, society and safety, parents' impact and child's activity preferences (Irwin et al., 2005).

\subsubsection{Early educational interaction}

Social environment factors, such as positive prompts by early educators have been shown to be associated with increased PA behaviour in children (Brown, Googe, McIver, \& Rathel, 2009a; Brown et al. 2009b; Gubbels et al., 2011). Girls, in particular, seem to be more compliant to activity prompts than boys at the 
age of 4 years (McKenzie et al., 1997). Despite these positive associations, early educators rarely encourage or use teacher-arranged physical activities to promote children's PA, even during outdoor playtime (Brown et al. 2009b, Gubbels et al., 2011; Hannon \& Brown, 2008). Teacher-initiated play has been negatively associated with children's levels of PA in the United States (US) (Brown et al., 2009b). Similarly, European studies have also indicated negative relationships between the presence of more early educators (Cardon, Van Cauwenberghe, Labarque, Haerens, \& De Bourdeaudhuij, 2008) or direct involvement of early educators in children's play and children's activity levels (Gubbels et al., 2011). In general, children tend to be less active the more early educators there are present or involved with children's play (Brown et al., 2009b; Cardon et al., 2008; Gubbels et al., 2011).

Brown and colleagues (2009a) believe that using teacher-planned activities to provide children with many additional, albeit brief, opportunities to be physically active during the childcare day is a practical approach in encouraging children's PA and general health. Similarly, Bower et al. (2008) concluded that inclusion of short play-based activities led by trained and knowledgeable staff could be used to enhance childcare programs and increase children's activity levels. Indeed, children attending preschools with more resources and bettereducated early educators have demonstrated significantly higher levels of MVPA (Dowda, Pate, Trost, Almeida, \& Sirard, 2004). Gagné and Harnois (2014) showed that to improve childcare workers' perception of control, it would be necessary to help them to overcome perceived barriers such as loaded schedule, lack of time, and inclement weather. Children's parents and co-workers approve of the involvement of childcare workers in children's PA, and the availability of a bigger outside yard could also motivate childcare workers to engage the children in PA (Gagné \& Harnois, 2014).

Sandberg and Pramling-Samuelsson (2005) found that despite emphasising the importance of creating inspiring environments for play and outdoor play, early educators' participation in play differed by gender. For instance, male early educators had more play willingness and participated more in physically active play, whereas female early educators tended to prioritise calm play, which, for the most part, they also experienced in their own childhood (Sandberg \& Pramling-Samuelsson, 2005). Nevertheless, well-defined contextual information about moment-to-moment factors such as indoor and outdoor activity contexts and teacher-arranged activities to promote children's PA levels is generally lacking (Bower et al., 2008; Brown et al., 2009a).

\subsection{Physical environment}

The physical environment (mesosystem) comprises the linkages and processes taking place between two or more settings containing the developing person (e.g., the relations between the home and childcare settings) (Bronfenbrenner, 1979, p. 25, 1994). 


\subsubsection{Home settings}

A review by Maitland, Stratton, Foster, Braham, and Rosenberg (2013) highlighted the importance of the influence of the home environment on children's PA and SB. The results showed that the availability of media equipment was positively associated with children's screen-based SB. The availability of PA equipment, however, was unrelated to PA; moreover, no associations between house and yard (the least investigated factors) and PA were found (Maitland et al., 2013), although access to safe play areas and the availability of PA facilities have been shown to influence children's PA behaviour (Dwyer et al. 2008). Further, a recent study by Barnett, Hinkley, Okely, and Salmon (2013) indicated that having a supportive home environment in terms of toys and equipment can help develop children's motor skill competence, and that children with better locomotor and object control skills tend to have more equipment. This finding is supported by Cools et al. (2010), who reported an association between the frequency with which parents acquired new equipment for their child and motor skill. According to the Finnish study by Nupponen, Halme, Parkkisenniemi, Pehkonen, and Tammelin (2010) the most popular equipment among 3-to 6year-old children were bicycle, running shoes, skis and skates. Interestingly, boys more often than girls had access to physically active equipment (Nupponen et al., 2010).

Screen time (e.g., TV viewing, electronic game playing and computer use) has been the most commonly examined SB in preschool children (Hinkley, Salmon, Okely, \& Trost, 2010; Owen et al., 2010). However, it is clear that preschool children's TV viewing habits are complex (Cox, Skouteris, Dell'Aquila, Hardy, \& Rutherford, 2012), and recent TV-time findings for younger children have been inconsistent (Hinkley et al., 2008). A review by De Decker et al. (2012) concluded that European pre-schoolers tend to like watching TV (from $20 \mathrm{~min}$ to $4 \mathrm{~h}$ daily) more than playing on the computer or playing active games, and that children watched more TV on weekend days than weekdays. In line with this finding, a Belgium study indicated that preschool children's mean screen time was 74 minutes on weekdays and 140 minutes on weekend days (Cardon \& De Bourdeaudhuij, 2008). Recently, Jago, Sebire, Edwards, and Thompson (2013) reported that approximately two- thirds of preschool-aged children in the United Kingdom (UK) watched two hours or more of TV per day. Limited evidence also has been found that TV viewing is already common in infants and toddlers (Cardon et al. 2011).

In Finland, the Children's Media Barometer (2013) research project confirmed that not only TV viewing but also use of the Internet is common in early childhood. Internet use often begins in the early years as audio-visual programs are widely followed on Internet video services and on-demand program services. Additionally, playing digital games becomes common between 2 and 4 years of age, and one-third of 3-to 4-year-olds play games weekly (Suoninen, 2014). 
Higher parental TV viewing has been associated with increased risk for high levels of TV viewing for both boys and girls (Jago et al., 2010; Jago et al., 2014; Jago et al., 2013). Further, children who live in homes with increased access to media equipment have been shown to engage in greater TV viewing (Jago et al., 2013). 'Weather conditions' and 'the habits parents have at home' appeared to be most important factors influencing children's screen time (De Decker et al., 2012). Although a review by Hinkley et al. (2010) identified potential correlates across four of the domains of the social ecological model (demographic and biological; behavioural; social and cultural; physical environmental), consistent evidence was reported for only two variables: gender and outdoor playtime, both of which were shown to have no association with TV viewing in preschool children.

Tremblay et al. (2011) indicated that increased sedentary time was associated with increased BMI, increased weight status, and increased risk for being overweight. Recently, Väistö et al. (2014) emphasized that decreased watching of TV and videos and other SB reduces cardio metabolic risk among 6-to 8year-old children. Moreover, watching TV has also been linked with lowered scores for self-esteem and pro-social behaviour and decreased academic achievement (Tremblay et al., 2011), sleeping difficulties, increased aggression and anxiety (Rutherford, Bittman, \& Biron, 2010), and higher consumption of snacks and sweet beverages (De Craemer et al., 2012). Moreover, evidence shows that TV behaviours track from early childhood to adolescence (Biddle et al., 2010). Cox et al. (2012) have suggested that current guidelines should, for example, limit TV time to no more than one hour a day, limit screen time to advertising-free programs, limit food intake while watching TV, and encourage children in active TV viewing. Moreover, with TVs off children might to be more likely to choose PA or educational pursuits inside, including playing with manipulative or gross motor toys (McIver, Brown, Pfeiffer, Dowda, \& Pate, 2009).

It is widely known that children who spend more time outdoors are more physically active (e.g., Boldemann et al., 2006; Hinkley et al., 2008; Sallis et al., 2000). For example, an observational study by McIver et al. (2009) indicated that when outdoors, children tended to be more physically active than when they were indoors. For instance, children spent a larger proportion of the observed intervals in MVPA when riding wheeled toys, playing in open spaces, and using balls and other gross motor toys. Studies on independent mobility have suggested that children who have the freedom to play outdoors and travel actively without adult supervision engage in more PA than those who do not (Schoeppe, Duncan, Badland, Oliver, \& Curtis, 2013). Further, Cools et al. (2010) identified positive associations of FMS performance with transport to preschool by bicycle and the high value placed by parents high on sport-specific aspects of children's PA. Finnish children and youth actively commute short distances to school - most often walking, or biking - clearly more often than pupils, for example, in Ireland, Canada or Australia (Liukkonen et al., 2014). However, 57\% of Finnish preschool children were conveyed to childcare centre by car or in 
some other physically passive way (Nupponen et al., 2010). Fjørtoft's (2001) Norwegian study indicated that the natural environment as a playground, such as a forest, had a positive effect on children's balance and coordination abilities. Today, safety concerns (e.g., neighbourhood safety) have become increasingly dominant in parental decision-making on whether a child should be allowed to spend time outdoors (Hodges et al., 2013; Malina et al., 2004, p. 473).

\subsubsection{Childcare centre settings}

Because children spend a considerable amount of time in childcare, on average $81 \%$ of 3-to 5-year-old children in the Organisation for Economic Co-operation and Development (OECD) countries (OECD, 2014), this setting can make an important contribution to the welfare and health of young children through influencing their levels of activity behaviour (e.g., Cosco, Moore, \& Islam, 2010; Finn et al., 2002; Gubbels, Van Kann, \& Jansen, 2012; Pate et al., 2008; Pate et al., 2004; Ward, 2010). Further, as sedentary lifestyles have increased, awareness of the importance of childcare centre's environments has become more common (Cosco et al., 2010; Pate et al., 2008,). Hinkley et al. (2008), in their review, showed that the preschool a child attends is significantly associated with the child's PA. Similarly, Finn et al. (2002) concluded that among children attending childcare, the childcare centre was the strongest predictor of activity levels, with more than $50 \%$ of the daily PA performed during childcare hours.

Investigators using descriptive methods such as direct observation have clearly indicated that preschool children's PA in childcare settings is primarily sedentary (e.g., Brown et al., 2009b; Gubbels et al., 2011; Nicaise et al., 2011; Pate et al., 2008; Reilly et al., 2004). It is commonly known that children tend to be more active outdoors than indoors (Baranowski et al., 1993; Brown et al., 2009b; Gubbels et al., 2011, Hinkley et al., 2008; Reunamo et al., 2014), spending 11\%$21 \%$ of outdoor recess time in MVPA (Brown et al., 2009b; Cardon, Labarque, Smits, \& De Bourdeaudhij, 2009; Gubbels et al., 2011; Nicaise et al., 2011), although other researchers has indicated that even outdoors children nevertheless engage in high amount of sedentary-level activities, and that their PA levels may even decline with increased duration of outdoor play (Cardon et al., 2008; McKenzie et al., 1997; Pate, Dowda, Brown, Mitchell, \& Addy, 2013).

Features of the physical environment of the childcare setting, such as the ground surface, playground markings, open space, and the availability of play equipment, have also been linked to higher levels of PA (Bower et al., 2008; Cardon et al., 2008; Cosco et al., 2010; Gubbels et al., 2012; Hannon \& Brown, 2008; Nicaise et al., 2011; Reunamo et al., 2014; Ridgers, Stratton, Fairclough, \& Twisk, 2007). A Dutch study showed that children were significantly more active when jumping equipment was continuously present, and when a fixed track was marked on the playground (Gubbels et al., 2012). Similarly, Nicaise et al. (2011) concluded that activity-genic portable equipment and riding vehicles appeared to foster MVPA. A playground redesign which utilizes multicolour playground markings and physical structures may be a suitable stimulus for increasing children's recess PA levels (Ridgers et al., 2007). Scheduling recesses 
to minimize the number of children sharing the playground (Cardon et al., 2008), reducing recess duration (Cardon et al., 2008; Dowda et al., 2004; Pate et al., 2013), and minimizing the time spent in sedentary locations, such as the sandbox (Cosco et al., 2010), may also help to increase children's engagement in MVPA. Cardon et al. (2009) have stated that playground markings and play equipment are not sufficient alone to increase activity levels and decrease levels of sedentary activity during recess, but more activating supervision and structured PA are needed. In its current format, however, PE plays a very small role in meeting the PA requirements of pre-schoolers (Van Cauwenberghe, Labarque, Gubbels, De Bourdeaudhuij, \& Cardon, 2012b).

\subsubsection{Time and seasonal variations}

Earlier studies have revealed that even young children's PA can occur at almost any time of the day; no time-period differences have been found, at least with respect to morning and afternoon (Baranowski et al., 1993; Jackson et al., 2003). Benham-Deal's (2005), however, recorded the highest number of accumulated minutes of MVPA during the afternoons, when more activity occurred outdoors, and Van Cauwenberghe, Jones, Hinkley, Crawford, and Okely (2012a) found that sedentary time was the lowest and MVPA the highest during the period from mid-afternoon till evening. Based on children's heart rate patterns, Durant et al. (1992) found three distinct time segments during the day: morning, early afternoon, and late afternoon. The most active hours of the day were between 4 p.m. and 7.p.m. Interestingly, children who were very active during the morning hours were not necessarily the same children who were active during the afternoon or early evening hours (Durant et al., 1992).

Moreover, until recently, previous research investigating within-day variability had mostly focused on specific time-frames across the day (e.g., during recess in childcare) or average daily PA was measured in different relatively large time blocks (e.g., morning/afternoon hours) (Van Cauwenberghe et al., 2012b; Verbestel et al., 2011). Verbestel et al. (2011), however, using hour-byhour quantification, found variation in PA levels across the day, especially during weekdays. Van Cauwenberghe et al. (2012b) also reported hour-by-hour patterns of SB and MVPA, and found less variability during weekend days than weekdays. However, it can be concluded that the increases in activity were substantially related to daily living activities such as recess and outdoor time (Van Cauwenberghe et al., 2012b; Verbestel et al., 2011).

In the field, researchers have also been investigating possible daily influence on children's PA levels and patterns. So far, the study findings have varied widely. For instance, Jackson et al. (2003) found no differences in activity levels between weekdays and weekend days, whereas Cardon and De Bourdeaudhuij (2008) reported higher levels of SB on weekdays compared to weekend days, and Van Cauwenberghe et al. (2012b) reported that pre-schoolers were less sedentary and engaged in more MVPA across the weekend days compared to weekdays. Further, no significant differences in intensity levels or total PA were 
observed between childcare days and homecare days in Belgium (Verbestel et al., 2011).

Seasonal variation often affects activity behaviour, mostly because of associated climatic changes, especially in countries like Canada and Finland, where winters are often harsh and winter daylights short (Malina et al., 2004, p. 473). To date, the few studies that have sought to determine young children's PA levels across different seasons have yielded conflicting findings (Carson \& Spence, 2010). Commonly children's PA has been observed to increase in warm seasons and decrease in colder seasons (Carson, Spence, Cutumisu, Boule, \& Edwards, 2010; Fisher et al., 2005; Poest, Williams, Witt, \& Atwood, 1989; Sääkslahti, 2005). In Finland, for instance, in autumn and in winter 3-to 8-yearold children were significantly less physically active than during the spring or summertime (Nupponen et al., 2010). Similarly, Burdette, Whitaker, and Daniels (2004) reported that the highest levels of outdoor playtime occurred in the summer and the lowest in the winter. In Scotland, season had a small but significant effect with slightly higher PA and slightly lower levels of SB in summer than in spring (Fisher et al., 2005), whereas, Finn et al. (2002) found no seasonal variations in US children's total daily PA. Another recent US study indicated no significant variations in minutes in light, moderate, and vigorous PA during childcare attendance time between the autumn and the winter, although a significant seasonal difference in PA during after-preschool time was found for both boys and girls (Shen, Alexander, Milberger, \& Jen, 2013). Baranowski and colleagues (1993) indicated in their observational study that differences in children's PA were more related to time spent outdoors than to season or weather conditions. Finally, Goodman, Paskins, and Mackett (2012) reported higher PA levels during long days ( $\geq 14$ hours daylight), partly because children spent more time playing outside the home during those days.

\subsection{Public policies}

Here, the fourth layer of socio-ecological model, describes the influence of both local and national regulations, and historical time on child growth and development (Bronfenbrenner, 1979; exosystem, macrosystem, chronosystem). This layer is a larger social system in which the child does not function directly, but nevertheless feels the positive or negative force stemming from interaction with his/her own system (Bronfenbrenner, 1979, p. 237).

National childcare policies and practices have an important influence on the overall activity levels of the children receiving childcare serves (Pate et al., 2008; Pate et al., 2004). Although each country has its own particular issues in the national debate, many countries debate also centres similar topics, as discussed below. From a policy perspective, for example, the quality of childcare services, particularly the quality of staff, as well as group size, physical spaces, use of time, and the interaction between adults and children are important childcare practices common to most countries (Dowda et al., 2004). If policies 
are to be designed and disseminated for the purpose of increasing PA among preschool-aged children, then those policies should be developed on the basis of careful studies of the PA levels of children in that age range (Pate et al., 2004). Further, since public health policies can target practices in official childcare settings, it is important to document the activity levels of the children in them (Pate et al., 2004). However, very little research has examined the ways that preschool policies/practices and quality of care affect the PA behaviour of preschool children (Dowda et al., 2004).

In the following sections, national childcare regulations in Finland, the Netherlands and Australia are described to enable a better understanding of their national public policies. It is also necessary to determine what policies and regulations are associated with children's PA and SB and in what ways.

\subsubsection{National curriculum guidelines}

Many countries have created a curricula framework for early childhood education and care (ECEC), covering birth to compulsory education. However, the age period varies across countries. In Finland, ECEC covers children up to age eight years (National curriculum guidelines on early childhood education and care in Finland, 2003). Policy documents governing ECEC exist on both the national (e.g., National Curriculum Guidelines on ECEC, legislation on child day care and pre-primary education,) and local (e.g., a local ECEC curriculum, a unit-specific ECEC curriculum, and an individual ECEC plan) levels.

A guiding principle in early childhood education, 'educare', combines care, education and teaching into a whole that is then realised in daily activities, with the focus on the child's full development (Quality in Early Childhood Education and Care, 2013). The core role of preschool education is to promote children's growth, development and learning opportunities as well support and observe physical, psychological, social, cognitive and emotional development with a view to preventing any difficulties that may rise (Quality in Early Childhood Education and Care, 2013). In 2013, the administration of ECEC was transferred from the Ministry of Social Affairs and Health to the Ministry of Education and Culture. Throughout 2013, the Ministry of Education worked on new legislation for ECEC to replace the old legislation of 1973. The new law will shift the focus of ECEC from functioning as a labour market tool for parents to being a child's right. It is likely that the law, for instance, will include requirements for staff education, staff-child ratios and maximum group sizes (Quality in Early Childhood Education and Care, 2013).

In the Netherlands, the Ministry of Social Affairs \& Employment is responsible for formal childcare. Since 2010, the national standard for all forms of early childhood education is the national law on childcare and quality demands for preschool playgroups (kinderopvang en kwaliteitseisen peuterspeelzalen) (Quality in Early Childhood Education and Care, 2013). The goals of ECEC are formulated in terms of emotional safety, social competences, personal competences and transfer of norms and values. The law contains several aspects of quality, such as safety and health regulations, staff educational requirements, require- 
ments for staff-child ratios, maximum group sizes, and pedagogical approaches, and quality criteria concerning buildings and, sleeping areas. The current government aims to further improve overall quality and opportunities for all children (e.g., continuous screening of staff to detect criminal records, a stronger focus on pedagogical quality) (Quality in Early Childhood Education and Care, 2013).

In Australia, The National Quality Standard sets a new national benchmark for the quality of education and care services, as well as gives families better understanding of a quality service (Guide to the National Quality Standard, 2011). The National Quality Standard is linked to national learning frameworks: Belonging, Being and Becoming: the Early Years Learning Framework for Australia, and My Time, Our Place: Framework for School Age Care in Australia (Guide to the National Quality Standard, 2011). The Early Years Learning Framework guides educators in developing quality programs, principles and practices in early childhood pedagogy, and the outcomes required to support and enhance young children's learning from birth to five years of age (Guide to the National Quality Standard, 2011).

\subsubsection{Physical activity recommendations}

Due to the lack of evidence-based literature, particularly in relation to how much PA is required for positive health outcomes in childhood and later adulthood, it is only in recent years that PA recommendations for children under five years have been developed (Skouteris et al., 2012). There is also a lack of consensus on the recommended duration of PA for preschool children. The recommendation of 60 minutes per day in MVPA developed for school-aged youth has been used for preschool-aged children as well (Strong et al., 2005; Tucker, 2008; World Health Organization [WHO], 2010).

To date, consistent with children's characteristics and activity patterns, many countries have developed their own PA and SB guidelines, including for children under age five. For instance, a recommendation of three hours of PA of any intensity per day for toddlers and preschool children are recommended worldwide in several countries such as Australia (Department of Health and Ageing, 2010), Canada (Canadian Society for Exercise Physiology, 2012) and UK (Department of Health, Physical Activity, Health Improvement and Protection, 2011). Similarly, the Institute of Medicine of the National Academies (IOM) (2011), an independent organisation in the US, has also issued recommendations related to childcare environments. These state that pre-schoolers should be physically active for 15 minutes each waking hour, given a 12-hour waking day, this equals around three hours of PA each day. It is noteworthy that, in the Netherlands, no national guidelines exist for Dutch children up to age four.

In Finland, Recommendations for Physical Activity in Early Childhood Education (2005) are a part of the National Guidelines on ECEC. These recommendations describe more precisely than overall criteria how children's holistic growth, development, learning and well-being can be supported by means of PA and play (Recommendations for Physical Activity in Early Childhood Edu- 
cation, 2005). The recommendations concern the amount of PA (two hours of daily brisk PA), its quality, settings, and suitable equipment for implementing it. They also include guidelines for the planning and realization of PE. While the recommendations for PA in early childhood education focus on childcare, they are also meant to guide all educational interaction in different spheres of life where these apply to children under school age.

According to the Quality Recommendations for Health Promotion (2009), childcare centres in Finland should have appropriate, exuberant and safe gymnasiums, grounds and equipment for PE. Childcare centres should take part in sport campaigns and support staff knowledge on the importance of PA. Every childcare centre should also have a person with designated responsibility for dealing with issues concerning PE (Quality Recommendation for Health Promotion, 2009). Early childhood educators should plan and arrange purposeful and varied PE and encourage children's parents to be physically active themselves and participate in PA with their children. They should also co-operate actively and interactively with children's parents for the promotion of health in families (Recommendations for Physical Activity in Early Childhood Education, 2005, Quality Recommendation for Health Promotion, 2009).

Currently, different health-enhancing guidelines have been formulated that recommend limiting the length of SB time in general (Canadian Society for Exercise Physiology, 2012; Department of Health Physical Activity Health Improvement and Protection, 2011; IOM, 2011; The National Association for Sport and Physical Education [NASPE], 2009), or minimizing screen time, including TV viewing and the use of other electronic media (Department of Health and Ageing, 2010; Tremblay et al., 2012). Developing and updating such guidelines is necessary to ensure they remain true to the most current evidence. Therefore, it is recommended that the guidelines for each age group are updated in a cyclical manner such that each set of guidelines (i.e., both PA and SB guidelines) is updated every five years (Tremblay et al., 2012). The current PA and SB guidelines for 3-to 6-year-olds are shown in Table 1. 
TABLE 1 Overview of the physical activity and sedentary behaviour recommendations in preschool children.

\begin{tabular}{|c|c|c|c|}
\hline $\begin{array}{l}\text { Organization, year and } \\
\text { country }\end{array}$ & $\begin{array}{l}\text { Age } \\
\text { group }\end{array}$ & PA/SB & Recommendations \\
\hline $\begin{array}{l}\text { Department of Health and } \\
\text { Ageing, } 2010\end{array}$ & $1-5 y$ & PA & $\begin{array}{l}\text { Children should be physically active every } \\
\text { day for at least three hours, spread through- } \\
\text { out the day. And accumulate at least } 60 \\
\text { minutes of MVPA daily. }\end{array}$ \\
\hline Australia & $2-5 y$ & SB & $\begin{array}{l}\text { Children should not be sedentary, re- } \\
\text { strained, or kept inactive, for more than one } \\
\text { hour at a time, with the exception of sleep- } \\
\text { ing. Sitting and watching television and the } \\
\text { use of other electronic media (DVDs, com- } \\
\text { puter and other electronic games) should be } \\
\text { limited to less than one hour per day. }\end{array}$ \\
\hline $\begin{array}{l}\text { Canadian Society for Exercise } \\
\text { Physiology, Canadian Physi- } \\
\text { cal Activity Guidelines for } \\
\text { the Early Years ( } 0-4 \text { years), } \\
2012\end{array}$ & $3-4 y$ & PA & $\begin{array}{l}\text { Children should accumulate at least } 180 \\
\text { minutes of PA at any intensity spread } \\
\text { throughout the day, including a variety of } \\
\text { activities in different environments, activi- } \\
\text { ties that develop movement skills, and pro- } \\
\text { gression toward at least } 60 \text { minutes of ener- } \\
\text { getic play by } 5 \text { years of age. }\end{array}$ \\
\hline $\begin{array}{l}\text { Canadian Sedentary Behav- } \\
\text { iour Guidelines for the Early } \\
\text { Years (aged 0-4 years), } 2012\end{array}$ & $0-4 \mathrm{y}$ & SB & $\begin{array}{l}\text { Caregivers should minimize the time spend } \\
\text { being sedentary during waking hours. This } \\
\text { includes prolonged sitting or being re- } \\
\text { strained (e.g., stroller, high chair) for more } \\
\text { than } 1 \mathrm{~h} \text { at a time. For children } 2-4 \text { years, } \\
\text { screen time (e.g., TV, computer, electronic } \\
\text { games) should be limited to under } 1 \mathrm{~h} \text { per } \\
\text { day; less is better. For those under } 2 \text { years, } \\
\text { screen time is not recommended. }\end{array}$ \\
\hline $\begin{array}{l}\text { Department of Health, Phys- } \\
\text { ical Activity, Health Im- } \\
\text { provement, and Protection, } \\
2011\end{array}$ & Under & PA & $\begin{array}{l}\text { Children who are capable of walking unaid- } \\
\text { ed should be physically active daily for at } \\
\text { least } 180 \text { minutes ( } 3 \text { hours), spread through- } \\
\text { out the day. }\end{array}$ \\
\hline United Kingdom & 5 years & SB & $\begin{array}{l}\text { Children should minimise the amount of } \\
\text { time spent being sedentary (being restrained } \\
\text { or sitting) for extended periods (except time } \\
\text { spent sleeping). }\end{array}$ \\
\hline $\begin{array}{l}\text { Institute of Medicine of the } \\
\text { National Academies (IOM), } \\
2011\end{array}$ & & PA & $\begin{array}{l}\text { Children should participate in LMVPA at } \\
\text { least } 15 \text { minutes every hour ( } 3 \text { hours/day } \\
\text { and quarter of the time spend in childcare). } \\
\text { The community and its built environment } \\
\text { should promote PA. }\end{array}$ \\
\hline United States & & SB & $\begin{array}{l}\text { The amount of time toddlers and pre- } \\
\text { schoolers spend sitting or standing still is } \\
\text { limited to no more than } 30 \text { minutes at a } \\
\text { time. }\end{array}$ \\
\hline
\end{tabular}




\begin{tabular}{|c|c|c|c|}
\hline $\begin{array}{l}\text { The National Association for } \\
\text { Sport and Physical Education } \\
\text { (NASPE), } \\
2009\end{array}$ & $3-5 y$ & PA & $\begin{array}{l}\text { Children should accumulate at least } 60 \\
\text { minutes of structured PA each day. Chil- } \\
\text { dren should engage in at least } 60 \text { minutes - } \\
\text { and up to several hours - of unstructured } \\
\text { PA each day. Children should be encour- } \\
\text { aged to developed competence in motor } \\
\text { skills that will serve as the building blocks } \\
\text { for future motor skilfulness and PA. Chil- } \\
\text { dren should have access to indoor and out- } \\
\text { door areas that meet or exceed recommend- } \\
\text { ed safety standards for performing large } \\
\text { muscle activities. Caregivers and parents in } \\
\text { charge of pre-schoolers' health and wellbe- } \\
\text { ing are responsible for understanding the } \\
\text { importance of PA and for promoting } \\
\text { movement skills by providing opportunities } \\
\text { for structured and unstructured PA. }\end{array}$ \\
\hline United States & & SB & $\begin{array}{l}\text { Children should not be sedentary for more } \\
\text { than } 60 \text { minutes at a time, except when } \\
\text { sleeping. }\end{array}$ \\
\hline $\begin{array}{l}\text { Recommendations for Physi- } \\
\text { cal Activity in Early Child- } \\
\text { hood Education, } \\
2005\end{array}$ & $\begin{array}{l}\text { Under } \\
7 \text { years }\end{array}$ & PA & $\begin{array}{l}\text { A child needs at least two hours of brisk PA } \\
\text { every day. Children should be able on a } \\
\text { daily basis to train their FMS in various } \\
\text { settings and in a diversified way. Early } \\
\text { childhood educators should plan and ar- } \\
\text { range purposeful and diversified PE on a } \\
\text { daily basis. Early childhood educators } \\
\text { should create an environment that encour- } \\
\text { ages children to be active physically, remove } \\
\text { obstacles to PA and teach how to move safe- } \\
\text { ly in different environments. Day care units } \\
\text { should have the basic equipment for chil- } \\
\text { dren's PA. There should be a sufficient } \\
\text { amount of equipment and it should be easi- } \\
\text { ly accessible to children also during self- } \\
\text { motivated activity. Early childhood educa- } \\
\text { tion and care staff should co-operate active- } \\
\text { ly and interactively with children's parents. }\end{array}$ \\
\hline Finland & & SB & None specified. \\
\hline $\begin{array}{l}\text { *World Health Organization } \\
\text { (WHO) } \\
2010\end{array}$ & $5-17 y$ & PA & $\begin{array}{l}\text { Accumulate at least } 60 \text { minutes of MVPA } \\
\text { daily. } \\
\text { Most daily PA should be aerobic. Vigorous } \\
\text { activities, including those that strengthen } \\
\text { muscle and bone, should be incorporated at } \\
\text { least three times per week. }\end{array}$ \\
\hline Worldwide & & SB & None specified. \\
\hline
\end{tabular}

In recent years, research findings on the extent to which children meet the PA recommendations show wide variation. For instance, Bornstein et al. (2011), found that preschool children accumulated anywhere from 40 to 100 minutes of MVPA daily. Several other studies in the field have concluded that many young 
people do not even reach 60 minutes of daily MVPA (e.g., Beets, Bornstein, Dowda, \& Pate, 2011; Reilly, 2010; Tucker, 2008). In addition, a large proportion of American (e.g., Baranowski et al., 1993; Dowda et al., 2004), and Canadian (Bates, 2006; Cantell et al., 2012) preschool children have been shown to fail to meet their own recommended PA guidelines. In line with this, only $26 \%$ of Belgium children met the NASPE recommendation (2009) of 120 minutes of total PA daily (Cardon \& De Bourdeaudhuij, 2008). Vale, Silva, Santos, SoaresMiranda, \& Mota, (2010) showed that around 75\% and $>90 \%$ of their child sample met the NASPE standard in Portugal. In Australia, just over half of preschool children (56\%) meet current PA recommendations for this age group on weekdays, and just under $80 \%$ on weekends (Okely, Trost, Steele, Cliff, \& Mickle, 2009).

In Finland, Sääkslahti et al. (2004) reported that, based on the NASPE guidelines, the majority of pre-schoolers were sufficiently active. However, other Finnish studies showed that the proportion of 3-year-old children engaging in at least two hours PA daily varied from $40 \%$ (Nupponen et al., 2010) to $88 \%$ (Mäki, Laatikainen, Koponen, Hakulinen-Viitanen, \& LATE-työryhmä, 2008). It is noteworthy that parents completing a questionnaire and/or/a diary were asked to assess their children's PA behaviour, and that in no cases were levels of intensity of activity precisely defined (Mäki et al., 2008; Nupponen et al., 2010; Sääkslahti et al., 2004).

Considerable variation in prevalence estimates makes it difficult to determine the "true" prevalence of PA and time spent sedentary in preschool children (Hnatiuk, Salmon, Hinkley, Okely, \& Trost, 2014), therefore, also comparison of PA in preschool children based on published recommendations is difficult. A number of methodological factors influence the interpretation of PA patterns: 1) the application of different measurement methods (e.g., proxy reports versus accelerometer surveys, and inconsistency between cut points of intensity); 2) the reporting of different indices of PA (e.g., percentages versus averages, and minutes per hour compared with minutes per day); and 3) the use of different guidelines (Skouteris et al., 2012). These kinds of methodological issues are addressed in Chapter 7.3.

\subsubsection{Parental leaves, childcare services, fees, and participation rates}

Most of the OECD countries provide paid and job-protected maternity or parenting leaves (European Commission's Expert Group on Gender and Employment Issues [EGGE], 2009). For instance, in the Finnish case, the duration of maternity leave is up to 105 working days, and either parent can take parental leave (158 working days) after the expiry of maternity leave; however, take-up by fathers is rare. From 2013, fathers have been able to take up to 18 working days of paternity leave while the mother is on post-partum maternity leave. The total duration of paternity leave is 54 working days, and the remaining 36 days can only be taken when the mother is not on leave. Maternity allowance, paternity allowance and parental allowance are paid for the duration of the leave determined on the basis of income (Ministry of Social Affairs and Health, 2013). 
Finland scores below the OECD average regarding paid maternity leave entitlements, while paid paternity leave entitlements are longer than the OECD average (Taguma, Litjens, \& Makowiecki, 2012).

The Finnish family leave system is nevertheless more favourable in comparison to many other OECD countries. For example, in the Netherlands, women are eligible for 16 weeks maternity leave during which they receive benefit equivalent to $100 \%$ of their normal earnings. Father's leave (0.8 weeks/ 4 days) is also paid at $100 \%$ with no upper ceiling. Parental leave (both parents), however, consists of 13 weeks unpaid, and 13 weeks partially paid, but sometimes also unpaid, depending on the employer (Bennett, 2008). In Australia, there is no general entitlement to paid maternity leave. Generally, women take 6-12 weeks' leave around a birth, and approximately $40 \%$ receive some workplace payments. Further, parents have a statutory entitlement to one year of unpaid, shared parental leave (family-based). The total length of all leave is 52 weeks (Bennett, 2008).

In Finland, all children have a subjective right for day care. Before compulsory educations starts at the age of seven, ECEC services are generally offered education and care to 0-to 6-year-old children in municipal childcare institutions, private childcare institutions (e.g., family day care, private childcare centres), or parents can take care of their children themselves (Quality in Early Childhood and Care, 2013). The number of children in childcare centres ranges roughly from ten to a hundred, and they are generally divided into care groups according to age, viz. under 3-year-olds and 3-to 6-year-olds, although currently there is no legislation on how they should be divided (Early Childhood Education and Care Policy in Finland, 2000). Where parents choose to take care of their child at home, they receive a child home care allowance (average 300 euros/month) from the municipal authority, if the youngest child in the family is under age three. In 2012, around half of all children aged nine months to 2 years received home care (Säkkinen, \& Kuoppala, 2012). The right to the home care allowance starts immediately after the parental allowance period ends (Quality in Early Childhood and Care, 2013). Childcare costs depend on family size and income, with free care for low-income families. Meals and healthcare are considered an integral part of childcare services, and are included in the childcare costs. For 6-year-olds a specific pre-primary education programme (4 hours a day) is offered free of charge by schools and/or childcare institutions, and it is often combined with day-care arrangements (Quality in Early Childhood and Care, 2013).

In the Netherlands, childcare consists of childcare centres (kinderdagverblijven) and family care hosts (gastouders) for children aged from six weeks to 4 years (Quality in Early Childhood and Care, 2013). The providers of childcare are located in the private sector, however, while quality requirements are set and monitored at both central and local government levels. Preschool playgroups are open to children between 2 and 4 years of age, and are operated by the public sector. Children typically play in playgroups two mornings or afternoons a week, for a total of 5-6 hours. Further, childcare centres include out-of- 
school-hours care for children from 4 to 12 years of age. Compulsory education in the Netherlands starts at age five, and most children start primary school at age four (Quality in Early Childhood and Care, 2013). General childcare is a demand-side funded system, with responsibility shared between the central government, employers and parents (Quality in Early Childhood and Care, 2013). Parents pay private childcare providers an hourly rate, but are eligible for childcare subsidy (kinderopvangtoeslag). The Tax Office pays this subsidy, which is dependent on family income and number of children, to parents, as in Finland. Playgroups, although operated by the public sector, are subsidised by the municipal authorities with a small parental contribution (Quality in Early Childhood and Care, 2013).

Australia has a wide range of childcare types and early learning services, e.g., long-day care, family day care, in- home care, outside-school-hours care, and occasional care. Long-day care centres offer care for children from 0 to 6 years of age, grouped in rooms according to age and developmental stage. These centres are run by private companies, local councils, community organizations, individuals, non-profit organizations, or by employers for their staff (Department of Education, 2013). The starting age of compulsory education in Australia is six years (OECD, 2013). The out-of-pocket costs of childcare for Australian families are determined by a combination of the fees charged, the type of child care used, the amount of care used by families for their children and the size of the state subsidies that families are entitled to (Department of Education, 2013). There are two main forms of child care support: Child Care Benefit (CCB), which helps families with the cost of CCB-approved child care, and provides financial assistance that is proportionally higher for lower income families, and Child Care Rebate (CCR), which is a payment available to working families using CCB-approved childcare for work, training or study purposes. Families can receive $50 \%$ of their out-of-pocket childcare expenses up to an annual cap (Department of Education, 2013).

According to the OECD Family Database (2014), 73\% of Finnish 3-to 5year-old children attend childcare or early education services. In 2011, more than $60 \%$ of children between 0 and 6 years of age received municipal childcare or family day care services, about $40 \%$ remained at home with their parent(s), while the remainder attended private day-care services (Quality in Early Childhood and Care, 2013). As is typical in the Nordic countries, Finnish children aged 3 to 5 years commonly attend formal care full-time (maximum 10 hours per day) five days a week, for more than 30 hours per week. However, the current day-care policy aims at encouraging families to use early education and care services in more 'individual' and 'flexible' ways, and when possible, only on a part-time basis, rather than full-time care (EGGE, 2009). In the Netherlands and Australia, enrolment rates in early childhood education for children aged 3 to 5 years are $95 \%$ and $80 \%$, respectively (OECD, 2014). Participation rates in both the Netherlands and Australia are lower after adjusting for intensity of use. For instance, most Dutch and Australian 3-year-old children either attend playgroups, or attend childcare facilities on a part-time basis (EGGE, 2009; OECD, 
2014), however, the Netherlands is clearly moving towards fuller coverage childcare services (EGGE, 2009).

In general, families with low incomes and less education more commonly use the home care allowance, whereas the private care allowance is most popular among parents with higher incomes, higher education and a good labour market position (EGGE, 2009). Empirical studies on the relationship between childcare costs and labour force participation are consistent with the prediction that when costs go down, the size of the labour force goes up, especially among mothers. Moreover, women without children have higher employment rates than women with children (EGGE, 2009). The long leave periods available to Finnish women, has been seen as weakening their career opportunities and making the goal of gender equality harder to attain (EGGE, 2009). The female employment rate (age 15-64 years) in Finland (68\%), the Netherlands $(70 \%)$, and Australia (66\%) was higher than the OECD mean (58\%) (OECD.StatExracts.).

Taken together, parental leaves, and childcare services, fees, and enrolment rates influence, in particular, the setting in which a child lives and grows, therefore are important in determining the child's everyday life and PA behaviour. For instance, short maternity and parental leaves lead children to start outof-home care early on, whereas higher childcare costs cause inequality between families in different SES categories.

\subsubsection{Quality of childcare services}

UNICEF and the World Bank have compiled 10 suggested standards on which to evaluate and compare early childhood services in the 25 OECD countries (UNICEF, 2008). These are: 1) parental leave of one year at $50 \%$ of salary, 2) a national plan with priority for disadvantage children, 3) subsidized and regulated childcare services for $25 \%$ of children under three, 4) subsidized and accredited early education services for $80 \%$ of 4 -year-olds, 5) $80 \%$ of all childcare staff trained, 6) $50 \%$ of staff in accredited early education services tertiary educated with relevant qualification, 7) minimum staff-to-children ratio of 1:15 in pre-school education, 8) $1.0 \%$ of gross domestic product (GDP) spent on early childhood services, 9) child poverty less than 10\%, and 10) near-universal outreach of essential child health services. Finland meets eight of these benchmarks (4 and 6 not achieved), whereas, the Netherlands meets five $(2,3,5,6,7)$, and Australia only two (3 and 6) (UNICEF, 2008).

Throughout Europe, group size in childcare settings ranges from 10 to 14 children for 0-to 3-year-olds and from 20 to 25 children for 4-to 6-year-olds (EGGE, 2009). In Finland group size is not yet regulated, but this item is under discussion (Quality in Early Childhood Education and Care, 2013). On numbers of childcare staff, most countries have regulations specifying the minimum child-to-staff ratio, which typically increases with the child age (OECD Family Database, 2010). The child-to-staff ratio in Finland is currently seven children per member of staff (1:7) for 3-to 6-year-olds, in the Netherlands 1:6 for 3-year- 
old children, and in Australia 1:10 for 2-to 3-year-olds (OECD Family Database, 2010).

Currently, in most countries, the childcare labour market is characterized by a female workforce (EGGE, 2009). In Finland, for example, only 3\% of teachers are male (Quality in Early Childhood Education and Care, 2013). However, in some countries, such as in the Netherlands, the top management positions may be occupied by men (EGGE, 2009). The qualifications of childcare staff differ greatly from country to country. In most countries, lead childcare staff have a vocational level diploma, generally at the children's nurse level (upper secondary, vocational level), although many countries will also have specialist staff trained to secondary level graduation, plus a 1-to 2-year tertiary level vocational diploma (OECD Family Database, 2010; Taguma et al., 2012). Moreover, a higher level of education is associated among other things with higher pedagogic quality in ECEC settings (Taguma et al., 2012).

In Finland, childcare centres have multi-professional staff, and therefore variation exists in the level of education among staff. At least one-third of the staff (teachers, social pedagogues) must have a tertiary or higher education level degree (Bachelor or Master of Arts in Education or Bachelor of Social Sciences at the university level), and the remaining staff (practical nurses) an upper secondary-level education (National curriculum guidelines on early childhood education and care in Finland, 2003; Taguma et al., 2012). Consequently, Finland does not meet the recommendations that at least half of the childcare staff must have a tertiary degree/university level education (UNICEF, 2008). However, the teaching profession is highly esteemed (only 10\% of applicants are admitted) (Quality in Early Childhood Education and Care, 2013). Further, in many countries, ECEC professionals need to renew their licences at regular intervals. In Finland however, no such licensing procedure is required to work in ECEC (Quality in Early Childhood Education and Care, 2013).

In the Netherlands, playgroup workers and workers in childcare centres need a qualification on the secondary vocational level. Childcare is an area of specialisation within the field of social work (e.g., including care for children, persons with disabilities, and the elderly, leading to qualification as a pedagogical worker (Quality in Early Childhood Education, 2013). Pre-primary teachers are trained for both the pre-school and primary sectors (children between 0 and 4 years of age). The basic training requirement for primary school (children between 4 and 12 years of age) teachers is a 4-year programme of vocational higher education (OECD Family Database, 2010). In Australia, kindergarten/preschool teachers are generally trained at the same level and in the same training institution as primary school teachers. The basic for childcare workers (children between 0 and 5 years of age) are tertiary training lasting either 2 or 3 years or 4 years, and for teachers (children between 0 and 8 years of age) tertiary training lasting 3 to 4 years (OECD Family Database, 2010).

Finally, the quality of formal childcare and early education services is difficult to measure as there is no single indicator that adequately reflects the qual- 
ity of the service environment and the quality of the interaction between staff and children (OECD Family Database, 2010).

\subsubsection{The changing socio-economic trends}

The outermost layer in the socio-ecological model is the chronosystem (Brofenbrenner 1994). According to Bronfenbrenner (1994), this layer encompasses change or consistency over time not only in the characteristics of the individual but also of the environment in which that individual lives. Elements within this system can be either external (e.g., timing of parent's death), or internal (e.g., psychological changes that occur with the growing up of a child). As children get older, they may react differently to environmental changes and may be better able to assess how that change will influence them (Bronfenbrenner, 1994). Of paramount importance is to recognize these ecological circumstances and changes that determine with whom and how the child spends his/her time (Bronfenbrenner, 1974).

First, women are increasingly engaging in salaried work outside the home, and hence the role of a full-time mother is becoming less common. This trend towards greater female engagement in the labour market it is likely to continue (UNICEF, 2008). Today's rising generation is the first in which a majority will spend a large part of their early childhood in some form of out-of-home childcare (UNICEF, 2008). On average across the OECD countries with 2005 and 2011 data, enrolments in early childhood education programs rose from $64 \%$ of 3 -year-olds in 2005 to $70 \%$ in 2011, and similarly from $78 \%$ of 4 -year-olds in 2005 to $84 \%$ in 2011 (OECD, 2013).

Second, quick changes in the prevalence of overweight and obesity among preschool children indicate that the preschool population has undergone rapid changes in lifestyle in recent years (Reilly, 2008). Lifestyle changes over the past generations include reduced levels of PA (e.g., reduced school PE, occupational PA, transport-related PA, such as walking, cycling), increased TV viewing and other forms of $\mathrm{SB}$, reduced energy intake but a marked change in eating patterns (e.g., fast food, eating out), and changes in family and community structure (e.g., dual-earner families, single parent families, safety concerns) among others (Malina, 2001). Gubbels, Van Kann, de Vries, Thijs, and Kremers (2014) have reported that the interaction between childcare and home is influencing children's health behaviour. Moreover, even where parents and childcare staff may have different child-rearing values and practices, parents should communicate clear and realistic expectations to childcare workers concerning their involvement in children's PA, and they should support them in this role (Gagné \& Harnois, 2014; Gubbels et al., 2014).

Third, the physical, economic, and social environments in which modern humans sit or move within the contexts of their daily lives have been changing rapidly, particularly since the middle of the last century (Owen et al., 2010). For instance, changes in transportation, communications, workplace, and domestic entertainment technologies have been associated with significantly reduced demands for PA (Owen et al., 2010). Further, in recent years, Internet use has 
increased among European children (Livingstone \& Haddon, 2009). In line with this, a recent Children's Media Barometer (2013) showed that whereas on average half of 0- to 8-year-old Finnish children used the Internet in 2010, by 2013 this had risen to $90 \%$ (Suoninen, 2014). In 2013, $40 \%$ of 0 -to 2 -year-olds, $60 \%$ of 3 - to 4 -year-olds, and $66 \%$ of 5-to 6-year-olds used the Internet weekly. In 2010, the Internet was used mainly for playing games, whereas in 2013 it was more often used for watching audio-visual programmes, with playing games in second place. Playing digital games was the only use of media in which there was a clear difference between boys and girls: boys started playing a bit younger and played games more often than girls (Suoninen, 2014).

The importance of the Internet for work, education, community, politics, family life and social relationships raises new questions for researchers, policy makers and the public (Livingstone \& Haddon, 2009). Currently, schools have a key role to play in encouraging and supporting creative, critical and safe uses of the Internet, crucially throughout the curriculum but also at home and elsewhere (Livingstone \& Haddon, 2009). However, it seems that now, and in the future, Internet use will play a major role in the daily lives of children already in early childhood. Additionally, it is expected that the use of the Internet and new online technology such as portable tablet computers will also increase among preschool children. This emphasizes the need to develop supporting media education for safer Internet use already in childcare settings.

All these earlier mentioned phenomena are leading toward lifestyle with low PA and high SB (Reilly, 2010), and that the majority of preschool children do not participate in adequate amounts of PA and engage in excessive amounts of screen-based entertainment (Hinkley et al., 2012). Indeed, children today are overly passive in nature, and active outdoor play is decreasing (Clements, 2004). Further, the secular trends in children's motor performance (e.g., decline in running and coordination) have been relatively constant and rapid over the last 20 years (Tomkinson, Léger, Olds, \& Cazorla, 2003; Vandorpe et al., 2011). In contrast, children's participation in organized sport has increased, at least in Finland (Kansallinen liikuntatutkimus, 2009-2010; Nupponen et al., 2010). This may lead one to expect that in the future children's natural and spontaneous physically active play outdoors will be replaced partially by participation in structured PA in sport clubs, but mainly by spending more time indoors in SB. Currently, however, the question is how to tempt children to engage in spontaneous outdoor play, rather than how to increase their PA intensity levels. 


\section{METHODS OF ASSESSING PHYSICAL ACTIVITY IN CHILDREN}

A wide range of methods has been used to measure PA in children. Measurement methods should be at the same time accurate and practical when assessing the relationship between children's PA and health, estimating or describing the prevalence of PA behaviour in a population, setting PA recommendations or when evaluating the efficacy of interventions (Oliver et al., 2007; Pate et al., 2010). Ideally PA measurement methods should provide valid and reliable assessments of frequency, duration, intensity and type in specific behavioural settings (e.g., home, childcare) (Oliver et al., 2007; Pate et al., 2010; Trost, 2007; Welk, 2002, p. 4). In measuring PA behaviour, a variety of units, such as EE, METs, minutes of time spent at different activity intensity levels (e.g., sedentary, light, moderate, vigorous, MVPA), frequency of continuous bouts, and ordinal activity ratings (i.e. low, moderate and highly active) have been used (Trost, 2007; Welk, 2002, p. 5). When measuring PA in children, it is important note the difference between PA, which refers to body movement, and $\mathrm{EE}$, which is a result of body movement. For instance, a lean child and an overweight child may engage in the same PA, but expend different amount of energy on that activity (Trost, 2007). When measuring children, researchers must also ensure that there is nothing in the research setting or activity that could harm, e.g., frighten, embarrass, or negatively affect, the participants (Thomas, Nelson, \& Silverman, 2011, p. 90). Further, researchers should value the well being and rights of participants, such as the right to privacy or nonparticipation, the right to remain anonymous, the right to confidentiality, and the right to expect experimenter responsibility (Thomas et al., 2011, p. 90).

The purpose of this chapter is to provide an overview of the methods that have been developed for measuring PA in preschool age children. These include accelerometers, direct observation, self-reports, pedometers, heart rate monitors and doubly labelled water (DLW) (Oliver et al., 2007; Pate et al., 2010; Trost, 2007; Welk, 2002, p. 21). Here, the emphasis is on accelerometers and direct observation, as these have been the research methods used in the present doctoral research. 
In epidemiological research and surveillance studies, PA has traditionally been measured with a variety of self-report methods (Trost, 2007). These include self-administered recall, interviewer-administered recall, diaries and proxy reports completed by parents or teachers (Trost, 2007). A distinct advantage of self-report methods is that are low cost, less time consuming and easy to administer and interpret with a large survey population, while they also provide information on the type and context of PA (Oliver et al., 2007; Trost, 2007; Welk, 2002, p. 21). Although the Previous Day Physical Activity Recall (PDPAR) and Three-Day Physical Activity Recall (3DPAR) instruments have been shown to be valid, reliable and able to detect changes in PA behaviour in children (Trost, 2007), no standardised questionnaire has been developed and sufficiently evaluated for the assessment of PA in preschool-aged children (Oliver et al., 2007). Because children under age 10 cannot report their own PA owing to limitations in their cognitive- and recall ability, proxy reports by parents are considered a suitable option for questionnaires and surveys (Oliver et al., 2007; Pate et al., 2010; Trost et al., 2007). However, a disadvantage of proxy reports is that they do not provide accurate estimates of the amount and intensity of activity (Corder et al., 2009). Furthermore, it is challenging for parents to evaluate the sporadic and intermittent nature of their child's activity behaviour, and impossible in situations where they are not constantly observing the child's behaviour, such as during childcare attendance time.

Pedometers-small devices typically mounted at the hip-measure the frequency of movement in the vertical plane (up and down movement) (Oliver et al., 2007; Pate et al., 2010). Pedometers are easy to use, they do not require researcher or participant training or software, or any initializing or downloading; moreover, step counts can be read directly from the device (Oliver et al; Pate et al. 2010). However, pedometers are specifically designed to assess steps and distances in walking or running only, they do not provide information on the frequency, duration, type, intensity, or context of PA (Pate et al., 2010; Trost, 2007; Welk, 2002, pp. 164-165). Furthermore, pedometer steps are influenced by factors such as body size and speed of locomotion, and therefore researchers should exercise particular caution when using pedometers with growing children (Trost, 2007). Nevertheless, electronic pedometers provide valid assessments of the relative volume of PA in children (Trost, 2007; Welk, 2002, p. 174).

Heart rate monitoring also can be used to measure PA in preschool-aged children. The method assumes a linear relationship between increase in PA and heart rate (Pate et al., 2010). Heart rate monitors have shown good associations with EE, they describe intensity, frequency, and duration well (adults), and they are relatively inexpensive with multiple day storage capacity (Welk, 2002, p. 21). However, Trost (2007) has listed several limitations associated with the method. For instance, factors such as age, body size, and proportion of muscle mass used, emotional, stress and cardiorespiratory fitness influence the heart rate $\mathrm{VO}_{2}$ relationship. Second, heart rate monitoring may mask the sporadic activity patterns of young children. Finally, heart rate monitoring is especially suited to aerobic activities, and therefore may be of limited use in assessing total daily 
PA, as a large percentage of a child's day is spent in relatively inactive pursuits such as sitting (Trost, 2007; Welk, 2002, p. 21).

Finally, the DLW method offers an unobtrusive and non-invasive means to measure total daily EE related to PA in free-living children (Trost, 2007). Although the method provides accurate estimates of PA-related EE over one- to two-week periods, it does not provide duration or intensity estimates of EE in different categories of PA, such as light, moderate or vigorous (Welk, 2002, p. 205), or associations with assessments of patterns of PA (Trost, 2007; Welk, 2002, p. 21). Another major limitation associated with the DLW method is its high cost (Welk, 2002, p. 21). Despite these limitations DLW is useful for the validation of other methods, such as accelerometers (Corder et al., 2009; Oliver et al., 2007).

\subsection{Accelerometers}

Accelerometers have become one of the most widely used methods for assessing preschool-aged children's PA and SB in population-based research (Cliff et al., 2009; Oliver et al., 2007; Pate et al., 2010; Reilly et al., 2008; Rowlands, 2007; Ward, Evenson, Vaughn, Brown Rodgers, \& Troiano, 2005). Accelerometers are relatively inexpensive compared to DLW (Corder et al., 2009), although higher cost than pedometers or questionnaires (Welk et al., 2012). Accelerometers provide a real-time indication of the frequency, intensity and duration of activity, EE and daily step counts for prolonged periods with minimal interference in daily life (Cliff et al., 2009; Oliver et al., 2007; Pate et al., 2010; Reilly et al., 2008; Rowlands, 2007). A number of different accelerometers are commercially available for researchers; until now, ActiGraph accelerometers have been the most widely used monitors (Trost, 2007). ActiGraph accelerometers have been used throughout this study, and therefore will be described and discussed in more detail.

The ActiGraph accelerometer is small (38x37x18 mm), lightweight $(27 \mathrm{~g})$ (ActiGraph, GT3X-Specifications [http://www.theactigraph.com/wpcontent/uploads/GT3X-Specs.pdf]), aunobtrusive to wear, and imposes a minimal participant burden (Cliff et al., 2009; Oliver et al., 2007). As reported in the previous literature, receptivity to wearing the monitor has been shown to be high among preschool children (Cardon \& De Bourdeaudhuij, 2008; Costa, Barber, Griffiths, Cameron, \& Clemes, 2013; Pate et al., 2004; Van Cauwenberghe, Gubbels, De Bourdeaudhuij, \& Cardon, 2011a). In addition, the device does not contain buttons/keypads or screens that could be pressed, and therefore the child cannot affect the measurement. However, there remains the possibility of children taking the device off or playing with it if its presence is noted (Costa et al., 2013).

Accelerometers are typically worn on an elastic belt, and placed at the right side of the hip (Pate et al., 2010; Ward et al., 2005), and so are capable of assessing whole-body movements (Cliff et al., 2009). The principle of acceler- 
ometry is to measure the acceleration of the body along one, two or three axes (John \& Freedson, 2012). The ActiGraph GT3X accelerometer (ActiGraph, LLC, Pensacola, FL, US), the model used in this study, measures movement along three axes (vertical, antero-posterior/horizontal, and medio-lateral/diagonal) (John \& Freedson, 2012). Although previous research has found that tri-axial accelerometers generate data with a higher level of validity than uniaxial accelerometers (Rowlands, 2007), conjecture remains as to whether tri-axial accelerometers detect PA better than uniaxial accelerometers in children (Oliver et al., 2007). A recent study has suggested that a tri-axial accelerometer has no advantage over a uniaxial model (Hislop, Bulley, Mercer, Reilly, 2012). Moreover, the vertical plane has been shown to be most important for measuring ambulatory movement (Oliver et al., 2007).

In 2009, ActiGraph released the GT3X, which contains an ADXL335 accelerometer and a tri-axial capacitive MEMS sensor, which measures acceleration in the range of -3 to $+3 \mathrm{~g}$ (John \& Freedson, 2012). The GT3X has the capability to measure both static acceleration (e.g., force of gravity detected when stationary) and dynamic acceleration, provides inclinometer output, and is able to utilise vector magnitude data from all three axes (John \& Freedson, 2012). A capacitive accelerometer detects change in acceleration through changes in the capacitance of the sensing element; in other words, variations in the sensor's electric charge storage. Therefore, this monitor is more accurate than the former piezoelectric sensor-based monitors (John \& Freedson, 2012).

Accelerometer output samples are summed over a user-specified time sampling interval, called an "epoch" and stored to an internal memory (Kim et al., 2012; Rowlands, 2007). Owing to the sporadic and intermittent nature of young children's PA behaviour, it is recommended to use epochs, such as 15 seconds or less (Cliff et al., 2009; Freedson, Pober, \& Janz, 2005; Rowlands, 2007; Ward et al., 2005). The use of short epochs might be particularly important in studies in which the outcome of interest is bone health, as short bursts of highintensity activity are particularly pertinent (Rowlands, 2007). Improvements in battery life and memory size data storage capacities have made it possible to use very short epochs (ActiGraph GT3X: minimum $1 \mathrm{~s}$ epoch, and more recent models (GT3X+: raw acceleration data up to $100 \mathrm{~Hz}$ ) and conduct measurements lasting several days or weeks (GT3X: 16Mb) (John \& Freedson, 2012). Despite the recommendation to use shorter epochs, Reilly et al. (2008) found no differences across epochs $(15,30,45$ and $60 \mathrm{~s})$ in minutes per day of sedentary time, although the estimates of minutes of MVPA did differ significantly, with shorter epochs overestimating the time spent engaged in MVPA. In line, Hislop et al. (2012) found a significant epoch effect, with longer epochs resulting in significantly fewer minutes being classified as MVPA. However, no previous study has determined which epochs are more accurate relative to a criterion method (Hislop et al., 2012). Since 2010, firmware modifications to the GT3X also enable measurement of $\mathrm{G}$ force in the pre-filtered raw mode (sampling frequency of $30 \mathrm{~Hz}$ ), a procedure which is highly recommended over activity counts (John \& Freedson, 2012). 
When measuring young children's PA, a seven-day monitoring protocol is needed to provide reliable estimates of habitual PA behaviour (Trost, Pate, Freedson, Sallis, \& Taylor, 2000; Ward et al., 2005), although in 3-to 5-year-olds a minimum of three days may be sufficient (Cliff et al., 2009). Dössegger et al. (2013) suggest that in the case of preschool-aged children researchers should plan two familiarization days and collect data over a period of at least seven days. Monitoring days should include both weekdays and weekend days, and the start days should be randomly assigned (Dössegger et al., 2013), although according to Cliff et al. (2009), daily PA in early childhood is more likely to be influenced by daytime sleeping patterns and less by difference between weekdays and weekend days. The goal is to monitor activity for a sufficient number of days so that the resulting daily average reflects the child's usual or habitual level of PA (Trost, 2007). Where the aim is to define PA during waking time, it is recommended to wear accelerometers the whole day and to take them off only for the purposes of sleeping, swimming, and bathing (Pate et al., 2010; Trost, 2007). However, as the child would have to remember to put the monitor on after waking, Rowlands (2007) suggests the accelerometer be worn night and day.

Cliff et al. (2009) suggest that, in the performing data reduction, data should be screened to determine non-wear time (e.g., 20 consecutive minutes of ' 0 ' counts) and the upper range of biologically plausible counts (e.g. ActiGraph: > 15,000 counts). It should be noted that definitions of a "complete day" vary. One approach to determining a day is the $70 / 80$ rule, where a day is defined as the period during which recorded accelerometer data exist for at least $70 \%$ of the study population, and that $80 \%$ of that observation period constitutes a minimal day for inclusion in the data analysis (Ward et al., 2005). The number of hours of monitoring required to represent a typical day might be less in the early developmental years than post entry into formal education (Cliff et al., 2009). Current evidence suggests that three hours per day of monitoring can provide reliable estimates of PA in 3- to 5-year-old children, and that the difference between monitoring three and 10 hours per day is minimal (Cliff et al., 2009).

A disadvantage of accelerometers is that they do not provide information on the type or context of PA (Pate et al., 2010). In addition, accelerometers are limited in their ability to measure non-weight-bearing activities, such as swimming, cycling, and skating or upper limb movements, (e.g., digging, carrying and pushing objects). They are not able to account for the increased energy cost associated with walking up stairs, on an incline or on soft surfaces (Cliff et al., 2009; Oliver et al., 2007; Pate et al., 2010; Rowlands, 2007; Trost, 2007). Also, accelerometers do not detect movements which are sedentary but need balance and/or concentration in order to develop motor skills or are integral to certain low intensity activities (e.g., singing, drawing and completing puzzles), which are particularly important for young preschool children (Cliff et al. 2009). Moreover, a recent study by Laukkanen et al. (2013) drew attention to the relationship between gross motor skills and PA, stressing the importance of both metabolic and neuromuscular systems in 5-to 8-year-old children. 
Accelerometry output does not have biological meaning per se and must be validated against criterion measures (either direct observation of activity or energy expended on activity) (Reilly et al., 2003). The key goal is to determine the relationship between the raw accelerometer output and actual levels of PA (Ward et al., 2005; Welk et al., 2012). To assess the amounts of the time children spend at the different intensity levels (i.e., sedentary, light, moderate, vigorous), separate cut points for preschool-aged children are needed (Ward et al., 2005). A total of seven studies have validated the ActiGraph accelerometer among preschool children (between 4 and 6 years of age) (Butte et al., 2013; Evenson, Catellier, Gill, Ondrak, \& McMurray, 2008; Pate, Almeida, McIver, Pfeiffer, \& Dowda, 2006; Reilly et al., 2003; Sirard, Trost, Pfeiffer, Dowda, \& Pate, 2005; Trost, Fees, Haar, Murrays, \& Crowe, 2012; Van Cauwenberghe, Labarque, Trost, De Bourdeaudhuij, \& Cardon, 2011b), yet only three of them have published cut points for 3-year-old or younger children (Pate et al., 2006; Sirard et al., 2005; Trost et al., 2012; see Table 2). 
TABLE 2 Description of the most common sets of ActiGraph accelerometer cut points used in the preschool-aged population.

\begin{tabular}{|c|c|c|c|c|c|c|c|c|c|}
\hline \multirow{2}{*}{ Study/Authors } & \multirow[t]{2}{*}{ Sample } & \multirow{2}{*}{$\begin{array}{l}\text { Criterion } \\
\text { measure }\end{array}$} & \multirow{2}{*}{ Calibration activities } & \multirow{2}{*}{$\begin{array}{l}\text { Analytical } \\
\text { procedure }\end{array}$} & \multicolumn{5}{|c|}{$\begin{array}{l}\text { Intensity specific ActiGraph accelerometer cut points } \\
\text { (counts/15 s) }\end{array}$} \\
\hline & & & & & sedentary & light & moderate & vigorous & MVPA \\
\hline $\begin{array}{l}\text { Butte et al.* 2013a } \\
\text { x-axes } \\
\text { Butte et al.* } 2013^{a} \\
\text { vector-magnitude }\end{array}$ & $\begin{array}{l}3-5 y \\
n=50+105 \\
\text { US }\end{array}$ & $\begin{array}{l}\text { Indirect } \\
\text { calorimetry, } \\
\text { DLW }\end{array}$ & $\begin{array}{l}\text { Performing a series of physical } \\
\text { activities (e.g., TV viewing, } \\
\text { playing with toys, dancing, } \\
\text { running and napping) }\end{array}$ & $\begin{array}{l}\text { Smoothing } \\
\text { splines; ROC } \\
\text { curve }\end{array}$ & $\begin{array}{l}0-59 \\
0-819\end{array}$ & $\begin{array}{l}60-529 \\
820-3907\end{array}$ & $\begin{array}{l}530-1112 \\
3908-6111\end{array}$ & $\begin{array}{l}\geq 1113 \\
\geq 6112\end{array}$ & $\begin{array}{l}\geq 530 \\
\geq 3908\end{array}$ \\
\hline $\begin{array}{l}\text { Evenson } \\
\text { et al. 2008b }\end{array}$ & $\begin{array}{l}5-9 \mathrm{y}, n=33 \\
\text { US }\end{array}$ & $\begin{array}{l}\text { Indirect } \\
\text { calorimetry }\end{array}$ & $\begin{array}{l}\text { Sit, watch DVD, colouring, } \\
\text { slow walking, stair climbing, } \\
\text { basketball, brisk walking, } \\
\text { bicycling, jumping jacks, run- } \\
\text { ning }\end{array}$ & ROC curve & $0-25$ & $26-573$ & $574-1002$ & $\geq 1003$ & $\geq 574$ \\
\hline $\begin{array}{l}\text { Pate } \\
\text { et al. 2006 b }\end{array}$ & $\begin{array}{l}3-6 y, n=29, \\
\text { US }\end{array}$ & $\begin{array}{l}\text { Indirect } \\
\text { calorimetry }\end{array}$ & $\begin{array}{l}\text { Resting, slow walking, brisk } \\
\text { walking, running }\end{array}$ & $\begin{array}{l}\text { Random coef- } \\
\text { ficient regres- } \\
\text { sion }\end{array}$ & $0-37$ & $38-419$ & $420-841$ & $\geq 842$ & $\geq 420$ \\
\hline $\begin{array}{l}\text { Reilly } \\
\text { et al.* } 2003^{b}\end{array}$ & $\begin{array}{l}3-4 \mathrm{y}, n=30 \\
\text { Scotland }\end{array}$ & $\begin{array}{l}\text { Direct obser- } \\
\text { vation (CPAF) }\end{array}$ & Usual nursery activities & ROC curve & $0-275$ & & & & \\
\hline $\begin{array}{l}\text { Sirard } \\
\text { et al. } 2005^{\mathrm{b}}\end{array}$ & $\begin{array}{l}3 \mathrm{y}, n=5 \\
\text { US }\end{array}$ & $\begin{array}{l}\text { Direct obser- } \\
\text { vation (CARS) }\end{array}$ & $\begin{array}{l}\text { Sitting, sitting and playing, } \\
\text { slow walking, fast walking, } \\
\text { jogging }\end{array}$ & ROC curve & $0-301$ & $302-614$ & $615-1230$ & $\geq 1231$ & $\geq 615$ \\
\hline $\begin{array}{l}\text { Trost } \\
\text { et al. 2012c }\end{array}$ & $\begin{array}{l}1-3 \mathrm{y}, n=22, \\
\text { US }\end{array}$ & $\begin{array}{l}\text { Direct obser- } \\
\text { vation (CARS) }\end{array}$ & Free play session & ROC curve & $0-48$ & $49-418$ & $\geq 419$ & & $\geq 419$ \\
\hline $\begin{array}{l}\text { Van Cauwen- } \\
\text { berghe } \\
\text { et al. } 2011 b^{c}\end{array}$ & $\begin{array}{l}4-6 y, n=18 \\
\text { Belgium }\end{array}$ & $\begin{array}{l}\text { Direct obser- } \\
\text { vation (CARS) }\end{array}$ & $\begin{array}{l}\text { Sitting, standing, drawing, } \\
\text { walking, jogging at seven } \\
\text { speed levels, free play session }\end{array}$ & ROC curve & $0-372$ & $373-584$ & $585-880$ & $\geq 881$ & $\geq 585$ \\
\hline
\end{tabular}

Note. ActiGraph $(a=$ GT3X+; $b=7164 ; c=$ GT1M); CARS = Child Activity Rating Scale; CPAF = Children's Physical Activity Form; ROC = Receiver Operating Characteristic; MVPA = moderate-to-vigorous physical activity; All cut points reported as counts $/ 15 \mathrm{~s}$. ${ }^{*}$ Originally developed as counts $/ 60 \mathrm{~s}$, all other developed as counts $/ 15 \mathrm{~s}$. 
The accuracy of the existing cut points has subsequently been tested in independent validation studies in different settings (e.g., criteria measures, participants, epoch lengths) (Kim et al., 2012). Evenson et al. (2008), Pate et al. (2006), Sirard et al. (2005), Trost et al. (2012) and Van Cauwenberghe et al. (2011b) validated a 15-second cut point, while Butte et al.'s (2013) and Reilly et al.'s (2003) cut points were originally validated as a one-minute cut point. In all studies, validation was based on single plane (vertical) counts, except in that of Butte and colleagues (2013), in which vector magnitudes were also computed. With the GT3X+ came on the market Vector magnitude is a new feature that came with the GT3X+, and Butte's cut-points are the first to use this system (Butte et al., 2013). Butte et al. (2013), Evenson et al. (2008) and Pate et al. (2006) used indirect calorimetry, a metabolic criterion measure, to calibrate their accelerometry cut points. In contrast, Reilly et al. (2003), Sirard et al. (2005), Trost et al. (2012) and Van Cauwenberghe et al. (2011b) used the direct observation scale, a behavioural criterion measure. However, both indirect calorimetry and direct observation are considered an appropriate criterion for validation (Freedson et al., 2005; Welk, 2005). To provide a true evaluation of how accelerometers perform under real-world conditions, the validation of accelerometers in freeliving activities in the field is recommended (Welk, 2005). The cut point that estimates the intensity level (e.g., MVPA) closest to that criterion measure is considered the most "accurate" and recommended for widespread application (Kim et al., 2012).

As Table 2 shows, for SB, the cut points ranged from $<25$ to $<372$ counts per 15 seconds, for light PA, they ranged from $>418$ to $>614$ counts per $15 \mathrm{sec}-$ onds, and for MVPA, they ranged from $>842$ to $>1231$ counts per 15 seconds. The application of different cut points makes comparison between studies problematic, leading to conflicting conclusions about different activity intensity levels (Hislop et al., 2012; Kim et al., 2012). Recent studies have indicated that the cut points proposed by Pate et al. (2006) and Van Cauwenberghe et al. (2011b) significantly overestimated minutes of MVPA in preschool children (Hislop et al., 2012). In turn, Reilly et al. (2003), Sirard et al. (2005) and Van Cauwenberghe et al. (2011b) seemed to overestimate SB time by over 10 minutes (Trost et al., 2012). The results of Janssen et al. (2013) and Trost et al. (2012) supported the use of $\geq 420$ counts per 15 seconds (Pate et al., 2006) for MVPA, whereas, Hislop et al. (2012) suggested the use of the age-specific cut points for MVPA suggested by Sirard et al. (2005). For the ActiGraph x-axes, the sedentary cut point of Butte et al. (2013) was similar to that of Trost et al. (2012), but much lower than those of Reilly et al. (2003), Sirard et al. (2005), and Van Cauwenberghe et al. (2011b), probably due to the different statistical approaches applied. Further, the cut points for MVPA of Butte et al. (2013) were slightly higher than those of Pate et al. (2006) and Trost et al. (2012), but lower than those of Sirard et al. (2005) (Butte et al., 2013). To date, the cut point of $<25$ counts per 15 seconds (< 100 counts per minute [cpm]) has been found to be the most appropriate for SB (Fischer, Yildırım, Salmon, \& Chinapaw, 2012; Janssen et al., 2013; Trost et al., 2012), while there is no widely agreed upon cut point for MVPA (Kim et al., 
2012). Moreover, in light of the on-going debate, there is no consensus as to which cut points are most appropriate for preschool children (Bornstein et al., 2011; Kim et al., 2012).

Taken together, majority of accelerometer validation studies have reported a strong positive correlation between ActiGraph accelerometer output and intensity of PA in children (Hislop et al., 2012; John \& Freedson, 2012; Pate et al., 2010; Rowlands, 2007; Trost, 2007). Strong evidence also exists for moderate to good validity and good reproducibility of the ActiGraph accelerometers in samples of preschool-aged children (de Vries et al., 2009). However, different methodological decisions and approaches to processing accelerometer data have led to the use of a variety assessment of methods (Cliff et al., 2009, Kim et al., 2012; Matthews, Hagströmer, Pober, \& Bowles, 2012; Rowlands, 2007). While their strengths and limitations continue to be widely discussed in the literature, accelerometers have been consistently acknowledged to be a reasonably accurate and reliable tool for measuring PA and SB in free-living preschool children (Cliff et al., 2009; Matthews et al., 2012; Pate et al., 2010; Rowlands, 2007; Trost, 2007; Van Cauwenberghe et al., 2011b).

\subsection{Direct observation}

Traditionally, PA type and patterns in early childhood have been determined by direct observation of a child and coding the PA performed (Oliver et al., 2007). Typically, in the direct observation method, two trained observers record PA behaviour for a predetermined period using codes that indicate specific types of PA behaviour. The length of an observation period varies from 30 minutes to an entire day (Pate et al., 2010). In recent years, many different direct observation systems have been used in PA research among young children: the Children's Activity Rating Scale (CARS), the Code for Active Student Engagement Revised (CASPER II), the Children's Physical Activity Form (CPAF), the Behaviors of Eating and Activity for Child Health Evaluation System (BEACHES), the System for Observing Fitness Instruction Time (SOFIT), the System for Observing Play and Leisure Activity in Youth (SOPLAY), the Environment and Policy Assessment and Observation (EPAO), and The Early Childhood Environment Rating Scale - Revised (ECERS-R), and OSRAC-P (Brown et al., 2006; Cosco et al., 2010; Pate et al., 2010).

The CARS and the CPAF focus solely on PA intensity. The CARS system categorizes activity intensity across five intensity levels: 1) stationary-no movement, 2) stationary-with movement, 3) translocation-slow, 4) translocation-moderate, and 5) translocation-fast, whereas the CPAF has four intensities: 1) stationary-no movement, 2) stationary-limb movement, 3) slow trunk movement, and 4) rapid trunk movement (Pate et al., 2010). The first, BEACHES, was developed specifically to assess the behaviours of young children at home and during preschool recess although it can also be used in other settings as well (Welk, 2002, p. 188). The BEACHES measures ten categories: 1) environment, 2) 
physical location, 3) activity level (i.e., lying down, sitting, standing, walking, and very active), 4) eating behaviour, 5) inter actor, 6) antecedents, 7) prompted event, 8) child response, 9) consequences, and 10) consequent event (Pate et al., 2010). The SOFIT was designed to measure student PA, lesson context, and teacher behaviour during PE classes (Welk, 2002, p. 189). While BEACHES and SOFIT were designed to measure the PA of individuals only, SOPLAY was developed to assess the PA of groups of people. SOPLAY assess the number of people in a designated activity area and their activity levels (i.e., sedentary, walking, very active) using momentary time sampling (Welk, 2002, pp. 189190). The EPAO instrument was created to evaluate the Nutrition and PA SelfAssessment for Child Care (NAP SACC) program, an environmental nutrition and PA intervention in childcare (Ward et al., 2008). The EPAO protocol consists of a full day visit to a childcare centre and includes direct observation (e.g., food and beverages served, staff-child meal interactions, active play time opportunities and SB opportunities) and document review (e.g., an evaluation of the teacher's lesson plan, past or future fund-raising documents, handbooks) activities (Ward et al., 2008). The ECERS-R has seven dimensions, which evaluate space and furnishings, personal care routines, language reasoning, activities, interaction, program structure, and parent-staff needs (Dowda et al., 2004). An eco-behavioural observational system, called the CASPER II, has been designed to collect information about preschool environments and the behaviour of children and adults within those environments. It consists of seven ecological variables and provides information about child behaviour, child social behaviour, and adult behaviour (Brown, Odom, Li, \& Zercher, 1999).

The OSRAC-P coding system was initially developed in 2002. It is a combination of three different observational systems, 1) the CARS, 2) the CASPER II, and 3) the Observational System for the Environmental Determinants of Physical Activity in Preschool Children Study (Brown et al., 2009c). The OSRAC-P method measures and enables researchers to record the following eight observational categories: 1$)$ children's PA intensity level category $(1=$ stationary or motionless, $2=$ stationary with limb or trunk movements, 3 = slow or easy movements, $4=$ moderate movements, and $5=$ fast movements), 2) PA type category (18 codes; e.g., sitting, standing, walking), 3) group composition category (solitary, one-to-one with adult/peer, group with adult or group without adult), 4) location category (i.e., inside, outside or transition), 5) indoor educational/play context category (16 codes; e.g., art, music, self-care), 6) outdoor educational/play context category (13 codes; e.g., open space, sandbox, wheel), 7) initiator of activity category (adult or child), and 8) prompt for PA category (no prompts, teacher/peer prompt to increase PA or teacher/peer prompt to decrease PA) (Brown et al., 2006).

For data collection purposes, Brown et al. (2006) used a momentary time sampling observation system with a 5-s observation interval accompanied by a 25-s coding interval for each focal child observed (i.e., two observations per minute for 30 minutes of observation $=60$ observational samples) (Brown et al., 
2006). Hand-held Dell Axim X5 computers and the INTMAN software system were used to collect and transfer field data into a computer database.

Interestingly, although some individuals are likely to modify their activity behaviour owing to observer presence, the younger the observed child is, the less the reactivity (Malina et al., 2004, p. 462). Research experiences with preschoolers have shown that, after only few minutes, they are oblivious of the presence of the observer (Malina et al., 2004, p. 462). Direct observation is an ecological and cognitive-behavioural way to examine children's PA without disturbing a childcare centre's daily routines and habits (Welk, 2002, p. 190). OSRAC-P data provide contextually and behaviourally rich information about the social and non-social factors related to preschool children's PA (Brown et al., 2006). The benefit of the observation format is that it records not only the intensity of activity, but it also defines "where" (operational environment and equipment) and "how" physical activities are done, and "what kind of interaction" is being engaged in (Brown et al., 2006, Pate et al., 2008, Trost, 2007).

Regardless of the advantages of the method, it has several limitations that should be noted. First, in real time and multiple days, researchers may find this method rather arduous (Trost, 2007). Regardless of which observation system is used, recorded data reflecting the actual occurrence of behaviours is largely dependent on the skills of human observers (Welk, 2002, p. 185). Therefore, to ensure data accuracy, observer training (e.g., initial observer orientation, study of the observation manual and the memorization of codes and categories, direct in situ training session in field settings) is recommended (Brown et al., 2009c; Welk, 2002, p. 185). In addition, to ensure reliability between two observers, an inter-rater reliability test is recommended (Brown et al., 2006; Gubbels et al., 2011). Second, the length of the observation may influence the ability to record "real time" information (Trost, 2007). For instance, an observation period may be too short to record all the relevant contextual factors, or too long, leading to uncertainty about the order of events during the observation (Brown et al., 2006; Gubbels et al., 2011). Third, the OSRAC-P system was developed with young children in preschool settings in the US. Some OSRAC-P categories and accompanying codes may not be as relevant for other settings or in other countries (Brown et al., 2006). For instance, in Finland, childcare centres rarely have an outdoor swimming pool, although indoor swimming pools may exist. Further, skating and skiing, which are very typical Finnish activity types in wintertime, may not be so common in countries with snowless winters. Finally, no information has been published on the sensitivity of the OSRAC-P system in monitoring children's PA behaviour during interventions designed to promote their PA levels (Brown et al., 2006).

Cohen's kappa is recommended for determination of the intertester or interrater reliability (IRR) of two observers coding the same subjects on the same occasion. This measures indicates the proportion of the agreement between the two observers, corrected for change agreement (Welk, 2002, p. 188). Landis and Koch (1977) propose the following standards for strength of agreement as indicated by in the kappa coefficient: $<0.00=$ poor, $.00-.20=$ slight, $.21-.40=$ 
fair, $.41-.60=$ moderate, $.61-.80=$ substantial, and $.81-1=$ almost perfect. Previous studies have indicated substantial similarities $(\mathrm{r}>.80)$ in the reproducibility of the OSRAC-P (Bower et al., 2008; Brown et al., 2006; Pate et al., 2008). Moreover, the OSRAC-P has been shown to be a valid and reliable tool for measuring PA among preschool-aged children (Brown et al., 2006; Pate et al., 2010; Trost, 2007). 


\section{THE AIMS OF THE STUDY}

The general purpose of this doctoral study was to determine the PA behaviour of Finnish 3-year-old preschool children. The main aims were to measure children's PA intensity levels and sedentary time with accelerometers (ActiGraph), and to examine PA levels, patterns and contextual information during childcare attendance with the (OSRAC-P; Brown et al., 2006) direct observation method (see Appendix 1).

The specific research questions were as follows:

1. What PA intensity levels and patterns exist among Finnish 3-year-old preschool children? (Studies I, II)

2. Are there variations between Finland and the Netherlands in 3-yearold children's observed PA levels and contexts in childcare? (Study III)

3. Are there variations between Finland and Australia in 3-year-old children's PA intensity levels measured with accelerometers? (Study IV) 


\section{METHODS}

The four different studies reported here varied in their study population, methods of assessments, and data collection procedures. These are all described below.

\subsection{The sample}

The study sample comprised preschool children from three different countries: Finland, the Netherlands and Australia. A brief description of the study sample and the recruitment protocols used are given next.

\subsubsection{Childcare centre recruitment}

In May 2010, the principals of approximately 60 childcare centres in the city of Jyväskylä in Central Finland were provided with information on the study at a regional administrative meeting. Initially, 11 childcare centres (18\%) agreed to participate. During the measurements, it was decided to expand the sample by asking four additional childcare centres to participate in the study. Three agreed to do so, yielding a total of 14 participating childcare centres $(23 \%$; 13 municipal and one private). All the childcare centres were located in or around the city area. (See Appendix 2.)

The participating Finnish childcare centres were providing care for an average of 74 children $(S D=20)$ in 4 groups $(S D=1)$, with a mean number of staff members per centre of $16(\mathrm{SD}=5)$. The average outdoor playground size was $2800 \mathrm{~m}^{2}$ (range: $250-6300 \mathrm{~m}^{2}$ ). One centre offered care services at flexible hours, between 5.30 a.m. and 10 p.m., while others followed the usual opening hours and timetables. Table 3 shows typical daily programmes of childcare centres in involved countries in this study. 
TABLE 3 Typical daily programmes of childcare centres involved in the study.

\begin{tabular}{|c|c|c|c|c|c|}
\hline Time & $\begin{array}{c}\text { Finland } \\
\text { Content of activity }\end{array}$ & Time & $\begin{array}{l}\text { The Netherlands } \\
\text { Content of activity }\end{array}$ & Time & $\begin{array}{c}\text { Australia } \\
\text { Content of activity }\end{array}$ \\
\hline $6.30 \mathrm{am}$ & $\begin{array}{l}\text { Centre opens, unstructured } \\
\text { play indoors }\end{array}$ & $7.30 \mathrm{am}$ & $\begin{array}{l}\text { Centre opens, unstructured } \\
\text { play indoors }\end{array}$ & $\sim 7.30 \mathrm{am}$ & $\begin{array}{l}\text { Centre opens, unstructured } \\
\text { play indoors and/or outdoors }\end{array}$ \\
\hline 8 am & Breakfast & $9.30 \mathrm{am}$ & Snack & $8 \mathrm{am}$ & Breakfast \\
\hline $9 \mathrm{am}$ & $\begin{array}{l}\text { Structured activities inside, } \\
\text { unstructured play indoors } \\
\text { and/or outdoors }\end{array}$ & $10 \mathrm{am}$ & $\begin{array}{l}\text { Structured activities inside, } \\
\text { unstructured play indoors } \\
\text { and/or outdoors }\end{array}$ & $9.30 \mathrm{am}$ & Morning tea \\
\hline $11 \mathrm{am}$ & Lunch & $11.30 \mathrm{am}$ & Lunch & $11.30 \mathrm{am}$ & Lunch \\
\hline $12 \mathrm{pm}$ & Resting time & $12.30 \mathrm{pm}$ & $\begin{array}{l}\text { Resting time (younger chil- } \\
\text { dren)/unstructured play } \\
\text { indoors (older children) }\end{array}$ & $12 \mathrm{pm}$ & Resting time or quiet activities \\
\hline $2 \mathrm{pm}$ & Snack & $3 \mathrm{pm}$ & Snack & $3 \mathrm{pm}$ & Afternoon tea \\
\hline $2.30 \mathrm{pm}$ & Unstructured play indoors & $3.30 \mathrm{pm}$ & Unstructured play indoors & $3.30 \mathrm{pm}$ & $\begin{array}{l}\text { Structured/unstructured play } \\
\text { indoors and/or outdoors }\end{array}$ \\
\hline $\begin{array}{l}3 \mathrm{pm} \\
5 \mathrm{pm}\end{array}$ & $\begin{array}{l}\text { Unstructured play outdoors } \\
\text { Centre closes }\end{array}$ & $6 \mathrm{pm}$ & $\begin{array}{l}\text { and/or outdoors } \\
\text { Centre closes }\end{array}$ & $\begin{array}{l}5.30 \mathrm{pm} \\
\sim 6 \mathrm{pm}\end{array}$ & $\begin{array}{l}\text { A late afternoon meal/snack } \\
\text { Centre closes }\end{array}$ \\
\hline
\end{tabular}

In the Netherlands, a large Dutch childcare coordinating organization in Maastricht, Maatwerk In Kinderopvang (MIK; i.e., customized childcare), was approached and agreed to conduct the study. All nine MIK childcare centres agreed to participate. Recruitment was implemented in 2008 by a research team from Maastricht University. In Australia, childcare centre managers were contacted one by one through emails and phone calls, and personal researcher visits to each selected childcare centre. The 13 Australian childcare centres involved in the study were based the inner and outer western urban regions of Melbourne. These childcare centres were either community based (i.e., administered by the local municipal authority) or privately managed facilities. The recruitment was done in collaboration with Victoria University in the year 2012.

\subsubsection{Participants}

In Finland, all the families of the 3-year-old children attending the participating childcare centres were invited to participate to the study via an information letter given by hand or emailed or mailed to their street address by the principal of their local childcare centre (Appendix 3). Inclusion criteria were that year of birth 2007, and good health status with no diagnosed disorders. One hundred and two $(57 \%)$ parents of 179 families provided informed consents (Appendix 4). A total of 96 children ( 48 boys, 48 girls), of whom six were in homecare during the measurements, participated in the autumn data collection. After the first phase of measurements, eight new participants were recruited. A total of 94 children (50 boys, 44 girls) of whom 14 were in homecare, participated in the corresponding winter collection. Furthermore, between the measurements, one child, who changed to another childcare centre, opted out, and one child did not participate in either of the measurements. The numbers of participants varied from 4 to 14 (autumn 2010) and from 3 to 13 (winter 2011) in each childcare centre.

During both data collection periods, the children's heights and weights were measured. Height was measured barefoot and in light clothing, to the nearest $0.001 \mathrm{~m}$ using a Charder HM 200P, and weight was measured to the nearest $0.1 \mathrm{~kg}$ using a digital scale SECA 877 . Both measurement tools were 
new and portable. The Seca 877 is marked CE, which ensures that the product conforms to the relevant EC directives. BMI was calculated and expressed as $\mathrm{kg} / \mathrm{m}^{2}$. The anthropometry characteristics of the children corresponded to the norms for same age children in Finland (Saari et al., 2011).

In the Netherlands, all the parents of the children attending childcare centres were informed about the study, and none of them refused to participate. A total of 973 -year-olds (46 boys, 51 girls) participated in the study. Participants' heights and weights were not measured or asked about in the Netherlands. In Australia, all the families of the 3 -year-old children attending the 13 childcare centres that agreed to participate were invited to be involved in the project. Parent completion of consent forms resulted in the involvement of 64 children (33 boys, 31 girls). Parents or legal guardians provided children's body weight and height information in Australia.

\subsection{Data collection}

In Finland, the children's PA data were collected in two phases using a repeatedmeasure design. The first phase lasted over nine weeks, from August to October (autumn), in 2010. The second phase was implemented over seven weeks in January and February (winter) 2011. Four researchers (two pairs), performed the measurements at the rate of one childcare centre per week per pair.

The observational data on the Dutch children were collected during early summer, in May and June, 2008, whereas, in Australia, the accelerometer-based data collection was executed during autumn to winter, i.e. from March to August, 2012. The data collection timetable and procedures of the study are shown in Figure 2.
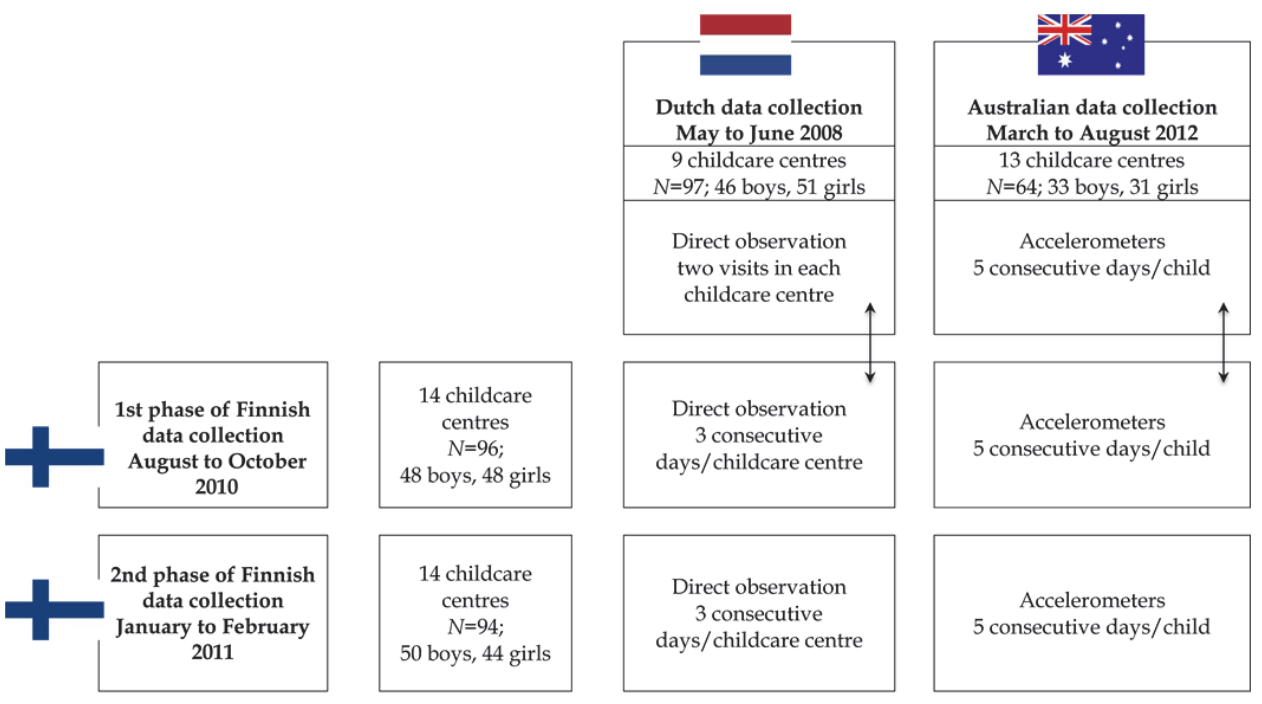

Accelerometers 5 consecutive days/child

FIGURE 2 Data collection timetable and study procedures. 


\subsubsection{Accelerometer measurements (studies I, IV)}

Accelerometers were used to assess PA intensity levels and sedentary time in 3year-old children. PA was quantified with ActiGraph GT3X (ActiGraph, LLC, Pensacola, FL, US) accelerometers on five consecutive days from Wednesday to Sunday, including childcare and homecare days. The children received accelerometers on the first morning of the study. All the children, together with their parents and childcare staff, were instructed in how to wear the accelerometer, using an adjustable elastic belt over the child's right hip for as long as possible during all waking hours, where possible removing it only for water-based activities and sleeping. In addition, parents and childcare staff were also issued with written information about the correct procedures of the accelerometer. Parents were asked to record the times at which their child woke up, went to bed, and their childcare attendance times. Additionally, parents were asked to report any abnormalities in the daily routine, for example, long periods of sitting (e.g., in a car), swimming, bathing, and if the child fell ill during the measurement period. On the first morning of the measurements, the child chose a sticker, which was attached to the accelerometer to make it more attractive, to motivate the child, and to ensure that the accelerometer was worn the right way round (Cardon \& De Bourdeaudhuij, 2008). The sticker also helped to lower the threshold for creating a connection between the unfamiliar researcher and the child. Additionally, stickers helped childcare staff to match the right device to the child after the day nap, if the devices were taken off. Finally, receptivity to wearing the instrument was rated by the parent on a five-point scale (from very pleasant to very unpleasant) (see Appendix 5).

The devices were initialized to record data over 5-s intervals (epochs) as recommended for children of this age (Cliff et al., 2009; Freedson et al., 2005). Despite the capability of ActiGraph GT3X to measure acceleration along three axes, only acceleration in the vertical plane was analysed. The vertical plane has been shown to provide the most important assessment of ambulatory movement (Oliver et al. 2007), in addition, the present results can be compared to results based on vertical plane movements.

Two different sets of cut points were used in the current study. First, the cut points recently published by Van Cauwenberghe and colleagues (2011b) were adapted for analyses of seasonal and daily variation among the Finnish 3year-old preschool children (study I). Second, Pate et al.'s (2006) cut points were used in comparing the PA patterns of the 3-year-old Finnish and Australian children (study IV). Differences in cut points for PA and SB in preschool children are more discussed in more detail in Chapter 3.1.1, and Chapter 7.3.1 (see also Tables 2 and 5). In Finland, accelerometers were loaned for data collection from LIKES - Research Center for Sport and Health Sciences.

The design of the Australian accelerometer data collection was based on that used in the Finnish study with some minor adjustments to suit the Australian context. For instance, childcare centre recruitment was implemented differently in light of the cultural differences between the countries. In Australia, on- 
ly a few children enrolled in the study in advance. The letters of invitation sent by the childcare managers to the families of the 3-year-old children did not reach them in the desired way. Additionally, on the first measurement day (a Wednesday) many children were in homecare and therefore could not receive the accelerometers. During the data collection, changes were needed to reach the families. After changes in strategy, families were able to enrol and sign consent forms, and receive accelerometers from the researchers in the childcare centre in the afternoon of the day before the measurements or on the first morning of the data collection. Moreover, a newer model of the ActiGraph accelerometer, the GT3X+, was used. Otherwise, the data collection protocols were the same as used in Finland.

\subsubsection{OSRAC-P observation procedures (studies II, III)}

To assess children's PA levels in the childcare settings the modified Brown et al. (2006) OSRAC-P method was used. The observation method was piloted in November 2009 for Finnish childcare settings (Seppälä, 2012). The OSRAC-P system was used to measure children's PA intensity levels, type of activity, group composition, location, indoor and outdoor contexts, initiator of activity, and prompts (Brown et al., 2006). Two trained researchers simultaneously observed the children's PA and contextual factors using a procedure in which 15 seconds of observation were followed by 30 seconds of recorded observation. Prerecorded signals were used for this function so that both observers, but not the children, heard the signals (Welk, 2002, p. 185). The observation sheets were completed manually and the procedure was repeated eight times over six minutes for each child $(8 x[15 s+30 s])$. Children were observed two to four times per day, in the morning (between 8 a.m. and 12 p.m.) and in the afternoon (between 2 p.m. and 5 p.m.), including indoor and outdoor play. Children were randomly selected for observations, but not observed during scheduled meal or rest times. This practice was implemented during three consecutive days from Wednesday to Friday. The data collection was conducted without disturbing the daily routines of the childcare centres and without undue influence on the children or teachers.

Before the observation, background information, such as the childcare centre, date and time of day, child's ID code and gender, climate, temperature and the observer's code were noted on the form (Appendix 6). Children's PA intensity levels were measured on a five-point scale (from $1=$ sedentary to $5=$ vigorous), and reflected the highest intensity level reached by the child during each 15-second observation interval. For the purpose of this study and further comparison, activity levels 1-2 were regarded as SB, activity level 3 as light PA and levels 4-5 as MVPA (Bower et al., 2008; Brown et al., 2009b; Gubbels et al., 2011; Nicaise et al., 2011; Pate et al., 2008).

Second, the type of activity engaged in was coded. In the present study, Brown and colleagues' (2006) original 18 activity-type codes (e.g., sitting, standing, walking) were complemented with four typical Finnish types of activity (i.e., balancing, sliding, skiing, ice-skating) and used as descriptive categories. Next the 
OSRAC-P scales assessing contextual variable such as primary location (indoor or outdoor) were used. The indoor contexts were complemented with the variables toys (e.g., playing with cars, dolls), household chores (e.g., baking, cleaning), temper tantrum (crying, refusing to participate in an activity), pool activities and small-group variables (less than half of the children group activities), and the outdoor contexts with the variables temper tantrum, forest, sport field (e.g., icerink, sport track) and transition. Finally, the following social OSRAC-P scales were assessed: group composition (solitary, one-to-one adult/peer, group adult/child), initiator of activity (child, adult) and prompts (no prompt for PA or teacher/peer prompt to increase/decrease PA). All the changes implemented were clearly specified on the forms to avoid excessive use of other variables (describing options other than those originally listed on the form) (see Appendix 6).

In the Netherlands, each of the nine childcare centres was visited twice for direct observations of the children's activity level. Each child (10 children/centre/day) was observed for two consecutive blocks of four observations per child (three minutes; $4 x[15 s+30 s])$. This protocol was implemented on two days at each childcare centre, with at least one week between the two observation days (Gubbels et al., 2011). The Dutch data collection was conducted by Maastricht University. Except for these few minor differences in the data collection procedures, the observations were executed similarly to the Finnish measurements described above. 
TABLE 4 Overview of the studies.

\begin{tabular}{|c|c|c|c|c|c|}
\hline & Title & Aims & Sample & Methods & Main analyses \\
\hline Study I & $\begin{array}{l}\text { Seasonal and Daily Varia- } \\
\text { tion in Physical Activity } \\
\text { Among 3-Year-Old Finnish } \\
\text { Preschool Children } \\
\text { Soini, A., Tammelin, T., } \\
\text { Sääkslahti, A., Watt, A., } \\
\text { Villberg, J., Kettunen, T., } \\
\text { Mehtälä, A., \& Poskiparta, } \\
\text { M. }\end{array}$ & $\begin{array}{l}\text { To assess the PA levels and seden- } \\
\text { tary time of 3-year-old children, } \\
\text { paying special attention to the } \\
\text { variation in PA and SB between } \\
\text { girls and boys, days, and seasons. } \\
\text { A secondary aim was to ascertain } \\
\text { whether preschool children } \\
\text { achieve the recommended levels of } \\
\text { PA proposed within national and } \\
\text { international current guidelines. }\end{array}$ & $\begin{array}{l}\text { Complete data for } \\
\text { both seasons } \\
\text { were obtained for } \\
47 \text { children ( } 26 \\
\text { boys and } 21 \text { girls). }\end{array}$ & $\begin{array}{l}\text { PA was quantified } \\
\text { with ActiGraph } \\
\text { GT3X accelerometers } \\
\text { on five consecutive } \\
\text { days. }\end{array}$ & $\begin{array}{l}\text { Nonparametric tests (Wilcoxon } \\
\text { and Mann-Whitney) and General } \\
\text { Linear Models (GLM) for repeat- } \\
\text { ed measures MANOVA were } \\
\text { used to analyse gender and sea- } \\
\text { sonal differences in children' s } \\
\text { PA on weekdays and weekend } \\
\text { days. Crosstabs utilizing Pearson } \\
\text { Chi-square were used to deter- } \\
\text { mine the percentages of children } \\
\text { who reached the current recom- } \\
\text { mended levels of PA. }\end{array}$ \\
\hline Study II & $\begin{array}{l}\text { Directly Observed Physical } \\
\text { Activity among 3-Year-Olds } \\
\text { in Finnish Childcare } \\
\text { Soini, A., Villberg, J., Sääks- } \\
\text { lahti, A., Gubbels, J., Mehtä- } \\
\text { lä, A., Kettunen, T., \& Pos- } \\
\text { kiparta, M. }\end{array}$ & $\begin{array}{l}\text { To examine Finnish 3-year-olds' } \\
\text { PA levels and SB during attend- } \\
\text { ance at childcare, and their sea- } \\
\text { sonal variation, related demo- } \\
\text { graphic and biological characteris- } \\
\text { tics, and physical and social con- } \\
\text { texts. }\end{array}$ & $\begin{array}{l}\text { In total, } 81 \text { chil- } \\
\text { dren ( } 42 \text { boys and } \\
39 \text { girls) were } \\
\text { observed in au- } \\
\text { tumn and in win- } \\
\text { ter. }\end{array}$ & $\begin{array}{l}\text { The OSRAC-P } \\
\text { (Brown et al. 2006) } \\
\text { was used to measure } \\
\text { PA levels and contex- } \\
\text { tual variables of chil- } \\
\text { dren attending child- } \\
\text { care centres. }\end{array}$ & $\begin{array}{l}\text { Three-level linear regression } \\
\text { analyses were used to assess } \\
\text { differences between the seasons } \\
\text { in the association between the } \\
\text { context variables and PA. }\end{array}$ \\
\hline Study IV & $\begin{array}{l}\text { Comparing the Physical } \\
\text { Activity Patterns of 3-Year- } \\
\text { Old Finnish and Australian } \\
\text { Children During Childcare } \\
\text { and Homecare Days } \\
\text { Soini, A., Watt, A., Tamme- } \\
\text { lin, T., Soini, M., Sääkslahti, } \\
\text { A., \& Poskiparta, M. }\end{array}$ & $\begin{array}{l}\text { To investigate variations in the } \\
\text { daily childcare and homecare PA } \\
\text { levels and patterns of Finnish and } \\
\text { Australian 3-year-olds. }\end{array}$ & $\begin{array}{l}\text { Complete PA } \\
\text { data were ob- } \\
\text { tained for } 80 \text { ( } 42 \\
\text { boys and } 38 \text { girls) } \\
\text { Finnish children } \\
\text { and } 41 \text { ( } 18 \text { boys } \\
\text { and } 23 \text { girls) Aus- } \\
\text { tralian children. }\end{array}$ & $\begin{array}{l}\text { PA was quantified } \\
\text { with ActiGraph } \\
\text { GT3X accelerometers } \\
\text { on five consecutive } \\
\text { days. }\end{array}$ & $\begin{array}{l}\text { A repeated measures MANOVA } \\
\text { was used to compare differences } \\
\text { in daily PA between childcare } \\
\text { and home days for gender, coun- } \\
\text { try, and hour of the day. }\end{array}$ \\
\hline
\end{tabular}




\subsection{Data reduction and statistical analyses}

Before the statistical analyses, all the accelerometer-based data were checked for normality. Periods of non-wear time (defined as 20 consecutive minutes of ' 0 ' counts [study I] and defined as 10 consecutive minutes of ' 0 ' counts [study IV]) and periods above an upper range of biological plausibility (defined as 15000 $\mathrm{cpm}$ ) were removed from the data (Cliff et al., 2009). The minimum requirement for valid PA data was at least 8 hours of monitored PA per day (from 7 a.m. to 9 p.m.) for at least 2 weekdays and 1 weekend day (study I), and at least 450 minutes of monitored PA per day (from 7 a.m. to 9 p.m.) for at least one childcare day and one homecare day (study IV). The days during which participants did not achieve the minimal wearing time were considered as noncompliant days and not used in the analyses. The data reduction was done using selfcustomized software (study I) and ActiLife version 6.5.2. (study IV).

Cohen's kappa was used to determine the IRR of the two observers for the observations of the OSRAC-P variables (see Chapter 7.2.1; Table 6). To assess cross-country IRR, a separate sample of children not included in the final study was independently observed via videotape by one of the two researchers in each country (Finland and the Netherlands). This resulted in cross-country coding of 305 observation intervals, i.e. $13.8 \%$ of the observation intervals in the main study (2 216 intervals), meeting the OSRAC-P norm of at least $12 \%$ independent coding (Brown et al., 2009c). The intraclass correlation used to determine the cross-country IRR of two observers for the activity intensity variable was set at $.70(p<.001)$.

The research aims and questions were approached using various statistical analyses. The main statistics used were: means (M), standard deviations (SD), $t$ tests, nonparametric tests, general linear model (GLM) for repeated measures of MANOVA, three-level linear regression, crosstabs utilizing Pearson's chisquared $\left(\chi^{2}\right)$ test, Cohen's kappa and Cohen's $d$ formula, and the intraclass correlation with cross-level interaction. Appendix 7 summarizes the statistical analyses implemented in each of the four studies.

All analyses were performed using IBM Statistical Package for the Social Sciences (SPSS) Statistics for Windows 18.0 (Armonk, NY: IBM Corp) (studies IIII), 20.0 (study IV) and STATA 12 (studies II, III). Statistical significance probability ( $p$-value) was set at an alpha level of .05 for all analyses.

\subsection{Ethical considerations}

During the data collection and analysis, the researchers adhered to the principles of good scientific behaviour and unconditional confidentiality. The data collection was conducted without disturbance to the daily routines of the childcare centres or the children's homes and without undue influence on the children, their families or teachers, and the children could interrupt the measure- 
ments at any time they wanted to. During the first measurement period, two boys and one girl (3\%) refused to wear an accelerometer. However, in the second measurement period these children were also willing to wear the instrument (their receptivity to wearing the instrument varied between pleasant and very pleasant).

Participants' personal information was replaced with ID codes. No childcare centre or individual was identifiable when the results were published. The data were kept in a researcher's personal computer, and accessible only with the user's personal code. During all the research phases, the data were absolutely confidential and used only for the purpose of this study.

In spring 2010, the ethics committee of the University of Jyväskylä, and the head of Social Affairs and Health in the city of Jyväskylä approved the doctoral study. The Dutch study complied with the Dutch 'Medical Research Involving Humans Act' and the affiliate Australian university and Department of Education and Early Childhood provided ethical approval in Australia. 


\section{OVERVIEW OF THE RESULTS}

This chapter presents an overview of the findings of the four different studies. The original studies conducted for this doctoral study aimed to extend accelerometer-based knowledge of PA intensity levels and sedentary time in 3-yearolds (studies I, IV), and to obtain better observation-based knowledge of PA and SB among the same age group during childcare attendance (studies II, III). The full results together with a thorough discussion of the findings of this research given in detail in the articles appended to this summarizing report.

\subsection{What physical activity intensity levels and patterns exist among Finnish 3-year-old preschool children? (Studies I, II)}

According to the accelerometer-based data (study I), mean total PA in the present sample of 3-year-olds was $632 \mathrm{cpm}$. Children were sedentary for nearly 10 hours per day, and engaged in MVPA for an hour per day. Only minor seasonal variations were observed in children's PA levels. The findings revealed that on weekdays in autumn the children engaged in light PA significantly more than on weekdays in winter. No difference was observed in PA levels between weekdays and weekend days, except in wintertime when the children spent more time in sedentary-level activities on weekdays than weekend days. Boys were physically more active than girls, particularly in winter and during weekdays. The observational findings (study II), however, showed were more pronounced gender differences, with significantly higher mean PA intensity levels among boys than girls in both seasons.

To analyse the amount of the time spent at different intensity levels, the separate count cut points for preschool-aged children established recently by Van Cauwenberghe et al. (2011b) were adopted in study I. Overall, the children did not meet either the recommendation for preschool children of three hours PA, of any intensity, daily (Canadian Society for Exercise Physiology, 2012; Department of Health and Ageing, 2010; Department of Health, Physical Activity, 
Health Improvement and Protection, 2011; IOM, 2011), or the Finnish guidelines of two hours daily of brisk PA (if defined as MVPA) (Recommendations for Physical Activity in Early Childhood Education, 2005). Approximately 20\% of children reached the NASPE (2009) standard of at least 120 minutes of PA per day, when light PA was included, and $46 \%$ fulfilled the requirement of at least 60 minutes of MVPA daily (Strong et al., 2005; WHO, 2010).

The observational data (study II) revealed that, for most of the childcare day, the children's PA levels were mostly sedentary in nature: 69\% (indoors $86 \%$; outdoors $46 \%$ ) of total intervals were recorded as sedentary, and only $2 \%$ (indoors 1\%; outdoors 2\%) as MVPA. Children were physically more active outdoors than indoors. The results indicated a significant gender difference in PA levels during childcare attendance, with boys showing significantly higher levels than girls. Early educators or peers rarely prompted children to increase or decrease their PA: no prompts were recorded in $92 \%$ of all observations. The initiators of activities were most frequently children (77\%), and the children's play was most frequently non-solitary $(74 \%)$. The three most frequently observed activity types were: sitting, standing, and walking.

The most frequently observed indoor context variable was toys. Children were sedentary when engaged in art or in large group activities organised or led by an early educator. Although several activity types, such as running, climbing, and pulling/pushing were associated with higher levels of PA, children were rarely observed engaging in these activities indoors. Outdoors, children were most frequently observed in an open space. Outdoor engagement at the sedentary level included playing in a sandbox and/or playing with sandbox materials, and activities with sociodramatic play props. Touching, riding, or pushing wheeled toys such as tricycles, scooters and wagons showed higher levels of PA.

The results further showed that, during childcare attendance in the winter, the children spent significantly more time on sedentary-level activities and less in MVPA than in the autumn. However, this seasonal variation in PA intensity level was observed only for boys and during the outdoor observations. All prompts (both positive and negative) were associated with an increase in PA in both seasons in comparison to observations where no prompts were observed. Child-initiated play was positively associated with PA in the autumn, but not in the winter. In the winter, the children showed significantly more SB and engaged less frequently in MVPA during child-initiated activities, whereas adultinitiated play showed no seasonal variation in PA levels. During both seasons, children's solitary play was associated with higher PA levels. The association of PA levels with the significant interactions between time of day and season showed that in the autumn the present sample of children were more physically active in the morning than afternoon, while in the winter their PA levels were unaffected by time of day. Finally, temperature was significantly associated with children's PA levels in winter, but not in autumn, whereas rain had no influence on PA during either season. 


\subsection{Are there variations between Finland and the Netherlands in 3-year-old children's observed physical activity levels and contexts in childcare? (Study III)}

During their childcare attendance, children's indoor PA levels were mostly sedentary in nature: $79 \%$ of total intervals were recorded as sedentary, and only $3 \%$ coded as MVPA. Outdoors, 53\% of PA observations were classified as sedentary, whereas 10\% were classified as MVPA. The initiators of the activities were most frequently children $(81 \%)$. Early educators and peers rarely prompted children to increase or decrease their PA: no prompts were recorded in $81 \%$ of all observations.

Cross-country differences between Finland and the Netherlands were more pronounced in the social and weather-related variables than in the nonsocial context variables. The Finnish children spent significantly more time in sedentary-level activities and less time in MVPA compared to the Dutch children in most of the observed categories.

With respect to the primary location of the observations, children were significantly more active outdoors than indoors (activity intensity 2.65 vs. 2.18 , respectively; $p<.001$ ). In the Netherlands, an outdoor location had a stronger positive influence on children's activity levels than in Finland $(p<.001)$, although the influence was significant in both countries. Despite the significant variation between the two countries in temperature and weather conditions, no significant association between the temperature or weather variables and children's PA levels were observed. All prompts (both positive and negative) were associated with an increase in the children's PA level in both countries. Nonsolitary play was associated with higher activity levels in the Netherlands, whereas in Finland child-initiated play was positively associated with the children's PA levels. Finally, the Finnish children were less active in the afternoon compared to the morning, while the Dutch children's PA levels were unaffected by time of day.

\subsection{Are there variations between Finland and Australia in 3-year- old children's physical activity intensity levels measured with accelerometers? (Study IV)}

Children's total PA was $730 \mathrm{cpm}$ (Finland $M=739 \mathrm{cpm}$; Australia $M=713 \mathrm{cpm}$ ). No significant differences were observed in mean daily cpm between childcare days $(M=715 \mathrm{cpm})$ and homecare days $(M=745 \mathrm{cpm} ; p=.101)$. During childcare days, boys' activity levels were higher than girls' $(p=.016)$, but no gender differences were observed during homecare days $(p=.158)$. No cross-country variations were recorded in activity intensities during either childcare or 
homecare days, except that during childcare days Finnish children spent more time (average 20 minutes) in light PA than Australian children ( $p=.027)$.

The separate count cut points for preschool-aged children established by Pate et al. (2006) were adopted for this study to assess the amounts of time children spent at the different intensity levels and to determine how many of the children achieved the PA recommendations for pre-schoolers. During childcare days, all the Finnish and 95\% of the Australian children engaged in 180 minutes or more of LMVPA, and $96 \%$ of the Finnish and $83 \%$ of the Australian children engaged in 60 minutes or more of MVPA. Only 10\% of the Finnish and 15\% of the Australian children engaged in 120 minutes or more of MVPA. During homecare days, $98 \%$ of the Finnish and $95 \%$ of the Australian children engaged in 180 minutes or more of LMVPA, $89 \%$ of the Finnish and $90 \%$ of the Australian children engaged in 60 minutes or more of MVPA and 14\% of the Finnish and $5 \%$ of the Australian children engaged 120 minutes or more of MVPA.

A significant main effect of hour $(p<.001)$ and interaction effect of hourcountry $(p<.001)$ revealed that PA levels per hour and country varied across a childcare day. Between-subjects analysis indicated that PA varied by country ( $p$ $=.029)$ and gender $(p=.019)$ during a childcare day. During childcare attendance hours, two significant increases in activity levels were monitored in both countries: between 10 and 11 a.m. and between 3 and 4 p.m. in Finland, and between 10 and 11 a.m. and between 4 and 5 p.m. in Australia. One major decline in PA levels was recorded during resting times (12 till 2 p.m. in Finland; 1 till 2 p.m. in Australia). In Finland, one increase in activity level was recorded after childcare hours, between 6 and 7 p.m. In Australia, during post-childcare attendance hours, children's PA levels declined. During their childcare attendance hours, the Finnish children engaged in MVPA for an average of 48 minutes (54\% of daily MVPA) and in LMVPA for 147 minutes (53\% of daily LMVPA) and the Australian children engaged in MVPA for 53 minutes (64\% of daily MVPA) and in LMVPA for 163 minutes (64\% of daily LMVPA) in Australia.

A significant main effect of hour $(p<.001)$ and interaction effect for hourcountry $(p=.002)$ indicated that PA levels varied by hour and country during a homecare day. Between-subjects analysis showed no variation between variables across a homecare day. In Finland, PA levels increased between 10 a.m. and 12 p.m., 3 and 5 p.m., and these activity levels remained the same until 8 p.m. A small decline in activity levels was observed between 1 and 2 p.m. In Australia, children's PA levels increased at 9 a.m. and remained on the same level until 4 p.m., when the next peak was recorded. After 5 p.m. children's PA levels decreased constantly. 


\subsection{Background information and conditions in the studied coun- tries}

The Finnish measurements were conducted from August to October 2010 and in January and February 2011, and, applying Finnish seasonal criteria (autumn = September-November; winter $=$ December-February; spring $=$ March-May; summer = June-August), were considered to represent two of the four seasons, i.e. autumn and winter. During the Finnish data collection periods, the participants attended their childcare settings for an average of 7.7 hours/day in the autumn and 7.5 hours/day in the winter. The results showed significant seasonal variation in mean outdoor time during childcare attendance (178 minutes in autumn vs. 116 minutes in winter; $p=.002$ ) (studies I, II).

Study I showed significant seasonal variation in mean daily temperature $\left(9.4^{\circ} \mathrm{C}\right.$ in autumn vs. $-13.1^{\circ} \mathrm{C}$ in winter; $\left.p<.001\right)$ (Weather Underground, 2013). These temperatures were lower than normally recorded for these seasons (Climatological Statistics of Finland, 1981-2010). Most of the time, the weather was cloudy but dry ( $49 \%$ autumn; $51 \%$ winter) or sunny with a clear sky $(27 \%$ autumn; 36\% winter); the least prevalent weather type was precipitation of rain ( $23 \%$ autumn) or snow (13\% winter). Differences in weather between seasons were significant $(p<.001)$ (study II). The mean daily temperatures on the data collection days were obtained from a meteorological website (Weather Underground, 2013), and the weather conditions were recorded by the researchers on each observation day. The differences in mean outdoor temperature between Finland $\left(12.5^{\circ} \mathrm{C}\right.$; range: $\left.2^{\circ} \mathrm{C}-20^{\circ} \mathrm{C}\right)$ and the Netherlands $\left(20.5^{\circ} \mathrm{C}\right.$; range: $14^{\circ} \mathrm{C}$ $26^{\circ} \mathrm{C}$ ) (study III), and between Finland $\left(9^{\circ} \mathrm{C}\right.$; range: $\left.16^{\circ} \mathrm{C}--1^{\circ} \mathrm{C}\right)$ and Australia $\left(12^{\circ} \mathrm{C}\right.$; range: $\left.22^{\circ} \mathrm{C}-6^{\circ} \mathrm{C}\right)$ (study IV) were significant $(p<.001)$.

In Finland, accelerometers were worn for an average of 4.6 days and 692 minutes/day (4.7. days and 697 minutes/day in autumn; 4.5 days and 688 minutes/day in winter). No differences in mean monitor wearing days $(p=.128)$ were observed between the Finnish and Australian children; however, the Finnish children had significantly higher mean wearing minutes/day than the Australian children: 42 minutes more on childcare days $(p=.001)$, and 44 minutes more on homecare days $(p=.001)$.

Receptivity to wearing the instrument was rated by the parent on a fivepoint scale (from very pleasant to very unpleasant). According to parents' reports (autumn $n=45$; winter $n=41$ ), $87 \%$ of the children found wearing the accelerometer a positive experience, either "pleasant", or "very pleasant". Only $3 \%$ of the children reported the experience as "unpleasant". None found it "very unpleasant", and one child found it either "not pleasant" or "not unpleasant". Eight per cent of the parents' did not return the reports. Receptivity rates in Australia were parallel to Finnish rates, although, 11\% of the Australian children reported the experience as "unpleasant".

A total of 1978 observations and 15824 single observation intervals (1 978 x 8 times); 966 observations, mean $5.96(\mathrm{SD}=2.49)$ observations and average 36 
minutes/child, were conducted in the autumn, and 1012 observations, mean $6.25(\mathrm{SD}=2.96)$ observations and average 38 minutes/child, in the winter. The total number of single observations in study III for both countries combined were thus 2216 (1 440 in Finland; 776 in the Netherland). 


\section{DISCUSSION}

This chapter presents an overview of this thesis. First, the main findings of the four studies are described. Second, the strengths and limitations and some methodological issues that need to be kept in mind when interpreting the findings are discussed. Third, practical implications of the findings are described. Finally, some general conclusions are drawn, along with suggestions for future research.

\subsection{Summary of the main research findings}

The main research findings will be discussed in light of the socio-ecological factors applied in this study to explain children's PA behaviour. Factors that were not included are discussed in connection with the directions for future research, in section 7.5.

\subsubsection{Child characteristics}

In line with previous studies (e.g., Baranowski, et al., 1993; Finn et al., 2002; Hinkley et al., 2008; Nicaise et al., 2011; Oliver et al., 2007; Pate et al., 2008; Pate et al., 2004; Reunamo et al. 2014; Sallis et al., 2000), boys overall were physically more active than girls. Gender differences in PA intensity levels were highlighted during childcare days, but not in homecare days (study IV), and particularly in wintertime (study I).

Currently, while there is no definitive explanation for the lower participation in PA of girls (Pate et al., 2004), some potential reasons can be suggested. First, variation in biological maturity status at young ages may influence activity levels, and the effect may differ in boys and girls. For instance, Eaton and $\mathrm{Yu}$ (1989) found that 5- to 8-year-old girls who were farther along the developmental path towards biological maturity appeared to be less active than less physically mature, but same-aged boys. In the present research, the child sample 
comprised 3-year-olds, and their maturity levels were not defined for the purpose of investigating PA levels. Moreover, the children's FMS development was not defined in relation to their PA levels.

Second, observational studies have demonstrated that boys are more interested in playing rougher games, engage in more risk-taking behaviour and play in larger groups and in more open settings than girls (Pate et al., 2004), and that their "desire to be active" has been positively associated with MVPA (Yamamoto et al., 2011). Boys' activities may also be strongly triggered by harder ground surfaces, which are mainly used for sports-related, competitive activities (Cardon et al., 2008).

One potential explanation may found in early educators' attitudes, which may also affect children's PA behaviour. It is possible that boys are regularly encouraged to engage in more physically active play and games, whereas girls are more exposed to stationary activities and expected to behave in a calmer manner (Pellegrini \& Smith, 1998; Pönkkö, 1999; Sääkslahti, 2005). Sandberg and Pramling-Samuelsson (2005) found that despite emphasising the importance of creating inspiring environments for play and outdoor play, preschool teachers' participation in play differed by gender. Male teachers, for instance, had more play willingness and participated more in physically active play, whereas female teachers tended to prioritise calm play, which, for the most part, they had also experienced in their own childhood (Sandberg \& Pramling-Samuelsson, 2005). Cardon et al. (2008) also found that girls preferred to stay close to their supervising teachers, who commonly supervise sitting down or standing still, and that this might be one cause of the lower levels of PA in girls. It remains unclear whether the gender difference in PA is environmentally determined or biologically based, or a combination of both (Timmons et al., 2007).

In this study, Finnish children's body weight and height were measured at the time of each PA data collection, and BMI was calculated for each child. BMI, however, in line with previous studies (Hinkley et al., 2008; Sallis et al., 2000), was not associated with children's activity levels (study II). Due the lack of demographic data in the Netherlands, and different measurement methods (parents provided children's body weight and height information) in Australia, it was not deemed appropriate to conduct cross-country comparisons (studies III, IV). In sum, owing to researcher interest, the children's BMI was calculated but not considered to be a relevant factor in this research (studies I, II).

\subsubsection{Early educational interaction}

Factors related to the social environment, such as positive prompts by early educators, have been associated with increased PA (Brown et al., 2009b; Gubbels et al., 2011). Despite this positive association, the majority of the observations in this study did not include any oral prompting (studies II, III). Moreover, our results, like those of Brown et al., (2009b), showed that even if early educators were present, they very rarely, if ever, implemented teacher- 
arranged activities and games to enhance children's PA or encouraged children to engage in PA.

This finding was observed both in Finland and in the Netherlands (study III). Early educators may assume that children are naturally very active and that they engage in sufficient activity, and therefore lay less emphasis on the importance for children of an active lifestyle (Benham-Deal, 2005; Pate et al., 2008). Clearly, early educators should not assume that, because children are playing outdoors, they are necessarily engaging in MVPA (Benham-Deal, 2005). Teacher help in getting play started is one effective method to increase the amount of children's PA (Reunamo et al., 2014).

In general, children tend to be less active the larger the number of staff members present or involved in children's play (Cardon et al., 2008; Brown et al., 2009b; Gubbels et al., 2011). This was also seen in the present study, where children were more sedentary when staff members were involved in their activities, or when the initiator of the play was an adult. Perhaps a more unstructured and flexible approach would be beneficial in raising children's PA levels. Here, children's solitary play was associated with increased PA levels (studies II, III), as also noted in the US by Brown et al. (2009b) and Nicaise et al. (2011). In contrast, in a Dutch study, non-solitary play was associated with higher activity levels (Gubbels et al., 2011). In this study, adult-initiated play had a negative association with the children's PA behaviour in the autumn, although not in the winter (study II). It may be that adults follow structured childcare programs, and hence plan more physically active play during wintertime, when the outdoor temperature is much lower, whereas child-initiated play is more affected by the possibilities attendant on the time of year.

\subsubsection{Physical environment}

This study focused on potential physical environment correlates, such as the childcare centre environment, outdoor playtime, and the effects of time of day and season on children's PA. Although home environments have been associated with children's PA and SB, this issue was not included here.

\subsubsection{Childcare centre environments}

The present findings support the view that the childcare centres children attend influence their levels of PA (studies II, III) (Bower et al., 2008; Finn et al., 2002; Pate et al., 2008; Pate et al., 2004; Ward, 2010). In this connection, the OSRAC-P observation format used in this research helps us to understand not only the intensity of activity, but also where, how and in what kind of interaction the activity was being performed.

In line with earlier studies (Brown et al., 2009b; Gubbels et al., 2011; Nicaise et al., 2011; Pate et al., 2008; Reilly et al., 2004), the present study found that, for most of the childcare day, the children's PA level and PA type was sedentary in nature, with MVPA accounting for only $2 \%$ of all observations (study II). The children were most commonly observed engaging in activities such as sitting, standing, and walking. The indoor context was primarily seden- 
tary in nature: $86 \%$ of indoor activities were observed as SB. This level of sedentariness is similar to that reported among US children (Brown et al., 2009b) and Finnish pre-schoolers (Reunamo et al., 2014), and considerably more than among children in the Netherlands (Gubbels et al., 2011).

Children were sedentary, for instance when engaged in art or in large group activities organized or led by an early educator. Although several activity types and contexts were associated with higher PA levels, children were rarely observed indoors in activities such as running, climbing, pulling or pushing. One potential explanation relates to childcare facilities and behavioural rules. For safety reasons, running or climbing indoors is likely to be prohibited, while indoor spaces are often small rooms with narrow corridors. Nevertheless, a place in hallways and corridors for children's play and PA is commonly found. To enable children to move around freely and engage in physically active play indoors, childcare centres need to optimize their indoor space specifically for these purposes (Gubbels et al., 2012). Although Finnish childcare centres mostly have a large room or hall with gross motor equipment for PA and play, children, in groups, typically use them only once a week, during a structured PE lesson, as laid down in the recommendations for PA in early childhood education (2005). Moreover, in its current format, PE plays a very small role in meeting the daily PA requirements of pre-schoolers (Van Cauwenberghe et al., 2012b); nevertheless, a teacher-led structured PA session integrated in the preschool curriculum is a promising means for decreasing sedentary time and increasing PA in preschool children (Van Cauwenberghe, De Craemer, De Decker, De Bourdeaudhuij, \& Cardon, 2013).

\subsubsection{Outdoor playtime}

Consistent with previous findings (e.g., Baranowski et al., 1993; Boldemann et al., 2006; Brown et al., 2009b; Gubbels et al., 2011, Hinkley et al., 2008; Sallis et al., 2000; Reunamo et al., 2014), the present sample of children was physically more active outdoors than indoors (studies II, III). Outdoor locations had a strong positive association with higher PA levels in both seasons (study II). However, even during outdoor play, nearly half of the children's activities were recorded as $\mathrm{SB}$, and only $2 \%$ as MVPA, which is much lower than has been reported previously (Brown et al., 2009b; Gubbels et al., 2011; Nicaise et al. 2011), indicating that opportunities exist to increase activity levels during recess in Finnish childcare settings.

More vigorous outdoor play activities aimed at promoting agility, power, flexibility, and cardiovascular fitness require appropriate physical play objects such as tricycles, push toys and a variety of balls, to increase the child's desire to be active (Clements, 2004). In this study, outdoor engagement at the sedentary level included children playing in a sandbox and/or playing with sandbox materials, and activities with sociodramatic play props, whereas, touching, riding, or pushing wheeled toys such as tricycles, scooters and wagons showed higher levels of PA (study II). Wheeled toys, however, were used less frequently than fixed equipment such as the sandbox. This might be explained by the fact that fixed equipment, like a sandbox, is available at all times, while portable equipment is 
held in storage. Children have to fetch these items and return them after use. In line with this, previous studies have showed children to be significantly more active when jumping equipment was continuously present, or when a fixed track was marked on the playground (Gubbels et al., 2012), and that activitygenic portable equipment and riding vehicles appeared to foster MVPA (Nicaise et al., 2011). Readily available equipment, and real, heavy tools to work with, are methods that can be used to increase children's PA (Reunamo et al., 2014). Furthermore, a playground redesign, which utilizes multicolour playground markings and physical structures, may be a suitable stimulus for increasing children's recess PA levels (Ridgers et al., 2007). Scheduling recesses to minimize the number of children sharing a playground or play equipment (Cardon et al., 2008; Van Cauwenberghe et al. 2012b), and minimizing the time spent in sedentary locations, such as the sandbox (Cosco et al., 2010), may also help to increase children's engagement in MVPA. In Finland, it is not uncommon in childcare settings for the playground to be shared in such a way that, for example, the recess/outdoor times of children under three years are scheduled so as not to clash with those of 3-to 6-year-olds. A Belgian study reported significant increases in children's objectively measured PA intensity during preschool recess and times of unstructured free plays that were taken as an opportunity to be physically active (Verbestel et al., 2011). However, more activating supervision, structured PA and rule play outdoors may be the best physical activator for preschool children (Cardon et al., 2009; Reunamo et al., 2014).

Benham-Deal (2005) suggests that outdoor activities that require large muscle movement should be included as often as possible. Local and community parks, playgrounds, and vacant ball fields offer the child settings in which to move vigorously and make free use of the large muscles (Clements, 2004). Vigorous outdoor play activity can help relieve boredom or stress and satisfy the child's natural urge for adventure. In addition, newly found skills are often acquired and tested outdoors. Moreover, self-esteem is also increased when early educators act as a positive audience for the child's imaginative outdoor play activities (Clements, 2004). Clements (2004) also noted that early educators can also use outdoor play activities as a way to observe the child's safety practices, and as an opportunity to watch for potentially dangerous behaviour as well as the child's ability to interact with children of different physical abilities, age groups, and ethnic backgrounds. Outdoor play also offers children opportunities to explore their community, enjoy sensory experiences with dirt, water, sand and mud; find or create their own places for play; collect objects and develop hobbies; and increase their liking for PA (Clements, 2004). Furthermore, according to Fjørtoft (2001), outdoor play, especially playing in a natural environment, seems to have positive effects on children. Natural environments represent dynamic and rough playscapes where children become more creative in their play and that also challenge their motor activity (Fjørtoft, 2001).

\subsubsection{Time and seasonal effects}

Previous research has reported higher engagement in MVPA levels during afternoons than mornings (Benham-Deal, 2005), and from mid-afternoon until the 
evening (Durant et al., 2012; Van Cauwenberghe et al., 2012a). In contrast to these findings, the present children were more physically active in the morning than afternoon (studies II, III). It may be that after their midday rest children are not as spontaneous and physically active as they are in the mornings. Alternatively, as in Benham-Deal's (2005) study, these differences in PA levels are explained by the duration of outdoor time. In this study, most of the children engaged in the morning outdoor recess, whereas in the afternoons children were quite commonly collected for a home before recess, or shortly after going outdoors. In the afternoons, children might have not started physically active play or games, as they were expecting their parents to arrive soon. Interestingly, in winter, however, children's PA levels were unaffected by time of day.

Children's daily variation in PA was compared between weekdays and weekend days (study I), and between childcare and homecare days (study IV). No difference was observed in PA levels between weekdays and weekend days, except in wintertime, when the children's sedentary time was greater on weekdays than weekend days (study I). Childcare attendance and shorter outdoor times in winter may in part explain the higher sedentary time during weekdays compared to weekend days. After all, the typical Finnish childcare day is characterized by essential activities of daily living, such as dressing, eating, engaging in self-care activities and structured classroom-based activities (e.g., fine motor activities, pre-academic activities), categorised in the present results as lower-level activities.

As children at the age of three may often spend weekdays in homecare, the fourth study was designed to compare childcare days to homecare days instead of weekdays to weekend days. In general, activity patterns during homecare days were much less flattened and structured than during childcare days. For instance, during the childcare attendance hours, the Finnish children's intensity levels peaked twice, reaching the highest MVPA levels during the day. This may be explained by specific Finnish childcare practices, whereby only non-home care settings generally offer children the opportunity to engage outdoor activities twice a day, in the morning and afternoons. In Finland, outdoor times are associated with unstructured and free play in the playground. Further, a noticeable decline in Finnish children's intensity levels were observed during the midday hours. Finnish children are required to have a nap during the day, or at least lie down for an average of 30 minutes.

Outside of childcare hours, the data revealed one increase in Finnish children's PA levels. This supports the view that parents take their children to the park, or that children are participating in structured activities in organized sport clubs. According to a national sport survey (Kansallinen liikuntatutkimus, 2009-2010), 87\% of Finnish 3-to 6-year-old children currently participate in organised sport; during the last 15 years, the participation rate has risen of by almost 30\%. The most popular sports among Finnish boys soccer, ice-hockey and floor ball, and among girls are gymnastics, horse riding and dance (Kansallinen liikuntatutkimus, 2009-2010). 
Homecare hourly PA patterns showed that children probably wake up later, and less often have nap during the on homecare days than on childcare days (study IV). Further, the fact that no major increases in children's PA were observed during homecare testifies to the need to encourage children and their parents to spend more time playing outdoors or in settings suitable for PA. The homecare hourly PA patterns determined in this study were similar to the recent findings of Verbestel et al. (2011). Despite the day of the week, the children who are the most active during weekdays also seem to be the most active during the weekend, while the least active children continued to be least active throughout and across the whole seven days (Benham-Deal, 2005). Similarly, in this study (study I), the boys and girls were identified who were physically very active, and others who were very inactive. The variation in PA time (described by SD and range) was somewhat higher during the weekend days than weekdays. Early educators and parents should look for ways to increase PA in children who are mostly inactive (Benham-Deal, 2005).

Despite these differences in children's hourly patterns between childcare and homecare days, the descriptive results revealed no significant differences in intensity levels or total PA between childcare days and homecare days (study IV). It is possible that essential daily living activities of the current sample of families do not differ from the structured programmes of childcare settings. Daily routines in childcare deal with a child's natural needs and habits such as dressing, eating, and engaging in natural play. Furthermore, parents may assume that their child is physically active by nature, and getting enough PA during the childcare day, which might be one explanation for not encouraging their child to be physically active or to play outdoors after childcare hours. Additionally, it is possible that children's physically active outdoor play is replaced at home with SB habits such as TV viewing, as observed in previous studies (Burdette \& Whitaker, 2005; Cardon \& De Bourdeaudhuij, 2008). Since SB tracks more consistently than PA, reducing children's SB, especially TV viewing, and promoting their PA during the early childhood period, can have sustained benefits that carry over into later childhood (Jones et al., 2013).

Whereas the Finnish data revealed one peak in post-childcare hours, the Australian data confirmed that the post-childcare hours were associated with reduced activity levels (study IV). Australian parents may assume that their child is getting enough PA during the childcare day. Or it is possible that children were engaged in activities such as cycling or swimming, which accelerometers do not detect. After all, swimming is one of the most popular sport activities among Australian children (Australian Bureau of Statistics [ABS], 2012). More information on accelerometers and their limitations is given in Chapters 3.1, and 7.2. Finally, it is understandable that children's levels of PA decline in the evening, as dinner, bath, and bedtime rituals are fairly sedentary in nature.

Despite a significant different in seasonal temperatures (study I), differences were only found for children's weekday PA. Indeed, in autumn the children engaged significantly more in light PA than on weekdays in winter. Moreover, the observational data revealed more pronounced seasonal variation in 
children's PA (study II). These findings support the view that childcare attendance influences children's PA levels, as discussed earlier.

The present accelerometer data found only minor seasonal variations in children's PA levels (study I). The observational results, however, showed that, in the winter during outdoor play in the childcare centre, the children spent significantly more time engaged in sedentary-level activities and less time in MVPA than in the autumn (study II).

In winter, temperature showed a significant association with children's PA levels, although no association was emerged between rain and children's PA (study II). Generally, childcare centres' daily schedules do not vary across seasons. However, in cold weather, such as $-20^{\circ} \mathrm{C}$ or colder, it is possible that children do not participate in outdoor activities, or that recess periods are shorter than normal. Significant seasonal variation in mean temperatures could explain why the average outdoor time during childcare attendance in winter (116 $\mathrm{min})$ was significantly less than in autumn (178 min) (studies I, II). Therefore, shorter outdoor activity times in winter may explain children's lower engagement in light PA on weekdays and lower MVPA during recess in childcare (study II). Baranowski and colleagues (1993) in fact reported that differences in children's PA levels were related more to time spent outdoors than to season or weather conditions. Similarly, Goodman et al. (2012) reported higher PA levels during long days, partly because on those days the duration and intensity of out-ofhome play was greater. In Finland, the number of daylight hours during the winter months (51 hours/month) is much shorter than in autumn (255 hours/month) (Finnish Meteorological Institute). It might be expected, therefore, that while in winter, daylight would a negative influence children's outdoor times on weekends and post-childcare attendance, however, it should not affect outdoor times during childcare hours, though.

In the autumn, the use of wheeled toys was more pronounced than in winter, whereas in the winter, children were more involved with portable equipment such as sleds. In winter, snow, ice and cold weather do not present the same possibilities for PA as autumn weather. During wintertime, for instance, children often play with snow or mounds of snow, and push and pull sleds. In Finland, as is typical in the Scandinavian countries, deep snow allows tumbling, rolling, and other acrobatics, and the forest can be categorized as a functional play area (e.g., climbing, crawling, making angels in the snow) (Fjørtoft, 2001). Furthermore, it is not rare to encounter young Finnish children in childcare skating or skiing. However, at the age of three, skiing and skating involve lower levels of PA and motors skills, such as balancing and learning to slide, than vigorous PA. Given the considerable contrast in environmental conditions, such as temperature and the presence of snow, the results were surprisingly similar for the two seasons (study I).

\subsubsection{Childcare policies and practices}

The characteristics of cultural policies and practices studied here in the early childhood domain focused on PA recommendations for preschool children, and 
childcare settings, including attendance times and practices. The purpose of this chapter is to provide more understanding on the facilities and practices, which increase or decrease the children's possibilities to engage in physically active play.

\subsubsection{Physical activity recommendations}

Preschool children are widely believed to be a continuously physically active (Reilly, 2008; Timmons et al., 2012), maybe due to their brief bouts of vigorous movements and the intermittent nature of PA (Benham-Deal, 2005; Pellegrini \& Smith, 1998). However, the low levels of PA and high levels of sedentary time reported for the present Finnish children, as also in comparable studies (Brown et al. 2009b; Cardon \& De Bourdeaudhuij, 2008; Gubbels et al. 2011; Hinkley et al. 2012), underlines a worrying trend among preschool-aged children regarding their failure to engage in sufficient levels of PA (study I). The results of the present study (I), when using Van Cauwenberghe et al. (2011b) cut points, were in line with the findings of systematic reviews of previous population surveys which have shown that many young children do not meet the international guidelines for PA (Bornstein et al., 2011; Reilly, 2010; Tucker, 2008), although, according to the cut points of Pate et al. (2006), used in study IV, almost all of Finnish children fulfilled the requirement of at least 60 minutes of MVPA daily (WHO, 2010), and the recommendations of three hours of LMVPA daily (Canadian Society for Exercise Physiology, 2012; Department of Health and Ageing, 2010; Department of Health, Physical Activity, Health Improvement and Protection, 2011; IOM, 2011). Notwithstanding, only a small number of the Finnish or Australian children managed to achieve the Recommendations for Physical Activity in Early Childhood Education (2005) of at least 120 minutes of daily brisk PA (if defined as MVPA). In conclusion, the choice of cut points significantly influences the amount of PA reported across different intensity levels (Bornstein et al., 2011). Therefore, the differences in PA predicted according to the ActiGraph cut points for preschool children in the present sample $(n=79)$ were assessed and discussed in more detail in the section on methodological issues (Chapter 7.2.1, see also Table 5).

The present sample spent a high amount of time in sedentary activities (studies I-IV). This gives us reason to speculate whether the Recommendations for Physical Activity in Early Childhood Education (2005) in Finland should also include limitation on sitting time, as is the case in several international PA guidelines (Canadian Society for Exercise Physiology, 2012; Department of Health and Ageing, 2010; Department of Health, Physical Activity, Health Improvement and Protection, 2011; NASPE, 2009; Tremblay et al., 2012). Limiting sitting time and reducing SB is valuable for increasing PA and health (Strong et al., 2005). From a public health perspective, a reduction in SB may also be easier than increasing PA, as there are fewer constraints, such as no need to change clothing or use special equipment, and can be easily attained with a minimal burden on a child's time or families' financial resources (Tremblay et al., 2011). 


\subsubsection{Cultural variations in practices}

No major differences were found in the Finnish and Australian children's daily total PA, although, during childcare days, the Finnish children engaged in light PA more than the Australian 3-year-olds (study IV). The main finding of the observational cross-country comparison data between Finland and the Netherlands, however, was that the Finnish children spent significantly more time engaged in sedentary-level activities and less time in MVPA compared to the Dutch children (study III). Study III showed that several contextual variables had a differential influence on PA depending on the country. Surprisingly, this mainly concerned non-social influences: time of day and location, in addition to group composition.

The significant interaction observed between country and time of day showed that the Finnish children were less active in the afternoon compared to mornings, while the Dutch children's PA levels were unaffected by time of day (study III). There were similarities in time-of-day variation in PA between the Finnish and Australian children, although the increases and declines were slightly more pronounced among the Finnish children (study IV). The most relevant differences in childcare policies and practices between the Finnish, Dutch, and Australian also concerned the opportunity for outdoor play. Whereas Finnish children have two structured recess sessions, in the Netherlands, and in Australia the childcare programmes are less strict, allowing children to play in the outdoor play area throughout the day (studies III, IV). This may explain why outdoor location had a stronger positive influence on PA in the Dutch than Finnish children (study III).

Non-solitary play was associated with higher activity levels in the Netherlands, whereas in Finland child-initiated solitary play was positively associated with PA level (study III). Despite the fact that a three-year-old child typically engages in solitary play, and is only beginning to learn about interaction and engagement in group play (Dwyer et al., 2009), children in this research were most often observed to be engaged in non-solitary play. This finding suggests that social interaction, which is important for social development, and a high level of PA, which is important for health and physical development, may be somewhat contradictory with their effects (Nicaise et al., 2011). Since a typical Finnish child is cared for at for the first three years of life, the encounter with many same-age peers in day care is naturally a fascinating experience. Nevertheless, the presence of peers did not help them to achieve higher levels of PA. Contrary to the present finding, Reunamo et al. (2014) suggested that peers play a role enhancing PA among children. However, timid, clumsy, uncertain children with weak peer contacts need teachers to help them become involved in the shared production of PA. Consequently, in the Finnish case, where children are engaging in non-solitary play, it would be important to encourage them to reach higher levels of PA in team games and other non-solitary play.

Despite significant variation in temperature and weather conditions between Finland and the Netherlands, no significant association between the temperature or weather variables and children's PA behaviour was found 
(study III). The absence of significant interactions between country and these variables indicates that these variables did not explain the differences in PA levels between the two countries.

Because in Australia, in comparison to Finland, the weather conditions are more favourable for outdoor play throughout the year, the Australian data collection was implemented at more comparable time period, i.e. from autumn to winter (March-August) (study IV). This was done to reduce the temperature differences between the countries. Even so, the mean temperatures between Finland and Australia showed a significant difference. Nevertheless, despite these more favourable opportunities to play outdoors in Australia, Australian children's PA levels were lower than initially expected. Moreover, the similarities in children's PA levels in the two countries did not present any reason to investigate the influence of temperature on PA.

Finally, the childcare daily schedules (e.g., service hours), outdoor times and activities (e.g., lunch and nap times) in all three countries were rather similar, and no major cross-country differences were observed in the childcare programmes (see also Table 3). One notable difference between the three countries involved in this study was revealed in the children's typical childcare attendance times. In the Netherlands, and in Australia children attend childcare services generally once or twice per week, or part-time, whereas Finnish children commonly attend childcare five days a week (EGGE, 2009; OECD, 2014).

In Finland, childcare is part of children's normal daily routine, and therefore, may not exert any particular influence on their PA intensity levels. Another explanation for the cross-country difference may be found in group membership: Finnish 3-year-olds were grouped with 4-to 5-year-old children, whereas the Dutch 3-year-old children were often grouped with 2-year-olds (study III). It is known that peers and friend influence children's PA (Fitzgerald el al., 2012; Reunamo et al., 2014; Salvy et al., 2012), although, it would be interesting to find out the influence of peers at different ages. Further, the Finnish observers may have unintentionally underrated the 3-year-olds' behaviour when this was observed against the backdrop of the older, more skilled children present, while in the Netherlands the opposite may have occurred: the observers may have overrated the PA of the Dutch 3-year-olds by unwittingly comparing them with the 2 -year-olds. The sufficiently high cross-country IRR, however, does not support this explanation.

\subsection{Strengths and limitations}

The studies (I-IV) included in this doctoral research project have several noteworthy strengths. To measure PA intensity levels and sedentary time among preschool children, accelerometers were used, avoiding the biases that can be introduced by methods such as proxy reports (Cliff et al., 2009; Oliver et al., 2007; Pate et al., 2010). Accelerometers further allowed recording of the frequency, intensity, and duration of PA during a whole day or hour-by-hour for 
part of the day, or across several days, including both weekdays and weekend days. Direct observation made it possible to observe children's PA levels, patterns and contextual information during their attendance in childcare. Most importantly, children's PA behaviour was investigated without disturbance to the daily routines of the childcare centres, and without undue influence on the children's free-living activities, both important considerations when measuring PA in preschool children (Cliff et al., 2009; Oliver et al., 2007; Welk, 2005).

Furthermore, in light of previous Finnish doctoral studies, discussed in this chapter, this study complements the existing Finnish scientific knowledge about preschool-aged children's PA behaviour. The novel methods used among Finnish 3-year-old children, in particular, provide further knowledge about their PA intensity levels. In addition, as the accelerometers and OSRAC-P used in this study have also been widely used globally, and hence these findings are internationally comparable. The strengths of the present methods were addressed in Chapter 3.1 and Chapter 3.2.

Another major strength of this study was the repeated-measure design, where the same 3-year-old children were measured during two distinct seasons, autumn and winter. The original aim had been to compare summer to winter, but because a large proportion of Finnish childcare centres are closed or open part-time only during the summer months (June to August), the first phase of data collection was implemented immediately after the summer holidays, starting in late summer and ending in autumn.

Anecdotal evidence obtained during the implementation of the study suggests that childcare centres are suitable places to reach families with 3-year-old children. Moreover, the children were co-operative and eager to take part in this study. Proxy reports by parents of their child's receptivity to wearing the accelerometer clearly indicated that it was a positive experience for the majority of the children. Although previous data on the receptivity of pre-schoolers to wearing accelerometers is relatively limited and not well understood (Oliver et al., 2007), the present results are in line with those of earlier studies (Cardon \& De Bourdeaudhuij, 2008; Pate et al., 2004; Van Cauwenberghe et al., 2011a). These positive findings, however, may have been due the fact that for both the childcare centres and families participation in the study was wholly voluntary.

Finally, a valuable aspect of the present research is that PA levels were directly observed using the OSRAC-P method in two European countries. Observations were made in a total of 23 childcare centres, both indoors and outdoors, and during both mornings and afternoons, thereby covering regular childcare attendance times in both countries. Further, children's PA levels were measured using the accelerometers in two countries in two different continents. Children's PA was measured over five days, covering both weekdays and weekend days, in both homecare and childcare (27 centres in total) settings that in Finland and Australia.

This doctoral study has limitations that should be noted. The study was limited by its relatively small sample size. In addition, the generalizability of the findings could be limited by the fact that all the participating childcare cen- 
tres and children were located in the same city. A different recruitment strategy, such as direct contacts to all the childcare centres in the city or the inclusion of more cities, might have produced more participants. Further, the sample size would have increased if 4-to 5-year-old children had also been recruited. However, this study was part of a larger longitudinal research project, in accordance with which the sample focused exclusively on 3-year-old children in one city area.

One of the reasons why some parents refused to allow their child to be involved in the study, was that the child had only recently started out-of home care, and the parents thought that taking part to the PA measurements would be too much at the same time for their 3-year-old child. It should be noted that, because participation in the study was based on voluntariness, the childcare centres and families involved could be expected to be more positive about the subject than if they had no choice in the matter, and this may also have influenced the final results. The limitations of the methods were addressed in Chapter 3.1, Chapter 3.2, and Chapter 7.3.1.

The following limitations should be considered when interpreting the results of the comparison studies (studies III, IV). First, in the Netherlands, the data collection had already been done in 2008, and therefore it was no longer possible to affect the Dutch study design. For instance, measurements of children's body height and weight were missing. In addition, a 3-day observation protocol would have been valuable. Second, in Australia, given the s small number of participants, alternative, more efficient, recruitment methods should have been considered. The measurements should have also included the entire week rather than a 3+2-day protocol as this may have yielded a larger number of valid childcare days. Cultural differences were also evident in families' attitudes to the equipment. Whereas in Finland, all the accelerometers were safely returned, in Australia three were lost during the measurements.

Finally, the present PA data could have been influenced by other factors described in the socio-ecological model, such as home environment, familial interaction, family-childcare interaction, and other public policies, which were not taken into account in the study.

\subsection{Methodological issues}

The designs of the four different studies described in this doctoral research raise various methodological issues including, e.g., the study population, assessment choices and the explanations for the variance of the PA data. The findings of these studies must therefore be interpreted in light of these issues, which are described below.

The accelerometers were piloted in May 2010. A total of six preschool children ( 2 boys, 4 girls; mean age 4.3 years) wore accelerometers over four consecutive days: three weekdays and one weekend day. The pilot revealed that accelerometers were a suitable method for recording young children's PA levels. 
The feasibility of accelerometers was also shown in the children's behaviour and dedication toward the measurements. One 3-year-old boy, for instance, thought that the accelerometer belt he was wearing would also be suitable to hold a sword that he was using in play. In addition, according to parents' feedback, the children remembered to put the belts on themselves, without parents needing to remind them to do so. Some of the children even liked to sleep wearing the belt. Where an abnormal event occurred in a family's weekend programme, such as unusual child PA behaviour (prolonged sitting in a car or stroller), an extra weekend day was added to the total of measurement days.

In Australia, the research measurements were the same as in Finland, and therefore a pilot test with children was not needed. However, the researchers wore accelerometers for few days, to practise test initializing, downloading the devices and saving and reducing data with ActiLife (ActiGraph, LLC, Pensacola, FL, US) version 6.5.2. Finally, piloting the methods was a very valuable experience and gave the researchers more confidence regarding the final measurements.

As discussed in Chapter 3.1.1, accelerometers are an accepted way to monitor PA and sedentary time in preschool children, and therefore, for the purposes of this study, it was not considered necessary to calibrate the ActiGraph accelerometer for use with 3-year-old children. Although Dössegger et al. (2013) have suggested that the starting day significantly influences the PA estimates, a paired sample $t$-test showed that the first day of the registration period did not differ from the other measurement days, and therefore all the days were included in the final analyses in this study (Soini et al., 2012).

A disadvantage of accelerometers is that they do not provide information on the type or context of PA (Pate et al., 2010). In addition, accelerometers are limited in their ability to measure non-weight-bearing activities or upper limb movements. They are not able to account for the increased energy cost associated with walking up stairs, on an incline or on soft surfaces (Oliver et al., 2007; Pate et al., 2010; Trost, 2007). These types of activities, however, are very typical among Finnish children, especially during wintertime, when children often climb up and slide down mounds of snow, pushing or pulling sleds, walk in soft snow, or ski and skate. Also, accelerometers do not detect movements, which are sedentary but need balance and/or concentration in order to develop motor skills or are integral to certain low intensity activities, which are particularly important for young preschool children (Cliff et al., 2009). In addition, a large number of children did not achieve the required eight hours of daily data during the winter. This may partly have been due to the effect of the extremely cold weather $\left(<-25^{\circ} \mathrm{C}\right)$ conditions on the functioning of the accelerometers.

The choice of cut points significantly influences the amount of PA reported across different intensity levels (Bornstein et al., 2011; Kim et al., 2012). While there are no pre-existing best cut points for pre-schoolers, in this study two set of cut points, those of Van Cauwenberghe et al. (2011b) and Pate et al. s (2006), were used. In addition, for this summarizing report, differences in predicted PA according to the ActiGraph cut points (Butte et al., 2013; Evenson et al., 2008; 
Pate et al., 2006; Reilly et al., 2003; Sirard et al., 2005; Trost et al., 2012; Van Cauwenberghe et al., 2011b) for preschool-aged children were assessed in the present sample $(n=79)$ (see Table 5). According to repeated measures (analysis of variance) ANOVA, the mean time spent per day in sedentary, light and MVPA were all significantly different from each other. For instance, when applying these different MVPA cut points among the Finnish pre-schoolers, meaningful differences were observed, with children engaging in approximately 85 minutes per day in MVPA when using the lowest cut point of Pate et al. (2006) and Trost et al. (2012) compared to 43 minutes when applying the highest cut point of Sirard et al. (2005), and 48 minutes when applying the cut point of Van Cauwenberghe et al. (2011b).

Further, based on Cochran's $Q$ test, the proportion of the sample complying with the PA recommendations (Canadian Society for Exercise Physiology, 2012; Department of Health and Ageing, 2010; Department of Health, Physical Activity, Health Improvement and Protection, 2011; IOM, 2011; Recommendations for Physical Activity in Early Childhood Education, 2005; WHO, 2010) differed significantly at each ActiGraph cut point. Indeed, when applying the cut points suggested by Butte et al. (2013), Evenson et al. (2008), Pate et al. (2006) and Trost et al. (2012), all the children met the recommendation of three hours of daily PA. However, when applying the cut points of Sirard et al. (2005) only $4 \%$, and when applying those of Van Cauwenberghe et al. (2011b), none of the children met the recommendation (Canadian Society for Exercise Physiology, 2012; Department of Health and Ageing, 2010; Department of Health, Physical Activity, Health Improvement and Protection, 2011; IOM, 2011). 
TABLE 5 Differences in predicted physical activity of Finnish children $(n=79)$ according to ActiGraph cut points for preschool children.

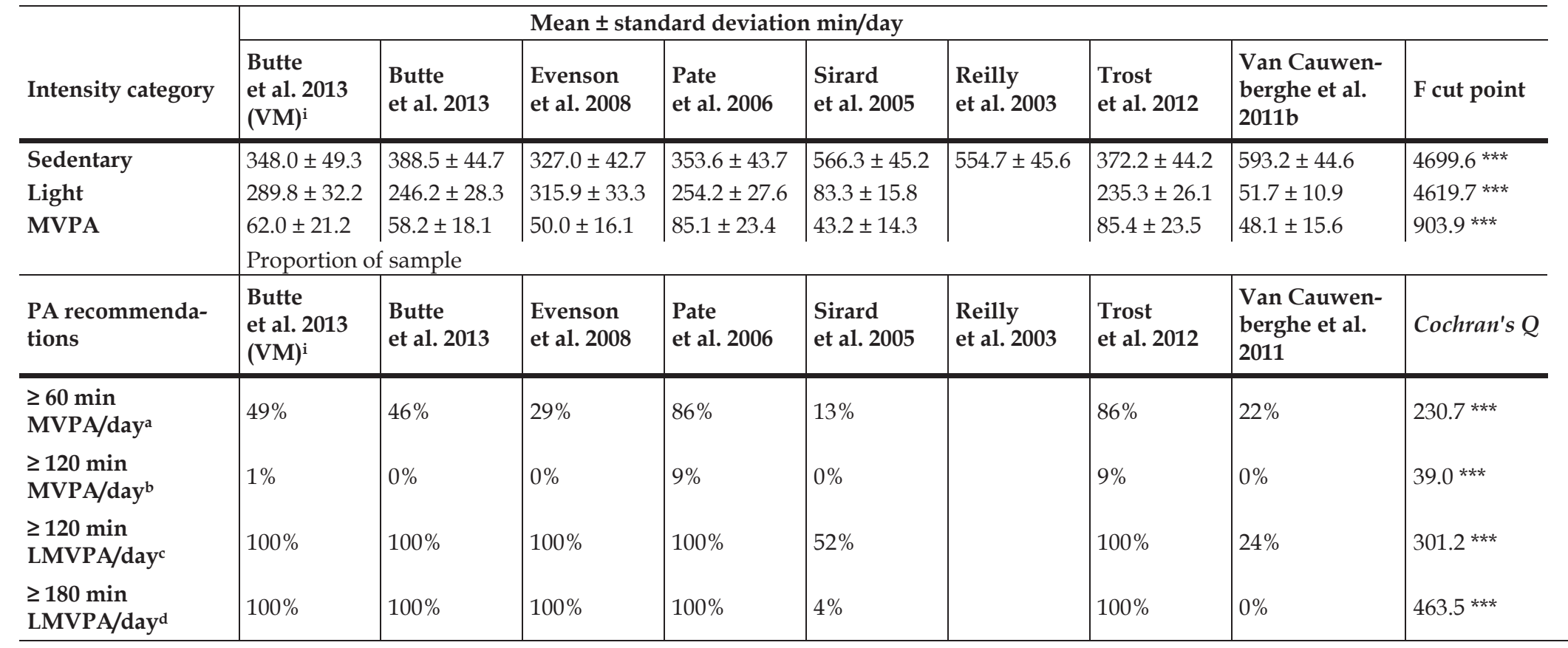

Note. aWorld Health Organization (WHO) 2010, Strong et al. 2005; ${ }^{\circ}$ Recommendations for Physical Activity in Early Childhood Education, 2005; cThe National Association for Sport and Physical Education (NASPE), 2009; dDepartment of Health and Ageing, 2010, Canadian Society for Exercise Physiology, 2012, Department of Health, Physical Activity, Health Improvement and Protection, 2011, Institute of Medicine of the National Academies (IOM), 2011; VMi = ***p $<.001$. 
The OSRAC-P observation method was piloted in November 2009 in a Finnish childcare setting (Seppälä, 2012). A total of 34 children ( $N=34,19$ boys, 15 girls; mean age 4.5 years) from one childcare centre in the city of Jyväskylä were involved in the pilot study. Children were randomly selected for observations and observed several times by two researchers, one Finnish and one Dutch researcher, resulting a total of 432 single observations. According to Seppälä (2012), the IRR in all the assessed categories, except prompts, were $r=.70$. A validity problem between the researchers from the two different countries was observed in the prompt category, as one of the researchers was Dutch and did not speak Finnish.

Owing to the imperfection of the OSRAC-P method, direct observation, and different protocols used in the field, some remedies needed to be considered. First, before the measurements, all the field researchers were trained in the method by studying the instrument (studies II, III). The original observation form was developed to assess children's PA levels and the effects of childcare environments on PA among preschool children in the US (Brown et al., 2006). Using this method in the Finnish childcare environment required paying extra attention to ensuring that the terms and concepts were similarly understood by the researchers. Terms and assessment categories were discussed and translated into Finnish; however, the English version of the observation form was used during the final observations (see Appendix 6). The researchers were also familiarized with the method by reading recent studies and literature, and subsequently observing children via videotape and 'live' in the childcare settings or playgrounds. Furthermore, observations in the very first childcare centre were performed by two pairs of researchers, although, only one pair's observations were saved for the final analyses. During those observations, the final protocols were decided and observers able to lay down common rules for observations without infringing the principles of good scientific practice.

Second, Cohen's kappa was used to determine the IRR of the two observers within each country during the observations of the OSRAC-P variables (i.e., activity intensity, activity types, group composition, contexts, initiator of activity, prompts; see Table 6). Mean IRR of the variables assessed showed sufficient agreement, $.70(\mathrm{SD}=0.2 ; p<.001)$. Low frequency of codes in certain categories, such as prompts, led to kappa coefficients below the substantial level of .60. Disagreement on the variables between researchers, and the limitations of the structured form are discussed in more detail below. 
TABLE 6 Cohen's kappa means for inter-rater reliability (IRR) of two observers for the OSRAC-P categories.

\begin{tabular}{lllll}
\hline \multirow{2}{*}{ Codes/categories } & \multicolumn{2}{l}{$\mathbf{2 0 1 0}$} & \multicolumn{2}{l}{$\mathbf{2 0 1 1}$} \\
& $\mathbf{M}$ & range & $\mathbf{M}$ & range \\
\hline Activity intensity & .48 & $.28-.56$ & .48 & $.30-.59$ \\
Activity type & .65 & $.00-.95$ & .73 & $.26-1.00$ \\
Group composition & .74 & $.71-.83$ & .70 & $.67-.82$ \\
Indoor context & .67 & $.00-1.00$ & .72 & $.39-1.00$ \\
Outdoor context & .66 & $.15-1.00$ & .72 & $.12-1.00$ \\
Initiator & .83 & $.83-.84$ & .82 & $.82-.83$ \\
Prompts & .35 & $.00-.54$ & .40 & $.33-.50$ \\
\hline
\end{tabular}

Note. OSRAC-P = Observational System for Recording Physical Activity in Children-Preschool Version (Brown et al., 2006); $M=$ mean.

Third, the fact that the observers in the two countries were not the same might have influenced the findings, possibly explaining the systematically higher PA levels found in the Dutch compared to Finnish children. For linguistic reasons, however, it would not have been possible to use the same researcher in each country, as Seppälä (2012) stated in her pilot study. Therefore, to assess crosscountry inter-observer agreement, a separate sample of children not included in the final study was independently observed via videotape by one of the two researchers in each country. This resulted in the cross-country coding of 305 observation intervals, i.e. $13.8 \%$ of the observation intervals in the main study ( 2 216 intervals), thereby meeting the OSRAC-P norm of at least $12 \%$ independent coding (Brown et al., 2009c). In summary, the IRR in both countries as well as cross-country indicated appropriate levels of agreement.

As previously discussed, the direct observation method is based on subjective assessments. For instance, evaluation of the intensity of activity among young children, such as three-year-olds, is very challenging. It is possible that the observers standardize the intensity scores of specific activity types; for example running might automatically be scored as five (fast or vigorous movements) and lying down as 1 (stationary or motionless) (Seppälä, 2012). In the current study, however this was not done; running, for example, was typically rated between three (light, slow or easy movements) and five, depending on whether the child was running, slowly or quickly, or running uphill, or carrying while running.

Further, it should also be noted that, although during the 15-second observation period a child would have engaged in various intensity levels, only the highest intensity score was used in analyses. This means that an observation period that may have consisted of sedentary time for the first 10 seconds followed only by a few seconds of vigorous PA, would be analysed as all vigorous PA. In addition, a child may have been physically active during each 30 -second coding period, and been sedentary during the 15-second observing period, and vice a versa, i.e. been sedentary during the observation period and engaged PA during the coding period. 
Some variation in activity coding occurred between observers. For instance, when children were in the pool, one observer may have record the activity as swimming, and the other observer as standing or sitting, or some other activity that the child was engaged in during the observation period.

Furthermore, the observers found it difficult to decide whether a child was engaged in solitary play in the middle of group of children, or was interacting with other children. Sometimes, it seemed as if even the child him/herself did not know if he/she was playing with someone or not. Additionally, during observation, a child might have been engaged in both solitary and non-solitary play, yet only one alternative was recorded per interval. In the final analyses, when one observer's rating was solitary play, and the other's non-solitary play, the non-solitary rating was invariably selected. Finally, as the researchers tried to ensure the child some privacy in play, and avoid being too close to the observed child, it is possible that some teachers' or peers' prompts were missed.

Some differences between the Finnish and Dutch study designs merit attention. Originally, this study aimed to replicate the study protocols and observations forms used by Gubbels and colleagues in the Netherlands in 2008. However, some changes to the observation protocols were made (see also Chapter 5.4). In the Netherlands, each of the nine childcare centres was visited twice for direct observations, whereas, in Finland, the observations were conducted on three measurement days, the aim being to observe the children as much as possible during these periods. This meant that the Finnish observations totalled 18 hours $(1440 x[15 s+30 s])$ as against nine $(776 x[15 s+30 s])$ in the Netherlands. In study III, all the Finnish observations were included to provide more reliable data on children's PA behaviour during their childcare attendance. As the analyses were based on the means of observations, the difference in the number of observations between the two countries was not regarded as a problem. An option would have been to select for the analyses an equal number of observations from each country. However, there could, for instance, have resulted in selection of all the high intensity level intervals of the Finnish observations, even after applying a randomising procedure.

In sum, several earlier studies have shown a strong positive correlation between ActiGraph accelerometer output and PA intensity in preschool children (Evenson et al., 2008; Pate et al., 2010; Reilly et al., 2003; Sirard et al., 2005; Trost et al., 2012; Van Cauwenberghe et al., 2011b), and that both ActiGraph accelerometers (e.g., Bornstein et al., 2011; Cliff et al., 2009; Kim et al., 2012; Matthews et al., 2012; Rowlands, 2007; Van Cauwenberghe et al., 2011b; Welk et al., 2012) and the OSRAC-P method (e.g., Brown et al., 2006; Pate et al., 2010; Trost, 2007) can be considered feasible and reliable tools for measuring PA and SB in free-living preschool children. 


\subsection{Practical implications}

The findings of this doctoral study hold various implications for practice. These practical implications concern the role of socio-ecological influences on children's PA behaviour, the development of intervention strategies for childcare and home settings, and methodological aspects regarding the use of accelerometers and direct observation in preschool children. As these implications are currently of considerable interest among researchers, policy makers, practitioners, and parents, the emphasis in this section will be on the practical value and applicability of the findings of the different studies.

The study was executed in light of the socio-ecological model modified Bronfenbrenner (1979). The findings revealed that the childcare setting itself plays an important part in promoting positive patterns of health PA behaviour during early childhood. A better understanding of the interaction between and within different contextual factors in children's PA behaviour helped to identify ways of promoting participation in PA during childcare attendance. Childcare settings, in collaboration with families, may find the results of this study useful in laying a foundation on which to promote children's PA. The findings provide important implications for the development of PA interventions aimed at increasing preschool children's PA behaviour in both the childcare and home settings. In fact, a one-year long Home- and childcare-based Intervention to Promote Physical Activity (HIPPA) has already been developed and carried out based on the present findings (Mehtälä et al., 2014). To ensure the sustainability of the intervention, the intervention program was planned to be low intensity (so as to minimize the burden on teachers and families) and easily implementable, primarily by early educators.

Finnish policy makers and childcare management organizations that set the regulations for childcare settings and curriculums should take into account the importance of reducing sedentary time and integrating increased levels of PA into the daily living activities of formal childcare. The present findings suggest that it would be important to integrate outdoor time into the daily schedule as much as possible, to ensure that playgrounds and equipment are appropriate for outdoor play, to ensure adequate free play time, and to decrease sedentariness, for instance, by reducing prolonged sitting times. While many of the preschoolers in the sample did not achieve the standards proposed in global guidelines for daily PA, the development of more specific recommendations and standards for PA, especially reducing SB (e.g., sitting, screen time), as is done in several international guidelines, may be warranted.

The present findings highlighted the existence of a group of boys and girls who were physically very active, and another who were very inactive. This finding should encourage early educators and parents to make extra effort to promote a healthy lifestyle in their daily activities with children. Gender differences also indicated that, already in the age of three, girls' PA levels were lower 
than boys'; therefore more attention and encouragement are needed to promote PA among preschool-aged girls.

Positive prompting and encouragement by early educators and peers showed a positive association with children's PA levels, although the early educators in this study very rarely implemented teacher-arranged activities and games to enhance children's PA or encouraged children to engage in PA. Developing healthy patterns of PA among children requires that both parents and early educators have positive attitudes towards PA and awareness of PA behaviour tracking from early childhood to adulthood.

No major differences in children's PA levels between weekdays and weekend days, or between childcare and homecare days were observed. However, the findings indicated that during their childcare hours children engaged in both MVPA and LMVPA for over half of their daily PA time, and that the highest levels of PA occurred during childcare attendance. Therefore, promoting children's PA throughout the day, with a little extra attention to the afternoon and post-childcare hours, would increase the total amount of PA in children. The evidence adduced in this research may make a partial contribution toward encouraging and stimulating parents to work towards improved provision of opportunities for physical activities, such as visiting parks or playground areas.

All parents and early childhood professionals should regard the issue of increased outdoor play as one of major importance. To minimize the time spent sitting and in sedentary locations such as the sandbox, encouraging children to climb and run, and to touch, ride or push wheeled toys, can also help to increase children's engagement in MVPA. Furthermore, Finnish childcare centres could make more frequent use of the natural environment, such as the forest, in their daily programme. Moreover, childcare settings could be organised more as outdoor childcare, where the children spend more time outdoors in the natural environment.

Although no major variations were observed in children's PA levels between autumn and winter, it is recommended that children engage in a high amount of outdoor PA throughout the year, with an additional attention to outdoor play on weekdays in wintertime.

The Finnish children spent significantly more time in sedentary-level activities and less time in MVPA than the Dutch children. Study IV, however, indicated that during their childcare days the Finnish children engaged significantly more in light PA than the Australian children. The present findings indicate that better understanding of the contextual factors and their interaction in children's PA behaviours across countries could help in planning childcare interventions aimed at increasing the PA levels of preschool children not only in the present countries, but also in other countries with similar childcare settings. Finnish childcare policy makers should take advantage of international practices and guidelines that have been shown to be beneficial for children's health behaviour. 
While this research did not aim to calibrate or validate the methods used, on the basis of the findings and practical experience gained in the course of this study, some suggestions can be offered to researchers in field using accelerometers and OSRAC-P methods among preschool children. Accelerometers were unobtrusive to use, and appropriate when measuring the frequency, intensity, and duration of 3-year-old children's free-living PA. The OSRAC-P system provided contextually and behaviourally rich information about the social and non-social factors related to 3-year-olds' PA in childcare settings, without disturbing childcare centres' daily habits and routines. Moreover, combined, these methods provided multi-faceted tools for measuring PA and SB in 3-year-old children, and therefore can be warmly recommended in early childhood research. However, the limitations of the methods, also addressed in this summarizing report, call for further investigation.

In summary, the following suggestions can be offered for increasing PA and decreasing sedentary time among preschool children:

- $\quad$ The childcare setting plays an important role in a child's everyday life and in PA during early childhood, and therefore is a suitable target when seeking to promote children's PA behaviour.

- Throughout the day, children should be encouraged to engage for a high amount of time in MVPA-level activities, and to minimize the time spent sitting or engaged in sedentary-level activities.

- Throughout the year, whenever possible, preschool children should be given the possibility to play outdoors.

- Positive prompting and encouragement by early educators are needed to promote PA, especially among preschool-aged girls.

- Accelerometers, which provide detailed information on the intensity and duration of PA, and direct observation, which can provide information on the type and context of activity, are both suitable and recommended methods for use in early childhood research.

- The development of more specific recommendations and standards for PA, especially reducing SB (e.g., sitting, screen time), as is done in several international guidelines, should be considered.

- $\quad$ Finnish childcare policy makers should take notice of the present research findings as well as of existing international practices and guidelines that have been demonstrated to be beneficial for children's health, and PA behaviour. 


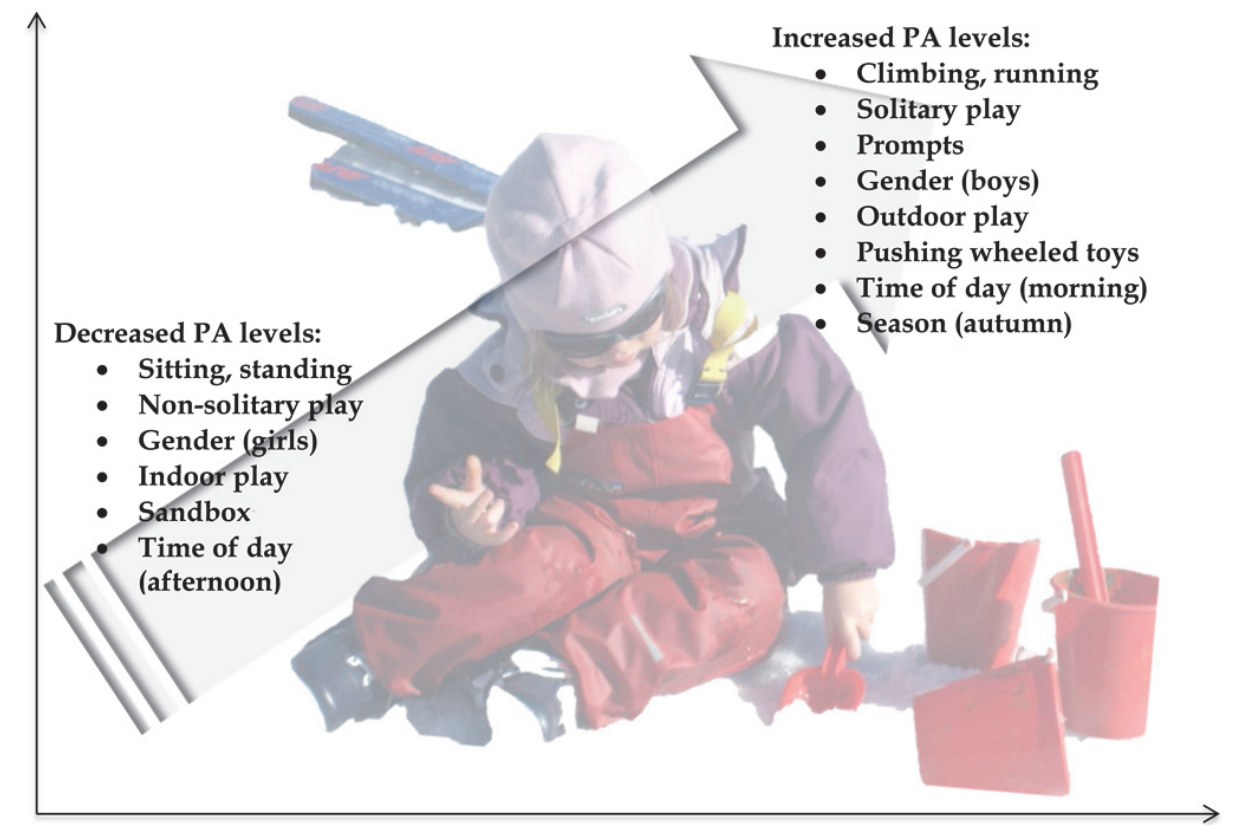

FIGURE 3 Conclusions on 3-year-old preschool children's PA behaviour.

\subsection{Conclusions and directions for future research}

This doctoral study examined the PA behaviour of Finnish 3-year-old preschool children. The findings make a strong contribution to the current evidence on accelerometer-based and observational based PA measurement in early childhood in Finland. Although preschool children are traditionally viewed as highly active, the present sample of 3-year-old children spent the major part of their time in sedentary-level activities. The children was observed for the most part in non-solitary play; however, during solitary play children showed higher levels of PA intensity. The children were more physically active in the mornings than afternoons, although no major differences were observed in PA levels between days or seasons. The Finnish children spent significantly more time in sedentary-level activities and less time in MVPA than the Dutch children, whereas, during childcare days the Finnish children spent more time (average 20 minutes) in light PA than the Australian children. Clearly, much works remains to be done, and some suggestions for future work are made below.

In the future, larger and more heterogeneous samples are required to raise the reliability and the generalizability of the research findings. Further, more versatile use of biological, psychological, cognitive and emotional factors merit more detailed study, especially in the context of the multiple demands on children's development and PA behaviour. From the educational point of view, it 
would be interesting to learn how to support physically active group play in ways that children find to be fun. In addition, it would be important to investigate the relationships between PA behaviour, SB and nutrition, and their influence on the risk for obesity. Moreover, longitudinal studies, which focus on secular trends in activity and eating behaviours, are urgently needed.

This research investigated environmental influences on children's PA behaviour, in both the homecare and childcare settings, showing that both play a crucial role in the development of PA habits. In the social environment, parents, early educators, and peers are the primary actors of importance for 3-year-old children. Familial interaction in this study was not a focus, and therefore an additional direction for future research is to look further into the effects of the home environment, SES of the family, different types of parenting practices, and role modelling. Parental health counselling, for instance, would help parents to adopt a more physically active lifestyle, which in turn would benefit the health both of their child and of the whole family (Sääkslahti, 2005).

Furthermore, the interactions between home and childcare settings deserve more detailed attention. All the more so, given that parents and early educators are likely to have different values, attitudes, practices and styles when it comes to PA and child rearing. Further, the interaction between socio-ecological factors, such as psychological factors (e.g., motivational factors), the quality of the childcare centre (e.g., educational levels of teachers) and children's PA behaviour in different contexts, merits further examination.

Consistent methodologies (e.g., cleaning, analysing and reporting) and the use of age-appropriate cut points for studies using accelerometers are required in order to gain a better understanding of how preschool children are spending their day (Hnatiuk et al., 2014; Rowlands, 2007; de Vries et al., 2009). Qualitative data on why participants choose not to wear a monitor, or to remove it prematurely, are needed. Additionally, factors associated with monitor size, placement site, monitor number, and methods of attachment should be investigated (Matthews et al., 2012). Processing decisions include e.g., the choice of accelerometer epoch lengths, the most appropriate cut points, number of axes used, minimum wearing time per day, minimum number of registration days and what outcomes should be reported. Moreover, researchers in the field should begin using raw accelerations instead of activity counts when measuring PA (John \& Freedson, 2012). Vähä-Ypyä, Vasankari, Husu, Suni, \& Sievänen (2014) have recently stated that an easy-to-calculate, physically meaningful, mean amplitude deviation (MAD) with universal cut-off limits would provide a universal method to evaluate PA and SB using raw accelerometer data expressed in Gforce, and thus facilitate comparability between different accelerometer studies. According to Troiano et al. (2014), raw acceleration signal data inspire new paradigms of movement data interpretation. In deed, modelling experts and statistician are utilising the power of pattern recognition, machine learning and fusion of different techniques to respond to an ever-expanding fields of application (Troiano et al., 2014). In addition, new competing technologies, such as the mobile global positioning system (GPS) with synchronous heart rate recordings 
(Fjørtoft, Kristoffersen, \& Sageie, 2009), and electromyography (EMG) clothes (Finni et al., 2011), are continuously being launched, and can be expected to become more common also in early childhood studies. However, it can be assumed that researchers still continue to use accelerometers and cut points among preschool children, at least for the immediate future.

So far, research that has adopted similar study designs and methodologies to compare PA and SB in childcare and home settings between children from different countries is limited. To our knowledge, this is the first study (study III) to compare children's PA in two European countries using the same study design and a standardized OSRAC-P measurement, and one of the few European studies where a range of contextual variables have been taken into account in examining young children's PA behaviour during childcare attendance. This study addressed the continuing need for both observed measured evidence on PA levels in very young children, and investigation of the contextual factors that influence PA participation in this age group. The comparative studies (III, IV) in this study should encourage researchers to undertake more cross-country comparisons in the future. Although, a wider cultural perspective is needed in the future studies.

Today, we are a long way from forming universal or comparable guidelines for preschool children. In addition, to comparing trends across countries, and to harmonise data collection internationally, empirically supported PA guidelines that can be used to determine whether preschool children are sufficiently active need to be developed (Skouteris et al., 2012). To date, Finnish children and youth spend an alarming amount of time sitting down and in front of screens (Liukkonen et al., 2014), in addition, SB habits have shown associations with a number of health outcomes, even in preschool-aged children (Hinkley et al., 2010; Tremblay et al., 2011). Therefore, researchers in the field should gather more detailed evidence of the SB habits of preschool children in Finland. This information would help in developing strategies that target, in particular, reducing time spent sitting and time spent being sedentary. To ensure children engage in a sufficient amount of PA daily and reduce their sitting and sedentary times, and to increase international comparability between studies, developing and updating PA recommendations, and especially SB guidelines for preschoolers, is necessary also in Finland.

Taken together, the PA setting is of especial importance in achieving positive behavioural outcomes (Strong et al., 2005). However, more research is needed to evaluate the effects of PA on children's health and well-being in the early years of life, and what constitutes a sufficient level of health-enhancing PA (Beets et al., 2011). In particular, it would be very important to find answers to the following questions: how much daily MVPA should a child engage in? Is light PA sufficient to ensure health benefits for a child? How much is too much sedentariness daily? What is the quantity and quality of daily safe PA required to ensure child's optimal growth and maturation? The most important, how to support children to be "always on the move"? 


\section{YHTEENVETO (FINNISH SUMMARY)}

\section{Jatkuvasti liikkeessä? Kolmevuotiaiden päiväkotilasten mitattu fyysinen ak- tiivisuus}

\section{Lapsen fyysinen aktiivisuus varhaislapsuudessa}

Pienen lapsen kiinnostus ympäristöön ilmenee usein uteliaisuutena, kokeilunhaluna ja fyysisesti aktiivisena toimintana (Gallahue \& Ozmun, 2006, s. 176). Lapselle leikki on luonnollinen osa jokapäiväistä elämää, ja sen avulla lapsi oppii ymmärtämään ympäristöä (Pramling Samuelsson \& Asplund Carlsson, 2008), sekä hahmottamaan omaa kehoa ja käyttämään motorisia taitojaan (Gallahue \& Ozmun, 2006, s. 174). Lasten leikki on luonteeltaan tyypillisesti moniulotteista ja intensiteetiltään vaihtelevaa, siksi sitä voidaankin kutsua fyysisesti aktiiviseksi leikiksi (Pellegrini \& Smith, 1998; Timmons ym., 2007). Lasten käyttäytymistä, joka usein pienillä lapsilla ilmenee leikkinä, kutsutaan tässä tutkimuksessa yleisesti fyysiseksi aktiivisuudeksi (physical activity).

Aikaisemmat tutkimukset ovat osoittaneet että fyysinen aktiivisuus on yhteydessä moniin myönteisiin terveysvaikutuksiin (mm. Haskell ym., 2009). Sen lisäksi se on edellytys lapsen normaalille kasvulle ja kehitykselle (Malina ym., 2004). Fyysinen aktiivisuus ja fyysisesti passiiviset ajanviettotavat (sedentary behaviour), kuten yhtäjaksoinen istuminen ja tv:n katselu, ovat sellaisia käyttäytymistottumuksia, jotka opitaan jo varhaislapsuudessa (Janz ym., 2005; Timmons ym., 2007; Ward ym., 2010). Nuorena opittu aktiivinen elämäntapa luo hyvän perustan aktiiviselle elämäntavalle myös myöhemmin elämässä (Janz ym., 2005; Telama ym., 2014; Yang, 1997).

Lasten normaalin kokonaisvaltaisen kasvun ja kehityksen turvaamiseksi laadittiin vuonna 2005 suomalaiset Varhaiskasvatuksen liikunnan suositukset. Suositusten määrällisen tavoitteen mukaan alle kouluikäisten lasten tulisi liikkua päivittäin kaksi tuntia reippaasti. Vastaavissa kansainvälisissä suosituksissa, mm. Australiassa, Kanadassa ja Englannissa, päiväkoti-ikäisten lasten tulisi liikkua kolme tuntia päivittäin. Sen lisäksi lapsen passiivisen ajanvieton määrän tulisi olla hereillä ollessa korkeintaan tunti kerrallaan (Canadian Society for Exercise Physiology, 2012; Department of Health and Ageing, 2010; Department of Health, Physical Activity, Health Improvement and Protection, 2011). Vaikka pienten lasten uskotaan olevan luonnostaan fyysisesti aktiivisia, viimeaikaiset kansainväliset tutkimukset ovat osoittaneet, että päiväkoti-ikäisten lasten fyysinen aktiivisuus on kuormittavuudeltaan alhaista, eikä monenkaan lapsen aktiivisuuden määrä täytä maansa liikuntasuosituksia (mm. Bornstein ym., 2011; Hinkley ym., 2012; Reilly, 2010; Tucker, 2008).

Alle kouluikäisten lasten fyysisen aktiivisuuden mittaaminen on sen spontaanin ja ennalta arvaamattoman luonteensa vuoksi haastavaa (mm. Cliff ym., 2009; Oliver ym., 2007; Pate ym., 2010; Trost, 2007). Luotettavien tulosten saamiseksi onkin suositeltavaa käyttää rinnakkain useita erilaisia, sekä subjektiivisia että objektiivisia mittausmenetelmiä. Tällaisia ovat erityisesti suoran ha- 
vainnoinnin ja kuten kiihtyvyysmittareiden käyttö (Oliver ym., 2007; Pate ym., 2010; Rowlands, 2007; Trost, 2007).

Vaikka kahden viime vuosikymmenen ajan kiihtyvyysmittareiden käyttö on kansainvälisesti yleistynyt myös päiväkoti-ikäisten liikuntatutkimuksissa (Bornstein ym., 2011; Kim ym., 2012; Welk ym., 2012), toistaiseksi Suomessa kiihtyvyysmittarein toteutettuja lapsuudenajan tutkimuksia on tehty vähän (Aittasalo ym., 2010; Husu ym., 2011; Soini ym., 2012). Jotta ymmärretään paremmin lasten fyysistä aktiivisuutta ja saataisiin ohjeita lasten arkiaktiivisuuden lisäämiseen sekä istumisen vähentämiseen, tarvitaan lisää tarkkaa tutkimustietoa.

\section{Tutkimuksen tavoitteet ja tutkimuskysymykset}

Tässä neljästä tieteellisestä julkaisusta koostuvassa väitöskirjatutkimuksessa tavoitteena oli selvittää kolmevuotiaiden päiväkotilasten fyysistä aktiivisuutta, ja selvittää mitkä tekijät mahdollistavat ja estävät lasten fyysisen aktiivisuuden. Tutkimuksessa lasten fyysistä aktiivisuutta tarkasteltiin Bronfenbrennerin (1979) ekologisesta systeemiteoriasta (tunnettu myös ekologisten järjestelmien teoriana) mukaillun sosioekologisen mallin (Kuvio 1) mukaisesti. Lapsen fyysistä aktiivisuutta tarkasteltiin yksilön, sosiaalisen ympäristön ja fyysisen ympäristön sekä päivähoidon ja yhteiskunnan yleisten käytäntöjen välisenä kaksisuuntaisena vuorovaikutuksena.

Tutkimuskysymyksiksi muodostuivat:

1. Millaista on suomalaisten kolmevuotiaiden päiväkotilasten fyysinen aktiivisuus?

2. Eroavatko lasten havainnointiin perustuva fyysinen aktiivisuus ja aktiivisuuden kontekstit päiväkodissa Suomen ja Hollannin välillä?

3. Eroavatko lasten fyysinen aktiivisuus Suomessa ja Australiassa kiihtyvyysmittarilla mitattuna?

\section{Aineisto ja mittausmenetelmät}

Suomessa tutkimuksen aineisto kerättiin 14 vapaaehtoisesta päiväkodista. Syksyn 2010 (elo-lokakuu) aikana tutkimukseen osallistui 96 lasta (48 poikaa ja 48 tyttöä) ja talven 2011 (tammi-helmikuu) mittauksiin osallistui 94 lasta (50 poikaa ja 44 tyttöä) (julkaisut I ja II). Lisäksi vertailuaineistoa kerättiin 97 lapselta (46 poikaa ja 51 tyttöä) yhdeksästä päiväkodista Hollannissa (julkaisu III) ja 64 lapselta (33 poikaa ja 31 tyttöä) 13 päiväkodista Australiassa (julkaisu IV). Kaikki tutkimukseen osallistuneet lapset olivat kolmevuotiaita.

Lasten fyysisen kokonaisaktiivisuuden tutkimusaineistoa kerättiin ActiGraph GT3X-kiihtyvyysmittareilla viitenä peräkkäisenä päivänä, keskiviikosta sunnuntaihin (julkaisut I, IV). Lapsia vanhempineen neuvottiin pitämään mittaria mahdollisimman paljon lapsen hereillä oloajasta ja riisumaan mittari vain unien, uinnin ja kylvyn ajaksi. Lyhyiden tallennusvälien ansiosta mittari pystyi taltioimaan lapsen pyrähdyksenomaiset intensiteettivaihtelut (Cliff ym., 2009; Oliver ym., 2007), ja raja-arvoja käyttämällä määritettiin sykäysten intensiteettiä 
eri alueilla $($ sedentary $=$ erittäin kevyt, light $=$ kevyt, moderate $=$ kohtuullinen, $v i$ gorous $=$ raskas) (Ward ym., 2005).

Tietoa lasten käyttäytymisestä, toimintaympäristöstä sekä sosiaalisista tekijöistä päiväkotipäivän aikana kerättiin Brownin tutkimusryhmän vuonna 2006 kehittämällä (Observational System for Recording Physical Activity in Children - Preschool version) OSRAC-P -havainnointimenetelmällä (julkaisut II, III). Menetelmässä määritettiin lapsen fyysisen aktiivisuuden intensiteettitasot, muodot, sijainnit, toimintaympäristöt, ryhmäkokoonpanot, toiminnan käynnistäjät sekä toimintaan vaikuttavat kehotukset ja kannustukset (Brown ym., 2006). Havainnointiaineisto kerättiin neljän tutkijan voimin. Tutkijat havainnoivat päiväkodeissa pareittain, kolmen päivän ajan, keskiviikosta perjantaihin. Lapset havainnoitiin satunnaisesti yksitellen normaalin päiväkotiarjen keskellä, jättäen ruokailu- ja lepohetket havainnointien ulkopuolelle. Havainnointeja pyrittiin suorittamaan tasapuolisesti sekä aamupäivän että iltapäivän aikana, päiväkotipäivän eri tilanteissa niin sisä- kuin ulkotiloissa.

Tutkimusaineisto analysoitiin IBM SPSS Statistics (18.00/20.00) ja STATA 12 -ohjelmilla, käyttämällä $t$-testiä, parametritonta testiä, toistettujen mittausten monimuuttujaista varianssianalyysiä, 3-tasoista lineaarista regressioanalyysia sekä ristiintaulukointia ja Pearsonin Khiin neliö $\left(\chi^{2}\right)$-testiä. Havainnoijien arvioiden välinen yhtenevyys selvitettiin Cohenin Kappa kertoimen avulla. Tulosten tilastollisen merkitsevyyden raja-arvona käytettiin, $p<.05$.

Tutkimuspaikkakunnan yliopiston eettinen toimikunta ja Lasten päivähoitopalvelut antoivat keväällä 2010 puoltavat lausunnot Opetus- ja kulttuuriministeriön rahoittamalle Suomalaisten ja Hollantilaisten 2-6-vuotiaiden lasten fyysinen aktiivisuus kotona ja päiväkodissa -tutkimushankkeelle tutkimuksen toteuttamiseen, jonka osana tämä väitöskirjatyö toteutui.

\section{Tulokset}

Tutkimukseen osallistuneiden kolmevuotiaiden lasten kokonaisaktiivisuus oli intensiteetiltään pääosin erittäin kevyttä. Tutkimustulokset osoittivat että poikien fyysinen aktiivisuus oli tyttöjen fyysistä aktiivisuutta kuormittavampaa, ja että sukupuolten väliset erot korostuivat erityisesti talvella (julkaisu I) ja päiväkotipäivien aikana (julkaisu IV).

Lasten fyysinen aktiivisuus päiväkodissa vietetystä ajasta oli pääosin intensiteetiltään erittäin kevyttä, ja vain noin $2 \%$ havainnoineista kuului vähintään kohtuullisesti kuormittavaan leikkiin (julkaisu II). Syksyn aineiston tarkempi tarkastelu paljasti lasten fyysisen aktiivisuuden olevan aamupäivisin kuormittavampaa kuin iltapäivisin (julkaisu II). Vaikka kolmevuotiaalle lapselle on tyypillistä leikkiä yksin, (Dwyer ym., 2009), tässä tutkimuksessa lapsi havainnoitiin useimmiten leikkimässä toisen lapsen kanssa tai ryhmässä. Yksin leikkiessä lapsen leikit olivat kuitenkin fyysisesti aktiivisempia kuin ryhmässä (julkaisut II, III).

Tutkimukseen osallistuneet lapset havainnoitiin useimmiten paikallaan; istumassa, seisomassa tai kävelemässä. Sisällä tapahtuneista havainnoinneista 86 \% tapahtui intensiteetiltään erittäin kevyissä toiminnoissa, kuten askartelun 
(art) ja opettajajohtoisten ryhmätuokioiden (group activity) aikana (julkaisu II). Koska havainnointien ulkopuolelle jäivät ruokailut ja lepohetket, lasten rauhallisten toimintojen määrä oli todellisuudessa saatuja tuloksia suurempi. Lasten fyysinen aktiivisuus oli kuormittavampaa juoksun, kiipeilyn, työntämisen ja vetämisen yhteydessä, tosin sisällä näitä toimintoja havainnoitiin vain hyvin harvoin.

Ulkona lasten leikki oli sisäleikkejä kuormittavampaa (julkaisut II, III). Yllättävää oli, että ulkoleikeistä lähes puolet (46\%) oli intensiteetiltään erittäin kevyttä, ja vain $2 \%$ vähintään kohtuullisesti kuormittavaa toimintaa. Ulkoleikeistä, leikit hiekkalaatikolla tai hiekkalaatikkovälineillä sekä roolileikit, olivat fyysisesti vähemmän kuormittavampia, kun taas työnnettävät pyörälliset lelut (wheeled toys) kuten kuorma-autot, taaperokärryt ja pyörät olivat yhteydessä fyysisesti kuormittavampiin leikkeihin.

Vaikka varhaiskasvattajien antamilla fyysiseen aktiivisuuteen kannustavilla kehotuksilla oli myönteinen vaikutus lasten fyysiseen aktiivisuuteen, suurin osa tutkimuksen havainnoista ei sisältänyt fyysiseen aktiivisuuteen liittyviä kehotuksia (julkaisut II, III). Lisäksi, vaikka varhaiskasvattajat olivat läsnä lasten leikkitilanteissa, he järjestivät harvoin opettajajohtoisia leikkejä tai kannustivat lapsia fyysisesti aktiivisiin leikkeihin. Itse asiassa, tulosten mukaan lapset olivat vähemmän aktiivisia aikuisen osallistuessa leikkiin, tai kun aikuinen oli käynnistänyt leikin.

Lasten fyysisessä aktiivisuudessa ei ilmennyt suuria eroja arki- ja viikonlopun päivien tai päiväkodissa ja kotihoidossa vietettyjen päivien välillä (julkaisut I, IV). Tosin päiväkotipäivän aikana lasten fyysisen aktiivisuuden intensiteettivaihtelut korostuivat kotihoitopäiviä selkeämmin (julkaisu IV). Tulosten perusteella voidaankin olettaa, että lasten ulkoilu- ja lepoajat ovat päiväkodissa aikataulutetumpia kuin kotona, ja siksi selkeämmin erotettavissa.

Vuodenaikojen (syksy vs. talvi) merkittävistä olosuhde-eroista (lumi, lämpötila, päivänvalon pituus) huolimatta, sekä kiihtyvyysmittariaineisto (julkaisu I) että havainnointiaineisto (julkaisu II) osoittivat vain pientä vaihtelua lasten fyysisen aktiivisuuden määrässä. Kiihtyvyysmittarilla kerätty aineisto osoitti lapsille kertyvän talvella arkisin syksyä vähemmän kevyttä liikkumista. Päiväkodissa talven ulkoiluhavainnoinnit puolestaan osoittivat lasten viettävän useammin intensiteetiltään erittäin kevyissä ja harvemmin vähintään kohtuullisesti kuormittavissa aktiviteeteissa, kuin syksyn havainnoinneissa.

Koska kiihtyvyysmittarin fyysisen aktiivisuuden intensiteetin määrittämiseen tarvitaan raja-arvoja (Ward ym., 2005), eivät tämän tutkimuksen tulokset liikuntasuositusten saavuttamisen suhteen olleet täysin yksiselitteisiä. Kuten taulukosta 5 voidaan nähdä, eri raja-arvoja käyttämällä tutkimukseen osallistuneista lapsista 0-9 \% saavutti alle kouluikäisille suunnatun suomalaisen Varhaiskasvatuksen liikunnan suosituksen (2005) kahden tunnin reippaan liikunnan määrällisen tavoitteen, kun reippaaksi liikkumiseksi määriteltiin intensiteetiltään vähintään kohtuullisesti kuormittava liikkuminen. Päivittäisen kolmen tunnin kevyen liikunnan määrän suosituksen (Canadian Society for Exercise Physiology, 2012; Department of Health and Ageing, 2010; Department of 
Health, Physical Activity, Health Improvement and Protection, 2011) saavuttaneiden lasten määrä vaihteli 0-100 \% välillä, raja-arvojen määrittelytavasta riippuen (taulukko 5).

Suomen, Hollannin ja Australian väliset vertailuaineistot nostivat esiin lasten fyysisessä aktiivisuudessa maakohtaisia eroja (julkaisut III, IV). Havaintoaineisto osoitti, että suomalaislapsilla esiintyi enemmän intensiteetiltään erittäin kevyttä sekä vähemmän vähintään kohtuullisesti kuormittavaa fyysistä aktiivisuutta kuin hollantilaisilla kolmevuotiailla (julkaisu III). Hollannissa lasten fyysinen aktiivisuus oli kuormittavampaa lasten leikkiessä ryhmässä, kun taas Suomessa lapset olivat fyysisesti aktiivisempia yksin leikkiessään. Lisäksi kellonaika ei vaikuttanut lasten fyysiseen aktiivisuuteen Hollannissa, kun Suomessa lasten leikit olivat aamupäivisin iltapäiviä fyysisesti kuormittavampia. Kiihtyvyysmittariaineiston perusteella päiväkotipäivisin suomalaislapset viettivät australialaisia ikätovereitaan noin 20 minuuttia enemmän aikaa intensiteetiltään kevyissä toiminnoissa (julkaisu IV).

\section{Tutkimuksen rajoitteet ja vahvuudet}

Tutkimus sisältää joitakin rajoituksia, jotka on hyvä nostaa esille. Ensinnäkin, tämän tutkimuksen tulosten yleistettävyyttä rajoittaa Suomen kohderyhmän koko ja sen valikoituminen maantieteellisesti suppealta alueelta. Toiseksi, valittuihin tutkimusmenetelmiin liittyy puutteita. Havainnointimenetelmän heikkoutena voidaan pitää sen subjektiivisuutta. Yhtenäisistä kriteereistä huolimatta ja koulutuksesta huolimatta havainnoijat voivat tulkita lapsen käyttäytymistä eri tavoin. Fyysisen aktiivisuuden intensiteetin määrittämät raja-arvot vaikuttavat puolestaan merkitsevästi kiihtyvyysmittareilla saatuihin tuloksiin (Hislop ym., 2012; Kim ym., 2012). Koska päiväkoti-ikäisille lapsille ei ole pystytty osoittamaan parhaiten soveltuvia raja-arvoja, käytettiin tässä tutkimuksessa Van Cauwenberghe ym. (2011b) (julkaisu I) ja Pate ym. (2006) (julkaisu IV) laatimia raja-arvoja. Kolmanneksi, lapsen käyttäytymiseen ja lasten fyysiseen aktiivisuuteen on voinut vaikuttaa useat muut sosioekologisen mallin mukaiset tekijät, kuten vanhemmat, koti ja sen pihapiiri, vanhempien ja varhaiskasvattajien välinen kasvatuskumppanuus, ja yhteiskunnalliset tekijät (mm. lait ja varhaiskasvatussuunnitelmat), sekä ajalliset trendit, kuten teknologian kehittyminen, joita ei kuitenkaan otettu huomioon tässä tutkimuksessa.

Tutkimusmenetelmiin liittyvistä rajoitteista huolimatta, tämän tutkimuksen vahvuutena voidaan pitää siinä käytettyjä mittausmenetelmiä. Sekä ActiGraph -kiihtyvyysmittarit (mm. Bornstein ym., 2011; Cliff ym., 2009; Kim ym., 2012; Matthews ym,. 2012, Rowlands, 2007; Van Cauwenberghe ym., 2011b; Welk ym., 2012), että OSRAC-P havainnointimenetelmä (mm. Brown ym., 2006; Pate ym., 2010; Trost, 2007) ovat useissa kansainvälisissä julkaisuissa todettu luotettaviksi mittausmenetelmiksi määrittämään pienten lasten fyysistä aktiivisuutta. Tiettävästi tämä tutkimus on ensimmäinen, jossa suomalaisten kolmevuotiaiden päiväkotilasten fyysistä aktiivisuutta on mitattu kiihtyvyysmittarein. Menetelmien ansiosta tämä tutkimus paitsi täydentää olemassa olevaa suoma- 
laista tieteellistä tutkimustietoa, mahdollistaa myös tutkimustulosten kansainvälisen vertailun.

\section{Johtopäätökset}

Tämän väitöskirjan tulosten valossa voidaan päätyä seuraaviin johtopäätöksiin pienten päiväkotilasten fyysisen aktiivisuuden lisäämiseksi ja passiivisen ajanvieton vähentämiseksi:

- Päiväkotiympäristöllä on merkittävä rooli lapsen fyysisen aktiivisuuden muodostumiseen varhaislapsuudessa, siksi ne myös soveltuvat interventioiden toteuttamiseen.

- Varhaiskasvattajat ovat avainasemassa luomassa omalla toiminnallaan ja kannustuksellaan lapselle mahdollisuuden monipuoliseen liikuntaan.

- $\quad$ Lasta tulisi kannustaa ulkoiluun kaikkina vuodenaikoina ja fyysisesti aktiivisiin leikkeihin sekä minimoida pitkäkestoinen paikallaanolo ja istuminen.

- Sekä kiihtyvyysmittari että suora havainnointi ovat soveltuvia menetelmiä pienten lasten fyysisen aktiivisuuden määrittämiseen.

- Suomalaisiin Varhaiskasvatuksen liikunnan suosituksiin (2005) olisi hyvä lisätä myös fyysistä passiivisuutta sisältäviä rajoitteita, esimerkiksi yhtäjaksoista istumista ja ruutuaikaa sisältäviä suosituksia.

- Varhaiskasvatuksen säädöksistä ja käytänteistä vastaavien tulisi hyödyntää nykyistä tutkimustietoa lasten fyysisen aktiivisuuden lisäämisen edistämisessä.

Tässä tutkimuksessa saatua tietoa voidaan käyttää lähtökohtana liikkumisen mahdollisuuksien lisäämisessä erityisesti päiväkotiympäristössä, sekä laadittaessa nykyistä tarkempia liikunta- ja arkiaktiivisuusohjeistuksia päiväkotiikäisille lapsille.

Asiasanat: fyysinen aktiivisuus, fyysisesti passiivinen aika, kiihtyvyysmittari, suora havainnointi, päiväkoti 


\section{REFERENCES}

Aittasalo, M., Tammelin, T., \& Fogelholm, M. (2010). Lasten ja nuorten fyysisen aktiivisuuden arviointi - menetelmät puntarissa [Physical activity assessment methods for children and youth]. Liikunta $\mathcal{E}$ Tiede, 47(1), 11-21.

Australian Bureau of Statistics (ABS) (2012). Swimming and soccer the most popular sports for children. Media release. Retrieved May 17, 2014, from http://www.abs.gov.au/ausstats/abs@.nsf/mediareleasesbyReleaseDate /801D271AA0D36498CA2572440076A67E

Baranowski, T., Thompson, W.O., DuRant, R.H., Baranowski, J., \& Puhl, J. (1993). Observations on physical activity in physical locations: age, gender, ethnicity, and month effects. Research Quarterly for Exercise and Sport, 64(2), 127-133.

Barkley, J.E., Salvy, S.-J., Sanders, G.J., Dey, S., Von Carlowitz, K.-P., \& Williamson, M.L. (2014). Peer influence and physical activity behaviour in young children: an experimental study. Journal of Physical Activity and Health, 11, 404-409. doi: 10.1123/jpah.2011-0376

Barnett, L.M., Hinkley, T., Okely, A.D. \& Salmon, J. (2013). Child, family and environmental correlates of children's motor skill proficiency. Journal of Science and Medicine in Sport, 16(4), 332-336.

Bates, H. (2006). Daily physical activity for children and youth: a review and synthesis of the literature. Canadian Fitness and Lifestyle research Institute. Retrieved May 17, 2014, from https://education.alberta.ca/media/318711/dpa4youth.pdf

Beets, M.W., Bornstein, D., Dowda, M., \& Pate, R.R. (2011). Compliance with national guidelines for physical activity in U.S. preschoolers: measurement and interpretation. Pediatrics, 127, 658-664. doi: 10.1542 / peds.2010-2021

Benham-Deal, T. (2005). Preschool children's accumulated and sustained physical activity. Perceptual and Motor Skills, 100, 443-450.

Bennett, J. (2008). Early childhood services in the OECD countries: review of the literature and current policy in the early childhood field. Innocenti Working Paper No. 2008-01. Florence, UNICEF Innocenti Research Centre. Retrieved March 25, 2014, from http://www.unicef-irc.org/publications/pdf/iwp_2008_01_final.pdf

Biddle, S.J.H., Pearson, N., Ross, G.M., \& Braithwaite, R. (2010). Tracking of sedentary behaviours of young people: a systematic review. Preventive Medicine, 51, 345-351. doi: 10.1016/j.ypmed.2010.07.018

Boldemann, C., Blennow, M., Dal, H., Mårtensson, F., Raustorp, A., Yuen, K., \& Wester, U. (2006). Impact of preschool environment upon children's physical activity and sun exposure. Preventive Medicine, 42, 301-308. doi: 10.1016/j.ypmed.2005.12.006

Bornstein, D.B., Beets, M.W., Byun, W., \& McIver, K. (2011). Accelerometerderived physical activity levels of preschoolers: a meta-analysis. Journal of Science and Medicine in Sport, 14, 504-511. doi: 10.1016/j.jsams.2011.05.007 
Bower, J.K., Hales, D.P., Tate, D.F., Rubin, D.A., Benjamin, S.E., \& Ward, D.S. (2008). The childcare environment and children's physical activity. American Journal of Preventive Medicine, 34(1), 23-29. doi: 10.1016/j.amepre.2007.09.022

Bronfenbrenner, U. (1974). Developmental research, public policy, and the ecology of childhood. Child Development, 45(1), 1-5.

Bronfenbrenner, U. (1979). The ecology of human development: experiments by nature and design. Cambridge, MA: Harward University Press.

Bronfenbrenner, U. (1994). Ecological models of human development. International Encyclopedia of Education, 3(2nd ed.), 1643-1647.

Brown, W.H., Googe, H.S., McIver, K.L., \& Rathel, M.J. (2009a). Effects of teacher-encouraged physical activity on preschool playgrounds. Journal of Early Intervention, 31(2), 126-145. doi: 10.1177/1053815109331858

Brown, W.H., Odom, S.L., Li, S., \& Zercher, C. (1999). Ecobehavioral assessment in early childhood programs: a portrait of preschool inclusion. The Journal of Special Education, 33(3), 138-153.

Brown, W.H., Pfeiffer, K.A., McIver, K.L., Dowda, M., Addy, C.L., \& Pate, R.R. (2009b). Social and environmental factors associated with preschoolers' nonsedentary physical activity. Child Development, 80(1), 45-58.

Brown, W.H., Pfeiffer, K.A., McIver, K.L., Dowda, M., Almeida, M.J.C.A., \& Pate, R.R. (2006). Assessing preschool children's physical activity: the observational system for recording physical activity in children-preschool version. Research Quarterly for Exercise and Sport, 77(2), 167-176.

Brown, W.H., Pfeiffer, K.A., McIver, K.L., Dowda, M., Almeida, M.J., \& Pate, R.R. (2009c). Observational System for Recording Physical Activity in Children-Preschool (OSRAC-P). OSRAC-P Training Manual for Observers, Columbia: University of South Carolina.

Burdette, H.L., \& Whitaker, R.C. (2005). A national study of neighborhood safety, outdoor play, television viewing, and obesity in preschool children. Pediatrics, 116, 657-662. doi: 10.1542/ peds.2004-2443

Burdette, H.L., Whitaker, R.C., \& Daniels, S.R. (2004). Parental report of outdoor playtime as measure of physical activity in preschool-aged children. Archives of Pediatrics and Adolescent Medicine, 158, 353-357.

Butte, N.F., Wong, W.W., Soo Lee, J., Adolph, A.L., Puyau, M.R. \& Zakeri, I.F. (2013). Prediction of energy expenditure and physical activity in preschoolers. Medicine \& Science in Sports \& Exercise, published ahead of print. doi: 10.1249/MSS.0000000000000209

Canadian Society for Exercise Physiology (2012). Canadian physical activity guidelines and Canadian sedentary behaviour guidelines. Retrieved May 17, 2014, from http:/ / www.csep.ca/english/view.asp?x=804

Cantell, M., Crawford, S., \& Dewey, D. (2012). Daily physical activity in young children and their parents: a descriptive study. Paediatrics and Child Health, 17(3), 20-24. 
Cardon, G., \& De Bourdeaudhuij, I. (2008). Are preschool children active enough? Objectively measured physical activity levels. Research Quarterly for Exercise and Sport, 79(3), 326-332.

Cardon, G., Van Cauwenberghe, E., \& De Bourdeaudhuij, I. (2011). What do we know about physical activity in infants and toddlers: a review of the literature and future research directions. Science \& Sports, 26, 127-130. Doi: 10.1016/j.scispo.2011.01.005

Cardon, G., Labarque, V., Smits, D., \& De Bourdeaudhuij, I. (2009). Promoting physical activity at the pre-school playground: the effects of providing markings and play equipment. Preventive Medicine, 48, 335-340. doi: 10.1016/j.ypmed.2009.02.013

Cardon, G., Van Cauwenberghe, E., Labarque, V., Haerens, L., \& De Bourdeaudhuij, I. (2008). The contribution of preschool playground factors in explaining children's physical activity during recess. International Journal of Behavioral Nutrition and Physical Activity, 5(11). doi: 10.1186/1479-5868-5-11

Carson, V., \& Spence, J.C. (2010). Seasonal variation in physical activity among children and adolescents: a review. Pediatric Exercise Science, 22, 81-92.

Carson, V., Spence, J.C., Cutumisu, N., Boule, N., \& Edwards, J. (2010). Seasonal variation in physical activity among preschool children in a northern Canadian city. Research Quarterly for Exercise and Sport, 81(4), 392-399.

Caspersen, C.J., Powell, K.E., \& Christenson, G.M. (1985). Physical activity, exercise, and physical fitness: definitions for health-related research. Public Health Reports, 100(2), 126-131.

Clements, R. (2004). An investigation of the status of outdoor play. Contemporary Issues in Early Childhood, 5(1), 68-80.

Cliff, D.P., Reilly, J.J., \& Okely, A.D. (2009). Methodological considerations in using accelerometers to assess habitual physical activity in children aged 0-5 years. Journal of Science and Medicine in Sport, 12, 557-567. doi: $10.1016 /$ j.jsams.2008.10.008

Climatological Statistics of Finland (1981-2010). [Tilastoja Suomen ilmastosta 1981-2010]. Finnish Meteorological Institute. Statistical report. Retrieved February 17, 2012 from http://ilmatieteenlaitos.fi/ilmastollinen-vertailukausi-1981-2010

Cools, W., De Martelaer, K., Samaey, C., \& Anries, C. (2011). Fundamental movement skill performance of preschool children in relation to family context. Journal of Sport Sciences, 29(7), 649-660.

Corder, K., van Sluijs, E.M.F., Wright, A., Whincup, P., Wareham, N.J., \& Ekelund, U. (2009). Is it possible to assess free-living physical activity and energy expenditure in young people by self-report? The American Journal of Clinical Nutrition, 89, 862-870. doi: 10.3945/ajcn.2008.26739

Cosco, N.G., Moore, R.C., \& Islam, M.Z. (2010). Behavior mapping: a method for linking preschool physical activity and outdoor design. Medicine $\mathcal{E}$ Science in Sports \& Exercise, 42(3), 513-519.

doi: 10.1249/MSS.0b013e3181cea27a 
Costa, S., Barber, S.E., Griffiths, P.L., Cameron, N., \& Clemes, S.A. (2013). Qualitative feasibility of using three accelerometers with 2-3-year-old children and both parents. Research Quarterly for Exercise and Sport, 84(3), 295-304. doi: 10.1080/02701367.2013.812002

Cox, R., Skouteris, H., Dell'Aquila, D., Hardy, L.L., \& Rutherford, L. (2012). Television viewing behaviour among pre-schoolers: implications for public health recommendations. Journal of Paediatrics and Child Health, 1-4. doi: 10.1111/jpc.12041

De Decker, E., De Craemer, M., De Bourdeaudhuij, I., Wijndaele, K., Duvinage, K., Koletzko, B., Grammatikaki, E., Iotova, V., Usheva, N., FernándezAlvira, J.M., Zych, K., Manios, Y., \& Cardon, G. (2012). Influencing factors of screen time in preschool children: an exploration of parents' perceptions through focus groups in six European countries. Obesity reviews, 13(1), 75-84. doi: 10.1111/j.1467-789X.2011.00961.x

De Craemer, M., De Decker, E., De Bourdeaudhuij, I., Vereecken, C., Deforche, B., Manios, Y., \& Cardon, G. (2012). Correlates of energy balanced-related behaviours in preschool children: a systematic review. Obesity reviews, 13(1), 13-28. doi: 10.1111/j.1467-789X.2011.00941.x

de Vries, S.I., Van Hirtum, H.W.J.E.M., Bakker, I., Hopman-Rock, M., Hirasing, R.A., \& Van Mechelen, W. (2009). Validity and reproducibility of motion sensors in youth: a systematic update. Medicine $\mathcal{E}$ Science in Sports $\mathcal{E}$ Exercise, 41(4), 818-827. doi: 10.1249/MSS.0b013e31818e5819

Department of Education (2013). Child Care \& Early Learning in Summary. Retrieved May 17, 2014, from https:/ / education.gov.au/child-care-and-early-learning-summary

Department of Health and Ageing (2010). Physical activity recommendations for children 0-5 years. Retrieved May 18, 2014, from

http://www.health.gov.au/internet/main/publishing.nsf/Content/9D83 1D9E6713F92ACA257BF0001F5218/\$File/0-

5yrACTIVE_Brochure_FA\%20SCREEN.pdf

Department of Health, Physical Activity, Health Improvement and Protection (2011). Start Active, Stay Active: a report on physical activity for health from the four home countries' Chief Medical Officers. Retrieved May 18, 2014 from

https://www.gov.uk/government/uploads/system/uploads/attachmen t_data/file/216370/dh_128210.pdf

Dowda, M., Pate, R.R., Trost, S.G., Almeida, M.J.C.A., \& Sirard, J.R. (2004). Influences of preschool policies and practices on children's physical activity. Journal of Community Health, 29(3), 183-196.

Durant, R.H., Baranowski, T., Davis, H., Thompson, W.O., Puhl, J., Greaves, K.A., \& Rhodes, T. (1992). Reliability and variability of heart rate monitoring in 3-, 4-, or 5-yr-old children. Medicine and Science in Sports and Exercise, 24(3), 265-271.

Dwyer, G.M., Baur, L.A., \& Hardy, L.L. (2009). The challenge of understanding and assessing physical activity in preschool-aged children: thinking 
beyond the framework of intensity, duration and frequency of activity. Journal of Science and Medicine in Sport, 12(5), 534-536.

Dwyer, G.M., Higgs, J., Hardy, L.L., \& Baur, L.A. (2008). What do parents and preschool staff tell us about young children's physical activity: a qualitative study. International Journal of Behavioral Nutrition and Physical Activity, 5(66). doi: 10.1186/1479-5868-5-66

Dössegger, A., Ruch, N., Jimmy, G., Braun-Fahrländer, C., Mäder, U., Hänggi, J., Hofmann, H., Puder, J.J., Kriemler, S. \& Bringolf-Isler, B. (2013). Reactivity to accelerometer measurement of children and adolescents. Medicine $\mathcal{E}$ Science in Sports \& Exercise, published ahead of print. doi: 10.1249/MMS.0000000000000215

Early Childhood Education and Care Policy in Finland (2000). Background report prepared for the OECD Thematic Review of Early Childhood Education and Care Policy. Retrieved March 6, 2014, from http:// www.oecd.org/finland/2476019.pdf

Eaton, W.O., \& Yu, A.P. (1989). Are sex differences in child motor activity level a function of sex differences in maturational status? Child Development, 60, 1005-1011.

España-Romero, V., Mitchell, J.A., Dowda, M., O’Neill, J.R., \& Pate, R.R. (2013). Objectively measured sedentary time, physical activity and markers of body fat in preschool children. Pediatric Exercise Science, 25, 154-163.

European Commission's Expert Group on Gender and Employment Issues (EGGE) (2009). The provision of childcare services. A comparative review of 30 European countries. Luxemburg: Office for Official Publications of the European Communities. Retrieved May 19, 2014,

http:/ / ec.europa.eu/social/keyDocuments.jsp?advSearchKey=the+provis ion + of + childcare+services\&mode=advancedSubmit\&langId=en\&policyAr ea=\&type $=0 \&$ country $=0 \&$ year $=2009$

Evenson, K.R., Catellier, D.J., Gill, K., Ondrak, K.S., \& McMurray, R.G. (2008). Calibration of two objective measures of physical activity for children. Journal of Sport Sciences, 26(14), 1557-1565. doi: 10.1080/02640410802334196

Finn, K.J., Johannsen, N., \& Specker, B. (2002). Factors associated with physical activity in preschool children. The Journal of Pediatrics, 140, 81-85. doi: 10.1067/mpd.2002.120693. Retrieved May 19, 2014, from http://www.biomedcentral.com/1471-2458/11/944

Finni, T., Sääkslahti, A., Laukkanen, A., Pesola, A., \& Sipilä, S. (2011). A family based tailored counselling to increase non-exercise physical activity in adults with a sedentary job and physical activity in their young children: design and methods of year-long randomized controlled trial. BioMed Central Public Health, 11(Dec), 944. doi: 10.1186/1471-2458-11-944

Finnish Meteorological Institute. Daylight in Finland through the year. Statistical report. Retrieved February 21, 2012, from http://193.166.221.29/weather/climate_7.html 
Fischer, C., Yıldırım, M., Salmon, J., \& Chinapaw, M.J.M. (2012). Comparing different accelerometer cut-points for sedentary time in children. Pediatric Exercise Science, 24, 220-228.

Fisher, A., Reilly, J.J., Montgomery, C., Kelly, L.A., Williamson, A., Jackson, D.M., Paton, J.Y., \& Grant, S. (2005). Seasonality in physical activity and sedentary behavior in young children. Pediatric Exercise Science, 17, 31-40.

Fitzgerald, A., Fitzgerald, N., \& Aherne, C. (2012). Do peers matter? A review of peer and/or friends' influence on physical activity among American adolescents. Journal of Adolescence, 35, 941-958. doi: 10.1016/j.adolescence.2012.01.002

Fjørtoft, I. (2001). The natural environment as playground for children: the impact of outdoor play activities in pre-primary school children. Early Childhood Education Journal, 29(2), 111-117.

Fjørtoft, I., Kristoffersen, B., \& Sageie, J. (2009). Children in schoolyards: tracking movement patterns and physical activity in schoolyards using global positioning system and heart rate monitoring. Landscape and Urban Planning, 93, 210-217. doi: 10.1016/j.landurbplan.2009.07008

Freedson, P., Pober, D., \& Janz, K.F. (2005). Calibration of accelerometer output for children. Medicine \& Science in Sports \& Exercise, 37(11), S523-S530. doi: 10.1249/01.mss.0000185658.28284.ba

Gabbard, C.P. (2004). Lifelong motor development. (4th ed.) San Francisco, CA.: Benjamin Cummings.

Gagné, C., \& Harnois, I. (2014). How to motivate childcare workers to engage preschoolers in physical activity. Journal of Physical Activity and Health, 11, 364-374. doi: 10.1123/jpah.2011-0325

Gallahue, D.L., \& Ozmun, J.C. (2006). Understanding motor development: infants, children, adolescents, adults. (6 $6^{\text {th }}$ ed.) New York, NY.: McCrawHill.

Goodman, A., Paskins, J., \& Mackett, R. (2012). Day length and weather effects on children's physical activity and participation in play, sports, and active travel. Journal of Physical Activity and Health, 9(8), 1105-1116.

Gubbels, J.S., Kremers, S.P.J., Van Kann, D.H.H., Stafleu, A., Candel, M.J.J.M., Dagnelie, P.C., Thijs, C., \& de Vries, N.K. (2011). Interaction between physical environment, social environment, and child characteristics in determining physical activity at child care. Health Psychology, 30, 84-90. doi: $10.1037 / \mathrm{a} 0021586$

Gubbels, J.S., Van Kann, D.H.H., \& Jansen, M.W.J. (2012). Play equipment, physical activity opportunities, and children's activity levels at childcare. Journal of Environmental and Public Health, 2012, 326520. doi: $10.1155 / 2012 / 326520$

Gubbels, J.S., Van Kann, D.H.H., de Vries, N.K., Thijs, C., \& Kremers, S.P.J. (2014). The next step in health behaviour research: the need for ecological moderation analyses - an application to diet and physical activity at childcare. International Journal of Behavioral Nutrition and Physical Activity, 11(52). doi: 10.1186/1479-5868-11-52 
Guide to the National Quality Standard (2011). Australian Children's Education \& Care Quality Authority. Retrieved March 6, 2014, from http://ccccnsw.org.au/wp-content/uploads/guide-to-the-nationalquality-standard.pdf

Halme, T. 2008. Fyysismotorinen suorituskyky ja sitä selittävät tekijät 3-8vuotiailla lapsilla [Physical and motor performance and the factors explaining them in 3-to 8-year-old children] (Doctoral dissertation). Liikunnan ja kansanterveyden julkaisuja 207. Jyväskylä: LIKES.

Hannon, J.C., \& Brown, B.B. (2008). Increasing preschoolers' physical activity intensities: an activity-friendly preschool playground intervention. Preventive Medicine, 46, 532-536. doi: 10.1016/j.ypmed.2008.01.006

Haskell, W., Blair, S.N., \& Hill, J.O. (2009). Physical activity: health outcomes and importance for public health policy. Preventive Medicine, 49, 280-282. doi: 10.1016/j.ypmed.2009.05.002

Hennessy, E., Hughes, S.O., Goldberg, J.P., Hyatt, R.R., \& Economos, C.D. (2010). Parent-child interactions and objectively measured child physical activity: a cross-sectional study. International Journal of Behavioral Nutrition and Physical Activity, 7(71). doi: 10.1186/1479-5868-7-71

Hinkley, T., Crawford, D., Salmon, J., Okely, A.D., \& Hesketh, K. (2008). Preschool children and physical activity. American Journal of Preventive Medicine, 34, 435-441. doi: 10.1016/j.amepre.2008.02.001

Hinkley T., Salmon J., Okely A.D., Crawford D., \& Hesketh, K. (2012). Preschoolers' physical activity, screen time, and compliance with recommendations. Medicine \& Science in Sports \& Exercise, 44(3), 458-465. doi: 10.1249/MSS.0b013e318233763b

Hinkley, T., Salmon, J., Okely, A.D., \& Trost, S.G. (2010). Correlates of sedentary behaviours in preschool children: a review. International Journal of Behavioural Nutrition and Physical Activity, 7(66). doi: 10.1186/1479-5868-766

Hinkley, T., Teychenne, M., Downing, K.L., Ball, K., Salmon, J., \& Hesketh, K.D. (2014). Early childhood physical activity, sedentary behaviors and psychosocial well-being: a systematic review. Preventive Medicine, 62, 182192.

Hislop, J.F., Bulley, C., Mercer, T.H., \& Reilly, J.J. (2012). Comparison of epoch and uniaxial versus triaxial accelerometers in the measurement of physical activity in preschool children: a validation study. Pediatric Exercise Science, $24,450-460$.

Hnatiuk, J.A., Salmon, J., Hinkley, T., Okely, A.D., \& Trost, S. (2014). A review of preschool children's physical activity and sedentary time using objective measures. American Journal of Preventive Medicine. Advance online publication. doi: 10.1016/j.amepre.2014.05.042

Hodges, E.A., Smith, C., Tidwell, S., \& Berry, D. (2013). Promoting physical activity in pre-schoolers to prevent obesity: a review of the literature. Journal of Pediatric Nursing, 28, 3-19. doi: 10.1016/j.pedn.2012.01002 
Husu, P., Paronen, O., Suni, J., \& Vasankari, T. (2011). Suomalaisten fyysinen aktiivisuus ja kunto 2010. Terveyttä edistävän liikunnan nykytila ja muutokset [Physical activity and fitness of Finns in 2010]. Opetus- ja kulttuuriministeriön julkaisuja 2011:15.

Iivonen, S. (2008). Early steps -liikuntaohjelman yhteydet 4-5-vuotiaiden päiväkotilasten motoristen perustaitojen kehitykseen [The associations between an Early Steps physical education curriculum and the fundamental motor skills development of 4-5-year-old preschool children] (Doctoral dissertation). Jyväskylän yliopisto. Studies in Sport, Physical Education and Health 131. Retrieved March 2, 2010, from https://jyx.jyu.fi/dspace/handle/123456789/19401

Iivonen, S., \& Sääkslahti, A.K. (2014). Preschool children's fundamental motor skills: a review of significant determinants. Early Child Development and Care, 184(7), 1107-1126. doi: 10.1080/03004430.2013.837897

Iivonen, K.S., Sääkslahti, A.K., Mehtälä, A., Villberg, J.J., Tammelin, T.H., Kulmala, J.S., \& Poskiparta, M. (2013). Relationship between fundamental motor skills and physical activity in 4-year-old preschool children. Perceptual \& Motors Skills: Physical Development \& Measurement, 117(2), 627646. doi: 10.2466/10.06.PMS.117x22z7

Institute of Medicine of the National Academies (IOM) (2011). Early childhood obesity prevention policies, goals, recommendations, and potential actions. Retrieved September 4, 2012, from

http://www.iom.edu/Reports/2011/Early-Childhood-Obesity-

Prevention-Policies/Recommendations.aspx

Irwin, J.D., He, M., Bouck, L.M.S., \& Tucker, P. (2005). Prechoolers' physical activity behaviours: parents' perspectives. Canadian Journal of Public Health, 96(4), 299-303.

Jackson, D.M., Reilly, J.J., Kelly, L.A., Montgomery, C., Grant, S., \& Paton, J.Y. (2003). Objectively measured physical activity in a representative sample of 3- to 4-year-old children. Obesity Research, 11, 420-425.

Jago, R., Fox, K.R., Page, A.S., Brockman, R., \& Thompson, J.L. (2010). Parent and child physical activity and sedentary time: do active parents foster active children? BioMed Central Public Health, 10(194). doi: 10.1186/14712458-10-194

Jago, R., Sebire, S.J., Edwards, M.J., \& Thompson, J.L. (2013). Parental TV viewing, parental self-efficacy, media equipment and TV viewing among preschool children. European Journal of Pediatrics, published online. doi: 10.1007/s00431-013-2077-5

Jago, R., Thompson, J.L., Sebire, S.J., Wood, L., Pool, L., Zahra, J., \& Lawlor, D.A. (2014). Cross-sectional associations between the screen-time of parents and young children: differences by parent and child gender and day of the week. International Journal of Behavioral Nutrition and Physical Activity, 11(54). doi: 10.1186/1479-5868-11-54

Janssen, X., Cliff, D.P., Reilly, J.J., Hinkley, T., Jones, R.A., Batterham, M., Ekelund, U., Brage, S., \& Okely, A.D. (2013). Predictive validity and 
classification accuracy of ActiGraph energy expenditure equations and cut-points in young children. PLoS ONE, 8(11), e79124.

doi: 10.1371/journal.pone.0079124

Janz, K. F., Burns, T. L. \& Levy, S. M. 2005. Tracking of activity and sedentary behaviours in childhood: the Iowa Bone Development Study. American Journal of Preventive Medicine 29(3), 171-178.

Janz, K.F., Dawson, J.D., \& Mahoney, L.T. (2000). Tracking physical fitness and physical activity from childhood to adolescence: the Muscatine study. Medicine E Science in Sports \& Exercise, 32(7), 1250-1257. doi: 01959131/00/3207-1250/0

Javanainen-Levonen, T. (2009). Terveydenhoitajat liikunnanedistäjinä lastenneuvolatyössä [Public health nurses as physical activity promoters in Finnish child health clinics] (Doctoral dissertation). Jyväskylän yliopisto. Studies in Sport, Physical Education and Health 138. Retrieved September 5, 2013, from https://jyx.jyu.fi/dspace/handle/123456789/21305

John, D., \& Freedson, P. (2012). ActiGraph and Actical physical activity monitors: a peek under the hood. Medicine \& Science in Sports \& Exercise, 44(1 Suppl 1), S86-S89. doi: 10.1249/MSS.0b013e3182399f5e

Jones, R.A., Hinkley, T., Okely, A.D., \& Salmon, J. (2013). Tracking physical activity and sedentary behaviour in childhood. A systematic review. American Journal of Preventive Medicine, 44(6), 651-658. doi: 10.1016/j.amepre.2013.03.001

Kansallinen liikuntatutkimus (2009-2010) [National Sport Survey 2009-2010]. SLU, Nuori Suomi, Suomen Kuntoliikuntaliitto, Suomen Olympiakomitea ja Helsingin kaupunki. Opetus- ja kulttuuriministeriön julkaisuja. TNS Gallup Oy. Retrieved June 1, 2014 from http://verkkolehti.nuorisuomi.fi/files/nslehti/Uutiskuvat/100422_liikun tatutkimus_2009-2010_lapset_ja_nuoret_urheiluvaki.pdf

Kantomaa, M., Tammelin, T., Demakakos, P., Ebeling, H.E., \& Taanila, A.M. (2010). Physical activity, emotional and behavioural problems, maternal education and self-reported educational performance of adolescents. Health Education Research, 25(2), 368-379.

Kelly, L.A., Reilly, J.J., Jackson, D.M., Montgomery, C., Grant, S., \& Paton, J.Y. (2007). Tracking physical activity and sedentary behaviour in young children. Pediatric Exercise Science, 19, 51-60.

Kim, Y., Beets, M.W., \& Welk, G.J. (2012). Everything you wanted to know about selecting the "right" Actigraph accelerometer cut-points for youth, but. ... a systematic review. Journal of Science and Medicine in Sport, 15, 311321. doi: 10.1016/j.jsams.2011.12.001

Landis, R., \& Koch, G.G. (1977). The measurement of observer agreement for categorical data. Biometrics, 33(1), 159-174.

Laukkanen, A., Pesola, A., Havu, M., Sääkslahti, A., \& Finni, T. (2013). Relationship between habitual physical activity and gross motor skills is multifaceted in 5-to 8-year-old children. Scandinavian Journal of Medicine $\mathcal{E}$ Science in Sports, 24(2), e102-e110. doi: 10.1111/sms.12116 
Liukkonen, J., Jaakkola, T., Kokko, S., Gråsten, A., Yli-Piipari, S., Koski, P., Tynjälä, J., Soini, A., Ståhl, T., \& Tammelin, T. (2014). Results from Finland's 2014 report card on physical activity for children and youth. Journal of Physical Activity and Health, 11(Supp 1), S51-S57. doi. 10.1123/jpah.2014-0168

Livingstone, S., \& Haddon, L. (2009). EU Kids Online: Final report. LSE, London: EU Kids Online. (EC Safer Internet Plus Programme Deliverable D6.5). Retrieved March 28, 2014, from http://www.lse.ac.uk/media@lse/research/EUKidsOnline/EU\%20Kids\% 20I\% 20(2006-

9)/EU\%20Kids\%20Online\%20I\%20Reports/EUKidsOnlineFinalReport.pdf

Malina, R.M. (2001). Tracking of physical activity across the lifespan. Research Digest, 3(14), 1-8.

Malina, R.M., Bouchard, C., \& Bar-Or, O. (2004). Growth, maturation, and physical activity. (2nd ed.) Champaign, IL.: Human Kinetics.

Maitland, C., Stratton, G., Foster, S., Braham, R., \& Rosenberg, M. (2013). A place for play? The influence of the home physical environment on children's physical activity and sedentary behaviour. International Journal of Behavioral Nutrition and Physical Activity, 10(99), open access. Retrieved May 22, 2014, from

http://www.ijbnpa.org/content/pdf/1479-5868-10-99.pdf

Matthews, C.E., Hagströmer, M., Pober, D.M., \& Bowles, H.R. (2012). Best practices for using physical activity monitors in population-based research. Medicine E Science in Sports \& Exercise, 44(1Suppl1) S68-S76.

doi: 10.1249/MSS.0b013e3182399e5b

McIver, K.L., Brown, W.H., Pfeiffer, K.A., Dowda, M., \& Pate, R.R. (2009). Assessing children's physical activity in their homes: the observational system for recording physical activity in children-home. Journal of Applied Behavior Analysis, 42, 1-6. doi: 10.1901/jaba.2009.42-1

McKenzie, T.L., Sallis, J.F., Elder, J.P., Berry, C.C., Hoy, P.L., Nader, P.R., Zive, M.M., \& Broyles, S.L. (1997). Physical activity levels and prompts in young children at recess: a two-year study of a bi-etnic sample. Research Quarterly for Exercise and Sport, 68(3), 195-202.

Mehtälä, M.A.K., Sääkslahti, A.K., Soini, A.J., Tammelin, T., Kulmala, J., Villberg, J., \& Poskiparta M.E.H. (2014). The effect of the HIPPA intervention on childcare children's overall physical activity. Manuscript submitted for publication.

Ministry of Social Affairs and Health (2013). Child and family policy in Finland. Brochures of the Ministry of Social Affairs and Health 9eng. Retrieved June 1, 2014, from http://www.stm.fi/c/document_library/get_file?folderId=6511570\&nam e=DLFE-25916.pdf

Moore, L.L., Gao, D., Bradlee, M.L., Cupples, L.A., Sundarajan-Ramamurti, A., Proctor, M.H., Proctor, M.H., Hood, M.Y., Singer, M.R., \& Ellison, R.C. (2003). Does early physical activity predict body fat change throughout 
childhood? Preventive Medicine, 37, 10-17. doi: 10.1016/S00917435(03)00048-3

Mäki, P., Laatikainen, T., Koponen, P., Hakulinen-Viitanen, T., \& LATEtyöryhmä (2008). Lasten ja nuorten terveysseurannan kehittäminen, LATE-hanke [The development of health monitoring among children and the young, LATE project]. Kansanterveyslaitoksen julkaisuja. Helsinki: Yliopistopaino.

National Association for Sport and Physical Education (NASPE) (2009). Active Start: a statement of physical activity guidelines for children from birth to age 5. ( $2^{\text {nd }}$ ed.) American Alliance for Health, Physical Education, Recreation, and Dance.

National curriculum guidelines on early childhood education and care in Finland (2003). (Stakes, 2003:56, 2nd ed., 2005). Helsinki: Publications of the Ministry of Social Affairs and Health 2002:9. Retrieved November 16, 2012, from http:/ / www.thl.fi/thl-client/pdfs/267671cb-0ec0-4039-b97b-7ac6ce6b9c10

Nicaise, V., Kahan, D., \& Sallis, J. (2011). Correlates of moderate-to-vigorous physical activity among pre-schoolers during unstructured outdoor periods. Preventive Medicine, 53, 309-315. doi: 10.1016/j.ypmed.2011.08018

Numminen, P. 1991. The role of imagery in physical education (Doctoral dissertation). University of Jyväskylä. Studies in Sport, Physical Education and Health 27.

Nupponen, H., Halme, T., Parkkisenniemi, S., Pehkonen, M., \& Tammelin, T. 2010. Laps Suomen-tutkimus 3-12-vuotiaiden lasten liikunta-aktiivisuus [Child of Finland research, physical activity of 3-to 12-year old children]. Liikunnan ja kansanterveyden julkaisuja 239. Jyväskylä: LIKES.

OECD (2013). Education at a Glance 2013: OECD Indicators, OECD Publishing. Retrieved March, 27, 2014 from http://static.publico.pt/DOCS/educacao/educationglance2013.pdf

OECD (2014). OECD Family Database, OECD, Paris. Last updated May 2014. Retrieved June 1, 2014, from http://www.oecd.org/social/family/database

OECD Family Database (2010). PF4.2: Quality of childcare and early education services. Social Policy Division-Directorate of Employment, Labour and Social Affairs. Last updated July, 2010. Retrieved March 27, 2013, from http://www.oecd.org/social/soc/37864559.pdf

OECD.StatExracts. Short-term labour market statistics. Retrieved June 3, 2014, http:// stats.oecd.org/Index.aspx?DatasetCode=STLABOUR\#

Okely, A.D., Trost, S.G., Steele, J.R., Cliff, D.P., \& Mickle, K. (2009). Adherence to physical activity and electronic media guidelines in Australian preschool children. Journal of Pediatrics and Child Health, 45, 5-8. doi: 10.1111/j.1440-1754.2008.01445.x

Oliver, M., Schofield, G.M., \& Kolt, G.S. (2007). Physical activity in preschoolers. Understanding prevalence and measurement issues. Sports Medicine, 37(12), 1045-1070. 
Owen, N., Healy, G.N., Matthews, C.E., \& Dunstan, D.W. (2010). Too much sitting: the population health science of sedentary behavior. Exercise and Sport Sciences Reviews, 38(3), 105-113.

Pate, R.R., Almeida, A.J., McIver, K.L., Pfeiffer, K.A., \& Dowda, M. (2006). Validation and calibration of an accelerometer in preschool children. Obesity, 14(11), 2000-2006.

Pate, R.R., Dowda, M., Brown, W.H., Mitchell, J., \& Addy, C. (2013). Physical activity in preschool children with the transition to outdoors. Journal of Physical Activity and Health, 10, 170-175.

Pate, R.R., McIver, K., Dowda, M., Brown, W.H., \& Addy, C. (2008). Directly observed physical activity levels in preschool children. Journal of School Health, 78(8), 438-444.

Pate, R.R., O’Neill, J.R., \& Mitchell, J. (2010). Measurement of physical activity in preschool children. Medicine $\mathcal{E}$ Science in Sports \& Exercise, 42, 508-512. doi: 10.1249/MSS.0b013e3181cea116

Pate, R.R., Pfeiffer, K.A., Trost, S.G., Ziegler, P., \& Dowda, M. (2004). Physical activity among children attending preschools. Pediatrics, 114(5), 1258-1263. Doi: $10.1542 /$ peds.2003-1088-L

Pellegrini, A.D., \& Smith, P.K. (1998). Physical active play: the nature and function of a neglected aspect of play. Child Development, 69(3), 577-598.

Pfeiffer, K.A., Dowda, M., McIver, KL., \& Pate, R.R. (2009). Factors related to objectively measured physical activity in preschool children. Pediatric Exercise Science, 21, 196-208.

Poest, C.A., Williams, J.R., Witt, D.D., \& Atwood, M.E. (1989). Physical activity patterns of preschool children. Early Childhood Research Quarterly, 4, 367376.

Pramling Samuelsson, I., \& Asplund Carlsson, M. (2008). The playing learning child: towards a pedagogy of early childhood. Scandinavian Journal of Educational Research, 52(6), 623-641.

Pönkkö, A. 1999. Vanhemmat ja lastentarhanopettajat päiväkotilasten minäkäsityksen tukena [Parents' and teachers' role in self-perception of children in kindergarten] (Doctoral dissertation). Jyväskylän yliopisto. Studies in Sport, Physical Education and Health 62.

Quality in Early Childhood Education and Care (2013). Annex report country \& case studies. European Parliament's Committee on Culture and Education. Retrieved April 17, 2014, from http://www.europarl.europa.eu/RegData/etudes/etudes/join/2013/495 867/IPOL-CULT_ET(2013)495867(ANN01)_EN.pdf

Quality Recommendations for Health Promotion (2009). Publications of the Ministry of Social Affairs and Health 2009:8. Retrieved June 2, 2014, from http://www.stm.fi/c/document_library/get_file?folderId=39503\&name= DLFE-10023.pdf

Recommendations for Physical Activity in Early Childhood Education (2005). Handbooks of the Ministry of Social Affairs and Health 2005:17. Retrieved February 3, 2012, from 
http://www.stm.fi/c/document_library/get_file?folderId=28707\&name= DLFE-3739.pdf\&title=Varhaiskasvatuksen_liikunnan_suositukset_fi.pdf

Reilly, J.J. (2008). Physical activity, sedentary behaviour and energy balance in the preschool child: opportunities for early obesity prevention. Proceedings of the Nutrition Society, 67, 317-325. doi: 10.1017/S0029665108008604

Reilly, J.J. (2010). Low levels of objectively measured physical activity in preschoolers in child care. Medicine $\mathcal{E}$ Science in Sports \& Exercise, 42(3), 502-507. doi: 10.1249/MSS.0b013e3181cea100

Reilly, J.J., Coyle, J., Kelly, L., Burke, G., Grant, S., \& Paton, J.Y. (2003). An objective method for measurement of sedentary behaviour in 3- to 4-year olds. Obesity Research, 11(10), 1155-1158.

Reilly, J.J., Jackson, D.M., Montgomery, C., Kelly, L.A., Slater, C., Grant, S., \& Paton, J.Y. (2004). Total energy expenditure and physical activity in young Scottish children: mixed longitudinal study. Lancet, 363, 211-212.

Reilly, J.J., Penpraze, V., Hislop, J., Davies, G., Grant, S., \& Paton, J.Y. (2008). Objective measurement of physical activity and sedentary behaviour: review with new data. Archives of Disease in Childhood, 93, 614-619. doi: $10.1136 /$ adc. 2007.133272

Remmers, T., Sleddens, E.F.C., Gubbels, J.S., de Vries, S.I., Mommers, M., Penders, J., Kremers, S.P.J., \& Thijs, C. (2014). Relationship between physical activity and the development of body mass index in children. Medicine \& Science in Sports \& Exercise, 46(1), 177-184. doi: 10.1249/MSS.0b013e3182a36709

Reunamo, J., Hakala, L., Saros, L., Lehto, S., Kyhälä, A.-L., \& Valtonen, J. (2014). Children's physical activity in day care and preschool. Early Years: An International Research Journal, 34(1), 32-48. doi: 10.1080/09575146.2013.843507

Ridgers, N.D., Stratton, G., Fairclough, S.J., \& Twisk, W.R. (2007). Long-term effects of a playground markings and physical structures on children's recess physical activity levels. Preventive Medicine, 44, 393-397. doi: 10.1016/j.ypmed.2007.01009

Rowlands, A.V. (2007). Accelerometer assessment of physical activity in children: an Update. Pediatric Exercise Science, 19, 252-266.

Rutherford, L., Bittman, M., \& Biron, D. (2010). Young children and the media: a discussion paper. Perth: Australian Research Alliance for Children and Youth. Retrieved March 16, 2014, from

http://www.aracy.org.au/publicationsresources/command/download_file/id/169/filename/Young_Children_ and_the_Media.pdf

Saari A., Sankilampi, U., Hannila, M.L., Kiviniemi, V., Kesseli, K., \& Dunkel, L. (2011). New Finnish growth references for children and adolescents aged 0 to 20 years: length/height-for-age, weight-for-length/height, and body mass index-for-age. Annals of Medicine, 43(3), 235-248. 
Sallis, J.F., Prochaska, J.J., \& Taylor, W.C. (2000). A review of correlates of physical activity of children and adolescents. Medicine $\mathcal{E}$ Science in Sports $\mathcal{E}$ Exercise, 32(5), 963-975.

Salvy, S.-J., de la Haye, K., Bowker, J.C., \& Hermans, R.C.J. (2012). Influence of peers and friends on children's and adolescents' eating and activity behaviors. Physiology \& Behavior, 106, 369-378.

doi: 10.1016/j.physbeh.2012.03.022

Sandberg, A., \& Pramling-Samuelsson, I. (2005). An interview study of gender differences in preschool teachers' attitudes toward children's play. Early Childhood Education Journal, 32(5), 297-305. doi: 10.1007/s10643-005-4400-x

Schoeppe, S., Duncan, M.J., Badland, H., Oliver, M., \& Curtis, C. (2013). Associations of children's independent mobility and active travel with physical activity, sedentary behaviour and weight status: a systematic review. Journal of Science and Medicine in Sport, 16, 312-319. doi: 10.1016/j.jsams.2012.11.001

Sedentary Behaviour Research Network (2012). Standardized use of the terms "sedentary" and "sedentary" behaviours. Applied Physiology, Nutrition and Metabolism, 37, 540-542.

Shen, B., Alexander, G., Milberger, S., \& Jen, K.-L. C. (2013). An exploratory study of seasonality and preschoolers' physical activity engagement. Journal of Physical Activity and Health, 10, 993-999.

Seppälä, A. (2012). Päiväkoti-ikäisten lasten fyysisen aktiivisuuden mittaaminen Suomessa OSRAC-P mittarilla [Measuring physical activity in Finnish preschool children using the OSRAC-P method] (Master's thesis). Jyväskylän yliopisto. Liikuntapedagogiikan pro gradu-tutkielma. Retrieved February 13, 2012, from https://jyx.jyu.fi/dspace/handle/123456789/26870

Singh, A.S., Mulder, C., Twisk, J.W.R., van Mechelen, W., \& Chin A Paw, M.J.M. (2008). Tracking of childhood overweight into adulthood: a systematic review of the literature. Obesity reviews, 9, 474-488. doi: 10.1111/j.1467789X.2008.00475.x

Sirard, J.R., Trost, S.G., Pfeiffer, K.A., Dowda, M., \& Pate, R.R. (2005). Calibration and evaluation of an objective measure of physical activity in preschool children. Journal of Physical Activity and Health, 3, 345-357.

Siren-Tiusanen, H. (1996). Saako lapsi nukkua, liikkua ja elää omassa rytmissään. Näkökulmia nuorimpien päiväkotilasten kuormittuvuuteen [Can a child sleep, move, and live, to his/her own rhythm? Perspectives on the stress tolerance of younger day care children] (Doctoral dissertation). Research Reports on Sport and Health 102. Jyväskylä: LIKES-tutkimuskeskus.

Skouteris, H., Dell'Aquila, D., Baur, L.A., Dwyer, G.M., McCabe, M.P., Ricciardelli, L.A., \& Fuller-Tyszkiewicz, M. (2012). Physical activity guidelines for preschoolers: a call for research to inform public health policy. Medical Journal of Australia, 196(3), 174-176.

doi: $10.5694 /$ mja11.11015 
Soini, A., Kettunen, T., Mehtälä, A., Sääkslahti, A., Tammelin, T., Villberg, J., \& Poskiparta, M. (2012). Kolmevuotiaiden päiväkotilasten mitattu fyysinen aktiivisuus [Physical activity levels of 3-year-old preschool children]. Liikunta \& Tiede, 49(1), 52-58. Retrieved March 16, 2012, from

http://www.lts.fi/sites/default/files/page_attachment/lt112_tutkimusar tikkelit_soini.pdf

Stodden, D.F., Goodway, J.D., Langendorfer, S.J., Roberton, M.A., Rudisill, M.E., Garcia, C., \& Garcia, L.E. (2008). A developmental perspective on the role of motor skill competence in physical activity: an emergent relationship. Quest, 60, 290-306.

Strong, W.B., Malina, R.M., Blimkie, C.R., Daniels, S.R., Dishman, R.K., \& Gutin, B. (2005). Evidence based physical activity for school-age youth. Journal of Pediatrics, 146, 732-737. doi: 10.1016/j.jpeds.2005.01.055

Suoninen, A. (2014). Lasten mediabarometri 2013. 0-8-vuotiaiden mediankäyttö ja sen muutokset vuodesta 2010 [Children's media barometer 2013. Media uses of 0-8 year-old children and changes in media uses during the 2010s]. Nuorisotutkimusseuran verkkojulkaisuja 75. Helsinki: Nuorisotutkimusseura. Retrieved March 28, 2014, from

http://www.nuorisotutkimusseura.fi/julkaisuja/lastenmediabarometri20 13.pdf

Säkkinen, S., \& Kuoppala, T. (2012). Lasten päivähoito 2012 [Childcare 2012]. Helsinki: Tilastoraportti, Terveyden ja hyvinvoinnin laitos. Retrieved June 1, 2014, from http://urn.fi/URN:NBN:fi-fe201312197687

Sääkslahti, A. 2005. Liikuntaintervention vaikutus 3-7-vuotiaiden lasten fyysiseen aktiivisuuteen ja motorisiin taitoihin sekä fyysisen aktiivisuuden yhteys sydän- ja verisuonitautien riskitekijöihin [Effects of physical activity intervention on physical activity and motor skills and relationships between physical activity and coronary heart disease risk factors in 3-7-year-old children] (Doctoral dissertation). Jyväskylän yliopisto. Studies in Sport, Physical education and Health 104. Retrieved March 9, 2010, from https://jyx.jyu.fi/dspace/handle/123456789/13496

Sääkslahti, A., Numminen, P., Varstala, V., Helenius, H., Tammi, A., Viikari, J., \& Välimäki, I. (2004). Physical activity as a preventive measure for coronary heart disease risk factors in early childhood. Scandinavian Journal of Medicine \& Science in Sports, 14, 143-149. doi: 10.1046/j.16000838.2003.00347.x

Taguma, M., Litjens, I., \& Makowiecki, K. (2012). Quality matters in early childhood education and care: Finland 2012. Publication of the SecretaryGeneral of the OECD. Retrieved June 5, 2014, from http:// www.oecd.org/edu/school/49985030.pdf

Takala, K. (2015). 3-4-vuotiaiden päiväkotilasten sosioemotionaalisten taitojen ilmeneminen ja arviointi liikunnassa [Emergence and assessment of 3-to 4year-old preschoolers' socioemotional skills in physical education] (Unpublished doctoral dissertation). Jyväskylän yliopisto. Studies in Sport, Physical Education and Health 213. 
Tandon, P.S., Zhou, C., Sallis, J.F., Cain, K.L., Frank, L.D., \& Saelens, B.E. (2012). Home environment relationships with children's physical activity, sedentary time, and screen time by socioeconomic status. Journal of Behavioral Nutrition and Physical Activity, 9(88). doi: 10.1186/1479-5868-9-88

Telama, R. (2009). Tracking of physical activity from childhood to adulthood: a review. Obesity Facts, 3. Published online. doi: 10.1159/000222244

Telama, R., Yang, X., Leskinen, E., Kankaanpää, A., Hirvensalo, M., Tammelin, T., Viikari, J.S.A., \& Raitakari O.T. (2014). Tracking physical activity from early childhood through youth into adulthood. Medicine $\&$ Science in Sports E Exercise, 46(5), 955-962. doi: 10.1249/MSS0000000000000181

Thomas, J.R., Nelson, J.K., \& Silverman, S.J. (2011). Research methods in

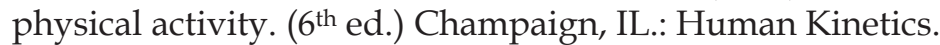

Timmons, B.W., LeBlanc, A.G., Carson, V., Connor Gorber, S., Dillman, C., Janssen, I., Kho, M.E., Spence, J.C., Stearns, J.A., \& Tremblay, M.S. (2012). Systematic review of physical activity and health in the early years (aged 0-4). Applied Physiology, Nutrition and Metabolism, 37, 773-792. doi: 10.1139/H2012-070

Timmons, B.W., Naylor, P.J., \& Pfeiffer, K.A. (2007). Physical activity for preschool children - how much and how? Applied Physiology, Nutrition and Metabolism, 32, S122-S134. doi: 10.1139/H07-112

Tomkinson, G.R., Léger, L.A., Olds, T.S., \& Cazorla, G. (2003). Secular trends in the performance of children and adolescents (1980-2000). Sports Medicine, 33(4), 285-300.

Tremblay, M.S., LeBlanc, A.G., Janssen, I., Kho, M.E., Hicks, A., Murumets, K., Colley, R.C., \& Duggan, M. (2012). Canadian sedentary behaviour guidelines for children and youth. Applied Physiology, Nutrition and Metabolism, 36, 59-64.

Tremblay, M.S., LeBlanc, A.G., Kho, M.E., Saunders, T.J., Larouche, R., Colley, R.C., Goldfield, G., \& Gorber, S.C. (2011). Systematic review of sedentary behaviour and health indicators in school-aged children and youth. International Journal of Behavioral Nutrition and Physical Activity, 8(98). doi: 10.1186/1479-5868-8-98

Troiano, R.P., McClain, J.J., Brychta, R.J., \&Chen, K.Y. (2014). Evolution of accelerometer methods for physical activity research. British Journal of Sports Medicine. Published online April 29, 2014. doi: 10.1136/bjsports2014-093546

Trost, S.G. (2007). Measurement of physical activity in children and adolescents. American Journal of Lifestyle Medicine, 1, 299-314. doi: $10.1177 / 1559827607301686$

Trost, S.G., Fees, B.S, Haar, S.J., Murray, A.D., \& Crowe, L.K. (2012). Identifications and validity of accelerometer cut-points for toddlers. Obesity, 20, 2317-2319. doi: 10.1038/oby.2011.364

Trost, S.G., Pate, R.R., Freedson, P.S., Sallis, J.F., \& Taylor, W.C. (2000). Using objective physical activity measures with youth: how many days of 
monitoring are needed? Medicine \& Science in Sports \& Exercise, 32(2), 426431.

Tucker, P. (2008). The physical activity levels of preschool-aged children: a systematic review. Early Childhood Research Quarterly, 23, 547-558.

UNICEF (2008). The child care transition, Innocenti Report Card 8, UNICEF Innocenti Research Centre, Florence.

Vale, S., Silva, P., Santos, R., Soares-Miranda, L., \& Mota, J. (2010). Compliance with physical activity guidelines in preschool children. Journal of Sports Sciences, 28(6), 603-608. doi: 10.1080/02640411003702694

Van Cauwenberghe, E., De Craemer, M., De Decker, E., De Bourdeaudhuij, I., \& Cardon, G. (2013). The impact of a teacher-led structured physical activity session on preschooler's sedentary and physical activity levels. Journal of Science and Medicine in Sport, 16(5), 422-426. doi: 10.1016/j..sams.2012.11.883

Van Cauwenberghe, E., Gubbels, J., De Bourdeaudhuij, I., \& Cardon, G. (2011a). Feasibility and validity of accelerometer measurements to assess physical activity in toddlers. International Journal of Behavioral Nutrition and Physical Activity, 8(67). doi: 10.1186/1479-5868-8-67

Van Cauwenberghe, E., Jones, R., Hinkley, T., Crawford, D., \& Okely, A.D. (2012a). Patterns of physical activity and sedentary behavior in preschool children. International Journal of Behavioral Nutrition and Physical Activity, 9(138). doi: 10.1186/1479-5868-9-138

Van Cauwenberghe, E., Labarque, V., Gubbels, J., De Bourdeaudhuij, I. \& Cardon, G. (2012b). Preschooler's physical activity levels and associations with lesson context, teacher's behavior, and environment during preschool physical education. Early Childhood Research Quarterly, 27, 221230. doi: 10.1016./j.ecresq.2011.09.007

Van Cauwenberghe, E., Labarque, V., Trost, S., De Bourdeaudhuij, I., \& Cardon, G. (2011b). Calibration and comparison of accelerometer cut points in preschool children. International Journal of Pediatric Obesity, 6(2-2), e582e589. doi: 10.3109/17477166.2010.526223

Vandorpe, B., Vandendriessche, J., Lefevre, J., Pion, J., Vaeyens, R., Matthys, S., Philippaerts, R., \& Lenoir, M. (2011). The körperkoordinationstest für kinder: reference values and suitability for 6-12-year-old children in Flanders. Scandinavian Journal of Medicine E Science in Sports, 21, 378-388. doi: 10.1111/j.1600-0838.2009.01067.x

Verbestel, V., Van Cauwenberghe, E., De Coen, V., Maes, L., De Bourdeaudhuij, I., \& Cardon, G. (2011). Within- and between-day variability of objectively measured physical activity in pre-schoolers. Pediatric Exercise Science, 23, 366-378.

Vähä-Ypyä, H., Vasankari, T., Husu, P., Suni, J., \& Sievänen, H. (2014). A universal, accurate intensity-based classification of different physical activities using raw data of accelerometer. Clinical Physiology and Functional Imaging, 1-7. doi: 10.1111/cpf.12127 
Väistö, J., Eloranta, A.-M., Viitasalo, A., Tompuri, T., Lintu, N., Karjalainen, P., Lampinen, E.-K., Ågren, J., Laaksonen, D.E., Lakka, H.-M., Lindi, V., \& Lakka, T.A. (2014). Physical activity and sedentary behaviour in relation to cardiometabolic risk in children: cross-sectional findings from the Physical Activity and Nutrition in Children (PANIC) study. International Journal of Behavioral Nutrition and Physical Activity, 11(55). doi: 10.1186/1479-586811-55

Ward, D.S. (2010). Physical activity in young children: the role of child care. Medicine E Science in Sports E Exercise, 42, 499-501. doi: 10.1249/MSS.0b013e3181ce9f85

Ward, D.S., Evenson, K.R., Vaughn, A., Brown Rodgers, A., \& Troiano, R.P. (2005). Accelerometer use in physical activity: best practices and research recommendations. Medicine \& Science in Sports \& Exercise, 37(11 Suppl), S582-S588. doi: 10.1249/01.mss.0000185292.71933.91

Ward, D., Hales, D., Haverly, K., Marks, J., Benjamin, S., Bell, S., \& Trost, S. (2008). An instrument to assess the obesogenic environment of child care centres. American Journal of Health Behavior, 32(4), 380-386.

Ward, D.S., Vaughn, A., McWilliams, C. \& Hales, D. (2010). Interventions for increasing physical activity at childcare. Medicine $\mathcal{E}$ Science in Sports $\mathcal{E}$ Exercise, 42(3), 526-534. doi: 10.1249/MSS.0b013e3181cea406

Weather Underground (2013) Weather History \& Data Archive available at: www.wunderground.com/history

Welk, G.J. (Ed.). (2002). Physical activity assessments for health-related research. Champaign, IL.: Human Kinetics.

Welk, G.J. (2005). Principles of design and analyses for the calibration of accelerometry-based activity monitors. Medicine $\mathcal{E}$ Science in Sports $\mathcal{E}$ Exercise, 37(11Suppl), S501-S511. doi: 10.1249/01.mss.0000185660.38335.de

Welk, G.J., McClain, J., \& Ainsworth, B.E. (2012). Protocols for evaluating equivalency of accelerometry-based activity monitors. Medicine $\mathcal{E}$ Science in Sports \& Exercise, 44(1Suppl), S39-S49.

doi: 10.1249/MSS.0b013e3182399d8f

World Health Organization (WHO) 2010. Global recommendations on physical activity for health. Geneva. Switzerland.

Yang, X. (1997). A multidisciplinary analysis of physical activity, sport participation and dropping out among young Finns - a 12-year follow-up study (Doctoral dissertation). University of Jyväskylä. LIKES-Research Reports on Sport and Health 103.

Yamamoto, S., Becker, S., Fischer, J., \& De Bock, F. (2011). Sex differences in the variables associated with objectively measured moderate-to-vigorous physical activity in preschoolers. Preventive Medicine, 52, 126-129.

doi: 10.1016/j.ypmed.2010.11.014 


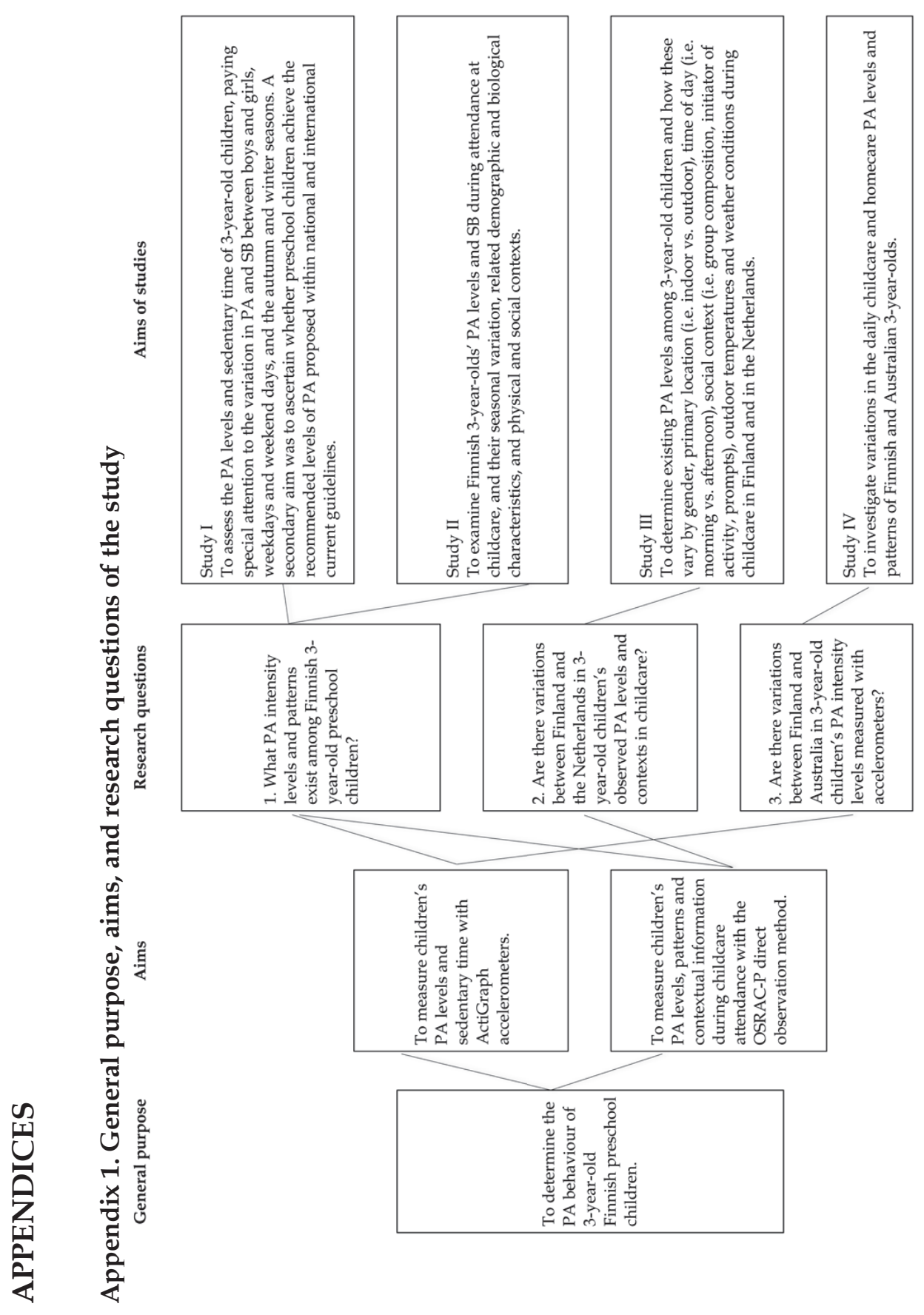




\title{
Appendix 2. Information for participating Finnish childcare centers \\ INFORMAATIOKIRJE TUTKIMUKSEEN OSALLISTUVALLE PÄIVÄKODILLE
}

\author{
Tutkimuksen nimi: \\ Suomalaisten ja hollantilaisten 2-6-vuotiaiden lasten liikunta-aktiivisuus kotona ja \\ päiväkodissa.
}

Tutkimustieto alle kouluikäisten lasten fyysisestä aktiivisuudesta ja liikunta-aktiivisuuden motivointi- ja ylläpitokeinoista on vähäistä niin suomalaisessa kuin kansainvälisessä tutkimuskentässä. Lisäksi lasten ylipaino on yleistynyt ja sen on todettu usein johtavan merkittäviin kansansairauksiin. Jyväskylän yliopiston Terveyden edistämisen tutkimuskeskus yhteistyössä University of Maastricht Department of Health Education and Promotionin kanssa toteuttaa vertailevan seurantatutkimuksen, jonka tarkoituksena on selvittää suomalaisten ja hollantilaisten 2-6-vuotiaiden lasten fyysisen aktiivisuuden määrää, sen luonnetta ja ravitsemustottumuksia heidän päiväkotivuosinaan. Seuranta-aika on 2010-2012. Tutkimus tapahtuu vapaaehtoisissa päiväkodeissa. Päiväkotien lasten määrä on noin 30 lasta/päiväkoti, yhteensä 150 lasta.

Tutkimuksen taustalla on ajatus kartoittaa päiväkodin arkea, miten ympäristö ja päiväkodin tarjoamat mahdollisuudet vaikuttavat lasten liikkumiseen ja ruokailuun. Tarkkailemme miten, missä ja milloin lapset leikkivät ja syövät. Aineiston keruu tapahtuu havainnoiden päiväkodin normaalia päiväohjelmaa, rutiineihin puuttumatta. Tutkimuksessa arvioidaan ja määritetään keskeiset tekijät, jotka mahdollistavat tai estävät fyysisen aktiivisuuden ja terveelliset ruokatottumukset päiväkodissa ja perheissä.

Lasten fyysistä aktiivisuutta ja ruokatottumuksia arvioidaan havainnoimalla lasta hoitopäivän aikana sekä askel- ja kiihtyvyysmittareilla. Lasten ja vanhempien fyysisen aktiivisuuden määrää ja ruokatottumuksia kotona arvioidaan kyselylomaketutkimuksella ja askelja kiihtyvyysmittareilla. Päiväkotien henkilökunnan haastatteluilla tarkennetaan havainnointilomakkeiden tuloksia.

Päiväkodista kerätty tutkimusaineisto on luottamuksellista, eivätkä päiväkodit tai henkilöt ole siitä tunnistettavissa. Saatu aineisto tulee ainoastaan tutkimuskäyttöön. Tutkimusaineiston kerääminen toteutetaan niin, ettei se häiritse lapsia tai päiväkodin henkilökuntaa. Ensimmäinen aineisto kerätään vuonna 2010, elo-syyskuun aikana ja seuraava aineisto vuonna 2011, tammi-helmikuun aikana. Tutkimusaineistoa kerätään kerrallaan neljän päivän ajan, kolmena arkipäivänä ja yhtenä viikonlopun päivänä. Aineiston keruun yhteydessä lapsien pituus mitataan ja paino punnitaan.

Arviointitutkimusten perusteella päiväkoteihin suunnitellaan vuonna 2011 fyysisen aktiivisuuden ja terveellisten ruokatottumusten edistämiseksi interventio-ohjelmat. Interventio-ohjelmat toteutetaan kolmessa päiväkodissa, kontrollipäiväkoteja on kaksi. Lisäksi arvioidaan interventio-ohjelmien vaikuttavuutta 2-6-vuotiaiden lasten fyysisen aktiivisuuden määrään ja ruokatottumuksiin.

Uskomme tutkimustulosten antavan meille tärkeää tietoa lasten liikkumisesta ja ruokailusta. Myöhemmin tutkimustuloksia voidaan hyödyntää kehitettäessä päiväkoteja tukemaan lasten terveyttä ja hyvinvointia yhä enemmän. Mikäli haluatte lisätietoja tutkimusprojektista, voitte ottaa allekirjoittaneeseen yhteyttä.

Tutkimusryhmän puolesta

Anne Soini, LitM, tohtorikoulutettava

Jyväskylän yliopisto, Terveyden edistämisen tutkimuskeskus

PL 35 (L), 400014 Jyväskylän yliopisto

014-2604574, anne.soini@jyu.fi 
Appendix 3. Information for Finnish families with 3-year-old children (year of birth 2007)

\section{KUTSU 3-VUOTIAIDEN LASTEN LIIKUNTA-AKTIIVISUUS TUTKIMUK- SEEN}

Jyväskylän yliopiston terveyden edistämisen tutkimuskeskus yhdessä Jyväskylän kaupungin lasten päivähoitopalveluiden kanssa aloittavat syksyllä 2010 vuonna 2007 syntyneiden lasten liikunta-aktiivisuuden tutkimuksen. Tutkimuksella tuetaan lapsen luontaista tapaa liikkua ja leikkiä (Jyväskylän varhaiskasvatussuunnitelma, VASU 2010)

\section{Tutkimuksen taustalla on ajatus:}

- kartoittaa päiväkodin arkea, miten ympäristö ja päiväkodin tarjoamat mahdollisuudet vaikuttavat lasten liikkumiseen ja ruokailuun.

- tarkkailla miten, missä ja milloin lapset leikkivät, liikkuvat ja syövät.

\section{Tutkimusmenetelmät:}

1) Lasten liikunta-aktiivisuutta ja ruokatottumuksia arvioidaan havainnoimalla lasta päiväkodissa kolmen hoitopäivän aikana.

2) Lasten liikunta-aktiivisuutta mitataan neljän päivän ajan, kolmena arkipäivänä ja yhtenä viikonlopun päivänä kiihtyvyysmittareilla.

3) Lasten ja vanhempien liikunta- ja ruokatottumuksia kotona arvioidaan kyselylomaketutkimuksella.

Päiväkodista kerätty tutkimusaineisto on luottamuksellista, eivätkä päiväkodit tai henkilöt ole siitä tunnistettavissa. Saatu aineisto tulee ainoastaan tutkimuskäyttöön. Tutkimusaineiston kerääminen toteutetaan niin, ettei se häiritse lapsia tai päiväkodin henkilökuntaa. Tutkimuksesta voi kieltäytyä tai sen voi halutessaan keskeyttää kesken tutkimuksen.

\section{Mitä tarkoittaa...}

Lapset:

- Liikkuvat, leikkivät ja syövät päiväkodin ja kodin arjessa normaalisti.

- Pitävät neljän päivän ajan vyötä, jossa noin tulitikkuaskin kokoinen kiihtyvyysmittari.

\section{Vanhemmat:}

- Kiinnittävät aamuisin pukeutumisen yhteydessä vyön lapselle ja riisuvat iltaisin vyön ennen nukkumaan menoa.

- Pitävät neljän päivän ajan päiväkirjaa mittarin kiinnitys- ja riisumisajankohdista sekä lapsen uniajoista.

- Vastaavat liikunta- ja ruokatottumuskyselyyn.

\section{Päiväkodin henkilöstö:}

- Päiväkodin johtaja osallistuu haastatteluun.

- Auttaa lapsia ja vanhempia tutkimukseen liittyvissä kysymyksissä.

- Auttaa lapsia riisumaan mittarit päiväunien ajaksi. 


\section{Tutkimusryhmä:}

- Tutustuu etukäteen päiväkotiin ja sen henkilökuntaan.

- Tiedottaa päiväkodin henkilökunnalle sekä kirjallisesti että suullisesti tutkimuksen kulusta.

- Tiedottaa tutkimukseen osallistuvien lapsien vanhemmille sekä kirjallisesti että suullisesti tutkimuksen kulusta.

- Havainnoi lapsia kolmen päivän ajan päiväkodissa.

- Kiinnittää tutkimuksen ensimmäisenä päivänä (yhdessä vanhempien kanssa) kiihtyvyysmittarivyöt lapsille ja kerää mittarit aineiston keruun päätteeksi.

- Haastattelee päiväkotijohtajaa.

- Opastaa vanhempia kyselylomaketutkimukseen liittyvissä kysymyksissä.

Tarkempi kuvaus tutkimuksesta löytyy päiväkodin infotaululta sekä päiväkodin johtajalta. Tutkimusaikataulu varmistuu elokuun alkuun mennessä. Mikäli haluatte lisätietoja tutkimusprojektista, voitte ottaa allekirjoittaneisiin yhteyttä.

Tutkimusryhmän puolesta

Anne Soini, LitM, tohtorikoulutettava

014- 2604574, anne.soini@jyu.fi

Marita Poskiparta, terveyskasvatuksen professori

014-2602148, marita.poskiparta@jyu.fi

Jyväskylän yliopisto, Terveyden edistämisen tutkimuskeskus

PL 35 (L), 400014 Jyväskylän yliopisto 
Appendix 4. Finnish parental consent form

\title{
TIEDOTE TUTKITTAVILLE JA SUOSTUMUS TUTKIMUKSEEN OSALLISTUMISESTA
}

\author{
Tutkimuksen nimi: \\ Suomalaisten ja hollantilaisten 2-6-vuotiaiden lasten liikunta-aktiivisuus kotona ja \\ päiväkodissa.
}

Tutkimustieto alle kouluikäisten lasten fyysisestä aktiivisuudesta ja liikuntaaktiivisuuden motivointi- ja ylläpitokeinoista on vähäistä. Lisäksi lasten ylipaino on yleistynyt ja sen on todettu usein johtavan merkittäviin kansansairauksiin. Jyväskylän yliopiston Terveyden edistämisen tutkimuskeskus toteuttaa vertailevan seurantatutkimuksen yhteistyössä hollantilaisten tutkijoiden kanssa (University of Maastricht Department of Health Education and Promotion). Tutkimuksen tarkoituksena on selvittää suomalaisten ja hollantilaisten 2-6-vuotiaiden lasten fyysisen aktiivisuuden määrää, sen luonnetta ja ravitsemustottumuksia heidän päiväkotivuosinaan. Lasten seuranta-aika on kaksi vuotta $(2010$ - 2012). Tutkimus tapahtuu yhdessätoista vapaaehtoisissa päiväkodeissa. Päiväkodeista kutsutaan mukaan noin 150 vuonna 2007 syntynyttä lasta.

Tutkimuksessa kartoitetaan päiväkodin arkea ja sitä, miten ympäristö ja päiväkodin tarjoamat mahdollisuudet vaikuttavat lasten liikkumiseen ja ruokailuun. Seuraamme miten, missä ja milloin lapset leikkivät ja syövät päiväkodissa olleessaan. Aineiston keruu tapahtuu havainnoimalla päiväkodin normaalia päiväohjelmaa, päiväkodin toimintaan mitenkään puuttumatta. Tutkimuksessa selvitetään keskeisiä tekijöitä, jotka kannustavat tai estävät fyysistä aktiivisuutta ja terveellisiä ruokatottumuksia päiväkodeissa ja perheissä.

Lasten liikkumista ja ruokatottumuksia arvioidaan 1) havainnoimalla lasta hoitopäivän aikana sekä 2) seuraamalla ja mittaamalla liikkumisen määrää askel- ja kiihtyvyysmittareilla. (Liitteessä lisätietoa askel- ja kiihtyvyysmittareiden käytöstä.) 3) Perheen liikkumista ja ruokailutottumuksia kotona selvitetään kyselylomaketutkimuksella ja 4) lasten liikkumista mitataan askel- ja kiihtyvyysmittareilla. Päiväkotien henkilökuntaa haastattelemalla tarkennetaan havaintojen tuloksia.

Päiväkodista kerätty tieto on vain tutkijoiden käytössä. Tiedot säilytetään sellaisessa muodossa, että ketään yksittäistä lasta, henkilökuntaa tai päiväkotia ei voida tunnistaa. Tutkimusaineiston kerääminen toteutetaan niin, ettei se häiritse lapsia eikä päiväkodin henkilökunnan normaalia toimintaa. Ensimmäinen aineisto kerätään vuonna 2010, elo-syyskuun aikana ja seuraava aineisto vuonna 2011, tammi-helmikuun aikana. Tutkimusaineistoa kerätään kerrallaan neljän päivän ajan, kolmena arkipäivänä päiväkodissa ja yhtenä viikonlopun päivänä kotona. 5) Aineiston keruun yhteydessä lasten pituus mitataan ja paino punnitaan.

Alkumittaustutkimusten perusteella päiväkoteihin suunnitellaan vuonna 2011 toimenpiteitä fyysisen aktiivisuuden ja terveellisten ruokatottumusten edistämiseksi. Toimenpiteet toteutetaan kuudessa päiväkodissa. Vertailun vuoksi viisi päiväkotia toimii entisellä tavalla. Lisäksi arvioidaan miten toimenpiteet vaikuttavat 2-6-vuotiaiden lasten liikkumisen määrään ja ruokatottumuksiin.

Uskomme tutkimustulosten antavan meille tärkeää tietoa lasten liikkumisesta ja ruokailusta. Myöhemmin tutkimustuloksia voidaan hyödyntää kehitettäessä päiväkoteja tukemaan lasten terveyttä ja hyvinvointia yhä enemmän. 
Päiväkoti xx on antanut luvan tutkimuksen tekoon. Osallistuminen tutkimukseen on täysin vapaaehtoista. Päiväkodin henkilökunta ja tutkijat kertovat tutkimukseen osallistuville lapsille tutkimuksesta, sen tarkoituksesta, mittausmenetelmistä ja toteutuksesta. Tutkittavilla on oikeus saada lisätietoa tutkimuksesta tutkijaryhmän jäseniltä missä tutkimuksen vaiheessa tahansa. Tutkittavilla on tutkimuksen aikana oikeus kieltäytyä ja keskeyttää mittaukset ilman, että siitä aiheutuu mitään seuraamuksia. Tutkimuksen järjestelyt ja tulosten raportointi ovat luottamuksellisia. Tutkimuksesta saatavat tiedot tulevat ainoastaan tutkittavan ja tutkijaryhmän käyttöön ja tulokset julkaistaan tutkimusraporteissa siten, ettei yksittäistä tutkittavaa voi tunnistaa.

Pyydämme Teitä ystävällisesti ilmoittamaan alla olevalla lomakkeella, saako lapsenne osallistua tutkimukseen. Palautathan lomakkeen täytettynä xx.xx.xxxx mennessä päiväkodin henkilökunnalle. Suomessa tämänkaltainen tutkimus on vasta saamassa jalansijaa ja siten hyvin merkittävä. Tutkimukseen osallistua informoidaan erikseen mahdollisesta jatkohankkeesta ja jatkotutkimusta varten pyydetään uudet tutkimusluvat.

Lisätietoja tutkimuksesta antavat terveyskasvatuksen professori Marita Poskiparta, puh.014-260 2148, marita.poskiparta@jyu.fi ja tohtorikoulutettava Anne Soini, puh.014 -260 4574, anne.soini@jyu.fi.

Odotamme mielenkiinnolla tutkimuksen käynnistymistä ja yhteistyötä kanssanne.

Tutkimusryhmän puolesta

Anne Soini, LitM, tohtorikoulutettava

Jyväskylän yliopisto, Terveyden edistämisen tutkimuskeskus

PL 35 (L), 400014 Jyväskylän yliopisto

014- 2604574, anne.soini@jyu.fi

\section{Tutkimuksen nimi: \\ Suomalaisten ja hollantilaisten 2-6-vuotiaiden lasten liikunta-aktiivisuus kotona ja päiväkodissa.}

Lapsen nimi:

Rastita haluamasi vaihtoehto:

Annan luvan lapselleni osallistua tutkimukseen ja seuraaviin mittauksiin: havainnointitutkimus päiväkodissa kolmen päivän ajan, mittaaminen askelja kiihtyvyysmittareilla kolmena päivänä päiväkodissa ja yhtenä päivänä kotona, pituuden ja painon mittaaminen ja kyselytutkimus kotona.

\section{En anna lapselleni lupaa osallistua tutkimukseen}

Päiväys ja paikka:

Huoltajan allekirjoitus ja nimenselvennys: 


\section{Appendix 5. Accelerometer diary}

\section{Ohje liikemittarin käyttöön}

Tutkimusaineistoa lasten liikunta-aktiivisuudesta kerätään kiihtyvyysmittareilla. Mittarit ovat pienikokoisia, eivätkä vaikuta lapsen päivän perustoimintoihin.

- Mittarivyötä pidetään neljän päivän ajan, keskiviikkoaamusta lauantai-iltaan. Jos lapsi kokee mittarin pitämisen miellyttävänä, olisi suotavaa kerätä aineistoa vielä toiselta vapaapäivältä, sunnuntailta.

- Liikemittari otetaan pois nukkumaan mentäessä ja laitetaan takaisin vyötärölle heti herättyä.

- Vanhemmat huolehtivat aamuisin ja iltaisin mittareiden kiinnittämisestä ja riisumisesta.

- Mittausten aikana noudatetaan tavanomaista päivärytmiä ja suoritetaan jokapäiväiset askareet totutulla tavalla.

- Liikemittari ei ole vesitiivis. Ota se pois kun lapsesi käy suihkussa, saunassa tai uimassa. Laita mittari takaisin vyötärölle mahdollisimman pian.

- Mittari voi olla paikoillaan päiväunien ajan, jos se ei häiritse lasta.

- Vanhemmat kirjaavat oheiseen päiväkirjaan tutkimuspäivien ajalta kysyttyjä mittaamiseen liittyviä seikkoja. Kirjaa ylös tapahtumat ja olosuhteet, jotka poikkeavat normaalipäivästä sekä jos mittari riisutaan päivän aikana esimerkiksi uintireissua varten.

Liikemittari on kiihtyvyysanturi, joka vyötärölle kiinnitettynä mittaa kehon liikkeitä ja fyysistä aktiivisuutta. Mittaaminen voidaan keskeyttää jos lapsi ei halua käyttää mittaria.

\section{Liikemittarin sijoitus}

Kiinnitä liikemittari kuminauhavyön avulla vyötärön ympäri ja varmista, että laite on suurin piirtein keskellä oikealla lantiolla (katso kuva). Laitetta voi pitää vyössä joko vaatteiden päällä tai niiden alla, jolloin se ei häiritse lasta tai vie lapsen huomiota laitteeseen. Laitteen ei tarvitse olla kosketuksessa ihoon. Varmista, että laite on tiiviisti lantiota vasten, ettei vyö ole liian löysällä.
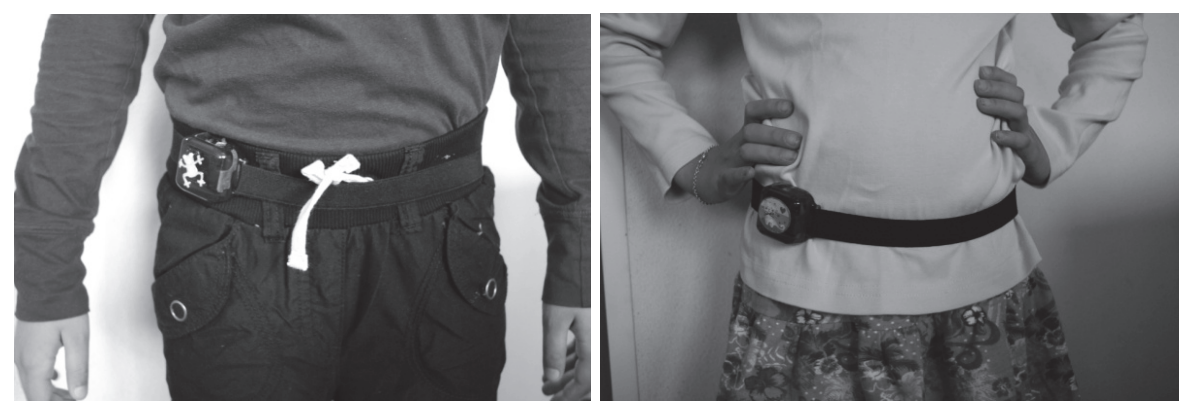

Lisätietoja: Anne Soini, LitM, tohtorikoulutettava 041-747 5586, anne.soini@jyu.fi 


\section{Liikemittarin päiväkirja:}

Lapsen nimi:

mittarin numero:

id-tunnus: (numero mittarin sisäpuolella, vyössä kuminauhan pituus) (tutkija täyttää)

$* * * * * * * * * * * * * * * * * * * * * * * * * * * * * * * * * * * * * * * * * * * * * * * * * * * * * * * * * * * * * * * * * * * * * * * * * * * * * *$

\section{Keskiviikko} (pvm)

Lapsi viety hoitoon klo ja haettu hoidosta klo

Kirjaa ylös tapahtumat ja olosuhteet, jotka poikkeavat normaalipäivästä. Esimerkiksi: automatka mummolaan klo 16-19, lapsi sairaana, kova vesisade jne. Merkitse aikaväli ja syy, jos mittari riisutaan päivän aikana, esim. uinti klo 17-18.

Lapsi nukahti klo

Torstai (pvm) lapsi heräsi klo

Lapsi viety hoitoon klo ja haettu hoidosta klo

Kirjaa ylös tapahtumat ja olosuhteet, jotka poikkeavat normaalipäivästä. Esimerkiksi: automatka mummolaan klo 16-19, lapsi sairaana, kova vesisade jne. Merkitse aikaväli ja syy, jos mittari riisutaan päivän aikana, esim. uinti klo 17-18

Lapsi nukahti klo

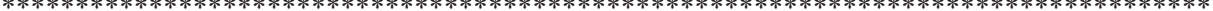

Perjantai (pvm) lapsi heräsi klo

Lapsi viety hoitoon klo ja haettu hoidosta klo

Kirjaa ylös tapahtumat ja olosuhteet, jotka poikkeavat normaalipäivästä. Esimerkiksi: automatka mummolaan klo 16-19, lapsi sairaana, kova vesisade jne. Merkitse aikaväli ja syy, jos mittari riisutaan päivän aikana, esim. uinti klo 17-18.

Lapsi nukahti klo 
Lauantai (pvm) lapsi heräsi klo

Lapsi päiväunilla klo

Kirjaa ylös tapahtumat ja olosuhteet, jotka poikkeavat normaalipäivästä. Esimerkiksi: automatka mummolaan klo 16-19, lapsi sairaana, kova vesisade, vanhempi/vanhemmat töissä jne. Merkitse aikaväli ja syy, jos mittari riisutaan päivän aikana, esim. uinti klo 17-18.

Lapsi nukahti klo

Jos lapsi kokee mittarin pitämisen miellyttävänä, olisi suotavaa kerätä aineistoa vielä toiselta vapaapäivältä, sunnuntailta.

Sunnuntai (pvm) lapsi heräsi klo

Lapsi päiväunilla klo

Kirjaa ylös tapahtumat ja olosuhteet, jotka poikkeavat normaalipäivästä. Esimerkiksi: automatka mummolaan klo 16-19, lapsi sairaana, kova vesisade, vanhempi/vanhemmat töissä jne. Merkitse aikaväli ja syy, jos mittari riisutaan päivän aikana, esim. uinti klo 17-18.

Tutkimuksen päätteeksi valitse yksi seuraavista vaihtoehdoista. Lapseni koki mittarin käytön:

$\square$ erittäin mieluisaksi

mieluisaksi

epämiellyttäväksi

$\square$ erittäin epämiellyttäväksi

en osaa sanoa

KIITOS!

\author{
PALAUTATHAN MITTARIN JA PÄIVÄKIRJAN \\ MAANANTAINA PÄIVÄKOTIIN!
}


Appendix 6. The modified OSRAC-P (Brown et al., 2006) observation form

CHILDCARE CENTRE:

DATE:

TIME:.....

OBSERVER'S ID:.

CHILD'S ID-CODE:

GENDER: M / F

TEMPERATURE OUTSIDE:

WEATHER:

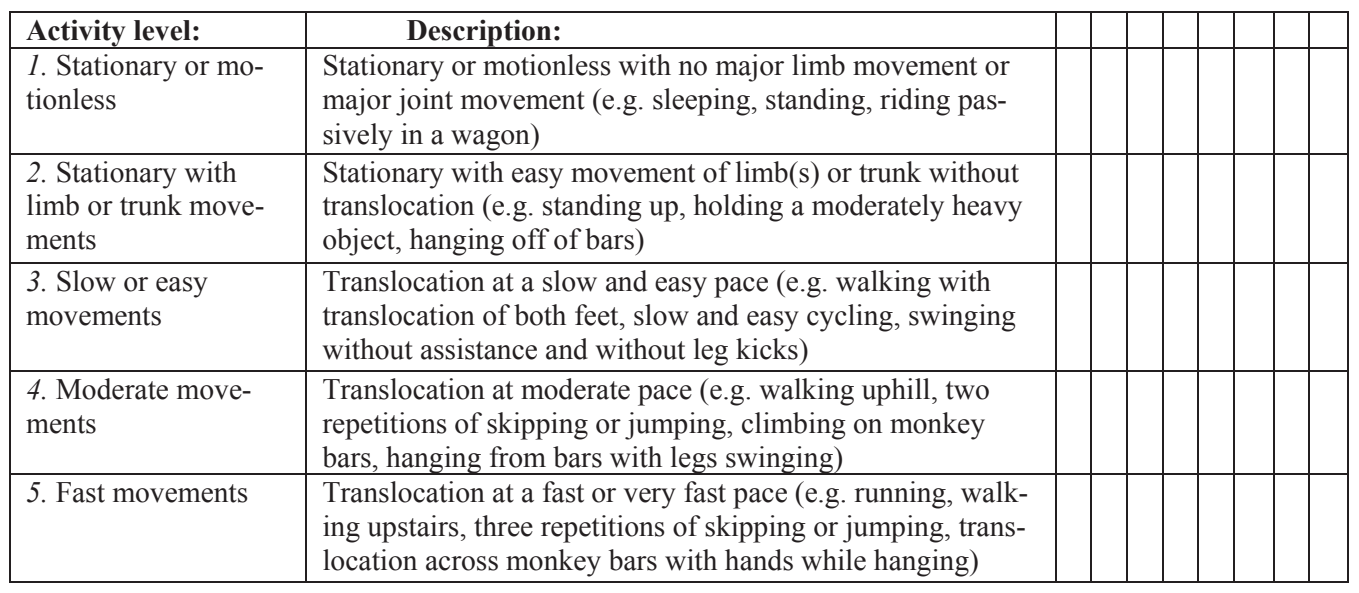

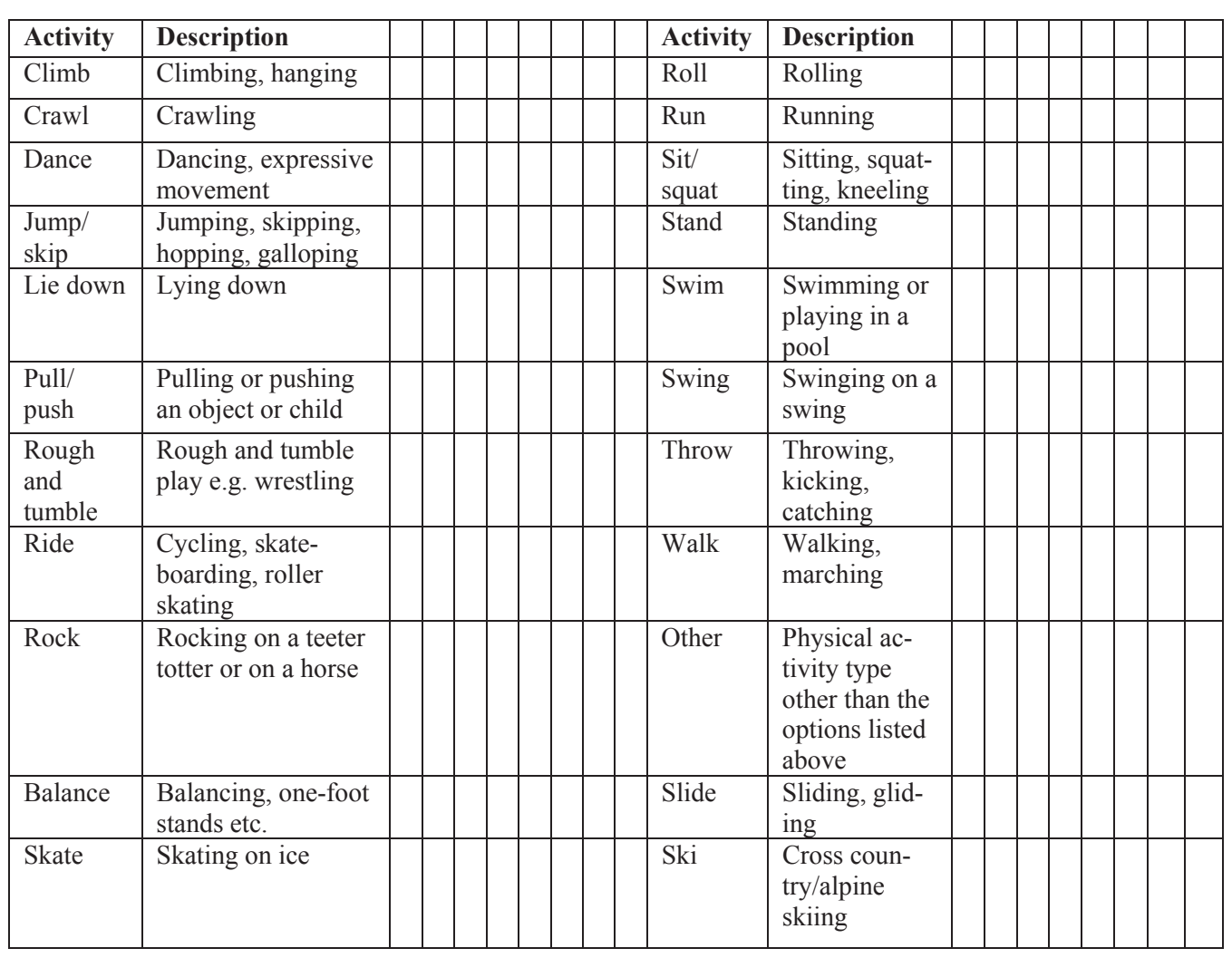




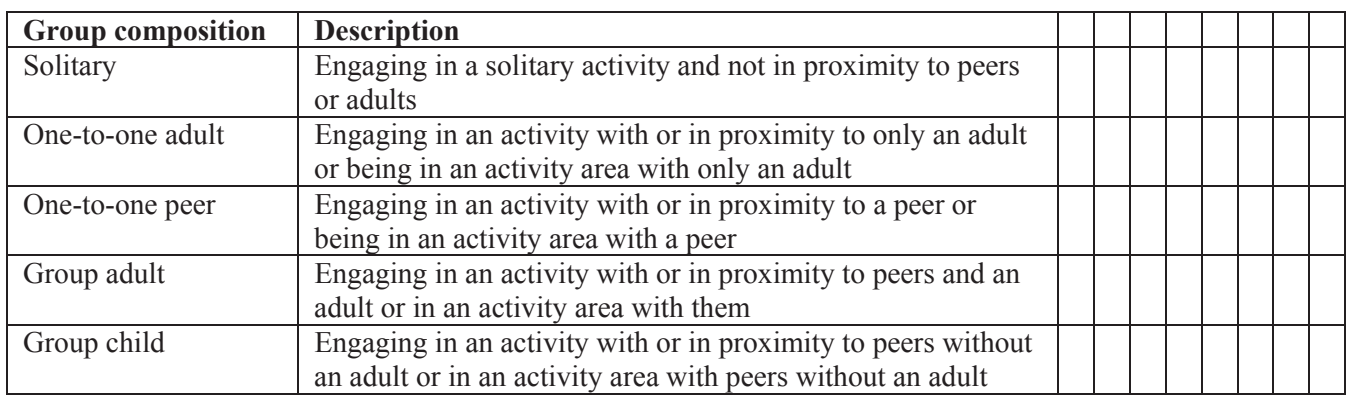

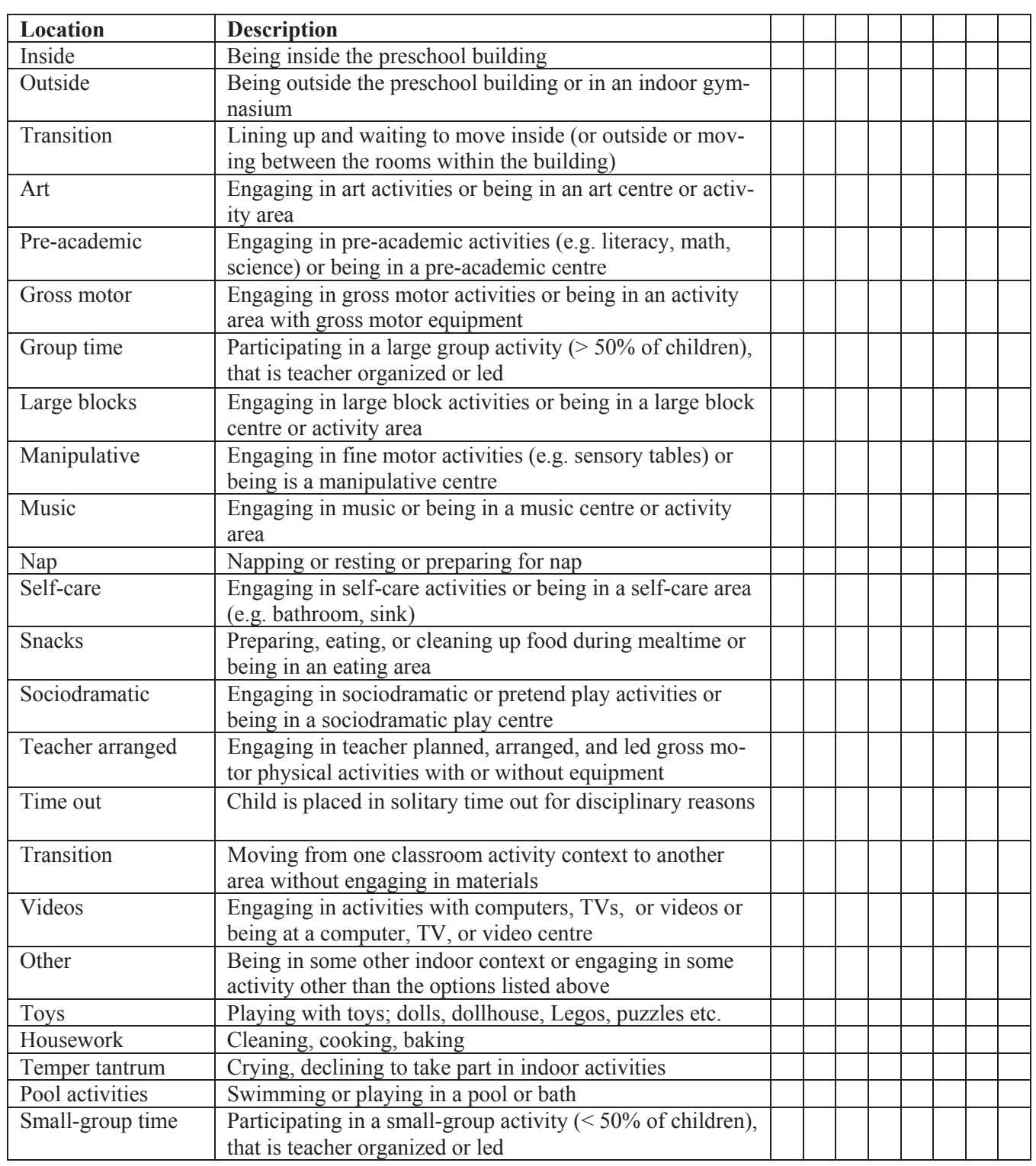




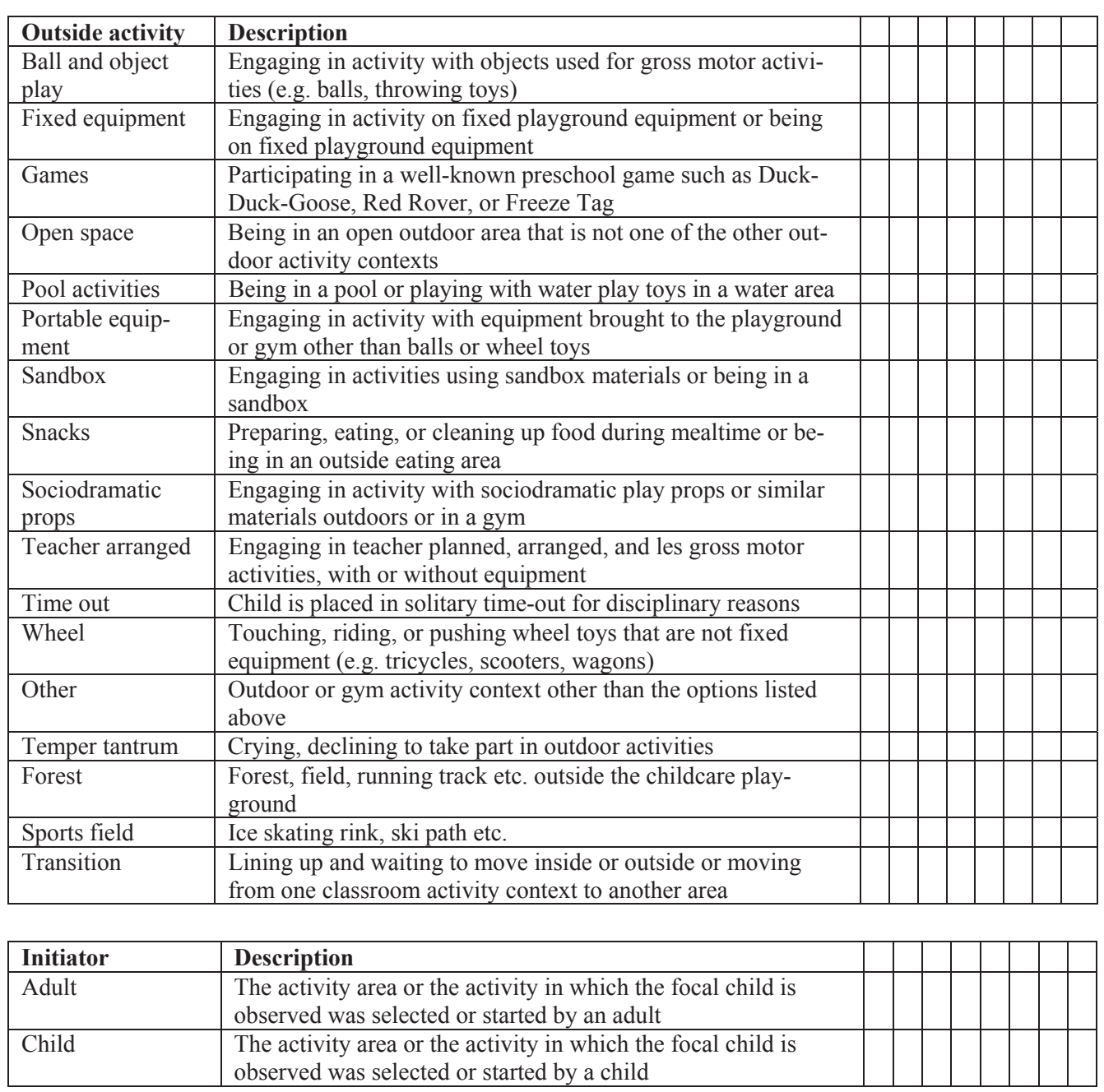

\begin{tabular}{|l|l|l|l|l|l|l|}
\hline Prompts & Description & & & & \\
\hline No prompt for PA & $\begin{array}{l}\text { Teacher did not explicitly prompt the focal child to in- } \\
\text { crease or decrease PA or the teacher's prompt is unrelat- } \\
\text { ed to PA }\end{array}$ & & & & & \\
\hline $\begin{array}{l}\text { Teacher prompt to in- } \\
\text { crease PA }\end{array}$ & $\begin{array}{l}\text { Teacher explicitly prompted the focal child to engage in } \\
\text { or maintain physical activity }\end{array}$ & & & & & \\
\hline $\begin{array}{l}\text { Teacher prompt to de- } \\
\text { crease PA }\end{array}$ & $\begin{array}{l}\text { Teacher explicitly prompted the focal child to stop or } \\
\text { decrease physical activity }\end{array}$ & & & & & \\
\hline $\begin{array}{l}\text { Peer prompt to increase } \\
\text { PA }\end{array}$ & $\begin{array}{l}\text { Peer explicitly prompted the focal child to engage in or } \\
\text { maintain physical activity }\end{array}$ & & & & \\
\hline $\begin{array}{l}\text { Peer prompt to decrease } \\
\text { PA }\end{array}$ & $\begin{array}{l}\text { Peer explicitly prompted the focal child to stop or de- } \\
\text { crease physical activity }\end{array}$ & & & & \\
\hline
\end{tabular}


Appendix 7. The statistical analyses implemented in each of the four studies

\begin{tabular}{|c|c|c|c|c|}
\hline \multirow{2}{*}{$\begin{array}{l}\text { Statistical } \\
\text { analyses }\end{array}$} & \multicolumn{2}{|c|}{ Accelerometer data } & \multicolumn{2}{|c|}{ Direct observation data } \\
\hline & Study I & Study IV & Study II & Study III \\
\hline $\begin{array}{l}\text { Means and } \\
\text { standard } \\
\text { deviations }\end{array}$ & $\begin{array}{l}\text { Daily total PA } \\
\text { expressed as cpm, } \\
\text { and time spent } \\
\text { (minutes/day) at } \\
\text { different intensity } \\
\text { levels (sedentary, } \\
\text { light, moderate, } \\
\text { vigorous, LMVPA } \\
\text { and MVPA); age, } \\
\text { weight, height and } \\
\text { BMI. }\end{array}$ & $\begin{array}{l}\text { Daily total PA ex- } \\
\text { pressed as cpm, and } \\
\text { time spent (percent- } \\
\text { ages/day) and aver- } \\
\text { age minutes/hour } \\
\text { during childcare or } \\
\text { homecare days at } \\
\text { different intensity } \\
\text { levels; age, weight, } \\
\text { height and BMI; daily } \\
\text { outdoor tempera- } \\
\text { tures; childcare at- } \\
\text { tending hours. } \\
\end{array}$ & $\begin{array}{l}\text { Age, weight, } \\
\text { height and BMI; } \\
\text { childcare attend- } \\
\text { ance hours. }\end{array}$ & \\
\hline $\begin{array}{l}\text { Independ- } \\
\text { ent-samples } \\
t \text {-test }\end{array}$ & $\begin{array}{l}\text { Gender differences } \\
\text { in total PA and in } \\
\text { engagement at } \\
\text { different intensity } \\
\text { levels; seasonal } \\
\text { differences in } \\
\text { childcare outdoor } \\
\text { times and mean } \\
\text { daily tempera- } \\
\text { tures. }\end{array}$ & $\begin{array}{l}\text { Gender and country } \\
\text { differences in total PA } \\
\text { and in engagement at } \\
\text { different intensity; } \\
\text { country differences in } \\
\text { monitor wearing days } \\
\text { and minutes/day. }\end{array}$ & $\begin{array}{l}\text { Gender differences } \\
\text { in mean PA inten- } \\
\text { sity levels; season- } \\
\text { al differences in } \\
\text { childcare outdoor } \\
\text { times and mean } \\
\text { daily tempera- } \\
\text { tures. }\end{array}$ & $\begin{array}{l}\text { Country differ- } \\
\text { ences in mean } \\
\text { activity intensity; } \\
\text { differences be- } \\
\text { tween indoor } \\
\text { and outdoor } \\
\text { mean activity } \\
\text { intensity. }\end{array}$ \\
\hline $\begin{array}{l}\text { Paired- } \\
\text { samples } t \text { - } \\
\text { test }\end{array}$ & $\begin{array}{l}\text { To compare PA } \\
\text { levels on week- } \\
\text { days and weekend } \\
\text { days, and between } \\
\text { autumn and win- } \\
\text { ter. }\end{array}$ & $\begin{array}{l}\text { To compare PA levels } \\
\text { on childcare and } \\
\text { homecare days; coun- } \\
\text { try variations in age, } \\
\text { weight, height and } \\
\text { BMI. }\end{array}$ & & \\
\hline 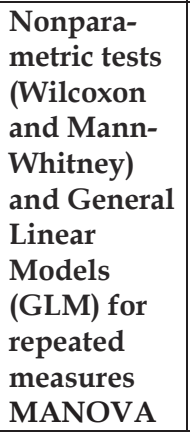 & $\begin{array}{l}\text { Gender and sea- } \\
\text { sonal differences } \\
\text { in children' s PA } \\
\text { on weekdays and } \\
\text { weekend days }\end{array}$ & $\begin{array}{l}\text { Gender, country and } \\
\text { hour of the day dif- } \\
\text { ferences in PA levels } \\
\text { between childcare } \\
\text { and home days. }\end{array}$ & $\begin{array}{l}\text { Gender and sea- } \\
\text { sonal differences } \\
\text { in mean PA levels } \\
\text { (indoors, outdoors; } \\
\text { morning, after- } \\
\text { noon) }\end{array}$ & \\
\hline
\end{tabular}




\begin{tabular}{|c|c|c|c|c|}
\hline $\begin{array}{l}\text { Crosstabs } \\
\text { utilizing } \\
\text { Pearson's } \\
\text { Chi-squared } \\
\left(\chi^{2}\right) \text { test }\end{array}$ & $\begin{array}{l}\text { To determine the } \\
\text { percentages of } \\
\text { children who } \\
\text { reached the cur- } \\
\text { rent recommended } \\
\text { levels of PA }\end{array}$ & $\begin{array}{l}\text { To determine the } \\
\text { percentages of chil- } \\
\text { dren who reached the } \\
\text { current recommended } \\
\text { levels of PA }\end{array}$ & $\begin{array}{l}\text { Seasonal differ- } \\
\text { ences in gender, } \\
\text { location, time of } \\
\text { day, morning } \\
\text { (in/out), afternoon } \\
\text { (in/out), group } \\
\text { composition, initi- } \\
\text { ator of activity, } \\
\text { prompts, tempera- } \\
\text { ture, weather con- } \\
\text { dition and varia- } \\
\text { tions in percent- } \\
\text { ages spent in sed- } \\
\text { entary, light and } \\
\text { MVPA levels in } \\
\text { these categories. }\end{array}$ & $\begin{array}{l}\text { Country differ- } \\
\text { ences in gender, } \\
\text { location, time of } \\
\text { day, morning, } \\
\text { afternoon, group } \\
\text { composition, } \\
\text { initiator of activi- } \\
\text { ty, prompts, } \\
\text { temperature, } \\
\text { weather condi- } \\
\text { tion and country } \\
\text { variations in } \\
\text { percentages } \\
\text { spent in seden- } \\
\text { tary, light and } \\
\text { MVPA levels in } \\
\text { these categories. } \\
\end{array}$ \\
\hline $\begin{array}{l}\text { Cohen's } d \\
\text { formula }\end{array}$ & Effect size & & & \\
\hline $\begin{array}{l}\text { Cohen's } \\
\text { kappa }\end{array}$ & & & $\begin{array}{l}\text { To determine the } \\
\text { inter-rater reliabil- } \\
\text { ity (IRR) of the two } \\
\text { observers for the } \\
\text { observations of the } \\
\text { OSRAC-P varia- } \\
\text { bles. }\end{array}$ & $\begin{array}{l}\text { To determine the } \\
\text { inter-rater relia- } \\
\text { bility (IRR) of the } \\
\text { two observers for } \\
\text { the observations } \\
\text { of the OSRAC-P } \\
\text { variables. }\end{array}$ \\
\hline $\begin{array}{l}\text { Three-level } \\
\text { linear re- } \\
\text { gression }\end{array}$ & & & $\begin{array}{l}\text { The association } \\
\text { between the mean } \\
\text { level of PA intensi- } \\
\text { ty as the depend- } \\
\text { ent variable and } \\
\text { independent vari- } \\
\text { ables such as, gen- } \\
\text { der, BMI, primary } \\
\text { location, time of } \\
\text { day, group com- } \\
\text { position, initiator } \\
\text { of activity, } \\
\text { prompts, tempera- } \\
\text { ture and weather } \\
\text { condition. }\end{array}$ & $\begin{array}{l}\text { The association } \\
\text { between gender*, } \\
\text { primary loca- } \\
\text { tion*, time of } \\
\text { day*, group }^{*} \text { composition*, }^{*} \\
\text { initiator of activi- } \\
\text { ty*, prompts*, } \\
\text { temperature* and } \\
\text { weather condi- } \\
\text { tion* as inde- } \\
\text { pendent, and } \\
\text { mean PA intensi- } \\
\text { ty levels as de- } \\
\text { pendent varia- } \\
\text { bles }\end{array}$ \\
\hline $\begin{array}{l}\text { Cross-level } \\
\text { interaction } \\
\text { (MLR; with } \\
\text { measure- } \\
\text { ment level, } \\
\text { child level, } \\
\text { centre level) }\end{array}$ & & & & $\begin{array}{l}\text { Country differ- } \\
\text { ences in these } \\
\text { associations } \\
(\text { above*). }\end{array}$ \\
\hline
\end{tabular}




\section{ORIGINAL PUBLICATIONS}

\section{I}

SEASONAL AND DAILY VARIATION IN PHYSICAL ACTIVITY AMONG THREE-YEAR-OLD FINNISH PRESCHOOL CHILDREN

by

Soini, A., Tammelin, T., Sääkslahti, A., Watt, A., Villberg, J., Kettunen, T., Mehtälä, A., \& Poskiparta, M. (2014).

Early Child Development and Care, 184(4), 586-601. doi: 10.1080/03004430.2013.804070

Reproduced with kind permission by Routledge, Taylor \& Francis Group. 
4

5

6

7 Seasonal and daily variation in physical activity among 3-year-old Finnish preschool 8 children 
Abstract

11 The purposes of this study were to assess seasonal, daily, and gender variations in children's

12 physical activity (PA). ActiGraph GT3X accelerometers were used to record the 3 year-old

13 children's PA levels for five consecutive days in autumn and winter. Complete data for both

14 seasons were obtained for 47 children. Despite a significant difference in seasonal

15 temperatures $(p<.001)$, differences were only found for weekdays light PA $(p=.021)$. No

16 difference in PA was observed between weekdays and weekend days. Only $20 \%$ of the

17 sample had $\geq 120$ minutes light-to-vigorous PA (LMVPA), and 46\% of children had $\geq 60$

18 minutes moderate-to-vigorous PA (MVPA). Boys spent more minutes in LMVPA $(p=.001)$

19 and MVPA $(p=.004)$ than girls. The current findings indicated that season and day of the

20 week only minimally influence children's PA levels, whereas gender continues to be a

21 significant factor.

22 Keywords: accelerometer; childcare; early childhood; physical activity 


\section{Introduction}

Early childhood has been identified as an important time for the development of healthy behaviours such as physical activity (PA) (Timmons, Naylor, \& Pfeiffer, 2007). Children's engagement in PA plays a key role in their physical growth and biological maturation (Strong et al., 2005) and exerts a positive influence on their cognitive, social, and psychological development (Timmons et al., 2007). Previous studies have demonstrated that PA not only appears to track reasonably well over time (Strong et al., 2005), but that physical inactivity (Telama, 2009) and obesity (Moore et al., 2003) demonstrate even stronger consistency in the transition from childhood to adulthood. In light of this trend, the enhancement of PA and reduction in sedentary behaviour in children are genuinely important from a public health perspective (Tremblay et al., 2011).

Preschool children's (3-5 years) PA may be described as "play" and occurs at various levels of intensity (Timmons et al., 2007). The assessment of young children's PA is demanding, primarily because their behaviour is intermittent and sporadic. Objective measures such as accelerometers can detect these short spurts of activity and determine frequencies, intensities, and duration of PA (Cliff, Reilly, \& Okely, 2009; Oliver, Schofield, \& Kolt, 2007; Pate, O’Neill, \& Mitchell, 2010). Accelerometers have become one of the most widely used methods for assessing preschool-aged children's PA (Pate et al., 2010). Although the use of accelerometers to assess PA in preschool children has increased over the past decade (Bornstein, Beets, Byun, \& McIver, 2011), Carson and Spence (2010) reported that there was only a small set of studies where preschool-aged children's PA levels have been determined with accelerometers across different seasons. Carson and Spence found that 29 out of a total of 35 studies assessed seasonal variations in PA among children and/or adolescents, but that only six exclusively examined preschool-aged groups, in which the pattern of findings were less clear. For example, in Scotland (Fisher et al., 2005), Canada 
49 (Carson, Spence, Cutumisu, Boule, \& Edwards, 2010) and the United States (Poest, Williams,

Witt, \& Atwood, 1989) children were less physically active in wintertime compared to summertime, whereas Finn, Johannsen, \& Specker (2002) found no seasonal variations in their US study. Burdette, Whitaker, and Daniels (2004) reported that the highest levels of outdoor playtime occurred in the summer and the lowest in the winter and that seasonal differences in children's PA levels, as measured by accelerometers, were less pronounced compared to children's parents' proxy reports. Differences in children's PA have related more to time spent outdoors than to season or weather conditions (Baranowski, Thompson, DuRant, Baranowski, \& Puhl, 1993). Seasonality merits study in young preschool children, as lifelong patterns of PA participation throughout the year are adopted in the early years of life (Poest et al., 1989). Because so few of these earlier studies were conducted in locations characterized by very cold winter temperatures, such as experienced in Finland, more knowledge is needed about seasonal variation in young children's PA in environmental conditions of this kind.

In Europe, the average enrolment rate of children aged 3 years in childcare and early education services is 69\% (OECD Family Database, 2008). During weekdays, children attend childcare approximately 6-9 hours/day, while on weekend days they spend the whole day typically engaged in activities based within the home setting. There is evidence that children's attendance at childcare influences their levels of PA (Finn et al., 2002; Pate, McIver, Dowda, Brown, \& Addy, 2008; Pate, Pfeiffer, Trost, Ziegler, \& Dowda, 2004), thereby underlining the importance of examining and comparing children's PA levels during weekdays and weekend days.

To date, studies of objectively measured PA and sedentary behaviour in preschoolaged children have drawn attention to the fact that levels of PA are typically low and sedentary behaviour high (Oliver et al., 2007; Reilly, 2010). On the basis of their 
accelerometer-derived meta-analysis, Bornstein et al. (2011), concluded that preschool children accumulate anywhere from 40 to 100 minutes of MVPA daily. Previous early childhood studies have investigated whether preschoolers are meeting PA guidelines, meaning at least 60 minutes of MVPA (Beets, Bornstein, Dowda, \& Pate, 2011; Cardon \& De Bourdeaudhuij, 2008; Reilly, 2010; Tucker, 2008). Despite the recommendations to engage in PA and its indisputable benefits, many young people do not achieve the guidelines for daily PA (Reilly, 2010; Tucker, 2008). For example, a review of studies from seven different countries found that nearly half of preschool-aged children did not engage in sufficient PA, and only $54 \%$ achieved the minimum of 60 minutes of PA daily (Tucker, 2008). Few earlier PA studies have focused exclusively on 3-year-olds, and therefore more research is needed to reach a comprehensive understanding of PA levels and sedentary behaviour during the very early preschool years.

The main purposes of this study were to assess the PA levels and sedentary time of 3year-old children, paying special attention to the variation in PA and sedentary behaviour between boys and girls, weekdays and weekend days, and the autumn and winter seasons. A secondary purpose was to ascertain whether preschool children achieve the recommended levels of PA proposed within national and international current guidelines (Australian Government, Department of Health and Ageing, 2010; Canadian Society for Exercise Physiology, 2012; Department of Health. UK physical activity guidelines, 2011; Institute of Medicine [IOM], 2011; The National Association for Sport and Physical Education [NASPE], 2009; Recommendations for Physical Activity in Early Childhood Education, 2005; World Health Organization [WHO], 2010).

\section{Method}

\section{Participants}


98 Principals of childcare centres in Jyväskylä were provided with information regarding the study at a regional administrative meeting. A total of 14 childcare centres volunteered to be involved in the study. All the families of the 3-year-old children (year of birth 2007) attending the participating childcare centres were invited to participate. One hundred and two (57\%) parents of 179 families provided informed consents. The PA data on the children were collected in two phases. The first data collection was in autumn (August to October) and the second during the winter (January to February).

A total of 96 children ( 48 boys and 48 girls) participated in the data collection in autumn and 94 children ( 50 boys and 44 girls) took part in winter. Before analysis, the data on 16 children from the autumn sub-sample, and 34 children from winter sub-sample were discarded, as 6 children (autumn) and 14 children (winter) were in homecare, and the remaining 30 participants did not have sufficient complete data. The minimum requirement for valid PA data was at least 8 hours of monitored PA per day (from 7 am to $9 \mathrm{pm}$ ) for at least 2 weekdays and 1 weekend day. Complete data were obtained for 81 children (41 boys and 40 girls) during autumn and for 60 children (33 boys and 27 girls) during winter. Complete data for both seasons were obtained for 47 children ( 26 boys and 21 girls). Body weight and height were measured at the time of each PA data collection and body mass index (BMI: $\mathrm{kg} / \mathrm{m}^{2}$ ) was calculated for each child. Demographic characteristics of the sample by gender and season are shown in Table 1. Results for BMI indicated, in accordance with the International Obesity Task Force BMI definition, four children (9\%) during the autumn assessments and three children (7\%) during the winter assessments were evaluated as overweight. All other children were in the normal BMI range (Cole, Bellizzi, Flegal, \& Dietz, 2000). [Table 1 near here]

\section{Instruments}


PA was quantified with ActiGraph GT3X accelerometers on five consecutive days (from Wednesday to Sunday), which were programmed to save data in 5-s intervals (epochs) as proposed for children this age (Cliff et al., 2009). In the present study, total physical activity (TPA) was expressed as mean counts per minute (cpm). To analyse the amount of the time children spent at different intensity levels, the separate count cut points for preschool-aged children established recently by Van Cauwenberghe, Labarque, Trost, De Bourdeaudhuij, and Cardon, (2011) were adapted for this study. The following cut-points were used: sedentary ( $\leq$ $1491 \mathrm{cpm})$; light (14922339 cpm); moderate (23403523 cpm); vigorous ( $\geq 3524 \mathrm{cpm})$; lightto-vigorous physical activity (LMVPA) ( $\geq 1492 \mathrm{cpm}$ ); and moderate-to-vigorous physical activity (MVPA) ( $\geq 2340 \mathrm{cpm})$ (Van Cauwenberghe et al., 2011).

\section{Procedures}

Before the data collection, all the participants were familiarized with the accelerometer. The children received an accelerometer on the first morning of the study, and all the children, together with their parents, were instructed to wear the accelerometer on an adjustable elastic belt over their right hip for as long as possible during all waking hours, removing it only for water-based activities and sleeping. Parents and early educators were informed about the correct procedures and proper accelerometer use via an information letter.

Parents were asked to record the times at which children woke up, went to bed, and their childcare attendance times. Additionally, parents were asked to report any abnormalities in daily routines, for example, long periods spent sitting (e.g., in a car), swimming, bathing and if the child falls ill during the measurement time. Receptivity to wearing the instrument was rated by the parent on a five-point scale (from very pleasant to very unpleasant). Outdoor times were recorded by the researchers during attendance at childcare. The ethics committee of the University of Jyväskylä, and the Social Affairs and Health officer in city of Jyväskylä approved the study. 


\section{Environmental conditions}

The city of Jyväskylä is located in central Finland $\left(62^{\circ} 15^{\prime} 36^{\prime \prime} \mathrm{N}, 25^{\circ} 45^{\prime} \mathrm{E}\right)$. The suburbs of the city of Jyväskylä are in close proximity to forests, hills and lakes, with good opportunities for active commuting and leisure time activities. The region experiences four distinct seasons. The average maximum air temperature in autumn (August to October) is around $13.0^{\circ} \mathrm{C}$, average precipitation $66 \mathrm{~mm} / \mathrm{month}$ and duration of sunshine approximately 255 hours/month. During the winter months (January and February) the average air temperature is around $8.4^{\circ} \mathrm{C}$, average precipitation of $39 \mathrm{~mm} / \mathrm{month}$, duration of sunshine approximately 51 hours/month and average snow depth $36 \mathrm{~cm}$ (Climatological Statistics of Finland, 19812010). In this study, the findings showed significant seasonal variation in mean daily temperature $\left(9.4^{\circ} \mathrm{C}\right.$ in autumn vs. $-13.1^{\circ} \mathrm{C}$ in winter; $\left.p<.001\right)$. These temperatures were lower than normally recorded for these seasons.

\section{Statistical analyses}

All data were checked for normality before statistical analysis. Periods of non-wear time (defined as 20 consecutive minutes of ' 0 ' counts) and an upper range of biological plausibility (defined as no more than $15000 \mathrm{cpm}$ ) were removed from the data (Cliff et al. 2009). The data reduction was done with using self-customized software.

The data were analysed using SPSS for Windows (version 18.0). Means and standard deviations (SD) were calculated for daily TPA expressed as cpm, and time spent (minutes per day) at different intensity levels (sedentary, light, moderate, vigorous, LMVPA and MVPA) to show the extent of activity behaviour for the independent variables of gender and season. Nonparametric tests (Wilcoxon and Mann-Whitney) and General Linear Models (GLM) for repeated measures (MANOVA) were used to analyse gender and seasonal differences in children's PA on weekdays and weekend days. To compare PA levels on weekdays and weekend days, paired-samples $t$-tests were conducted. Gender differences in TPA and in 
engagement at different intensity levels were analysed using independent-samples $t$-test.

Effect size was determined using the Cohen's $d$ formula. Crosstabs utilizing Pearson Chisquare were used to determine the percentages of children who reached the current recommended levels of PA. Statistical significance was set at an alpha level of .05 for all analyses.

\section{Results}

The results showed a significant seasonal variation in mean outdoor time during childcare attendance (178 minutes in autumn vs. 116 minutes in winter; $p=.002)$. During the data collection periods, the participants attended childcare settings for an average of 7.6 hours/day. Accelerometers were worn for an average of 4.6 days and 692 minutes/day.

The results indicated that the children engaged in sedentary activity for $85 \%$ of the time, in light activity for $6 \%$ of the time, and in MVPA for $9 \%$ of the time monitored. Mean TPA for the whole sample was $632 \mathrm{cpm}(S D=145)$, boys showing significantly higher TPA than girls ( 673 vs. $580 \mathrm{cpm} ; p=.001, d=0.70$ ). A paired-samples $t$-test indicated no significant differences in TPA or in PA levels between weekdays and weekend days, except in winter, when the children engaged significantly more in sedentary behaviour on weekdays compared to weekend days (596 vs. $570 \mathrm{~min} / \mathrm{day} ; p=.019, d=0.37$ ).

No seasonal difference was observed in children's PA levels, except for minor variation on weekdays light PA ( $p=.021$; see Table 2 ). Boys were more physically active than girls. Between-subjects comparisons in PA on weekdays and weekend days indicated significant gender differences for all the dependent variables, except for sedentary time on weekend days (see Table 2). Results of the independent-samples $t$-tests for the comparison of PA levels by gender revealed that especially during winter weekdays boys were physically more active than girls (see Table 3). Seasonal variations between boys and girls were also analysed with GLM for repeated measures. No significant differences were observed for any 
of six variables. Due to small sample size, the power of the tests was minimal on all occasions, and therefore the results of the MANOVA are merely indicative. [Tables 2 and 3 near here]

The proportions of children engaging in LMVPA were 1\% (under 60 minutes/day), 36\% (6089 minutes/day), 43\% (90119 minutes/day), 20\% (120 minutes or more/day). The proportions of children engaging in MVPA were 53\% (3059 minutes/day), 40\% (6089 minutes/day, and 6\% (90119 minutes/day). None of the children engaged in MVPA 120 minutes or more/day. Pearson Chi-Square tests confirmed the gender differences in the time spent in LMVPA $(p=.010)$ and MVPA $(p=.002)$. According to parents' reports of their children's receptivity to wearing the accelerometer, only $3 \%$ of the children reported the experience as "unpleasant" and none as "very unpleasant".

\section{Discussion}

The main purposes of this study were to assess seasonal, daily, and gender variations in 3year-old preschool children's PA and sedentary behaviour. The results indicated only minor seasonal variations in the children's light PA on weekdays, and no difference was observed in PA levels between weekdays and weekend days, except in winter in the children's sedentary behaviour. Boys were more active than girls, particularly in winter and during weekdays. The findings indicated that the children's PA levels were very low and sedentary time very high. Overall, the children did not meet the recommendations of three hours of daily LMVPA (Australian Government, Department of Health and Ageing, 2010; Canadian Society for Exercise Physiology, 2012; Department of Health. UK physical activity guidelines, 2011; IOM, 2011), or two hours of daily brisk PA (Recommendations for Physical Activity in Early Childhood Education, 2005). Approximately $20 \%$ of the present sample engaged in at least two hours of daily LMVPA (NASPE, 2009) and 46\% fulfilled the requirement of at least 60 minutes of MVPA daily (WHO, 2010). 
The mean TPA scores for the children in the present study were slightly lower than those reported in earlier similar studies (Cardon \& De Bourdeaudhuij, 2008; Fisher et al., 2005; Jackson et al., 2003). For example, Jackson et al. (2003) found total activity counts of $669 \mathrm{cpm}$ for 3-year-old Scottish children compared to the mean of $632 \mathrm{cpm}$ found in this study. Cardon and De Bourdeaudhuij (2008) reported that a sample of 4- and 5-year-old Belgian children engaged in 9.6 hours per day of sedentary behaviour and in MVPA for only 34 minutes per day. The present sample was similarly sedentary for 9.9 hours per day, although the children also engaged in MVPA for 61 minutes per day. Based on a metaanalysis of accelerometer based studies, Bornstein et al. (2011) indicated substantial variations in children's MVPA times, with no clear pattern emerging on the typical PA levels of preschool children. The pattern of low levels of PA and high levels of sedentary time reported for the present Finnish children as well as in comparable studies, underlines a worrying trend among preschool-aged children regarding their failure to engage in sufficient levels of PA.

Limited previous research has examined seasonal variations in younger age groups, and incorporated the use of accelerometers to evaluate PA (Carson \& Spence, 2010). Several studies have shown seasonal variation in young children's PA, with PA levels typically higher and sedentary time lower in summertime (Carson et al., 2010; Fisher et al., 2005; Poest et al., 1989). The highest levels of outdoor playtime occurred in the summer and the lowest in the winter (Burdette et al., 2004). Baranowski et al. (1993) also found seasonal variation in outdoor activity, with all the children showing lower outdoor activity levels during the summer months. Finn et al. (2002) found no effect for season. Similarly, the present study found only minor seasonal variations in children's PA levels. The data revealed that on weekdays in autumn the children engaged significantly more in light PA than on weekdays in winter. Generally, childcare centres' daily schedules do not vary within seasons. 
247 However, in cold weather, such as $-20^{\circ} \mathrm{C}$ or colder, it is possible, that children do not participate in outdoor activities, or recess periods are shorter than normally. Significant seasonal variations in mean temperatures could explain why the average outdoor time during childcare attendance in winter (116 min) was significantly less than in autumn (178 min). Furthermore, in winter, shorter outdoor activity times may explain children's lower engagement in light PA on weekdays. In addition, the amount of daylight hours during the winter months (51 hours/month) is much shorter than in autumn ( 255 hours/month), and might have an influence on children's outdoor times after childcare attendance. Given the considerable contrast in environmental conditions, such as temperature and the presence of snow, the results were surprisingly similar for the two seasons.

Aside from Finn et al. (2002), who concluded that attendance at the childcare centre was the strongest predictor of activity levels, with more than $50 \%$ of the daily activity counts performed during childcare hours, and Strong et al. (2005), who reported that preschools should provide opportunities for children to accumulate 60 minutes and more of MVPA each day, earlier studies have typically indicated that physical activity levels are very low among preschool children during their time in childcare settings (Pate et al., 2008; Reilly, 2010). Cardon and De Bourdeaudhuij (2008) reported higher levels of sedentary behaviour on weekdays compared to weekend days, although MVPA was as low during the weekend days as during the weekdays. In the present study, in wintertime, the children engaged more in sedentary behaviour on weekdays than weekend days. Childcare attendance and outdoor times may in part explain children's greater engagement in sedentary behaviours during weekdays compared to weekend days. The descriptive results revealed that the children tended to be more active on weekdays, although no significant difference in the time spent in different intensity levels was found between weekdays and weekend days. Similarly, Jackson et al. (2003) found no differences in activity levels between weekdays and weekend days. 
Interestingly, the present results showed that the variation in PA time (described by standard deviation and range) on weekend days was somewhat higher than on weekdays. In the present study, there were boys and girls who were physically very active, and others who were very inactive. This finding should encourage early educators and parents to make extra effort to promote a healthy lifestyle in their daily activities with children.

Previous preschool PA research has shown boys to be more active than girls (Finn et al., 2002; Hinkley, Crawford, Salmon, Okely, \& Hesketh, 2008; Jackson et al., 2003; Pate et al., 2004). In the present study, boys' TPA was significantly higher than girls', and boys also spent significantly more minutes in LMVPA and MVPA. On weekdays, girls spent significantly more minutes sedentary than boys. The gender differences were more pronounced on weekdays and during wintertime. It is possible that boys are more interested in rough and tumble play and winter-oriented physical activities (e.g., snow-based play) or enjoy more time in outdoor environments than girls. One potential explanation may be found in parents' and early educators' attitudes, which may affect children's PA. Boys are regularly encouraged to engage in more physically active play and games, whereas girls are exposed to stationary activities and expected to behave in a calmer manner (Pellegrini \& Smith, 1998). Although it is not clear whether the gender difference in PA is biologically based or environmentally determined, it is most likely a combination of both (Timmons et al., 2007).

The present findings provide further support for the recommendations that more attention and encouragement are needed to promote PA throughout the year for preschool-age girls (Pate et al., 2004).

Systematic reviews of previous population surveys have shown that many young children do not meet the international guidelines for PA (Bornstein et al., 2011; Reilly, 2010; Tucker, 2008); the results of the present study were in line with these findings. Approximately half of the children engaged in MVPA for at least 60 minutes per day. Only 
$20 \%$ of children reached the NASPE standard of at least 120 minutes of PA per day, when light PA was included. In addition, none of the present sample engaged in LMVPA for 180 minutes or more (Australian Government, Department of Health and Ageing, 2010; Canadian Society for Exercise Physiology, 2012; Department of Health. UK physical activity guidelines, 2011; IOM, 2011), or achieved the Finnish Recommendations for Physical Activity in Early Childhood Education (2005) of at least 120 minutes of daily brisk PA (defined as MVPA ( $\geq 2340 \mathrm{cpm})$ ). The current sample of 3 year-olds was sedentary for nearly 10 hours per day. Finnish recommendations for preschool children's PA currently do not include limitations on sedentary time, whereas international guidelines (Australian Government, Department of Health and Ageing, 2010; Canadian Society for Exercise Physiology, 2012; Department of Health. UK physical activity guidelines, 2011; IOM, 2011; NASPE, 2009) specifically state that children should not be sedentary for more than one hour at a time except when sleeping. More research is needed to evaluate the effects of PA on children's health and wellness in the early years of life and what constitutes sufficient levels of health-enhancing PA (Beets et al., 2011). In particular, it would be very important to determine the quantity and quality of daily PA required to ensure children's optimal growth and maturation.

A major strength of this study was the repeated-measure design, where the same 3year-old children were measured with accelerometers during two distinct seasons. However, caution should be exercised when comparing PA levels over short time periods (e.g., 3-6 months) because children's normal growth and maturation may influence their physical abilities and motor skills in relation to their engagement in physically active play (Fisher et al., 2005). Children's PA was measured over five days in both the childcare and home settings, including weekdays and weekend days. Anecdotal evidence derived from the implementation of the study suggests that childcare centres are suitable places to reach 
families with 3-year-old children. Moreover, the children were co-operative and eager to take part in this study. Proxy reports by parents of their child's receptivity to wearing the accelerometer clearly indicated that it was a positive experience for the majority of the children. Although previous data on the receptivity of preschoolers to wearing accelerometers is relatively limited and not well understood (Oliver et al., 2007), the present results are in line with those of earlier studies (Cardon \& De Bourdeaudhuij, 2008; Pate et al., 2004). The present study was limited by the relatively small sample size, although the sample was focused exclusively on 3-year-old children. Furthermore, the generalizability of the findings could be limited by the fact that all the participating childcare centres and children were located in the same city. It is noteworthy that a large number of children did not achieve the required 8 hours of daily data for at least two weekdays and one weekend day during the winter. This may partly have been due to the effect of the cold weather conditions on the functioning of the accelerometers.

A disadvantage of accelerometers is that they do not provide information on the type or context of PA (Pate et al., 2010). In addition, accelerometers are limited in their ability to measure non-weight-bearing activities, such as swimming, cycling, and skating or upper limb movements, (e.g., digging, carrying and pushing objects). They are not able to account for the increased energy cost associated with walking up stairs, on an incline or on soft surfaces (Oliver et al., 2007; Pate et al., 2010; Trost, 2007). Children playing outdoors in Finland during wintertime often climb up and slide down mounds of snow, pushing or pulling sleds, walking in soft snow, or skating on ice. Also, accelerometers do not detect movements, which are sedentary but need balance and/or concentration in order to develop motor skills or are integral to certain low intensity activities (e.g., singing, drawing and completing puzzles), which are particularly important for young preschool children (Cliff et al., 2009). 
Although previous research has found that triaxial accelerometers generate data with a

higher level of validity than uniaxial accelerometers (Rowlands, 2007), conjecture remains as to whether triaxial accelerometers detect PA better than uniaxial accelerometers in children (Oliver et al., 2007). In this study, we analysed acceleration in the vertical plane, which has been shown to provide the most important assessment of ambulatory movement (Oliver et al., 2007). The choice of cut points significantly influences the amount of PA reported across different intensity levels (Bornstein et al., 2011). Investigators in the field of PA need to resolve the issue of what accelerometer cut points are the most appropriate (Beets et al., 2011; Bornstein et al., 2011) and continue to focus on standardizing methods for the collection, cleaning, analysing and reporting of accelerometer data (De Vries et al., 2009). To date, the majority of validation and calibration studies have reported a strong positive correlation between ActiGraph accelerometer output and intensity of PA in children (Pate et al., 2010; Rowlands, 2007; Trost, 2007). Strong evidence also exists for good reproducibility of the data generated by ActiGraph accelerometers in samples of preschool-aged children (De Vries et al., 2009). Although the strengths and limitations of accelerometers are widely discussed in the literature, accelerometers remain a necessary tool for measuring PA and sedentary behaviour in free-living preschool children (Pate et al., 2010; Trost, 2007; Van Cauwenberghe et al., 2011).

\section{Conclusion}

The present findings have valuable implications for developing interventions that could contribute to improvements in preschool children's PA both in the home and childcare setting. Based on the current results the influence of season and day of the week is minimal. However, consistent with previously reported research, gender is shown to be a critical variable in relation to children's PA levels. Finnish children appear to achieve recommended guidelines regarding PA levels and sedentary behaviour, in a similar distribution to other studies (e.g., 
371 Reilly, 2010; Tucker, 2008). The levels of sedentary behaviour observed in current sample

372 may stimulate early educators and parents to work towards reducing the time children spend

373 in sedentary behaviour and increase time and opportunity for engaging in the recommended

374 levels of PA. This change in practice should particularly target girls. In future research, larger

375 and more heterogeneous samples are required to determine key characteristics of children's

376 PA such as type and context. This could be achieved through combining accelerometer

377 information with other methods, such as direct observation, that describe where and how PA

378 takes place among preschool-aged children.

379 Acknowledgements

380 The authors would like to thank all the children, childcare centre staff and parents for their

381 enthusiastic collaboration that made this research possible. 
383

384

385

386

387

388

389

390

391

392

393

394

395

396

397

398

399

400

401

402

403

404

405

406

407

\section{References}

Australian Government, Department of Health and Ageing. Physical activity recommendations for children 0-5 years. Published 2010. Retrieved August 28, 2012 from http://www.health.gov.au/internet/main/publishing.nsf/content/health-pubhlthstrateg-phys-act-guidelines\#rec 0 5 5.

Baranowski, T., Thompson, W.O., DuRant, R.H., Baranowski, J., \& Puhl. J. (1993). Observations on physical activity in physical locations: age, gender, ethnicity, and month effects. Research Quarterly for Exercise and Sport, 64(2), 127-133.

Beets, M.W., Bornstein, D., Dowda, M., \& Pate, R.R. (2011). Compliance with national guidelines for physical activity in U.S. preschoolers: measurement and interpretation. Pediatrics, 127, 658-664.

Bornstein, D.B., Beets, M.W., Byun, W. \& McIver, K. (2011). Accelerometer-derived physical activity levels of preschoolers: A meta-analysis. Journal of Science and Medicine in Sport, 14, 504-511.

Burdette, H.L., Whitaker, R.C., \& Daniels, S.R. (2004). Parental report of outdoor playtime as a measure of physical activity in preschool-aged children. Archives of Pediatrics \& Adolescent Medicine, 158, 353-357.

Canadian Society for Exercise Physiology. Canadian physical activity guidelines and Canadian sedentary behavior guidelines. Published 2012. Retrieved August 28, 2012 from http://www.csep.ca/CMFiles/Guidelines/CSEP-InfoSheets-early-years-ENG.pdf.

Cardon, G., \& De Bourdeaudhuij, I. (2008). Are preschool children active enough? Objectively measured physical activity levels. Research Quarterly for Exercise and Sport, 79, 326-332.

Carson, V., \& Spence, J.C. (2010). Seasonal variation in physical activity among children and adolescents: a review. Pediatric Exercise Science, 22, 81-92. 
Carson, V., Spence, J.C., Cutumisu, N., Boule, N., \& Edwards, J. (2010). Seasonal variation in physical activity among preschool children in a northern Canadian city. Research Quarterly for Exercise and Sport, 81, 392-399.

Cliff, D.P., Reilly, J.J., \& Okely, A.D. (2009). Methodological considerations in using accelerometers to assess habitual physical activity in children aged 0-5 years. Journal of Science and Medicine in Sport, 12, 557-567.

Climatological Statistics of Finland (1981-2010). Tilastoja Suomen ilmastosta 1981-2010. Finnish Meteorological Institute. Statistical report. Retrieved February 17, 2012 from http://ilmatieteenlaitos.fi/ilmastollinen-vertailukausi-1981-2010

Cole, T. J., Bellizzi, M. C., Flegal, K. M., \& Dietz, W. H. (2000). Establishing a standard definition for child overweight and obesity worldwide: international survey. British Medical Journal, 320, 1240.

De Vries, S.I., Van Hirtum, H.W.J.E.M., Bakker, I., Hopman-Rock, M., Hirasing, R.A., \& Van Mechelen, W. (2009). Validity and reproducibility of motion sensors in youth: A systematic update. Medicine \& Science in Sports \& Exercise, 41, 818-827.

Department of Health. UK physical activity guidelines. Published July 2011. Retrieved August 28, 2012 from http://www.dh.gov.uk/en/Publicationsandstatistics/Publications/PublicationsPolicyAn dGuidance/DH_127931.

Finn, K.J., Johannsen, N., \& Specker, B. (2002). Factors associated with physical activity in preschool children. The Journal of Pediatrics, 140, 81-85.

Fisher, A., Reilly, J.J., Montgomery, C., Kelly, L.A., Williamson, A., Jackson, D.M., ... Grant, S. (2005). Seasonality in physical activity and sedentary behavior in young children. Pediatric Exercise Science, 17, 31-40. 
432

433

434

435

436

437

438

439

440

441

442

443

444

445

446

447

448

449

450

451

452

453

454

455

Hinkley, T., Crawford, D., Salmon, J., Okely, A.D., \& Hesketh, K. (2008). Preschool children and physical activity. American Journal of Preventive Medicine, 34, 435-441.

Institute of Medicine (IOM). Early childhood obesity prevention: policies goals, recommendations, and potential actions. Published June 2011. Retrieved September 4, 2012 from http://www.iom.edu/Reports/2011/Early-Childhood-Obesity-PreventionPolicies/Recommendations.aspx.

Jackson, D.M., Reilly, J.J., Kelly, L.A., Montgomery, C., Grant, S., \& Paton, J.Y. (2003). Objectively measured physical activity in a representative sample of 3- to 4-year-old children. Obesity Research, 11, 420-425.

Moore, L.L., Gao, D., Bradlee, M.L., Cupples, L.A., Sundarajan-Ramamurti, A., Proctor, M.H., ... Ellison, R.C. (2003). Does early physical activity predict body fat change throughout childhood? Preventive Medicine, 37, 10-17.

National Association for Sport and Physical Education (NASPE) (2009). Active Start: A Statement of Physical Activity Guidelines for Children from Birth to Age 5, $2^{\text {nd }}$ edition. American Alliance for Health, Physical Education, Recreation, and Dance.

OECD Family Database 2008. Last updated June 2011. Retrieved June 2, 2012 from http://www.oecd.org/els/social/family/ database.

Oliver, M., Schofield, G.M., \& Kolt, G.S. (2007). Physical activity in preschoolers. Understanding prevalence and measurement issues. Sports Medicine, 37, 1045-1070.

Pate, R.R., McIver, K., Dowda, M., Brown, W.H., \& Addy, C. (2008). Directly observed physical activity levels in preschool children. Journal of School Health, 78(8), 438444.

Pate, R.R, O’Neill J.R., \& Mitchell, J. (2010). Measurement of physical activity in preschool children. Medicine \& Science in Sports \& Exercise, 42, 508-512. 
456

457

458

459

460

461

462

463

464

465

466

467

468

469

470

471

472

473

474

475

476

477

478

479

Pate, R. R., Pfeiffer, K. A., Trost, S. G., Ziegler, P., \& Dowda, M. (2004). Physical activity among children attending preschools. Pediatrics, 114, 1258-1263.

Pellegrini, A.D., \& Smith, P.K. (1998). Physical active play: the nature and function of a neglected aspect of play. Child Development, 69, 577-598.

Poest, C.A., Williams, J.J., Witt, D.D., \& Atwood, M.E. (1989). Physical activity patterns of preschool children. Early Childhood Research Quarterly, 4, 367-376.

Recommendations for Physical Activity in Early Childhood Education (2005). Handbooks of the Ministry of Social Affairs and Health 2005:17.

Reilly, J.J. (2010). Low levels of objectively measured physical activity in preschoolers in child care. Medicine \& Science in Sports \& Exercise, 42, 502-507.

Rowlands, A.V. (2007). Accelerometer assessment of physical activity in children: An Update. Pediatric Exercise Science, 19, 252-266.

Strong, W.B., Malina, R.M., Blimkie, C.R., Daniels, S.R., Dishman, R.K., \& Gutin, B. (2005). Evidence based physical activity for school-age youth. Journal of Pediatrics, $146,732-737$.

Telama, R. (2009). Tracking of physical activity from childhood to adulthood: a review. Obesity Facts. The European Journal of Obesity, 3: 000-000. Published online.

Timmons, B.W., Naylor, P.J., \& Pfeiffer, K.A. (2007). Physical activity for preschool children - how much and how? Applied Physiology, Nutrition and Metabolism, 32, $122-134$.

Tremblay, M.S., LeBlanc, A.G., Kho, M.E., Saunders, T.J., Larouche, R., Colley, R.C., ... Gorber, S.C. (2011). Systematic review of sedentary behavior and health indicators in school-aged children and youth. International Journal of Behavioral Nutrition and Physical Activity, 8. Downloaded 17.11.2011. http://www.ijbnpa.org/content/8/1/98 
480 Trost, S.G. (2007). Measurement of physical activity in children and adolescents. American 481 Journal of Lifestyle Medicine, 1, 299-314.

482 Tucker, P. (2008). The physical activity levels of preschool-aged children: A Systematic Review. Early Childhood Research Quarterly, 23, 547-558.

484 Van Cauwenberghe, E., Labarque, V., Trost, S., De Bourdeaudhuij, I., \& Cardon, G. (2011).

485 Calibration and comparison of accelerometer cut points in preschool children. International Journal of Pediatric Obesity, 6, e582-e589.

487 World Health Organization (2010). Global recommendations on physical activity for health. Geneva. Switzerland. 
Table 1. Demographic information for boys $(n=26)$ and girls $(n=21)$ by

season.

\begin{tabular}{lcccccccc}
\hline & \multicolumn{3}{c}{ Autumn } & \multicolumn{4}{c}{ Winter } \\
& Boys & Girls & \multicolumn{2}{c}{ Boys } & \multicolumn{2}{c}{ Girls } \\
& $M$ & $S D$ & $M$ & $S D$ & $M$ & $S D$ & $M$ & $S D$ \\
\hline Age (years) & 3.3 & 0.3 & 3.3 & 0.3 & 3.6 & 0.3 & 3.7 & 0.3 \\
Height $(\mathrm{cm})$ & 100.0 & 5.4 & 98.4 & 3.3 & 102.5 & 5.5 & 101.2 & 3.4 \\
Weight $(\mathrm{kg})$ & 16.1 & 2.0 & 15.6 & 1.4 & 17.0 & 2.0 & 16.4 & 1.6 \\
BMI $\left(\mathrm{kg} / \mathrm{m}^{2}\right)$ & 16.2 & 0.9 & 16.1 & 1.2 & 16.1 & 0.8 & 16.0 & 1.3 \\
\hline Note. $M=$ mean, $S D=$ standard deviation, $\mathrm{BMI}=$ body mass index \\
\hline
\end{tabular}


Table 2. Gender and seasonal differences in children's weekdays and weekend days' physical activity (PA)

(minutes/day).

\begin{tabular}{|c|c|c|c|c|c|c|c|c|c|c|c|}
\hline \multirow{3}{*}{$\begin{array}{l}\text { Physical activity } \\
\text { intensity }\end{array}$} & \multicolumn{3}{|c|}{ Total } & \multicolumn{8}{|c|}{ Season } \\
\hline & \multirow{2}{*}{$\begin{array}{c}\text { Boys } \\
(\mathrm{n}=26) \\
M S D\end{array}$} & \multirow{2}{*}{\multicolumn{2}{|c|}{$\begin{array}{c}\text { Girls } \\
(\mathrm{n}=21) \\
M S D\end{array}$}} & \multirow[t]{2}{*}{$p$} & \multirow[t]{2}{*}{$d^{*}$} & \multirow{2}{*}{\multicolumn{2}{|c|}{$\begin{array}{l}\text { Autumn } \\
(\mathrm{n}=47) \\
M S D\end{array}$}} & \multirow{2}{*}{\multicolumn{2}{|c|}{$\begin{array}{c}\text { Winter } \\
(\mathrm{n}=47) \\
M S D\end{array}$}} & \multirow[t]{2}{*}{$p$} & \multirow[t]{2}{*}{$d^{*}$} \\
\hline & & & & & & & & & & & \\
\hline \multicolumn{12}{|l|}{ Sedentary time } \\
\hline Weekdays & $585 \quad 51$ & 608 & 54 & .047 & 0.44 & 595 & 48 & 596 & 58 & .861 & 0.02 \\
\hline Weekend days & $576 \quad 71$ & 589 & 73 & .310 & 0.18 & 594 & 58 & 570 & 82 & .087 & 0.34 \\
\hline \multicolumn{12}{|l|}{ Light PA } \\
\hline Weekdays & 438 & 37 & 6 & .001 & 0.85 & 41 & 7 & 39 & 8 & .021 & 0.27 \\
\hline Weekend days & $41 \quad 12$ & 36 & 9 & .030 & 0.47 & 39 & 10 & 38 & 11 & .378 & 0.10 \\
\hline \multicolumn{12}{|l|}{ Moderate PA } \\
\hline Weekdays & 348 & 29 & 6 & .001 & 0.71 & 32 & 7 & 31 & 8 & .668 & 0.13 \\
\hline Weekend days & $33 \quad 12$ & 28 & 8 & .028 & 0.50 & 30 & 10 & 31 & 11 & .866 & 0.10 \\
\hline \multicolumn{12}{|l|}{ Vigorous PA } \\
\hline Weekdays & $32 \quad 12$ & 27 & 9 & .021 & 0.48 & 31 & 12 & 29 & 11 & .331 & 0.17 \\
\hline Weekend days & 3316 & 26 & 12 & .036 & 0.50 & 29 & 14 & 30 & 16 & .767 & 0.07 \\
\hline \multicolumn{12}{|l|}{ LMVPA } \\
\hline Weekdays & 10926 & 92 & 18 & .001 & 0.77 & 104 & 24 & 100 & 24 & .204 & 0.17 \\
\hline Weekend days & $106 \quad 37$ & 90 & 27 & .021 & 0.50 & 99 & 32 & 99 & 36 & .970 & 0.00 \\
\hline \multicolumn{12}{|l|}{ MVPA } \\
\hline Weekdays & $67 \quad 19$ & 55 & 14 & .005 & 0.73 & 62 & 18 & 61 & 18 & .328 & 0.06 \\
\hline Weekend days & $65 \quad 27$ & 54 & 19 & .029 & 0.48 & 60 & 23 & 61 & 26 & .707 & 0.04 \\
\hline
\end{tabular}


Table 3. Time (minutes/day) spent in different intensities of physical activity (PA) during weekdays and weekend days for each seasons in boys and girls.

\begin{tabular}{|c|c|c|c|c|c|c|c|c|c|c|c|c|c|c|}
\hline \multirow{3}{*}{$\begin{array}{l}\text { Physical activity } \\
\text { intensity }\end{array}$} & \multicolumn{7}{|c|}{ Autumn } & \multicolumn{7}{|c|}{ Winter } \\
\hline & \multicolumn{2}{|c|}{$\begin{array}{c}\text { Boys } \\
(n=26)\end{array}$} & \multicolumn{2}{|c|}{$\begin{array}{c}\text { Girls } \\
(\mathrm{n}=21)\end{array}$} & \multirow[t]{2}{*}{$t$} & \multirow[t]{2}{*}{$p$} & \multirow[t]{2}{*}{$d^{*}$} & \multicolumn{2}{|c|}{$\begin{array}{c}\text { Boys } \\
(\mathrm{n}=26)\end{array}$} & \multicolumn{2}{|c|}{$\begin{array}{c}\text { Girls } \\
(\mathrm{n}=21)\end{array}$} & \multirow[t]{2}{*}{$t$} & \multirow[t]{2}{*}{$p$} & \multirow[t]{2}{*}{$d^{*}$} \\
\hline & $M$ & $S D$ & $M$ & $S D$ & & & & $M$ & $S D$ & $M$ & $S D$ & & & \\
\hline \multicolumn{15}{|l|}{ Sedentary time } \\
\hline Weekdays & 587 & 48 & 604 & 48 & 1.22 & .230 & 0.35 & 584 & 54 & 612 & 60 & 1.69 & .097 & 0.49 \\
\hline Weekend days & 594 & 56 & 594 & 62 & 0.01 & .992 & 0.00 & 557 & 80 & 585 & 83 & 1.16 & .252 & 0.34 \\
\hline \multicolumn{15}{|l|}{ Light PA } \\
\hline Weekdays & 44 & 8 & 39 & 6 & 2.36 & .023 & 0.71 & 42 & 8 & 36 & 5 & 2.88 & .006 & 0.92 \\
\hline Weekend days & 41 & 11 & 37 & 8 & 1.66 & .105 & 0.42 & 40 & 12 & 36 & 10 & 1.14 & .260 & 0.36 \\
\hline \multicolumn{15}{|l|}{ Moderate PA } \\
\hline Weekdays & 34 & 7 & 30 & 6 & 2.00 & .052 & 0.62 & 35 & 9 & 27 & 5 & 3.46 & .001 & 1.14 \\
\hline Weekend days & 33 & 11 & 28 & 7 & 1.91 & .063 & 0.56 & 33 & 13 & 28 & 9 & 1.54 & .131 & 0.46 \\
\hline \multicolumn{15}{|l|}{ Vigorous PA } \\
\hline Weekdays & 33 & 13 & 28 & 10 & 1.53 & .133 & 0.44 & 32 & 12 & 26 & 8 & 2.14 & .038 & 0.60 \\
\hline Weekend days & 32 & 15 & 25 & 11 & 1.74 & .088 & 0.54 & 33 & 17 & 27 & 14 & 1.32 & .192 & 0.39 \\
\hline \multicolumn{15}{|l|}{ LMVPA } \\
\hline Weekdays & 110 & 25 & 96 & 20 & 2.11 & .041 & 0.62 & 108 & 27 & 89 & 15 & 3.09 & .004 & 0.91 \\
\hline Weekend days & 106 & 36 & 89 & 23 & 1.94 & .059 & 0.58 & 106 & 40 & 91 & 30 & 1.43 & .160 & 0.43 \\
\hline \multicolumn{15}{|l|}{ MVPA } \\
\hline Weekdays & 66 & 19 & 57 & 16 & 1.80 & .079 & 0.51 & 67 & 20 & 53 & 11 & 2.84 & .007 & 0.90 \\
\hline Weekend days & 65 & 26 & 53 & 17 & 1.93 & .060 & 0.56 & 66 & 29 & 55 & 22 & 1.46 & .152 & 0.43 \\
\hline Note. ${ }^{*}$ Effect size & ohen & & & & & & & & & & & & & \\
\hline
\end{tabular}


DIRECTLY OBSERVED PHYSICAL ACTIVITY AMONG 3-YEAROLDS IN FINNISH CHILDCARE

\author{
by \\ Soini, A., Villberg, J., Sääkslahti, A., Gubbels, J., Mehtälä, A., Kettunen, T., \& Poski- \\ parta, M. (2014). \\ International Journal of Early Childhood, 46(2), 253-269. doi: 10.1007/s13158-014-0111-z
}

Reproduced with kind permission by Springer. 
Running Head: 3-YEAR-OLDS’ PHYSICAL ACTIVITY IN CHILDCARE

Directly Observed Physical Activity among 3-Year-Olds in Finnish Childcare 


\title{
3-YEAR-OLDS' PHYSICAL ACTIVITY IN CHILDCARE
}

\begin{abstract}
The main purpose of the study was to determine 3-year-olds' physical activity levels and how these vary across season, gender, time of day, location, and the physical and social environment in childcare settings in Finland. A modified version of the Observational System for Recording Physical Activity in Children-Preschool (OSRAC-P) was used to measure physical activity levels and contextual variables (e.g., group composition, prompts) of children attending childcare centres. In total, 81 children (42 boys and 39 girls) were observed in autumn and in winter. Three-level linear regression analyses were used to assess differences between the seasons in the association between the context variables and physical activity. During the observations, the present sample of children was mostly sedentary in nature, engaging in moderate to vigorous physical activity in only $2 \%$ of all observations. The results further showed a significant difference between season and the children's physical activity levels: in winter, the children spent significantly more time in sedentary-level activities and less time in moderate to vigorous physical activity than in autumn. The present sample of children was physically more active outdoors than indoors. Boys showed significantly higher physical activity levels than girls. The majority of the observations did not include any oral prompting. We conclude that childcare centres offer good opportunities to increase children's physical activity. Interventions should focus on enhancing children's outdoor time, free play, and positive prompting and encouragement by teachers.
\end{abstract}

\section{Keywords}

childcare; direct observation; physical activity; preschool children

\section{Résumé}

L'objectif principal de l'étude était de déterminer les niveaux d'activité physique chez les enfants de trois ans, et la façon dont ils varient selon la saison, le sexe, le moment de la journée, le lieu et l'environnement physique et social dans les garderies en Finlande. Une version modifiée de l'Observational System for Recording Physical Activity in ChildrenPreschool (OSRAC-P) a été utilisée pour mesurer les niveaux d'activité physique et les variables contextuelles (notamment, la composition du groupe, les incitations) des enfants fréquentant les garderies. Au total, 81 enfants (42 garçons et 39 filles) ont été observés en automne et en hiver. Des analyses de régression linéaire à trois niveaux ont servi à évaluer les différences entre les saisons en lien avec les variables contextuelles et activité physique. Au cours des observations, l'échantillon d'enfants était principalement de nature sédentaire avec une activité physique d'intensité modérée à élevée dans seulement $2 \%$ de toutes les observations. Les résultats ont aussi révélé une différence 


\section{3-YEAR-OLDS' PHYSICAL ACTIVITY IN CHILDCARE}

significative entre la saison et les niveaux d'activité physique, en hiver les enfants passant sensiblement plus de temps dans des activités de niveau sédentaire et moins de temps dans des activités d'intensité modérée à élevée qu'en automne. L'échantillon d'enfants était physiquement plus actif à l'extérieur qu'à l'intérieur. Les garçons avaient des niveaux d'activité nettement plus élevés que les filles. La majorité des observations ne présentait aucune incitation verbale. Nous en concluons que les garderies offrent de bonnes possibilités pour augmenter l'activité physique des enfants. Les interventions devraient se concentrer sur l'augmentation du temps passé à l'extérieur, le jeu libre ainsi que l'incitation positive et l'encouragement des éducateurs.

\section{Resumen}

El objetivo principal del estudio fue determinar los niveles de actividad física (AF) y cómo estos varían en relación a la estación, al género, el momento del día y al ambiente físico y social de un centro de cuidado en Finlandia. Durante el día en la guardería, los niveles de actividad física y las variables contextuales (como la composición del grupo o incentivo) fueron determinados con un método de observación modificado de OSRAC-P (Observational System for Recording Physical Activity in Children - Preschool Version). En total 81 niños (42 niños, 39 niñas) participaron en las observaciones durante otoño e invierno. Análisis lineales de regresiones de tres niveles fueron utilizados para evaluar las diferencias entre las estaciones climáticas en relación con los contextos variables elegidos y la actividad física. Durante las observaciones, la muestra de niños fue, en su mayoría, naturalmente sedentaria, siendo semi-activa en solo un $2 \%$ de todas las observaciones. Los resultados mostraron una diferencia significante entre estaciones climáticas y los niveles de actividad física de los niños: en invierno los niños pasaban la mayor parte del tiempo en actividades físicas de nivel sedentario y menos tiempo en actividades semi-activas que durante el otoño. Los niños y niñas que participaron en la investigación fueron físicamente más activos fuera que dentro de la guardería. La actividad física de los niños fue de nivel más alto que el la de las niñas. La mayoría de las observaciones no incluyeron un incentivo verbal. En base a los resultados podemos concluir que las guarderías ofrecen buenas oportunidades para aumentar la actividad física de los niños. Las intervenciones tendrían que centrarse en el aumento de actividades al aire libre, de juego espontáneo y de consejos positivos e incentivo por parte de los/las educadores/as preescolares. 


\section{3-YEAR-OLDS' PHYSICAL ACTIVITY IN CHILDCARE}

Behavioural habits, such as physical activity and sedentary behaviours, are formed in early childhood (Janz et al. 2005; Timmons et al. 2007; Ward et al. 2010). Physical activity in preschool children (age 3-5 years) may be described as "play", and occurs at various levels of intensity (Timmons et al. 2007). Play, like learning, is a natural component of a child's everyday life and assists the child to make sense of his or her world (Pramling Samuelsson \& Asplund Carlsson 2008). Further, physical activity has been found to have a positive effect on children's physical, cognitive, emotional and social development (Timmons et al. 2007, Ward 2010). An active lifestyle in childhood serves as the foundation for an active lifestyle later in life (Janz et al. 2005; Singh et al. 2008). Therefore, the enhancement of physical activity and reduction in sedentary behaviour in early childhood are important from a public health perspective (Strong et al. 2005; Tremblay et al. 2011).

Various studies have shown that the childcare centres children attend influence their levels of physical activity (Bower et al. 2008; Finn et al. 2002; Pate et al. 2004; Pate et al. 2008; Ward 2010). Typically, very low physical activity levels and very high sedentary level activity have been reported among preschool children during attendance at childcare settings (Brown et al. 2009; Gubbels et al. 2011; Oliver et al. 2007; Pate et al. 2008; Reilly 2010). Features of the physical environment of the childcare setting, such as the ground surface, playground markings, open space, and the availability of play equipment, have previously been linked to higher levels of physical activity (Bower et al. 2008; Cardon et al. 2008; Cosco et al. 2010; Hannon \& Brown 2008; Gubbels et al. 2012; Nicaise et al. 2011; Ridgers et al. 2007). Children have been shown to be more active when they spend more time outdoors (Boldeman et al. 2006; Finn et al. 2002; Hinkley, Crawford et al. 2008; Pate et al. 2004) and when recess is shorter in duration (Cardon et al. 2008; Dowda et al. 2004). Furthermore, children's physical activity has been observed to increase in warm seasons and decrease in colder seasons (Carson \& Spence 2010; Fisher et al. 2005; Poest et al. 1989). Factors related to the social environment, such as positive prompts by teachers or peers, have also been associated with increased physical activity (Brown et al. 2009; Gubbels et al. 2011). Despite this positive association, Brown et al. (2009) reported that teachers and peers rarely prompt children to raise their level of physical activity. Finally, child-initiated instead of teacherinitiated play (Brown et al., 2009), smaller group size (Brown et al. 2009; Cardon et al. 2008) and higher educational level of teachers (Dowda et al. 2004) have been linked to increased levels of children's physical activity.

Although studies assessing physical activity and sedentary behaviour in preschool children have increased over the past decade (Bornstein et al. 2011), observational research yielding contextual information to promote physical activity is still lacking, especially in Europe (Bower et al. 2008; Brown et al. 2009; Gubbels et al. 2011). Additionally, only a small set of studies exists where preschool children's physical activity levels have been determined during different seasons (Carson \& Spence 2010). An improved understanding of the determinants of physical activity in the 


\section{3-YEAR-OLDS' PHYSICAL ACTIVITY IN CHILDCARE}

childcare setting could support the development of interventions aimed at promoting physical activity levels of younger preschool children throughout the year. Therefore, the purpose of this study was to examine Finnish 3-year-olds' physical activity levels and sedentary behaviour during attendance at childcare, and their seasonal variation, related demographic and biological characteristics, and physical and social contexts.

\section{Methods}

Sample and data collection

Participants were recruited in a city in central Finland. Principals of childcare centres were provided with information regarding the study at a regional administrative meeting. A total of 14 childcare centres volunteered their involvement in the study. The childcare centres were situated in different environmental and socioeconomic neighbourhoods in the city. All the families of the 3-year-old children (year of birth 2007) attending the participating childcare centres were invited to join the study. The parents of $102(57 \%)$ of the 179 families provided informed consent.

The children's physical activity data were collected in two phases using a repeated-measure design. The first data collection phase was between August and October 2010 (autumn), and the second between January and February 2011 (winter). A total of 96 children (48 boys and 48 girls) participated in the autumn data collection and 94 children ( 50 boys and 44 girls) in the corresponding winter collection. Data from both collection phases were gathered for 81 children (42 boys and 39 girls).

\section{Instruments}

A modified version of the Observational System for Recording Physical Activity in Children-Preschool Version (OSRAC-P; Brown et al. 2006) was used to measure children's physical activity intensity, type of activity, location, contexts, prompts and interactions. Two trained researchers observed the children's physical activity and contextual factors using a procedure in which 15 seconds of observation were followed by 30 seconds of recorded observation. The observation sheets were completed manually and the procedure was repeated eight times over six minutes for each child. Each child was observed at least twice per day, in the morning (between 8 a.m. and 12 p.m.) and in the afternoon (between 2 p.m. and 5 p.m.), including indoor and outdoor observations, during three consecutive days (from Wednesday to Friday). Children were randomly selected for observation and were not observed during the scheduled meal or rest times. The data collection was conducted without disturbing the daily routines of the childcare centres and without undue influence on the children or teachers.

Children's physical activity intensity levels were measured on a five-point scale $(1=$ stationary or motionless, $2=$ stationary with limb or trunk movements, $3=$ slow or easy movements, $4=$ moderate movements, and $5=$ fast 


\section{3-YEAR-OLDS' PHYSICAL ACTIVITY IN CHILDCARE}

movements) and reflected the highest intensity level reached by the child during each 15 -second observation interval. For the purpose of this study and further comparison, activity levels 1-2 were regarded as sedentary level activity, activity level 3 as light physical activity and levels 4-5 as moderate to vigorous physical activity (Bower et al. 2008; Brown et al. 2009; Gubbels et al. 2011; Nicaise et al. 2011; Pate et al. 2008).

OSRAC-P scales assessing contextual variables such as time of day and primary location were used. In addition, the following social OSRAC-P scales were assessed: group composition, initiator of activity and prompts. In the present study, Brown and colleagues' (2006) original 18 activity-type codes (e.g., sitting, standing, running) were complemented with four typical Finnish types of activity (i.e., balancing, sliding, skiing, ice-skating) and used as descriptive categories. Finally, the indoor contexts were complemented with i.e., toys (e.g., playing with cars, dolls), household chores (e.g., baking, cleaning), rage (crying scene), pool activities and small-group variables, and the outdoor contexts with i.e., rage, forest, sport field and transition variables.

\section{Background information}

Weather conditions and outdoor temperatures were recorded per observation day. Body weight and height of the children were measured between the two observation phases at the time of the physical activity data collection, and body mass index (BMI: $\mathrm{kg} / \mathrm{m}^{2}$ ) was calculated for each child. The BMI results indicated, in accordance with the International Obesity Task Force BMI definition, that nine children (12\%) during the autumn assessments and six children (8\%) during the winter assessments were overweight. All the other children were in the normal BMI range (Cole et al. 2000). Background information on children's attendance times was recorded in diaries kept by the children's parents. Outdoor times were recorded by the researchers during the observation days. In general, Finnish childcare centre hours are from 6.30 a.m. to 5 p.m. Meal (i.e., breakfast at 8 a.m., lunch 11.30 a.m. and snacks at 2 p.m.) and rest times give a rhythm to the childcare centre's daily schedule. Typically, a childcare day includes two outdoor recess periods, one in the morning and one in the afternoon. The ethics committee of the local university, and the city's social affairs and health officer approved the study.

\section{Statistical analyses}

The observers' scores for the dichotomous variables (e.g., prompt by teacher, yes/no) were combined by coding the variable as present (1) when one or both observers rated that variable as present, and coding it as absent (0) when both rated it as absent. For continuous variables (e.g., activity intensity), the mean of the scores of both observers was calculated. Cohen's kappa was used to determine the inter-rater reliability (IRR) of the two observers during the observations of the OSRAC-P variables (i.e., activity intensity, activity types, group composition, contexts, initiator of activity, prompts). Mean IRR of the variables assessed was $.70(\mathrm{SD}=0.2 ; \mathrm{p}<.001)$. 


\section{3-YEAR-OLDS' PHYSICAL ACTIVITY IN CHILDCARE}

Various background characteristics were explored using descriptive statistics. General Linear Models (GLM) for repeated measures (MANOVA) were used to analyse differences between autumn and winter. Differences in the observed contextual variables between observations and seasons were examined using Chi-square tests. The association between the mean level of physical activity intensity as the dependent variable and independent variables such as, gender (girl vs. boy), BMI (linear), primary location (outdoor vs. indoor), time of day (afternoon vs. morning), group composition (solitary vs. non-solitary), initiator of activity (adult vs. child), prompts (no prompts vs. negative or positive prompts), temperature (linear) and weather condition (rain vs. sunny, with clear sky or cloudy but dry), was examined using three-level linear regression. All analyses were performed using SPSS 18.0 and STATA 12 . In all analyses, $P$-values $<.05$ were considered statistically significant.

\section{Results}

\section{Childcare and outdoor times, temperature and weather conditions}

During the data collection periods, the participants attended their childcare settings for approximately 7.7 hours/day in the autumn and $7.5 \mathrm{~h}$ /day in the winter. A total of 1978 observations and 15824 single observation intervals (1 978 x 8 times) were analysed; 966 observations (an average $5.96(S D=2.49)$ observations/child) were observed in the autumn and 1012 observations (an average $6.25(S D=2.96)$ observations/child) in the winter. The results indicated a significant difference between autumn and winter in mean outdoor time during childcare attendance (minutes per day 179 vs. 120 , respectively; $p=.002$ ). The mean outdoor temperature was $11.6^{\circ} \mathrm{C}$ during the autumn observations (range: $-2^{\circ} \mathrm{C}$ to $20^{\circ} \mathrm{C}$ ) and $-9.9^{\circ} \mathrm{C}$ during the winter observations (range: $-30^{\circ} \mathrm{C}$ to $2^{\circ} \mathrm{C}$ ). The differences between the autumn and winter mean temperatures were significant $(p<.001)$. Most of the time, the weather was cloudy but dry (49\% autumn; $51 \%$ winter) or sunny with a clear sky ( $27 \%$ autumn; $36 \%$ winter); the least prevalent weather type was precipitation of rain (23\% autumn) or snow (13\% winter). The differences between the seasons in the percentages of intervals observed in the different temperature categories and weather conditions, and in engagement in sedentary level activity, light physical activity and moderate to vigorous physical activity associated with these categories, are described in Table 1.

\section{Prevalence of contextual variables and physical activity levels}

During the observations, the children's physical activity levels were mostly sedentary: 69\% (indoors $86 \%$; outdoors $46 \%$ ) of total intervals were recorded as sedentary, and only $2 \%$ (indoors $1 \%$; outdoors $2 \%$ ) as moderate to vigorous physical activity. The initiators of activities were most frequently children (77\%), and the children's play was most frequently non-solitary (74\%). Teachers or peers rarely prompted children to increase or decrease their physical activity: no prompts were recorded in $92 \%$ of all observations. In prevalence $(\%)$ of observations, significant seasonal 


\section{3-YEAR-OLDS' PHYSICAL ACTIVITY IN CHILDCARE}

differences were found in all the variables, except gender and time of day (see Table 1).

In winter, the children engaged in moderate to vigorous physical activity outdoors significantly less in than in autumn. Seasonal variations were observed in boys' but not in girls' physical activity levels. The percentages of physical activity in the categories sedentary, light and moderate to vigorous physical activity observed during autumn and winter are shown in Table 1.

Activity types, indoor and outdoor contexts and physical activity levels

In both seasons, the three most frequently observed physical activity types were: 1) sitting/squatting/kneeling, 2) walking/marching and 3) standing. In the autumn, the most frequently observed indoor activity variables were 1) toys (25\%) 2) other (25\%; e.g., being in some other indoor context or engaging in some activity other than the option listed, and 3) sociodramatic (8\%), whereas in the winter these were 1) toys (36\%), 2) other (26\%), 3) art (9\%) and transition ( $9 \%$; both lining up or moving from one activity context to another area). When examined more closely for seasonal variations, several differences in the activity variables were found; in the autumn, the children were engaged significantly more frequently in the variables large blocks $(p=.007)$, manipulative $(p=.017)$, music $(p=.035)$, snacks $(p<.001)$ and self-care $(p=.013)$ than in the winter, during which the children more often played with toys $(p<.001)$ and engaged in art activities $(p=.009)$ than in the autumn. The three most frequently observed outdoor context variables were 1) open space (30\%), 2) sandbox (20\%) and 3) fixed equipment (16\%) in the autumn, and 1) open space $(26 \%), 2)$ portable equipment $(14 \%)$, and 3$)$ fixed equipment $(13 \%)$ in the winter. In the autumn, the children more frequently played in an open outdoor area $(p=.016)$, touched, ride or pushed wheeled toys $(p<.001)$, used sandbox materials or played in the sandbox $(p<.001)$, played using sociodramatic props $(p=.003)$, and engaged in other activities $(p<.001)$ than in the winter. Finally, during the winter, the children more often made use of portable equipment (other than balls or wheeled toys) brought into the playground $(p<.001)$ than in the autumn. The most common activity types, physical and social environments at the different levels of physical activity are shown in Table 2.

Associations between observed contexts and physical activity in autumn and in winter

Gender was significantly associated with children's activity levels in both seasons. Boys showed significantly higher mean physical activity intensity levels than girls (activity intensity 2.42 vs. 2.24 , respectively $p<.001$ ). When controlled for other variables (i.e., gender, location, time of day, group composition, initiator of activity, prompts and weather conditions), BMI was not associated with children's activity levels. An outdoor location associated positively with children's activity levels in both seasons $(p<.001)$. In the autumn, children were less active in the afternoon compared to morning, while in the winter, the children's physical activity levels were unaffected by time of day. 


\section{3-YEAR-OLDS' PHYSICAL ACTIVITY IN CHILDCARE}

Similarly, child-initiated play was positively associated with physical activity in the autumn but not in the winter. Solitary play had a stronger association with the higher activity levels in the autumn, although the influence was significant in both seasons. All prompts (both positive and negative) were associated with an increase in physical activity in both seasons in comparison to observations where no prompts were observed. Finally, temperature associated with children's physical activity levels in the winter but not autumn, whereas rain had no influence on physical activity during either season. (See Table 3.)

\section{Discussion}

\section{Physical activity levels in childcare}

In line with earlier studies (Brown et al. 2009; Pate et al. 2008), the present study found that, for most of the childcare day, the children's physical activity levels and their activity types were sedentary in nature, with moderate to vigorous physical activity accounting for only $2 \%$ of all observations. The results further showed that, in the winter, the children spent significantly more time in sedentary-level activities than in the autumn. The seasonal variation in physical activity levels was more pronounced during the outdoor observations than indoor observations. The association on physical activity levels of the significant interaction between time of day and season showed that in the autumn the present sample of children were more physically active in the morning than afternoon, while in the winter their physical activity levels were unaffected by time of day.

\section{Indoor environment}

The most common activity types - sitting, standing, walking - and the indoor context were primarily sedentary in nature: $86 \%$ of indoor activities were observed as sedentary. This level of sedentariness is similar to that reported by Brown et al. (2009), and considerably more than found by Gubbels et al. (2011) in their Dutch study. Children were sedentary when engaged in art or in large group activities organized or led by a teacher. Although several activity types and contexts were associated with higher physical activity levels, children were rarely observed indoors in activities such as running, climbing, pulling or pushing. One potential explanation relate to the childcare facilities and behavioural rules. For safety reasons, running or climbing indoors is likely to be prohibited, while indoor spaces are often small rooms with narrow corridors. Nevertheless, a place in hallways and corridors for children's play and physical activities is commonly found. To enable children to move around freely and engage in physically active play indoors, childcare centres need to optimize their indoor space specifically for these purposes (Gubbels et al. 2012). Although Finnish childcare centres mostly have a large room or hall with gross motor equipment for physical activity and play, children, in groups, typically use them only once a week, during a structured physical education lesson, as laid down in the recommendations for physical activity in early childhood education (2005). Moreover, in its current format, 


\section{3-YEAR-OLDS' PHYSICAL ACTIVITY IN CHILDCARE}

physical education plays a very small role in meeting the physical activity requirements of pre-schoolers (Van Cauwenberghe et al. 2012).

\section{Outdoor environment}

In line with previous studies (Boldeman et al. 2006; Brown et al. 2009; Hinkley et al. 2008; Pate et al. 2004), the present sample of children was physically more active outdoors than indoors. Outdoor locations had a strong positive association with higher physical activity levels in both seasons. However, even during outdoor play, nearly half of the children's activities were recorded as sedentary, and only $2 \%$ as moderate to vigorous physical activity, which is much lower than the $17 \%$ found by Brown et al. (2009), $21 \%$ by Gubbels et al. (2011), and $12 \%$ and $21 \%$ by Nicaise et al. (2011). Outdoor engagement at the sedentary level included children playing in a sandbox and/or playing with sandbox materials and activities with sociodramatic play props. Touching, riding, or pushing wheeled toys such as tricycles, scooters and wagons showed higher levels of physical activity. However, wheeled toys were used less frequently than fixed equipment such as the sandbox. This might be explained by the fact that the sandbox is available at all times, while scooters and wagons are held in storage. Children have to fetch these items and return them after use. Gubbels et al. (2012) showed that children were significantly more active when jumping equipment was continuously present, and when a fixed track was marked on the playground. Similarly, Nicaise et al. (2011) concluded that activitygenic portable equipment and riding vehicles appeared to foster moderate to vigorous physical activity. A playground redesign, which utilizes multicolour playground markings and physical structures, may be a suitable stimulus for increasing children's recess physical activity levels (Ridgers et al. 2007). Scheduling recesses to minimize the number of children sharing playground or play equipment (Cardon et al. 2008), and minimize the time spent in sedentary locations, such as the sandbox (Cosco et al. 2010), may also help to increase children's engagement in moderate to vigorous physical activity (Nicaise et al. 2011). In this study, in the autumn, the use of wheeled toys was more pronounced than in winter. In winter, snow, ice and cold weather do not present the same possibilities for their as in autumn. In the winter, children were more involved with portable equipment such as sleds. Finnish childcare centres have the possibility to utilize the natural environment, such as the forest, in their daily programme. During wintertime, children often play with snow or mounds of snow, and push and pull sleds. Furthermore, it is not rare to encounter young Finnish children in childcare skating or skiing. However, at the age of three, skiing and skating involve lower levels of physical activity, such as balancing and learning to slide, than vigorous physical activity.

\section{Weather conditions}

In the present study, the differences between the autumn and winter mean temperatures were significant. Temperature was significantly associated with children physical activity in winter, but not in autumn. Baranowski and 


\section{3-YEAR-OLDS' PHYSICAL ACTIVITY IN CHILDCARE}

colleagues (1993) reported that differences in children's physical activity levels were related more to time spent outdoors than to season or weather conditions. In this study, significant seasonal variations in mean temperatures could explain why the average outdoor time during childcare attendance in winter (116 min) was significantly less than in autumn (178 $\mathrm{min})$. In cold weather, $-20^{\circ} \mathrm{C}$ or colder, children generally are not directed to play outdoors, or outdoor recesses are much shorter on such days. Shorter outdoor activity times in winter may also explain children's lower engagement in moderate to vigorous physical activity. However, in the autumn, engagement in sedentary levelactivities outdoors was higher than in the winter. Although temperature was associated with physical activity, no association emerged between rain and children's physical activity levels.

\section{Social contexts}

The majority of the observations did not include any oral prompting. In line with previous observational studies (Brown et al. 2009; Gubbels et al. 2011), prompts (both negative and positive) positively associated with children's physical activity intensity in both seasons. Moreover, our results, like those of Brown et al. (2009), showed that even if teachers were present, they very rarely, if ever, implemented teacher-arranged activities and games to enhance children's physical activity or encouraged children to engage in physical activity. Teachers may assume that children are naturally very active and that they engage in sufficient activity, and therefore lay less emphasis on the importance for children of an active lifestyle (Pate et al. 2008). In general, children tended to be less physically active when more staff members were present or were involved in children's play (Brown et al. 2009; Cardon et al. 2008; Gubbels et al. 2011). Similarly, in this study, adult-initiated play had a negative association with the children's physical activity behaviour in the autumn, although not in the winter. In the winter, the children showed significantly more sedentary level activity and engaged less frequently in moderate to vigorous physical activity during child-initiated activities, whereas adult-initiated play showed no seasonal variation in physical activity levels. Furthermore, in both seasons, children's solitary play was associated with increased physical activity levels, as also noted by Brown et al. (2009) and Nicaise et al. (2011). In contrast, in a Dutch study, non-solitary play was associated with higher activity levels (Gubbels et al. 2011).

\section{Gender variations}

This study indicated a significant gender difference in physical activity levels, with boys showing significantly higher levels than girls. In line with the present findings, boys have generally been reported to be more active than girls (Hinkley et al. 2008; Oliver et al. 2007; Pate et al. 2004, 2008). Currently, there is no definitive explanation why girls participate less in physical activity than boys (Pate et al. 2004). Observational studies have demonstrated that boys are more interested in playing rougher games, engage in more risk-taking behaviour and play in larger groups and in more 


\section{3-YEAR-OLDS' PHYSICAL ACTIVITY IN CHILDCARE}

open settings than girls (Pate et al. 2004). Also boys' activities may be more triggered by harder ground surfaces, which are mainly used for sports-related, competitive activities (Cardon et al. 2008). One potential explanation may found in teachers' attitudes, which may affect children's physical activity behaviour. It is possible that boys are regularly encouraged to engage in more physically active play and games, whereas girls are exposed to stationary activities and expected to behave in a calmer manner (Pellegrini \& Smith 1998). Sandberg \& Pramling Samuelsson (2005) found that despite emphasising the importance of creating inspiring environments for play and outdoor play, preschool teachers' participation in play differed by gender. For instance, male teachers had more play willingness and participated more in physically active play, whereas female teachers tended to prioritise calm play, which, for the most part, they also experienced in their own childhood (Sandberg \& Pramling Samuelsson 2005). Cardon et al. (2008) also found that girls preferred to stay close to their supervising teachers, who commonly supervise sitting down or standing still, and that this might be one cause of the lower levels of physical activity in girls. It remains unclear whether the gender difference in physical activity is biologically based or environmentally determined, or a combination of both (Timmons et al. 2007).

Strengths and limitations

The assessment of young children's physical activity is challenging, primarily because their behaviour is spontaneous, intermittent and sporadic. The benefit of the observation format used in the present study was that it recorded not only the intensity of activity, but also where, how and in what kind of interaction the activity was being performed. Moreover, the OSRAC-P has been shown to be a valid and reliable tool for measuring physical activity among preschool-aged children (Brown et al. 2006; Pate et al. 2010; Trost 2007). A major strength of this study was the use of a repeated-measure design, where the same 3-year-old children were measured using direct observation during two distinct seasons. However, one should be cautions when comparing physical activity levels over short time periods

(e.g., 3-6 months), as children's normal growth and maturation may influence their physical abilities and motor skills in relation to their engagement in physically active play (Fisher et al. 2005). It should also be noted that the direct observations subjective, although, the inter-rater reliabilities indicated substantial agreement and a validated observation protocol was deployed (Brown et al. 2006). Furthermore, the generalizability of the findings could be limited by the fact that all the participating childcare centres and children were located in the same city. Finally, the children's behaviour could have been influenced by other factors that were not taken into account in this study. For instance, fundamental motor skills (Stodden et al. 2008) and the educational level of teachers (Dowda et al. 2004) have been found to have an influence on children's physical activity behaviour, but these were not taken into account in this study. Therefore, the 


\section{3-YEAR-OLDS' PHYSICAL ACTIVITY IN CHILDCARE}

interaction between motor skills and/or educational levels of teachers and children's physical activity behaviour in different contexts merits further examination.

\section{Conclusion}

The present findings have important implications for the development of physical activity interventions aimed at increasing preschool children's physical activity behaviour in the childcare centre setting. Our findings yield comprehensive behavioural and contextual information on a sample of 3-year-old preschool children. A notable proportion of the activities observed as sedentary in the sample may encourage teachers to work towards reducing the time children spend in sedentary level and increasing time and opportunity for engaging in the higher levels of physical activity. Childcare centres offer good opportunities to increase children's physical activity and also support their learning. Childcare organizations in collaboration with families can use the findings of this study as a basis on which to promote children's physical activity. Interventions should focus on enhancing children's outdoor time, free play and positive prompting and encouragement by teachers. To enhance children's all-year-round physical activity, such changes should, in particular, target wintertime, given its consistently lower activity levels.

\section{Conflict of interest}

The Authors state that they have no conflicts of interest. 


\section{3-YEAR-OLDS' PHYSICAL ACTIVITY IN CHILDCARE}

\section{References}

Baranowski, T., Thompson, W. O., DuRant, R. H., Baranowski, J., \& Puhl, J. (1993). Observations on physical activity in physical locations: age, gender, ethnicity, and month effects. Research Quarterly for Exercise and Sport, 64, $127-133$.

Bornstein, D. B., Beets, M. W., Byun, W. \& McIver, K. (2011). Accelerometer-derived physical activity levels of preschoolers: A meta-analysis. Journal of Science and Medicine in Sport, 14, 504-511.

Boldeman, C., Blennow, M., Dal, H., Mårtensson, F., Raustorp, A., Yuen, K., \& Wester, U. (2006). Impact of preschool environment upon children's physical activity and sun exposure. Preventive Medicine, 42, 301-308.

Bower, J. K., Hales, D. P., Tate, D. F., Rubin, D. A., Benjamin, S. E., \& Ward, D. S. (2008). The childcare environment and children's physical activity. American Journal of Preventive Medicine, 34, 23-29.

Brown, W. H., Pfeiffer, K. A., McIver, K. L., Dowda, M., Almeida, M. J. C. A., \& Pate, R. R. (2006). Assessing preschool children's physical activity: The observational system for recording physical activity in childrenpreschool version. Research Quarterly for Exercise and Sport, 77, 167-176.

Brown, W. H., Pfeiffer, K. A., McIver, K. L., Dowda, M., Addy, C. L., \& Pate, R. R. (2009). Social and environmental factors associated with preschoolers' nonsedentary physical activity. Child Development, 80, 45-58.

Cardon, G., Cauwenberghe, E., Labarque, V., Haerens, L., \& De Bourdeaudhuij, I. (2008). The contribution of preschool playground factors in explaining children's physical activity during recess. International Journal of Behavioral Nutrition and Physical Activity, 5.

Carson, V., \& Spence, J. C. (2010). Seasonal variation in physical activity among children and adolescents: a review. Pediatric Exercise Science, 22, 81-92.

Cole, T. J., Bellizzi, M. C., Flegal, K. M., \& Dietz, W. H. (2000). Establishing a standard definition for child overweight and obesity worldwide: international survey. British Medical Journal, 320, 1240.

Cosco, N. G., Moore, R. C., \& Islam, M. Z. (2010). Behavior mapping: A method for linking preschool physical activity and outdoor design. Medicine \& Science in Sports \& Exercise, 42, 513-519.

Dowda, M., Pate, R. R., Trost, S. G., Almeida, M. J. C. A., \& Sirard, J. R. (2004). Influences of preschool policies and practices on children's physical activity. Journal of Community Health, 29, 183-196.

Finn, K. J., Johannsen, N., \& Specker, B. (2002). Factors associated with physical activity in preschool children. The Journal of Pediatrics, 140, 81-85. 


\section{3-YEAR-OLDS' PHYSICAL ACTIVITY IN CHILDCARE}

Fisher, A., Reilly, J. J., Montgomery, C., Kelly, L. A., Williamson, A., Jackson, D. M., Paton, J. Y., \& Grant, S. (2005). Seasonality in physical activity and sedentary behaviour in young children. Pediatric Exercise Science, 17, 3140.

Gubbels, J. S., Kremers, S. P. J., Van Kann, D. H. H., Stafleu, A., Candel, M. J. J. M., Dagnelie, P. C., Thijs, C., \& de Vries, N. K. (2011). Interaction between physical environment, social environment, and child characteristics in determining physical activity at child care. Health Psychology, 30, 84-90.

Gubbels, J. S., Van Kann, D. H. H., \& Jansen, M. W. J. (2012). Play equipment, physical activity opportunities, and children's activity levels at childcare. Journal of Environmental and Public Health, doi:10.1155/2012/326520.

Hannon, J. C., \& Brown, B. B. (2008). Increasing preschoolers' physical activity intensities: An activity-friendly preschool playground intervention. Preventive Medicine, 46, 532-536.

Hinkley, T., Crawford, D., Salmon, J., Okely, A. D., \& Hesketh, K. (2008). Preschool children and physical activity. American Journal of Preventive Medicine, 34, 435-441.

Janz, K. F., Burns, T. L., \& Levy, S. M. (2005). Tracking of activity and sedentary behaviours in childhood: the Iowa Bone Development Study. American Journal of Preventive Medicine, 29(3), 171-178.

Nicaise, V., Kahan, D., \& Sallis, J. (2011). Correlates of moderate-to-vigorous physical activity among pre-schoolers during unstructured outdoor periods. Preventive Medicine, 53, 309-315.

Oliver, M., Schofield, G. M., \& Kolt, G. S. (2007). Physical activity in preschoolers. Understanding prevalence and measurement issues. Sports Medicine, 37, 1045-1070.

Pate, R. R., O’Neill, J. R., \& Mitchell, J. (2010). Measurement of physical activity in preschool children. Medicine \& Science in Sports \& Exercise, 42, 508-512.

Pate, R. R., McIver, K., Dowda, M., Brown, W. H., \& Addy, C. (2008). Directly observed physical activity levels in preschool children. Journal of School Health, 78, 438-444.

Pate, R. R., Pfeiffer, K. A., Trost, S. G., Ziegler, P., \& Dowda, M. (2004). Physical activity among children attending preschools. Pediatrics, 114, 1258-1263.

Pellegrini, A. D., \& Smith, P. K. (1998). Physical active play: the nature and function of neglected aspect of play. Child Development, 69(3), 577-598.

Poest, C. A., Williams, J. R., Witt, D. D., \& Atwood, M. E. (1989). Physical activity patterns of preschool children. Early Childhood Research Quarterly, 4, 367-376.

Pramling Samuelsson, I., \& Asplund Carlsson, M. (2008). The playing learning child: towards a pedagogy of early childhood. Scandinavian Journal of Educational Research, 52(6), 623641. 


\section{3-YEAR-OLDS' PHYSICAL ACTIVITY IN CHILDCARE}

Recommendations for Physical Activity in Early Childhood Education. Handbooks of the Ministry of Social Affairs and Health 2005:17.

Reilly, J. J. (2010). Low levels of objectively measured physical activity in preschoolers in child care. Medicine \& Science in Sports \& Exercise, 42, 502-507.

Ridgers, N., D. Stratton, G., Fairlough, S. J., \& Twisk, J. W. R. (2007). Long-term effects of playground markings and physical structures on children's recess physical activity levels. Preventive Medicine, 44, 393-397.

Sandberg, A., \& Pramling Samuelsson, I. (2005). An interview study of gender differences in preschool teachers' attitudes toward children's play. Early Childhood Education Journal, 32(5), DOI: 10.1007/s10643-005-4400$\mathrm{x}$.

Singh, A. S., Mulder, C., Twisk, J. W. R., van Mechelen, W., \& Chin A Paw, M. J. M. (2008). Tracking of childhood overweight into adulthood: a systematic review of the literature. Obesity reviews, 9, 474-488.

Stodden, D. F., Goodway, J. D., Langendorfer, S. J., Roberton, M. A., Rudisill, M. E., Garcia, C., \& Garcia, L. E. (2008). A Developmental perspective on the role of motor skill competence in physical activity: an emergent relationship. Quest, 60, 290306.

Strong, W. B., Malina, R. M., Blimkie, C. R., Daniels, S. R., Dishman, R. K., Gutin, B., Hergenroeder, A. C., Must, A., Nixon, P. A., Pivarnik, J. M., Rowland, T., Trost, S., \& Trudeau, F. (2005). Evidence based physical activity for school-age youth. Journal of Pediatrics, 146, 732-737.

Timmons, B. W., Naylor, P. J., \& Pfeiffer, K. A. (2007). Physical activity for preschool children-how much and how? Applied Physiology, Nutrition, and Metabolism, 32, 122134.

Tremblay, M. S., LeBlanc, A. G., Kho, M. E., Saunders, T. J., Larouche, R., Colley, R. C., Goldfield, G., \& Connor Gorber, S. (2011). Systematic review of sedentary behaviour and health indicators in school-aged children and youth. International Behavioural Nutrition and Physical Activity, 8. http://www.ijbnpa.org/content/8/1/98. Accessed 17 Nov 2011.

Trost, S. G. (2007). Measurement of physical activity in children and adolescents. American Journal of Lifestyle Medicine, 1, 299-314.

Tucker, P. (2008). The physical activity levels of preschool-aged children: a systematic review. Early Childhood Research Quarterly, 23, 547-558.

Van Cauwenberghe, E., Labarque, V., Gubbels, J., De Bourdeaudhuij, I., \& Cardon, G. (2012). Preschooler's physical activity levels and associations with lesson context, teacher's behavior, and environment during preschool physical education. Early Childhood Research Quarterly, 27, 221-230. 


\section{3-YEAR-OLDS' PHYSICAL ACTIVITY IN CHILDCARE}

Ward, D. S. (2010). Physical activity in young children: the role of child care. Medicine \& Science in Sports \& Exercise, 42, 499-501.

Ward, D. S., Vaughn, A., McWilliams, C., \& Hales, D. (2010). Interventions for increasing physical activity at childcare. Medicine \& Science in Sports \& Exercise, 42, 526-534. 
Table 1. Percentages of observations $(N=15824)$ and percentages of observations in sedentary, light and moderate to vigorous physical activity in both seasons.

\begin{tabular}{|c|c|c|c|c|c|c|c|c|c|c|}
\hline \multirow{3}{*}{ Observed categories } & \multirow{3}{*}{\multicolumn{2}{|c|}{$\begin{array}{c}\text { Autumn Winter } \\
\text { Prevalence (\%) }\end{array}$}} & \multirow{3}{*}{$p$-value* } & \multirow{2}{*}{\multicolumn{2}{|c|}{ Autumn }} & \multirow{2}{*}{\multicolumn{4}{|c|}{ Activity levels (\%) }} & \multirow{3}{*}{$p$-value $* *$} \\
\hline & & & & & & & & & & \\
\hline & & & & Sedentary & Light & MVPA & Sedentary & Light & MVPA & \\
\hline All children & & & & 67.4 & 30.5 & 2.1 & 70.6 & 28.5 & 0.9 & .046 \\
\hline boys & 51 & 52 & \multirow{2}{*}{.435} & 61.1 & 35.5 & 3.5 & 66.5 & 32.3 & 1.1 & .017 \\
\hline girls & 50 & 48 & & 73.8 & 25.5 & 0.6 & 74.7 & 24.6 & 0.6 & .951 \\
\hline \multicolumn{11}{|l|}{ Location } \\
\hline indoor & 52 & 63 & \multirow{2}{*}{$<.001$} & 85.5 & 13.3 & 1.2 & 86.0 & 13.1 & 0.9 & .910 \\
\hline outdoor & 48 & 37 & & 47.6 & 49.4 & 3.0 & 43.7 & 55.5 & 0.8 & .028 \\
\hline \multicolumn{11}{|l|}{ Time } \\
\hline morning & 57 & 56 & \multirow{2}{*}{.787} & 64.4 & 33.2 & 2.4 & 68.8 & 30.3 & 0.9 & .066 \\
\hline afternoon & 43 & 44 & & 71.3 & 27.0 & 1.7 & 72.5 & 26.6 & 0.9 & .585 \\
\hline \multicolumn{11}{|l|}{ Morning } \\
\hline indoor & 48 & 62 & \multirow{2}{*}{$<.001$} & 84.0 & 14.9 & 1.1 & 82.9 & 16.0 & 1.1 & .931 \\
\hline outdoor & 52 & 38 & & 46.5 & 50.0 & 3.5 & 46.3 & 53.2 & 0.5 & .065 \\
\hline \multicolumn{11}{|l|}{ Afternoon } \\
\hline indoor & 58 & 66 & \multirow{2}{*}{.021} & 87.2 & 11.6 & 1.2 & 89.7 & 9.6 & 0.7 & .606 \\
\hline outdoor & 42 & 35 & & 49.4 & 48.3 & 2.3 & 39.9 & 58.8 & 1.3 & .150 \\
\hline \multicolumn{11}{|l|}{ Group composition } \\
\hline solitary & 29.7 & 22.9 & \multirow{2}{*}{$<.001$} & 50.1 & 35.7 & 14.2 & 55.9 & 35.7 & 8.4 & $<.001$ \\
\hline non-solitary & 70.3 & 77.1 & & 60.5 & 27.5 & 11.9 & 61.9 & 27.8 & 10.3 & .147 \\
\hline \multicolumn{11}{|l|}{ Initiator of activity } \\
\hline adult & 25.2 & 20.8 & \multirow{2}{*}{$<.001$} & 68.3 & 23.5 & 8.2 & 72.0 & 19.8 & 8.3 & .150 \\
\hline child & 74.8 & 79.2 & & 53.8 & 32.1 & 14.1 & 57.5 & 32.2 & 10.3 & $<.001$ \\
\hline \multicolumn{11}{|l|}{ Prompts } \\
\hline no prompts & 86.4 & 98.3 & \multirow{2}{*}{$<.001$} & 59.3 & 28.7 & 12.0 & 60.9 & 29.3 & 9.8 & .009 \\
\hline all prompts & 13.6 & 1.7 & & 45.4 & 38.2 & 16.3 & 38.9 & 45.8 & 15.3 & .451 \\
\hline \multicolumn{11}{|l|}{ Temperature } \\
\hline $10^{\circ} \mathrm{C}$ or warmer & 76.5 & - & \multirow{2}{*}{$<.001$} & 65.8 & 31.9 & 2.3 & - & - & - & - \\
\hline $9^{\circ} \mathrm{C}-0^{\circ} \mathrm{C}$ & 23.1 & 4.4 & & 72.2 & 26.5 & 1.3 & 75.6 & 24.4 & - & .697 \\
\hline
\end{tabular}




\begin{tabular}{|c|c|c|c|c|c|c|c|c|c|c|}
\hline$-1^{\circ} \mathrm{C}--9^{\circ} \mathrm{C}$ & 0.4 & 48.1 & & 100 & - & - & 67.6 & 32.0 & 0.4 & .384 \\
\hline$-10^{\circ} \mathrm{C}--19^{\circ} \mathrm{C}$ & - & 36.3 & & - & - & - & 71.7 & 26.4 & 1.9 & - \\
\hline$-20^{\circ} \mathrm{C}$ or colder & - & 11.2 & & - & - & - & 77.0 & 23.0 & - & - \\
\hline \multicolumn{11}{|l|}{ Weather } \\
\hline Sunny with clear sky & 27.3 & 36.3 & & 68.2 & 28.8 & 3.0 & 71.9 & 27.5 & 0.5 & .041 \\
\hline Cloudy but dry & 49.4 & 50.9 & $<.001$ & 64.4 & 33.8 & 1.9 & 72.4 & 26.2 & 1.4 & .024 \\
\hline Rain or snow rain & 23.3 & 12.8 & & 72.9 & 25.8 & 1.3 & 58.5 & 41.5 & - & .005 \\
\hline
\end{tabular}

Note. Sedentary $=$ levels 1 and 2 ; light $=$ level 3 ; moderate to vigorous physical activity (MVPA) $=$ levels 4 and $5 ; p$-values* from Pearson Chi-Square Tests to

compare seasonal differences in observed intervals, and $p$-values** from Pearson Chi-Square Tests to compare percentages spent in sedentary, light, and moderate to vigorous levels physical activity. 
Table 2. The most common (at least $12 \%$ of all observations) activity types, physical and social environments at different levels of physical activity in both seasons. Prevalence $(\%)$ of observations $(N=15824)$ at different activity intensity levels.

\begin{tabular}{|c|c|c|c|}
\hline Activity intensity & Activity type & Physical environment & Social environment \\
\hline MVPA & $\begin{array}{l}\text { Pull/push }(0.9 \%) \\
\text { Climb }(0.6 \%) \\
\text { Run }(0.6 \%)\end{array}$ & $\begin{array}{l}\text { Indoor: Group time }(2.0 \%) \text {, } \\
\text { Toys }(0.4 \%) \\
\text { Outdoor: Wheel }(2.1 \%) \text {, } \\
\text { Open space }(1.4 \%)\end{array}$ & $\begin{array}{l}\text { Group composition: Solitary }(11.3 \%) \\
\text { Initiator of activity: Child }(12.2 \%) \\
\text { Prompts: All prompts }(31.6 \%)\end{array}$ \\
\hline Light & $\begin{array}{l}\text { Jump/skip }(50.6 \%) \\
\text { Pull/push }(49.8 \%) \\
\text { Climb }(45.3 \%)\end{array}$ & $\begin{array}{l}\text { Indoor: Sociodramatic }(19.1 \%) \text {, } \\
\text { Other }(15.3 \%) \\
\text { Outdoor: Open space }(57.0 \%) \text {, Portable } \\
\text { equipment }(56.8 \%)\end{array}$ & $\begin{array}{l}\text { Group composition: Solitary }(35.7 \%) \\
\text { Initiator of activity: Child }(32.2 \%) \\
\text { Prompts: All prompts }(42.0 \%)\end{array}$ \\
\hline Sedentary & $\begin{array}{l}\text { Sit/squat }(71.8 \%) \\
\text { Stand }(69.8 \%) \\
\text { Walk }(68.1 \%)\end{array}$ & $\begin{array}{l}\text { Indoor: Art }(97.5 \%) \text {, } \\
\text { Group time }(96.0 \%) \\
\text { Outdoor: Sandbox }(58.2 \%) \text {, } \\
\text { Sociodramatic props }(55.2 \%)\end{array}$ & $\begin{array}{l}\text { Group composition: Non-solitary }(61.2 \%) \\
\text { Initiator of activity: Adult }(70.2 \%) \\
\text { Prompts: No prompts }(60.1 \%)\end{array}$ \\
\hline \multicolumn{4}{|c|}{ Note. $\mathrm{MVPA}=$ moderate to vigorous physical activity, levels 4 and 5 ; light $=$ level 3 ; sedentary $=$ levels 1 and 2 . Group composition (solitary vs. non- } \\
\hline
\end{tabular}


Table 3. Children's mean physical activity intensity in autumn and winter: three-level linear regression $(N=81)$.

\begin{tabular}{rcccccc}
\hline & \multicolumn{3}{c}{ Autumn } & Winter & 95\% confidence \\
\cline { 2 - 7 } Observed categories & $\begin{array}{c}\text { Regression } \\
\text { coefficient }\end{array}$ & p-value & $\begin{array}{c}\text { Regression } \\
\text { coefficient }\end{array}$ & $\begin{array}{c}\text { p-value } \\
\text { 95\% confidence } \\
\text { interval }\end{array}$ \\
\hline Girl & -.16 & .004 & $-.27 \pm-.05$ & -.12 & .017 & $-.22 \pm-.02$ \\
BMI & .01 & .544 & $-.03 \pm .06$ & .02 & .304 & $-.02 \pm .07$ \\
Outdoor & .40 & $<.001$ & $.36 \pm .44$ & .49 & $<.001$ & $.46 \pm .53$ \\
Afternoon & -.05 & .033 & $-.09 \pm-.00$ & -.02 & .265 & $-.06 \pm .02$ \\
Solitary & .11 & $<.001$ & $.07 \pm .15$ & .05 & .003 & $.02 \pm .09$ \\
Adult initiated & -.18 & $<.001$ & $-.23 \pm-12$ & -.01 & .750 & $-.06 \pm .04$ \\
No prompts & -.40 & $<.001$ & $-.46 \pm-.34$ & -.49 & $<.001$ & $-.64 \pm-.33$ \\
Temperature & -.01 & .079 & $-.02 \pm .00$ & -.01 & $<.001$ & $-.01 \pm-.00$ \\
Rain & -06 & .067 & $-.11 \pm .00$ & .03 & .338 & $-.03 \pm .10$ \\
\hline
\end{tabular}

Note. Girl vs. boy; BMI (Body Mass Index; linear), outdoor vs. indoor; afternoon vs. morning; solitary vs. non-solitary; adult

initiated vs. child initiated; no prompts vs. all prompts; temperature (linear); rain vs. cloudy but dry or sunny with clear sky 
III

\section{A COMPARISON OF PHYSICAL ACTIVITY LEVELS IN CHILD- CARE CONTEXTS AMONG FINNISH AND DUTCH 3-YEAR-OLDS}

by

Soini, A., Gubbels, J., Sääkslahti, A., Villberg, J., Kremers, S., Van Kann, D., Mehtälä,

A., De Vries, N., \& Poskiparta, M. (2017).

European Early Childhood Education Research, 25(3). (in press)

Reproduced with kind permission by Routledge, Taylor \& Francis Group. 


\title{
COMPARING THE PHYSICAL ACTIVITY PATTERNS OF 3-YEAR- OLD FINNISH AND AUSTRALIAN CHILDREN DURING CHILD- CARE AND HOMECARE DAYS
}

\author{
by \\ Soini, A., Watt, A., Tammelin, T., Soini, M., Sääkslahti, A., \& Poskiparta, M. (2014). \\ Baltic Journal of Health and Physical Activity, 6(3), 171-182. \\ doi: 10.2478/bjha-2014-0015
}

Reproduced with kind permission by De Gruyter. 
7 Comparing the Physical Activity Patterns of 3-Year-Old Finnish and Australian Children

During Childcare and Homecare Days 


\section{Abstract}

11 Background: Limited previous research has contrasted physical activity (PA) patterns in

12 preschool children across different hourly patterns or segments of day, or adopted similar

13 methodologies to compare the PA behaviors of children from different countries. The

14 purpose of this study was to examine how the PA levels and patterns varied among 3-year-

15 olds within and between childcare and homecare days in Finland and Australia.

16 Material and Methods: ActiGraph GT3X accelerometers were used to monitor 121 (80

17 Finnish, 41 Australian) children's PA for five consecutive days.

18 Results: No significant country differences were observed in children's daily total PA (lightto-vigorous PA [LMVPA]), except during childcare days Finnish children spent more time in light PA compared to Australian children. During childcare attendance hours children engaged in moderate-to-vigorous PA (MVPA) for an average of 48 minutes $(S D=24)$ covering 54\% of their daily MVPA in Finland, and for 53 minutes $(S D=34)$ covering $64 \%$ of their daily MVPA in Australia. Variation in children's hour-by-hour PA was more pronounced during childcare days than homecare days. Conclusions: Despite the variations based on cultural practices, no major differences were observed in children's daily total PA between the countries. However, these findings provide a better understanding of 3-year-olds' PA behavior patterns, and will serve as valuable evidence for the development of PA promotion in preschool children in both Finland and in Australia. 


\section{Background}

2

3
established during the early years of childhood [1,2]. Engaging in efficacious PA as a child can serve as a foundation for a physically active adult lifestyle [3, 4], however, SB seems to constitute an even stronger influence on later lifestyle [5, 6]. Moreover, decreasing SB and increasing children's PA is a worldwide health priority $[6,7]$.

The common preconception among adults, is that preschool children (3-to-5-years old) are naturally very active, however, studies of objectively measured PA and SB undertaken with this age group have drawn attention to the fact that levels of PA are typically low and SB high [8, 9]. It is possible that, childcare settings may act as barriers to PA [9], secondly, the habits associated with SB such as TV viewing are being formulated and maintained within Western populations in early childhood [5, 6]. Low levels of PA and high levels of SB are related to health-risk behaviors such as increased consumption of unhealthy foods [8], and abnormal weight gain [4]. Despite the benefits of PA to young children's physical, social and psychological development [1], previous studies have indicated that preschoolers do not achieve the standards proposed in global guidelines for daily PA $[9,10]$.

According to the Organization for Economic Co-operation and Development (OECD) Family database [11], 69\% in Europe, 36\% in US and 12\% of 3-year-old children in Australia attend childcare or early education services. Because children spend considerable time at childcare, this setting can make an important contribution to the welfare and health of young children via an influence on their levels of PA behavior [12, 13, 14]. For instance, Finn et al. [12] concluded that the childcare center was the strongest predictor of activity levels among children attending childcare, with more than $50 \%$ of the daily PA performed during childcare hours. Results of a review by Hinkley et al. [15] showed that boys were more active than girls, that children with active parents tended to be more active, and that children who spent more time outdoors were more active than children who spent less time outdoors. Similarly, a recent comparison study involving Swedish and US preschool children demonstrated that PA was significantly higher outdoors than indoors during preschool time for both countries, and that time spent outdoors seemed to be a supportive aspect of objectively measured MVPA for preschool children [16].

The assessment of young children's PA is challenging, primarily because their behavior is intermittent and sporadic, therefore objective measures such as accelerometers are recommended for use to detect these short spurts, and in determining frequencies, intensities and duration of PA $[8,17,18]$. Although, accelerometers have become one of the most 
widely used methods for measuring PA and SB in free-living preschool children $[17,18,19$, 20] only limited research exists that considered PA variability in preschool children across different segments of day or PA patterns hour-by-hour [21, 22]. Furthermore, the number of studies that have adopted similar designs and methodologies to compare PA behaviors of children from different countries in childcare and home settings is minimal. The aim of this study, therefore, was to investigate variations in the daily childcare and homecare PA levels and patterns of Finnish and Australian 3-year-olds.

\section{Material and Methods}

Participants in Finland. Finnish participants were recruited from Central Finland, in a large regional city. A total of 14 childcare centers volunteered to be involved in the study. All families of the 3-year-old children attending the participating childcare centers were invited to participate. A total of 96 (48 boys and 48 girls) children participated in the data collection from August to October (Autumn).

Participants in Australia. Australian participants were recruited from the inner and outer western urban regions of a major metropolitan city. All families of 3-year-old children attending the 13 childcare centers that agreed to participate were invited to be involved in the project. Parent completion of consent forms resulted in the involvement of 64 (33 boys and 31 girls) children with in the data collection from March to August (Autumn to Winter).

The minimum valid PA requirement for the use of participant accelerometer daily data was at least 450 minutes of monitored PA per day (from 7 a.m. to 9 p.m.) for at least one childcare day and one homecare day as recommended by Cliff et al. (25). From the total sample, 16 children (17\%) in Finland and 23 children (36\%) in Australia were excluded from further analyses because children did not satisfy the minimum wear time criteria. Complete PA data were obtained for 80 (53\% boys) Finnish children and 41 (44\% boys) Australian children.

PA assessment and data reduction. Daily PA was objectively quantified with the ActiGraph GT3X (ActiGraph, LLC, Pensacola, FL, US). For this study, children were requested to wear the accelerometer for five consecutive days (from Wednesday to Sunday). The devices were initialized to record data over 5-s intervals (epochs) as recommended for children of this age [17]. The separate count cut points for preschool-aged children established by Pate et al. [23] were adapted for this study to assess the amounts of the time children spent at the different intensity levels and to determine how many of children achieve the PA recommendations for preschoolers [24, 25, 26, 27, 28, 29]. The following cut points determined by counts per minute (cpm) were used: sedentary (0-149 cpm), light (150-1679 
cpm) and moderate-to-vigorous intensity physical activity (MVPA) ( $\geq 1680 \mathrm{cpm}$ ) (23). Recently, cut points of $<100 \mathrm{cpm}$ and $1680 \mathrm{cpm}$ for classifying SB and MVPA, respectively, are recommended [30].

All data were checked for normality before statistical analysis. Periods of non-wear time (defined as 10 consecutive minutes of ' 0 ' counts) and an upper range of biological plausibility (defined as no more than $15000 \mathrm{cpm}$ ) were removed from the data [17]. The days during which participants did not achieve the minimal wearing time were considered as a noncompliant day and not used in the analyses. PA levels in cpm were derived as the main PA outcome. Daily PA levels (cpm/day), PA levels per hour (cpm/hour) and time spent at different PA intensity levels (i.e., sedentary, light PA and MVPA) in minutes/hour were calculated to assess both within- and between-day variability. In both childcare and homecare day hours between 7 a.m. and 9 p.m. were included to analyze within-day variability. The data reduction was done with using ActiLife version 6.5.2.

Accelerometers were worn for an average of $4.5(S D=.65)$ days, $634(S D=55)$ minutes/childcare days and $623(S D=66)$ minutes/homecare days in Finland. In Australia accelerometers were worn for an average of $4.3(S D=.91)$ days, $592(S D=65)$ minutes/childcare day and $579(S D=49)$ minutes/homecare day. No differences in mean monitor wearing days $(p=.128)$ were observed between Finnish and Australian children, however, Finnish children had a significantly higher mean wearing minutes/day compared to Australian children of 42 minutes for childcare days $(p=.001)$ and of 44 minutes for homecare days $(p=.001)$.

$P A$ monitoring procedures. The parents and children were issued with an accelerometer on the first morning of their involvement in the research. All children, together with their parents and childcare teachers, were instructed how to wear the accelerometer using an adjustable elastic belt over children's right hip for as long as possible during all waking hours, and that to remove it only for water-based activities and when sleeping. Parents, childcare teachers and center managers were also provided written information about the correct procedures and proper accelerometer use.

Parents were asked to record childcare attendance times. Additionally, parents were asked to report any abnormalities in daily routines, for example, long periods spent sitting (e.g., in a car), swimming, bathing and if the child was ill during the measurement period. Receptivity to wearing the instrument was rated by the parent on a five-point scale (from very pleasant to very unpleasant). According to parents' reports of their children's receptivity to wearing the accelerometer, $95 \%$ of Finnish and $89 \%$ of Australian children reported 
experience as "pleasant" or "very pleasant". Only $1 \%$ of the Finnish and $11 \%$ of Australian children reported the experience as "unpleasant" and none as "very unpleasant".

Background information in Finland. Typically Finnish childcare centers are community based and catered care for less than hundred children. The typical age cohort that 3-year-old children are involved with at childcare are the 3-5-year-olds group. For 3-year-olds, childcare settings should provide one certified teacher per seven children [31]. Finnish childcare centers', involved in this study, typical daily timetable is scheduled by meal times (8 till 8.30 a.m. breakfast; 11 till 11.30 a.m. lunch; 2 till 2.30 p.m. snack) and rest (12 till 2 p.m.), morning (10 till 11 a.m.) and afternoon (3 till 5 p.m.) outdoor recess. After breakfast there are teacher-lead classroom activities. These sessions can include pre-academic activities, music, handicrafts, or physical education (P.E.). In this study during the data collection periods, the participants attended childcare settings for an average of $7.7(S D=.84)$ hours/day from 8 a.m. to 3.30 p.m. The mean outdoor temperature during Finnish data collection was average $9^{\circ} \mathrm{C}$ (range: $16^{\circ} \mathrm{C}--^{\circ} \mathrm{C}$ ) [32]

Background information in Australia. In contrast to the Finnish childcare system, Australian childcare centers are managed by government, community, and private organizations. The numbers of children in attendance varies considerably depending on the funding and resources available to the centers. Centers operate on a half or full day fee charged to parents for the care of their child. In the recruited childcare centers' a typical daily schedule involves the following general routine: breakfast at 8 a.m., morning tea at 9.30 a.m., lunch at 11.30 a.m., sleep time or quiet activities at 12 p.m., afternoon tea at 3 p.m. and a late afternoon meal/snack time at $5.30 \mathrm{p} . \mathrm{m}$. Between the meals children are allowed to play indoors or outdoors depending on the weather. During the day there might also be structured group time for 3-to-5-year-olds. The Australian participants attended childcare settings for an average of $8.1(S D=1.95)$ hours/day from $8.30 \mathrm{a} . \mathrm{m}$. to $4.30 \mathrm{p} . \mathrm{m}$. The mean outdoor temperature during Australian data collection was $12^{\circ} \mathrm{C}$ (range: $22^{\circ} \mathrm{C}-6^{\circ} \mathrm{C}$ ) [32].

In Finland body weight and height were measured by researchers at the time of PA data collection. In Australia, parents or the guardians were asked to provide children's body weight and height information. Body mass index (BMI: $\mathrm{kg} / \mathrm{m}^{2}$ ) was calculated for each child (see Table 1). In Finland, the ethics committee of the local University, and the Social Affairs and Health officer in the city approved the study. The affiliate Australian university and Department of Education and Early Childhood provided ethical approval in Australia. Statistical analysis. The data were analyzed using SPSS for Windows (version 20.0). Descriptive statistics were used to summarize the study sample in relation to the main 
variables. Means and standard deviations $(S D)$ were calculated for daily total PA expressed as cpm, and time spent (percentages/day) at different intensity levels (sedentary, light PA, and MVPA) to show the extent of activity behavior. To compare PA levels on childcare and homecare days, paired-samples $t$-tests were conducted. Gender differences in total PA and in engagement at different intensity levels were analyzed using independent-samples $t$-test. A repeated measure MANOVA was used to compare differences in daily PA between childcare and home days for gender, country, and hour of the day. Statistical significance was set at an alpha level of .05 for all analyses.

\section{Results}

Children's daily total PA. Children's total PA was $M=730 \mathrm{cpm}, S D=139$ (Finland $M$ $=739 \mathrm{cpm}, S D=143$ and Australia $M=713 \mathrm{cpm}, S D=132)$. No significant differences were observed in mean daily cpm between childcare days $(M=715 \mathrm{cpm}, S D=149)$ and homecare days $(M=745 \mathrm{cpm}, S D=192 ; t=-1.66, p=.101)$. During childcare days boys' $(M=748$ cpm, $S D=152)$ activity levels were higher than girls' $(M=683 \mathrm{cpm}, S D=141)(F=.702, t$ $=2.45, p=.016)$, but no gender differences were observed during homecare days $(p=.158)$.

No country variations were recorded in activity intensities during childcare or homecare days, except during childcare days Finnish children spent more time (average 20 minutes) in light PA than Australian children ( $p=.027)$. Descriptive characteristics and total PA of the participants by country are showed in Table 1 .

INSERT Table 1 NEAR HERE (Table 1. Descriptive characteristics and total physical activity of the participants by country.)

During childcare days all Finnish and 95\% of Australian children engaged 180 minutes or more in LMVPA and $96 \%$ of Finnish and $83 \%$ of Australian children engaged 60 minutes or more in MVPA. Only 10\% of Finnish and 15\% of Australian engaged 120 minutes or more in MVPA. During homecare days, 98\% of Finnish and 95\% of Australian children engaged 180 minutes or more in LMVPA, 89\% of Finnish and 90\% of Australian children engaged 60 minutes or more in MVPA and 14\% of Finnish and 5\% of Australian engaged 120 minutes or more in MVPA.

PA patterns during childcare days. A significant main effect of hour $(F=57.24, p$ $<.001)$, and interaction effect of hour-country $(F=14.52, p<.001)$ revealed that PA levels per hour and country varied across a childcare day (Figure 1). Between-subjects analysis indicated that PA varied by country $(F=4.87, p=.029)$ and gender $(F=5.65, p=.019)$ 
201

202

203

204

205

206

207

208

209

210

211

212

213

214

215

216

217

218

219

220

221

222

223

224

225

226

227

228

229

230

231

232

233

234

during a childcare day. During childcare attendance hours, two significant increases in activity levels were monitored in both countries: between 10 and 11 a.m. and between 3 and 4 p.m. in Finland, and between 10 and 11 a.m. and between 4 and 5 p.m. in Australia. One major decline in PA levels was recorded during the resting times (12 till 2 p.m. in Finland; 1 till 2 p.m. in Australia). In Finland, one increase in activity levels was recorded after childcare hours, between 6 and 7 p.m. In Australia, during post childcare attendance hours children's PA levels decreased. (See Figure 1.) Childcare days' average minutes/hour in different activity intensities (sedentary, light PA, MVPA) are shown in Table 2a. Children engaged in MVPA for an average of 48 minutes ( $S D=24 ; 54 \%$ of daily MVPA), in LMVPA for 147 minutes ( $S D=55 ; 53 \%$ of daily LMVPA) in Finland; and in MVPA for 53 minutes $(S D=34 ; 64 \%$ of daily MVPA) and in LMVPA for 163 minutes $(S D=79 ; 64 \%$ of daily LMVPA) in Australia during their childcare attendance hours.

INSERT Table 2a NEAR HERE (Table 2a. Average minutes/hour during childcare days in different activity intensities (sedentary, light PA and MVPA).)

INSERT Table $2 \mathrm{~b}$ NEAR HERE (Table 2b. Average minutes/hour during homecare days in different activity intensities (sedentary, light PA, MVPA).)

INSERT Figure 1 NEAR HERE (Figure 1. Physical activity levels per hour (cpm/hour) on childcare days in Finland and in Australia.)

INSERT Figure 2 NEAR HERE (Figure 2. Physical activity levels per hour (cpm/hour) on homecare days in Finland and in Australia.)

PA patterns during homecare days. A significant main effect of hour $(F=38.30, p$ $<.001)$, and interaction effect for hour-country $(F=2.80, p=.002)$ indicated that PA levels varied by hour and country during a homecare day (Figure 2). Between-subjects analysis showed no variation between variables across a homecare day. In Finland, PA levels increased between 10 and 12 p.m., 3 and 5 p.m., and these activity levels remained the same until 8 p.m. A small decline in activity levels was observed between 1 and 2 p.m. In Australia, children's PA levels increased at 9 a.m. and remained the same level until 4 p.m., when the next peak was recorded. After 5 p.m. children's PA levels were decreasing respectively. Homecare days' average minutes/hour in different activity intensities (sedentary, light PA, MVPA) are shown in Table $2 b$.

\section{Discussion}


The purpose of this study was to determine 3-year-old children's PA levels and compare how these levels varied within and between childcare days and homecare days and differed between Finnish and Australian children. No significant country differences were found in children's daily total PA, when PA was expressed as cpm. However, during childcare days Finnish children spent more time in light PA compared to Australian children. During childcare attendance hours children engaged in MVPA for 54\% of their daily MVPA in Finland, and 64\% of their daily MVPA in Australia. Children's PA levels' variation, hourby-hour, was more pronounced during childcare days than homecare days, especially in Finland. Most of the children engaged in three hours or more of daily LMVPA [24, 25, 26, 27], or 60 minutes or more of MVPA, as widely recommended for preschoolers [29].

The mean total PA scores for the children in the present study appeared to be higher than those reported previously in similar studies in different countries [22, 33, 34, 35, 36]. For example, in Scotland Jackson et al. [35] found total activity counts of $669 \mathrm{cpm}$ and Reilly et al. [36] 692 for 3-year-olds for compared to the mean of $730 \mathrm{cpm}$ found in this study. Earlier preschool PA research has shown boys to be more active than girls [12, 15, 35, 37]. Children tend to be less active the more staff members that are present or involved with children's play $[38,39]$. Girls in particular prefer to stay close to their teachers, thus, decreasing activity levels when teachers are present [40]. Similarly, the current study also found gender differences in PA intensity levels in childcare days, but not during homecare days.

Strong et al [4] reported that preschools should provide opportunities for children to accumulate 60 minutes and more of MVPA each day. Many studies, however, have typically indicated that PA levels are very low among preschool children during their time in childcare settings $[9,13]$. The current results tend to support this pattern whereby both samples of children did not meet the recommended minimum of 60 minutes of MVPA during childcare hours [4]. However, this study indicated that during childcare hours children engaged in $56 \%$ of their daily MVPA and 53\% of their daily LMVPA in Finland; and in 64\% of their daily MVPA and 64\% of their daily LMVPA in Australia. This finding supports the earlier research of Finn et al [12].

Children's PA patterns during childcare days. Despite no differences being found in children's childcare days' total PA between countries, Finnish children engaged more in light PA compared to Australian 3-year-olds. A Belgian study previously reported significant increases in children's objectively measured PA intensity during preschool recess and in times of unstructured free plays that were taken as an opportunity to be physically active [22]. 
Similarly, Finnish children's intensity levels peaked twice during childcare attending hours, at 10 a.m. and 3 p.m., reaching the highest MVPA levels during the day. This may be explained by the specific practices within Finnish childcare whereby settings generally only offer children the opportunity to engage outdoor activities twice a day, in the morning and afternoons.

In Finland, outdoor times are associated with unstructured and free play in the playground. Also, several previous studies have indicated that children who spend more time outdoors are more physically active $[12,15,17,37,41]$. Cardon et al. [40] have suggested that the provision of sufficient play space for recesses (e.g., splitting children into groups with different recess times), favoring shorter and more frequent recesses during preschool hours or encouraging supervisors to promote continued activity during outdoor play offer considerable potential for increasing activity levels in preschoolers. Increases in PA within the Australian sample were also found at $10 \mathrm{a} . \mathrm{m}$. and at $4 \mathrm{p.m}$. It is probable that during those hours children have been outdoors, however, the childcare programs in Australia are less restrictive in relation allowing children to play in the outdoor play area throughout the day. Despite these opportunities to play outdoors, Australian children's PA levels were surprisingly low. Relative to Cardon et al.'s [40] findings, it could be expected that Australian children in this study should have reached higher levels of activity.

A noticeable decline in Finnish children's intensity levels were observed during midday hours, between 12 p.m. and 1 p.m. Finnish children are required to have a day sleep, or at least lie down for an average of 30 minutes. For the Australian sample, intensity levels decreased minimally between 1 p.m. and 2 p.m., possibly because the day sleep time was less formally implemented than in Finland. The typical childcare days in both countries were also characterized by essential daily living activities such as dressing, eating, engaging in self-care activities and structured classroom-based activities (e.g., fine motor activities, pre-academic activities), which are shown in the current results as lower PA level behaviors. Integrating PA into an existing preschool curriculum is a potential strategy to enhance PA in preschoolers [42].

One notable difference between the countries was revealed in the children's typical childcare attendance times. Australian children attend childcare settings approximately 30 minutes more in comparison to Finnish children. However, in Finland, as is typical in the Nordic countries, children attend formal care full-time on five days, more than 30 hours per week, whereas, at the age of three children in Australia frequent childcare with substantial 
variation in attendance patterns (i.e., 1 day through to 5 days per week; less than 20 hours per week) [11].

Outside of childcare hours data revealed one increase (between 6 p.m. and 7 p.m.) in Finnish children's PA levels. This supports thinking that parents are taking their children to the park or children are participating structured activities managed by sport clubs or private organizations (e.g., swim school). During this peak however, children's MVPA levels were lower than during the childcare hours. Congruent with results of the study of Verbestel et al. [22], the Australian data confirmed that after childcare hours were associated with reduced activity levels. Parents may assume that their child is getting enough PA during the childcare day, which could limit encouragement of the child to be physically active or to play outdoors after childcare hours. It is possible that the present sample of children is engaged in SB such as TV viewing or using computers, similarly observed in Belgium [40]. While SB tracks more consistently than PA, therefore reducing children's SB, especially TV viewing, and promoting their PA during the early childhood period can have sustained benefits that carry over into childhood [6].

\section{Children's PA patterns during homecare days. Homecare hourly patterns of PA} determined in the current study are similar to the findings of Verbestel et al. [22], whereby, two increases in children's activity levels in homecare days (i.e., Finnish) were recorded between 10 a.m. and 11 a.m. and 3 p.m. and 6 p.m. Additionally, Australian children's PA intensity levels were higher during hours between $11 \mathrm{a} . \mathrm{m}$. and $12 \mathrm{p} . \mathrm{m}$. These minor activity peaks were recorded slightly later than in childcare days. Children probably wake up later during homecare days. Finnish children's afternoon increase in PA supports think that families are active in their home environment. No major increases in Australian children's PA during homecare serves as evidence supporting that children and their parents should be encouraged to spend more time playing outdoors or utilizing PA suitable settings. In general, activity patterns during homecare days were much less flattened and structured than during childcare days. Support for the current results is also found from Van Cauwenberghe et al.'s [21] report, that hour-by-hour patterns of SB and MVPA were less variable during weekend days than during weekdays.

At the age of three, children may often spend weekdays at homecare, especially in Australia, and for this reason the study was designed to compare childcare days to homecare days instead weekdays to weekend days. The descriptive results revealed that no significant differences in intensity levels or total PA were found between childcare days and homecare days, thus, constituting findings consistent with earlier studies [22,35]. It is possible the 
current sample of families' essential daily living activities do not differ to childcare settings' structured programs. In contrast, Cardon and De Bourdeaudhuij [33] reported higher levels of sedentary behavior on weekdays compared to weekend days, although MVPA was as low during the weekend days as during the weekdays. Furthermore, Van Cauwenberghe et al. [21] reported that preschoolers were less sedentary and engaged in more MVPA across the weekend days compared to the weekdays and therefore, weekdays offer the greatest opportunity to change SB and MVPA.

$P A$ recommendations for preschool children. According to trends detailed in a review of the physical activity levels of preschool-aged children presented by Tucker [10], only $54 \%$ of participants throughout the studies achieved the minimum of 60 minutes of PA daily. In the current study, almost all of Finnish children and the large part of Australian children fulfilled the requirement of at least 60 minutes of MVPA daily. Additionally, although most children met the recommendations of three hours of daily LMVPA [24, 25, 26, 27], only small number of the Finnish or Australian children achieved the Recommendations for Physical Activity in Early Childhood Education [28] of at least 120 minutes of daily brisk PA (if defined as MVPA).

Strengths and limitations. Continuing debate exists in the literature as to the strengths and limitations of accelerometers. The choice of cut points significantly influences the amount of PA reported across different intensity levels, however, no consensus has been reached regarding which cut points are most appropriate for preschool-aged children [19]. Investigators in the field of PA need to resolve the issue of which accelerometer cut points are the most appropriate [19] and continue to focus on standardizing methods for the collection, cleaning, analyzing and reporting of accelerometer data [43]. Nevertheless, it is acknowledged that accelerometer generated data remain relatively accurate and warrant continued support as a reliable methodology for measuring PA and SB in free-living preschool children [17, 18, 20, 42].

A valuable quality of the present research is that PA levels were objectively measured using the accelerometers in two countries. Children's PA was measured over five days that included childcare and home settings in each of total of 27 childcare centers, covering both weekdays and weekend days in Finland and Australia. However, in Australia measurement could have benefitted from the inclusion of data for the entire week as an option rather than a Wednesday to Friday 3-day protocol to facilitate the attainment of more valid childcare days. Moreover, the children were co-operative and eager to take part in this study. Proxy reports 
369

370

371

372

373

374

375

376

377

378

379

380

381

382

383

384

385

386

387

388

389

390

by parents of their child's receptivity to wearing the accelerometer clearly indicated that it was a positive experience for the majority of the children.

\section{Conclusion}

Despite cultural variation in certain methodological characteristics (i.e., variations in attendance times, seasonal time periods) no major differences associated with country were observed in children's daily total PA. During childcare attendance hours children engaged in MVPA for more than half of their daily MVPA. Variation in children's hour-by-hour PA level was more pronounced during childcare days than homecare days. This study provides a useful contribution to facilitating improved understanding of preschoolers' PA behavior and the development of future PA interventions in contrasting international contexts such as Finland and Australia. Reducing SB and integrating increased levels of PA into childcare settings' daily living activities has the potential to enhance PA in preschoolers. The basic evidence generated in this research may make a partial contribution toward encouraging and stimulating parents to work towards an improved provision of opportunities for physical activities, such as visiting parks or playground areas after childcare hours and during homecare days. In future, complementing accelerometer data with contextual information could provide clearer perceptions of the type of settings and contexts children are engaging in higher levels of PA.

\section{Acknowledgements}

The authors would like to sincerely thank the children, parents and teachers in the childcare centers who gave their time to participate in this study. 
391

392

393

394

395

396

397

398

399

400

401

402

403

404

405

406

407

408

409

410

411

412

413

414

415

416

417

418

419

420

421

422

\section{References}

1. Timmons BW, Naylor PJ, Pfeiffer KA. Physical activity for preschool children - how much and how? Appl Physiol Nutr Metab. 2007; 32: 122-134.

2. Ward DS, Vaughn A, McWilliams C, Hales D. Interventions for increasing physical activity at childcare. Med Sci Sports Exerc. 2010; 42: 526-534.

3. Singh AS, Mulder C, Twisk JWR, van Mechelen W, Chin A Paw MJM. Tracking of childhood overweight into adulthood: a systematic review of the literature. Obes rev. 2008; 9: 474-488.

4. Strong WB, Malina RM, Blimkie CR, Daniels SR, Dishman RK, Gutin B. Evidence based physical activity for school-age youth. J Pediatr. 2005; 146: 732-737.

5. Biddle SJH, Pearson N, Ross GM, Braithwaite R. Tracking of sedentary behaviours of young people: A systematic review. Prev Med. 2010; 51: 345-351.

6. Jones RA, Hinkley T, Okely AD, Salmon J. Tracking physical activity and sedentary behaviour in childhood. A systematic review. Am J Prev Med. 2013; 44(6): 651-658.

7. World Health Organization (WHO). Population-based approaches to childhood obesity prevention. 2012. Geneva, Switzerland.

8. Oliver M, Schofield GM, Kolt GS. Physical activity in preschoolers. Understanding prevalence and measurement issues. Sports Med. 2007; 37: 1045-1070.

9. Reilly JJ. Low levels of objectively measured physical activity in preschoolers in child care. Med Sci Sports Exerc. 2010; 42: 502-507.

10. Tucker P. The physical activity levels of preschool-aged children: A Systematic Review. Early Child Res Q. 2008; 23: 547-558.

11. OECD Family Database. [http://www.oecd.org/els/social/family/database] Published 2008. Updated June 2011. [Accessed June 2, 2012]

12. Finn KJ, Johannsen N, Specker B. Factors associated with physical activity in preschool children. J Pediatr. 2002; 140: 81-85.

13. Pate RR, McIver K, Dowda M, Brown WH, Addy C. Directly observed physical activity levels in preschool children. $J$ Sch Health. 2008; 78(8): 438-444.

14. Ward DS. Physical activity in young children: The role of child care. Med Sci Sports Exerc. 2010; 42: 499-501.

15. Hinkley T, Crawford D, Salmon J, Okely AD, Hesketh K. Preschool children and physical activity. Am J Prev Med. 2008; 34: 435-441. 
16. Raustorp A, Pagels P, Boldemann C, Cosco N, Söderström M, Mårtensson F. Accelerometer measured level of physical activity indoors and outdoors during preschool time in Sweden and the United States. J Phys Act. 2012; 9: 801-808.

17. Cliff DP, Reilly JJ, Okely AD. Methodological considerations in using accelerometers to assess habitual physical activity in children aged 0-5 years. J Med Sci Sports. 2009; 12: $557-567$.

18. Pate RR, O’Neill JR, Mitchell J. Measurement of physical activity in preschool children. Med Sci Sports Exerc. 2010; 42: 508-512.

19. Bornstein DB, Beets MW, Byun W, McIver K. Accelerometer-derived physical activity levels of preschoolers: A meta-analysis. J Sci Med Sport. 2011; 14: 504-511.

20. Van Cauwenberghe E, Labarque V, Trost S, De Bourdeaudhuij I, Cardon G. Calibration and comparison of accelerometer cut points in preschool children. Int $J$ Pediatr Obes. 2011; 6: e582-e589.

21. Van Cauwenberghe E, Jones R, Hinkley T, Crawford D, Okely AD. Patterns of physical activity and sedentary behavior in preschool children. Int J Behav Nutr Phys Act. 2012; 9: 138. Available from: [http://www.ijbnpa.org/content/9/1/138] [Accessed November 20, 2013]

22. Verbestel V, Van Cauwenberghe E, De Coen V, Maes L, De Bourdeaudhuij I, Cardon G. Within- and between-day variability of objectively measured physical activity in pre-schoolers. Pediatr Exerc Sci. 2011; 23: 366-378.

23. Pate RR, Almeida AJ, McIver KL, Pfeiffer KA, Dowda M. Validation and calibration of an accelerometer in preschool children. Obesity. 2006; 14(11): 2000-6.

24. Australian Government, Department of Health and Ageing. Physical activity recommendations for children $0-5$ years. [http://www.health.gov.au/internet/main/publishing.nsf/content/health-pubhlth-strategphys-act-guidelines\#rec 0 5] Published 2010. [Accessed August 28, 2012]

25. Canadian Society for Exercise Physiology. Canadian physical activity guidelines and Canadian sedentary behavior guidelines. [http://www.csep.ca/CMFiles/Guidelines/CSEP-InfoSheets-early-years-ENG.pdf] Published 2012. [Accessed August 28, 2012]

26. Department of Health. UK physical activity guidelines. [http://www.dh.gov.uk/en/Publicationsandstatistics/Publications/PublicationsPolicyAnd Guidance/DH_127931] Published July 2011. [Accessed August 28, 2012] 
27. Institute of Medicine (IOM). Early childhood obesity prevention: policies goals, recommendations, and potential actions. [http://www.iom.edu/Reports/2011/EarlyChildhood-Obesity-Prevention-Policies/Recommendations.aspx] Published June 2011. [Accessed September 4, 2012]

28. Recommendations for Physical Activity in Early Childhood Education (2005). Handbooks of the Ministry of Social Affairs and Health 2005:17.

29. World Health Organization (WHO). Global recommendations on physical activity for health. 2010. Geneva. Switzerland.

30. Janssen X, Cliff DP, Reilly JJ et al. Predictive validity and classification accuracy of ActiGraph energy expenditure equations and cut-points in young children. Plos One. 2013; 8(11): e79124. doi: 10.1371/journal.pone.0079124.

31. National Institute for Health and Welfare. Statistical report. [http://www.thl.fi/fi FI/web/fi/tilastot/aiheittain/lasten sosiaalipalvelut/paivahoito] Published 2012. [Accessed June 13, 2013]

32. Weather Underground. Weather History \& Data Archive available at: [www.wunderground.com/history] [Accessed May 30, 2013]

33. Cardon G, De Bourdeaudhuij I. Are preschool children active enough? Objectively measured physical activity levels. Res Q Exerc Sport. 2008; 79: 326-332.

34. Fisher A, Reilly JJ, Montgomery $\mathrm{C}$ et al. Seasonality in physical activity and sedentary behavior in young children. Pediatr Exerc Sci. 2005; 17: 31-40.

35. Jackson DM, Reilly JJ, Kelly LA, Montgomery C, Grant S, Paton JY. Objectively measured physical activity in a representative sample of 3- to 4-year-old children. Obes Res. 2003; 11: 420-425.

36. Reilly JJ, Jackson DM, Montgomery C et al. Total energy expenditure and physical activity in young Scottish children: mixed longitudinal study. Lancet. 2004; 9494: 211212.

37. Pate RR, Pfeiffer KA, Trost SG, Ziegler P, Dowda M. Physical activity among children attending preschools. Pediatrics. 2004; 114: 1258-1263.

38. Brown WH, Pfeiffer KA, McIver KL, Dowda M, Addy CL, Pate RR. Social and environmental factors associated with preschoolers' nonsedentary physical activity. Child Dev. 2009; 80: 45-58.

39. Gubbels JS, Kremers SPJ, Van Kann DHH et al. Interaction between physical environment, social environment, and child characteristics in determining physical activity at child care. Health Psychol. 2011; 30: 84-90. 
490

491

492

493

494

495

496

497

498

499
40. Cardon G, Van Cauwenberghe E, Labarque V, Haerens L, De Bourdeaudhuij I. The contribution of preschool playground factors in explaining children's physical activity during recess. Int J B Nutr Phys Act. 2008; 5.

41. Boldeman C, Blennow M, Dal H, Mårtensson F et al. Impact of preschool environment upon children's physical activity and sun exposure. Prev Med. 2006; 42: 301-308.

42. Trost SG, Fees B, Dzewaltowski D. Feasibility and efficacy of a "move and learn" physical activity curriculum in preschool children. J Phys Act Health. 2008; 5: 88-103.

43. Matthews CE, Hagströmer M, Pober DM, Bowles HR. Best practices for using physical activity monitors in population-based research. Med Sci Sports Exerc. 2012; 44: S68S76. doi: 10.1249/MSS.0b013e3182399e5b. 
Table 1. Descriptive characteristics and total physical activity of the participants by country.

\begin{tabular}{|c|c|c|c|c|c|}
\hline & \multicolumn{2}{|c|}{$\begin{array}{c}\text { Finland } \\
(N=\mathbf{8 0 , 5 3 \%} \text { boys })\end{array}$} & \multicolumn{2}{|c|}{$\begin{array}{c}\text { Australia } \\
(N=41,44 \% \text { boys })\end{array}$} & \multirow[b]{2}{*}{$p$-value } \\
\hline & Mean & $S D$ & Mean & $S D$ & \\
\hline Age (yrs) & 3.2 & 0.3 & 3.4 & 0.2 & $<.001$ \\
\hline Height $(\mathrm{cm})$ & 98.1 & 4.5 & 101.5 & 3.3 & .006 \\
\hline Weight (kg) & 15.7 & 1.7 & 16.3 & 2.1 & .114 \\
\hline BMI $\left(\mathrm{kg} / \mathrm{cm}^{2}\right)$ & 16.2 & 1.1 & 16.3 & 1.2 & .773 \\
\hline \multicolumn{6}{|l|}{ PA during childcare day } \\
\hline cpm & 728 & 136 & 687 & 170 & .157 \\
\hline Sedentary & \multicolumn{2}{|c|}{$55 \%$} & \multicolumn{2}{|c|}{$57 \%$} & .084 \\
\hline Light PA & \multicolumn{2}{|c|}{$31 \%$} & \multicolumn{2}{|c|}{$29 \%$} & .027 \\
\hline MVPA & \multicolumn{2}{|c|}{$14 \%$} & \multicolumn{2}{|c|}{$14 \%$} & .539 \\
\hline \multicolumn{6}{|l|}{ PA during homecare day } \\
\hline $\mathrm{cpm}$ & 749 & 212 & 737 & 145 & .743 \\
\hline Sedentary & \multicolumn{2}{|c|}{$55 \%$} & \multicolumn{2}{|c|}{$55 \%$} & .676 \\
\hline Light PA & \multicolumn{2}{|c|}{$31 \%$} & \multicolumn{2}{|c|}{$30 \%$} & .661 \\
\hline MVPA & \multicolumn{2}{|c|}{$15 \%$} & \multicolumn{2}{|c|}{$15 \%$} & .826 \\
\hline
\end{tabular}


Table 2a. Average minutes/hour during childcare days in different activity intensities (sedentary, light PA and MVPA).

\begin{tabular}{|c|c|c|c|c|c|c|c|c|c|c|c|c|}
\hline \multirow{3}{*}{ Time } & \multicolumn{6}{|c|}{ Finland $(N=80)$} & \multicolumn{6}{|c|}{ Australia $(N=41)$} \\
\hline & \multicolumn{2}{|c|}{ Sedentary } & \multicolumn{2}{|c|}{ Light PA } & \multicolumn{2}{|c|}{ MVPA } & \multicolumn{2}{|c|}{ Sedentary } & \multicolumn{2}{|c|}{ Light PA } & \multicolumn{2}{|c|}{ MVPA } \\
\hline & Mean & $S D$ & Mean & $S D$ & Mean & $S D$ & Mean & $S D$ & Mean & $S D$ & Mean & $S D$ \\
\hline 7 a.m. & 47.5 & 7.9 & 8.5 & 4.6 & 3.3 & 2.1 & 13.5 & 10.9 & 4.6 & 4.0 & 1.8 & 1.7 \\
\hline 8 a.m. & 40.4 & 7.1 & 13.2 & 3.9 & 6.3 & 4.0 & 26.0 & 11.7 & 11.3 & 5.7 & 5.0 & 3.5 \\
\hline 9 a.m. & 29.7 & 7.3 & 19.6 & 4.4 & 10.7 & 4.4 & 33.5 & 9.2 & 14.9 & 4.5 & 6.0 & 3.3 \\
\hline 10 a.m. & 25.2 & 6.9 & 22.2 & 4.3 & 12.6 & 5.0 & 29.2 & 8.1 & 19.8 & 4.3 & 10.1 & 5.4 \\
\hline 11 a.m. & 43.9 & 6.8 & 10.9 & 3.6 & 4.2 & 2.2 & 34.4 & 7.0 & 16.1 & 4.3 & 7.8 & 4.4 \\
\hline 12 p.m. & 52.3 & 13.0 & 3.9 & 5.4 & 1.2 & 1.9 & 21.3 & 14.1 & 11.6 & 7.3 & 5.8 & 4.6 \\
\hline 1 p.m. & 52.2 & 11.5 & 4.0 & 3.8 & 1.5 & 2.0 & 12.4 & 14.0 & 7.4 & 8.3 & 3.5 & 4.2 \\
\hline 2 p.m. & 38.8 & 5.8 & 14.8 & 3.6 & 6.3 & 2.8 & 22.5 & 13.5 & 9.2 & 6.0 & 3.9 & 3.3 \\
\hline 3 p.m. & 29.3 & 6.7 & 20.3 & 4.1 & 10.4 & 4.1 & 30.8 & 9.2 & 15.6 & 4.8 & 8.5 & 4.6 \\
\hline 4 p.m. & 35.0 & 6.1 & 17.4 & 4.0 & 7.5 & 2.9 & 26.9 & 7.0 & 19.7 & 5.2 & 10.1 & 4.5 \\
\hline 5 p.m. & 39.6 & 7.5 & 13.6 & 4.2 & 6.2 & 3.4 & 29.5 & 8.6 & 15.7 & 4.4 & 7.5 & 4.8 \\
\hline 6 p.m. & 34.8 & 7.1 & 17.2 & 4.7 & 8.0 & 3.4 & 24.3 & 10.9 & 12.6 & 6.1 & 5.7 & 3.9 \\
\hline 7 p.m. & 38.3 & 7.9 & 14.6 & 5.2 & 6.8 & 3.5 & 18.2 & 11.0 & 9.0 & 5.9 & 5.0 & 4.8 \\
\hline 8 p.m. & 46.4 & 10.4 & 8.5 & 6.2 & 4.1 & 3.2 & 7.1 & 9.4 & 4.2 & 6.4 & 2.2 & 3.9 \\
\hline
\end{tabular}

Note. MVPA: Moderate-to-vigorous physical activity; SD: standard deviations. 
Table 2b. Average minutes/hour during homecare days in different activity intensities (sedentary, light PA, MVPA).

\begin{tabular}{|c|c|c|c|c|c|c|c|c|c|c|c|c|}
\hline \multirow{3}{*}{ Time } & \multicolumn{6}{|c|}{ Finland $(N=80)$} & \multicolumn{6}{|c|}{ Australia $(N=41)$} \\
\hline & \multicolumn{2}{|c|}{ Sedentary } & \multicolumn{2}{|c|}{ Light PA } & \multicolumn{2}{|c|}{ MVPA } & \multicolumn{2}{|c|}{ Sedentary } & \multicolumn{2}{|c|}{ Light PA } & \multicolumn{2}{|c|}{ MVPA } \\
\hline & Mean & $S D$ & Mean & $S D$ & Mean & $S D$ & Mean & $S D$ & Mean & $S D$ & Mean & $S D$ \\
\hline 7 a.m. & 51.8 & 13.2 & 3.8 & 4.5 & 1.5 & 1.9 & 8.6 & 10.6 & 3.6 & 4.7 & 1.5 & 2.0 \\
\hline 8 a.m. & 46.7 & 10.3 & 8.2 & 5.4 & 3.3 & 2.6 & 18.4 & 11.5 & 9.2 & 6.6 & 4.2 & 3.3 \\
\hline 9 a.m. & 39.0 & 9.9 & 14.4 & 6.3 & 5.9 & 3.3 & 24.4 & 8.5 & 13.8 & 6.1 & 7.0 & 4.7 \\
\hline 10 a.m. & 34.1 & 8.6 & 17.5 & 5.0 & 8.2 & 4.7 & 26.2 & 9.3 & 14.6 & 5.3 & 7.1 & 3.7 \\
\hline 11 a.m. & 34.5 & 7.8 & 17.5 & 5.2 & 8.0 & 4.4 & 28.6 & 5.3 & 16.4 & 4.7 & 7.5 & 3.7 \\
\hline 12 p.m. & 38.1 & 10.0 & 14.6 & 6.6 & 6.9 & 4.4 & 28.8 & 6.5 & 16.7 & 4.4 & 7.7 & 3.7 \\
\hline 1 p.m. & 42.1 & 10.7 & 12.3 & 6.9 & 5.4 & 4.4 & 28.5 & 7.3 & 15.3 & 5.2 & 6.8 & 3.7 \\
\hline 2 p.m. & 39.6 & 10.6 & 14.0 & 6.8 & 6.4 & 4.7 & 26.5 & 9.6 & 14.2 & 6.0 & 6.7 & 4.1 \\
\hline 3 p.m. & 35.2 & 10.5 & 16.3 & 6.0 & 8.5 & 6.0 & 24.1 & 9.0 & 15.2 & 6.2 & 7.3 & 4.3 \\
\hline 4 p.m. & 34.8 & 9.3 & 16.6 & 5.4 & 8.7 & 5.2 & 23.1 & 8.1 & 15.7 & 5.6 & 8.8 & 5.0 \\
\hline 5 p.m. & 36.5 & 8.7 & 15.4 & 5.3 & 7.7 & 4.3 & 25.7 & 7.8 & 14.2 & 5.1 & 7.3 & 4.2 \\
\hline 6 p.m. & 37.3 & 9.7 & 15.1 & 6.2 & 7.6 & 4.3 & 26.4 & 8.7 & 12.3 & 5.1 & 5.1 & 2.6 \\
\hline 7 p.m. & 39.4 & 10.6 & 13.0 & 6.6 & 7.5 & 4.9 & 17.1 & 10.4 & 8.9 & 6.8 & 4.5 & 3.0 \\
\hline 8 p.m. & 45.6 & 12.8 & 8.6 & 6.9 & 4.6 & 4.7 & 7.6 & 8.6 & 4.4 & 5.9 & 2.2 & 3.1 \\
\hline
\end{tabular}

Note: MVPA: Moderate-to-vigorous physical activity; SD: standard deviations. 


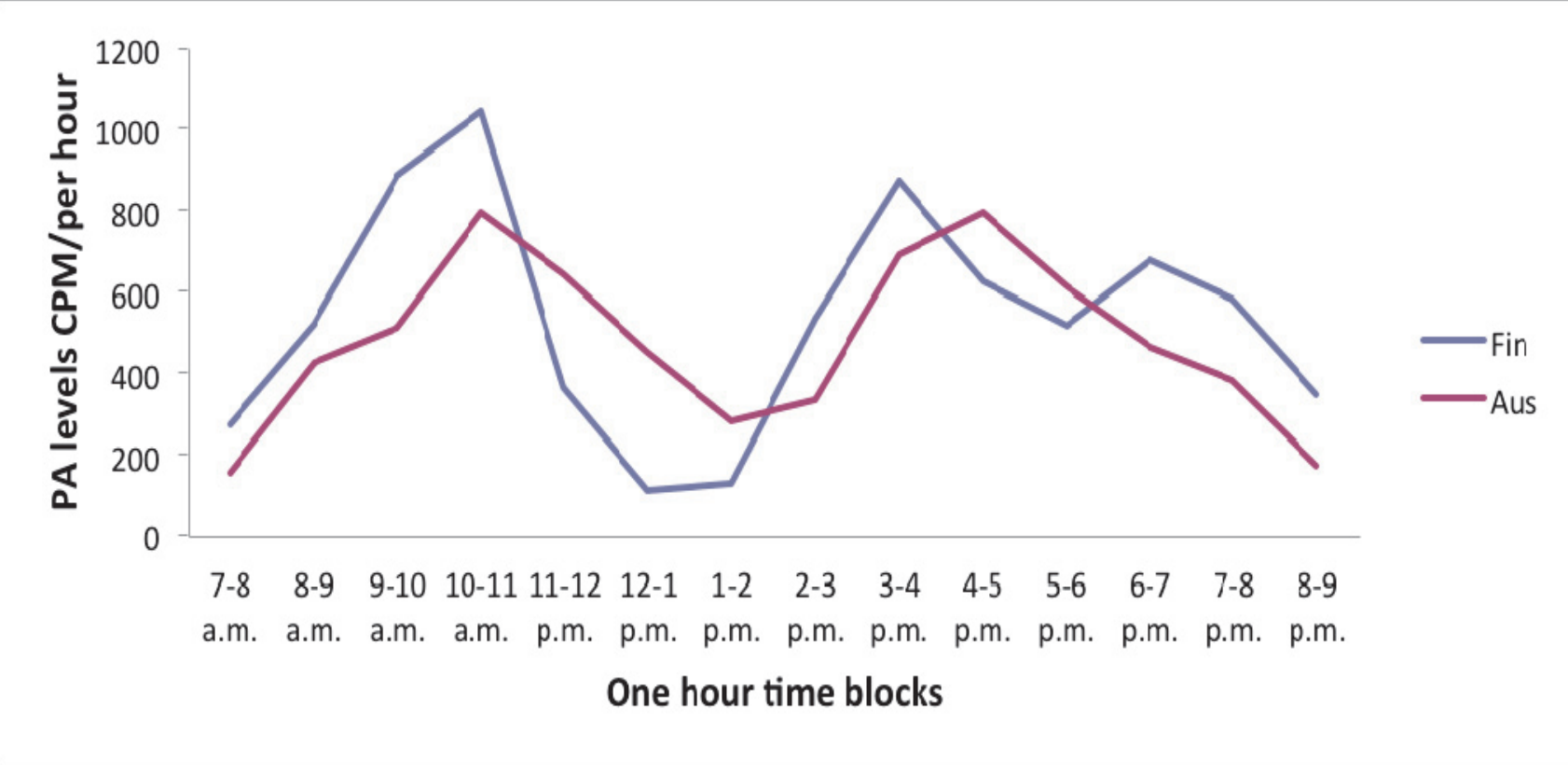

Figure 1. Physical activity levels per hour (cpm/hour) on childcare days in Finland and in Australia. 


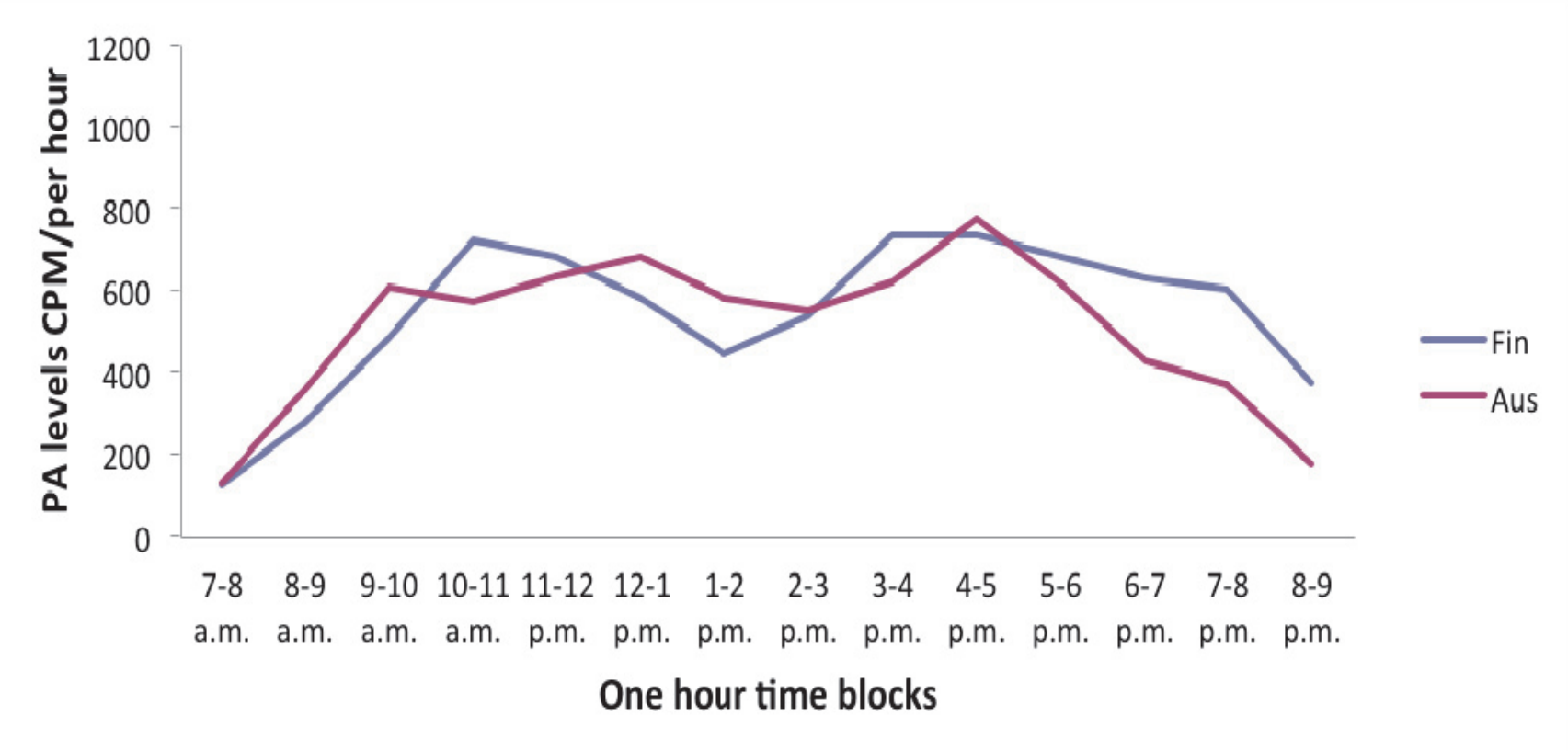

Figure 2. Physical activity levels per hour (cpm/hour) on homecare days in Finland and in Australia. 